Helgoländer wiss. Meeresunters. 21, 143-265 (1970)

\title{
Kalyptorhynchia (Turbellaria) aus dem Eulitoral der deutschen Nordseeküste*
}

\author{
K. SCHILKE \\ II. Zoologisches Institut und Museum der Universität Göttingen; \\ Göttingen, Deutschland (BRD)
}

\begin{abstract}
Kalyptorhynchia (Turbellaria) from the eulittoral beaches of the German North Sea coast. In the eulittoral beaches of the German North Sea coast 85 species of Kalyptorhynchia were found during investigations in 1966, 1967 and 1968. Studies were carried out mainly on the North Sea islands of Sylt, Amrum, Helgoland (Germany) and Rømø (Denmark). At Sylt, most species were found in more or less exposed beach slopes and in the adjacent sheltered sand flats on the east coast. 73 of the 85 species found in the North Sea are psammobiontic, 7 species prefer muddy substrata, and only 5 species live in the phytal. 29. new species are described. Many other species which were, bitherto, known only incompletely, have been studied in more detail. The Schizorhynchia are the group around which the present study centres. Eukalyptorhynchia (39 species): In the families Polycystidae, Koinocystidae, Cystiplanidae and Gnathorhynchidae new genera and species are described. Particularly notable is the addition of species to the Gnathorhynchidae, where many new combinations of characters for the proboscis have been discovered. Schizorhyndhia (47 species): 6 new genera are established. The diagnosis of the Schizorhynchidae is modified. In the large genus Proschizorbynchus, 2 subgenera (P. Proschizorbyncbus and P. Proschizorbynchella) are distinguished according to the structure of the male cuticular apparatus. In the new genus Neoschizorhynchus the shortest muscular tongues known to date are described. Particular emphasis is laid upon the fact that they occur in combination with specific features of the male organs. For the large genera Carcharodorbynchus and Thylacorbynchus a systematic key is given, which is founded on newly discovered combinations of morphological characters. The Karkinorhynchidae are subdivided into the new subfamilies, Karkinorhynchinae and Cheliplaninae, based on the form of the lateral proboscis gland sacs and the construction of the copulatory organ. The genus Karkinorbynchus is split into the subgenera K. Karkinorbynchus and $K$. Karkinorbynchoides. Further new species within the closely related genera Cheliplana and Rbinepera are described. To the Diascorhynchidae is added the new genus Diascorbynchides, which differs from the hitherto single genus Diascorbyndbus by pronounced asymmetric proboscis hooks and single stilett spines.
\end{abstract}

\section{EINLEITUNG}

Mit den Arbeiten von de Beauchamp (1927), Meixner $(1928,1929)$ und KarLING (1931) setzte eine neue Phase intensiver morphologisch-systematischer Untersu-

* Gefördert durch eine Sachbeihilfe der Deutschen Forschungsgemeinschaft im Schwerpunktprogramm „Litoralforschung - Abwassereinflüsse in Küstennähe“ 
chungen an Kalyptorhynchiern ein. Insbesondere das Studium der litoralen Sandmikrofauna führte zur Entdeckung zahlloser neuer Arten, deren organisatorische Vielfalt die Errichtung vieler neuer Gattungen und mehrerer neuer Familien notwendig machte.

Obwohl die Pionierarbeiten von MeIXner auf Material aus der Kieler Bucht basieren, blieben Untersuchungen über Kalyptorhynchia an den deutschen Küsten in der Folgezeit fragmentarisch. Neben der Bearbeitung einiger Arten durch Ax (1951, 1952a, b) hat nur KARLING hin und wieder Objekte von unseren Küsten in seine umfassenden Kalyptorhynchier-Studien aufnehmen können.

Aus dieser unbefriedigenden Sachlage erwuchs die Problemstellung vorliegender Untersuchung. Mit dem Ziel einer möglichst vollständigen Bestandsaufnahme der Ka* lyptorhynchia des Eulitorals der deutschen Nordseeküste wurde die Arbeit auf die diversen Strandbiotope der Inseln Sylt und Amrum konzentriert. Beobachtungen von Helgoland, Rømø (Dänemark) und einigen Stränden der Kieler Bucht sind in die Darstellung einbezogen.

In diesen Untersuchungen habe ich 78 Kalyptorhynchia bearbeitet, von denen 29 neu für die Wissenschaft sind. Neben den neuen Arten wurden weitere, bisher unvollständig behandelte Species in die morphologisch-systematischen Studien einbezogen.

Herr cand. rer. nat. S. HoxHoLd stellte mir Fundortangaben für mehrere Arten zur Verfügung. Schließlich wurden alle Fundmeldungen für die deutsche Nordseeküste aus den Publikationen von AtTems (1897), MeIxNer (1925-1938) und Karling (1947-1964) ausgewertet. Damit sind bis heute 85 Kalyptorhynchier für das Eulitoral der Deutschen Bucht nachgewiesen.

Die Veröffentlichung des umfangreichen Materials erfolgt in drei Abschnitten. Zwei Arten als Vertreter der neuen Familien Aculeorhynchidae und Nematorhynchidae sind bereits publiziert (SCHLKE 1969).

In der vorliegenden Studie werden nach einem kurzen Einblick in die ökologische Verteilung der Kalyptorhynchia alle Arten mit Fundorten erfaßt und in systematischer Reihenfolge abgehandelt.

Besondere Probleme ergaben sich innerhalb der Schizorhynchia. Neue Daten zur Morphologie des Rüsselapparates und der Geschlechtsorgane führten zu einer vergleichenden Merkmalsanalyse dieser Organsysteme im Hinblick auf die systematische Gliederung der Schizorhynchia. Mit einem Ausblick auf das phylogenetische System der Schizorhynchia werden diese Befunde gesondert veröffentlicht (Schrk 1970).

\section{ARTENVERZEICHNIS}

In der folgenden Übersicht bedeuten: $\mathrm{A}=$ Amrum, $\mathrm{H}=$ Helgoland, $\mathrm{KB}=$ Kieler Bucht Bülk, $\mathrm{R}=$ Rømø, $\mathrm{S}=\mathrm{Sylt}, \mathrm{W}=$ Westerhever Sand.

Um die Artenübersicht für die Deutsche Bucht vollständig zu erhalten, sind einzelne Species, die ich nicht selbst gefunden habe, mit aufgenommen worden. Die Namen der Autoren sind dann in Klammern im Kapitel D unter den Fundorten genannt. 
Eukalyptorhynchia

Familie Polycystidae Graff 1905, sensu Karding 1955, 1964 :

(1) Acrorbynchides robustus KaRLING 1931

A, S

(2) Acrorbynchides caledonicus (CLAPARk̀de 1861)

$\mathrm{H}$

(3) Gyratrix hermapbroditus EHRENBER 1831

$\mathrm{H}, \mathrm{S}$

(4) Gyratricella attemsi (GRAFF 1913)

$\mathrm{H}$

(5) Scanorbynchus forcipatus KARLING 1955

$S$

(6) Danorbynchus duplostylis KaRLING 1955

A, S

(7) Neopolycystis tridentata KARLING 1955

A, R, S

(8) Polycystis crocea (O. FABR. 1826)

$\mathrm{H}$

(9) Pbonorbyncbus belgolandicus (MeCzNIKorf 1865)

$\mathrm{H}, \mathrm{S}$

(10) Typblopolycystis coeca KaRLING 1956

$S$

(11) Typblopolycystis limicola nov. spec.

$S$

(12) Limipolycystis curvitubo nov. gen., nov. spec.

S

Familie Koinocystidae MEIXNer 1925:

(13) Utelga scotica KARLING 1954

\section{$\mathrm{S}$}

(14) Utelga beinckei (ATTEMs 1897)

$\mathrm{H}$

(15) Parautelga bilioi KarLIng 1964

$\mathrm{S}$

(16) Marirbynchus longasaeta nov. gen, nov. spec.

S

Familie Cystiplanidae Karling 1964:

(17) Cystiplana paradoxa KarLING 1964

A, S

(18) Cystiplana Karlingi HoxHoLd n. n.

$S$

(19) Nigerrbynchus opisthoporus nov. gen., nov. spec.

$\mathrm{S}$

Familie Psammorhyndidae KarLINg 1956:

(20) Psammorbynchus tubulipenis MEIXNER 1938

A, S

Familie Cicerinidae MEIXNer 1938:

(21) Cicerina brevicirrus MEIXNER 1928

A, H, S

(22) Cicerina remanei MEIXNER 1928

A, H, R, S

(23) Cicerina tetradactyla GIARD 1904

$\mathrm{H}, \mathrm{S}$

(24) Paracicerina laboeica MeIXner 1928

$\mathrm{S}$

(25) Paracicerina maristoi KARLING 1952

$S$

(26) Ptyalorbynchus coecus MeIXNeR in Ax 1951

A, R, S

(27) Zonorbynchus seminascatus KARLING 1956

$A, S, W$

(28) Zonorhynchus twaerminnensis (KARLING 1931)

S, R

Familie Placorhynchidae (MEIXNER 1938 n. n.) KARLINg 1947:

(29) Placorbynchus octaculeatus octaculeatus KARLING 1931

A, S

(30) Placorbynchus octaculeatus dimorphis KarLING 1947 
Familie Gnathorhynchidae MErxner 1929:

(31) Gnathorbynchus conocaudatus MEIXNER 1929

$A, R, S$

(32) Gnatborbynchus inermis nov. spec.

$\mathrm{R}, \mathrm{S}$

(33) Odontorbynchus lonchiferus KARLING 1947

$S$

(34) Uncinorbynchus flavidus KaRLING 1947

A, S

(35) Psittacorbynchus verweyi DEN HARTOG 1968

$\mathrm{S}$

(36) Neognathorbynchus suecicus KardING 1956

$\mathrm{S}$

(37) Neognathorbynchus longostilo nov. spec.

(38) Prognatborbynchus stilofer nov. spec.

$\mathrm{S}$

$\mathrm{R}, \mathrm{S}$

Familie Aculeorhynchidae Schuke 1969:

(39) Aculeorbynchus glandulis SchILKe 1969

\section{Schizorhynchia}

Familie Schizorhyndhidae GRAFF, sensu KARLING 1950:

(40) Proschizorbynchus gullmarensis KarLING 1950

A, S

(41) Proschizorbynchus triductibus nov. spec.

$S$

(42) Proschizorbynchus helgolandicus L'Hardy 1965

H, R, S

(43) Proschizorbynchus bivaginatus nov. spec.

$\mathrm{S}$

(44) Proschizorhyndhus spiracirro nov. spec.

$\mathrm{S}$

(45) Schizorbynchoides aculeatus L'HARDY 1963

A, S

(46) Schizorbynchoides meixneri BOADEN 1963

A, S

(47) Scbizorbynchoides canaliculatus L'HARDY 1963

$S$

(48) Schizorbynchoides rarus Ax 1951

$S$

(49) Paraschizorbynchoides glandulis nov. gen., nov. spec.

A, S

(50) Pseudoschizorbynchoides ruber nov. gen., nov, spec.

(51) Schizochilus choriurus BOADEN 1963

$\mathrm{S}$

(52) Schizochilus caecus L'HARDY 1963

S

(53) Schizochilus marcusi BOADEN 1963

$\mathrm{S}$

(54) Amphirbynchus caudatus nov. gen., nov. spec.

S

(55) Limirbynchus danicus nov, gen. nov. spec.

$\mathrm{S}$

(56) Neoschizorbynchus longipharynggus nov. gen., nov. spec.

(57) Neoschizorhynchus brevipharynggus nov. spec.

(58) Neoschizorbynchus parvorostro HeLleR 1970

(59) Carcharodorbynchus subterraneus Ax 1951

(60) Carcharodorbynchus listensis nov. spec.

(61) Carcharodorbynchus ambronensis nov. spec.

(62) Carcharodorbynchus isolatus nov. spec.

(63) Thylacorbynchus arcassonensis DE BEAUCHAMP 1927

(64) Thylacorbynchus conglobatus MEIXNER 1928

(65) Thylacorbynchus caudatus MEIXNER 1928

A, R, W

A, S

$\mathrm{S}$

$S$

$S$

A, S, W

A, $S$

$\mathrm{S}$

A

A. H, S

$\mathrm{S}$

S

(66) Thylacorbynchus pyriferus KARLING 1950

(67) Thylacorbynchus filostylis KARLING $1956 \mathrm{n} . \mathrm{n}$.

(68) Thylacorbynchus ambronensis nov. spec.

A, R, S 
Familie Nematorhynchidae SchILKe 1969:

(69) Nematorbynchus parvoacumine SCHuKE 1969

Familie Karkinorhynchidae MEIXNer 1928:

(70) Karkinorbynchus primitivus MEIXNER 1928

KB

(71) Karkinorbynchus bruneti nov. spec.

A, S, R

(72) Karkinorbynchus l'hardyi nov. spec.

$S$

(73) Karkinorbynchus listensis nov. spec.

$S$

(74) Karkinorbynchus purpureus nov. spec.

A, S

(75) Cheliplana stylifera KARLING 1949

A, R, W

(76) Cheliplana curvocirro nov. spec.

A

(77) Cheliplana boadeni nov. spec.

$\mathrm{S}$

(78) Rhinepera remanei MEIXNER 1928

(79) Rbinepera divisa nov. spec.

(80) Cheliplanilla caudata Merxner 1938

(81) Cheliplanilla rubra nov. spec.

(82) Baltoplana magna KARIING 1949

A, R, S

A

$A, S$

$S$

$S$

Familie Diascorhynchidae MerXner 1928:

(83) Diascorbynchus lappoikensis KarLING 1963

$S$

A, R, S

A, S

A, S

\section{OKOLOGIE}

In der vorwiegend morphologisch-systematisch orientierten Literatur über die Kalyptorhynchia fehlen bislang eingehendere ökologische Angaben über die differentielle Verteilung von Arten auf verschiedene Strandabschnitte eines umgrenzten geographischen Areals.

Aus der Bearbeitung der Inseln Sylt, Amrum und Rømø wird deshalb der Versuch unternommen, die Hauptlebensräume ökologisch gut charakterisierter Species herauszustellen. Die Befunde resultieren aus Untersuchungen in den Jahren 1966 (April, August, September, Oktober), 1967 (März, April, Mai, August, September, November) und 1968 (April).

Die Strandtypen der Inseln Sylt und Amrum sind durch zahlreiche ökologische Arbeiten hinreichend bekannt (SCHulz 1937, 1939, SCHUlz \& MeYER 1940, Ax 1951, 1969, Westheide 1966, 1967, Dörjes 1968a, b, Schmidt 1968, Pawlak 1969). Für Sandstrände übernehme ich die Terminologie des von $\mathrm{Ax}$ und ScHmid entwickelten Gliederungsschemas (Ax 1969, SCHMIDT 1968). Meine Untersuchungsstationen auf Sylt und Amrum sind in den Karten 1 und 2 und zugeordneten Tabellen erfaßt. 
Lebensräume und charakteristische Arten

\section{Stark lotische Sandbänge}

Sylt: Weststrand (S 1); Ellenbogen, Westleuchtturm (S 2); Ellenbogen, Bucht an der Nordseite (S 3); Ellenbogen, Ostspitze (S 4);

Amrum: Kniepsand, Weststrand (A 2, 4-6);

Rømø: Weststrand bei Lakolk.

Spezifische Arten: Thylacorbynchus caudatus, Proschizorbynchus belgolandicus, Cheliplana stylifera.

\section{Mittellotische Sandbänge}

Sylt: Südstrand des Ellenbogens, verschiedene Stellen (S 5); Lister Haken, Ostseite (S 10); sog. "Filmwatt" südlich des Lister Haken (S 10); List, nördlich des Hafens (S 11); List, Litoralstation der Biologischen Anstalt Helgoland (S 12); Hörnum, südlich des Hafens (S 28, 29);

Amrum: Wittdün, südlich der Anlegebriicke (A 16); Odde, Ostspitze (A 6, 7).

Spezifische Arten: Schizorbynchoides aculeatus, Karkinorbynchus purpureus.

\section{Schrwach lotische Sandhänge}

Sylt: Suidlich der Blidsel-Bucht (S 15); Braderup, weißes Kliff (S 17); Munkmarsch (S 18); Hindenburgdamm, Südseite (S 19); nördlich Gr. Fli (S 23); Waarding-Deelbucht (S 24); Puan Klent, verschiedene Stellen (S 25); Hörnum, nördlich des Hafens (S 27).

Spezifische Arten: Odontorbynchus lonchiferus, Baltoplana magna, Diascorbynchus lappvikensis.

\section{Sandige, vorwiegend lenitische Wattengebiete}

Sylt: Seewärts am Südstrand des Ellenbogens (S 5); List, Litoralstation der Biologischen Anstalt Helgoland (12); Buhne List-Süd (S 14); Sandbank im Wattenmeer östlich List (S 13); Sandbank im Königshafen (S 6).

Spezifische Arten: Paracicerina laboeica, Schizochilus choriurus, Diascorbynchus rubrus.

\section{Sandig-schlickige, lenitische Wattflächen}

Sylt: Halbinsel Lister Haken, Westseite (S 9); Blidsel-Bucht (S 15); Braderup, Sandbank (S 16); südlich Morsum (S 20); Rantum-Deich (S 21);

Amrum: Gesamte Wattfläche von Wittdün, nördlich der Anlegebrücke bis Odde, Ostspitze, verschiedene Stellen (A 8-A 15).

Spezifische Arten: Zonorbynchus seminascatus, Uncinorbynchus flavidus. 


\section{Farbstreifensandwatt}

Amrum: Kniepsand (A 1, 3); Lagune nordwestlich Wittdün (A 17).

Spezifische Arten: Placorbynchus octaculeatus octaculeatus, Carcharodorbynchus ambronensis.

\section{Salzwiesen und verlandende Wattflächen}

Sylt: Königshafen, Salzwiese (S 7); Halbinsel Uthörn, Ostseite (S 8); südlich Rantum, Salzwiese (S 22); nördlich Hörnumer Hafen, hinter Strandwall (S 26).

Spezifische Arten: Acrorbynchides robustus, Parautelga bilioi.

\section{Absolute Artenzahlen einzelner Biotope}

Der qualitativen Zuordnung spezifischer Arten zu den einzelnen Lebensräumen schließe ich einige Daten über die zahlenmäßige Verteilung der Species auf bestimmte Biotope an. Hierdurch möchte ich die als Siedlungsräume besonders ausgezeichneten Regionen hervorheben.

S y 1 t (Abb. 1): Von den insgesamt 75 beobachteten Arten wurden allein 67 Arten am mittellotischen Sandhang bzw. im sandigen, vorwiegend lenitischen Wattengebiet nachgewiesen. Stichproben am Strand von Puan Klent lassen auf eine vergleichbar hohe Artenzahl schließen.

Für die verschiedenen Strände ergeben sich im einzelnen folgende Artenzahlen: Stark lotische Sandhänge: 12 Arten, mittellotische Sandhänge und sandige Wattengebiete: 67 Arten, schwach lotische Sandhänge und sandig-schlickige Wattengebiete: 37 Arten, Salzwiesen und verlandende Wattfächen: 6 Arten, Algenwatten: 1 Art.

Aus dieser Übersicht wird ersichtlich, daß mittellotische Sandhänge und davorliegende sandige, vorwiegend lenitische Wattflächen bevorzugte Lebensräume der Kalyptorhynchia auf Sylt sind.

A m rum (Abb. 2): Insgesamt wurden 33 Arten festgestellt, die sich folgendermaßen verteilen: Stark lotische Sandhänge: 23 Arten, mittellotische Sandhänge und sandige Wattenflächen: 13 Arten, schwach lotische Sandhänge und sandig-schlickige Wattengebiete: 4 Arten, Farbstreifensandwatten: 6 Arten.

Hieraus ergibt sich als bevorzugter Lebensraum der Kalyptorhynchia auf Amrum der stark lotische Sandhang am Weststrand des Kniepsandes und der Odde. Die gesamte Wattfläche des Amrumer Oststrandes (A 8-A 15) bewohnen lediglich vier Species.

\section{Biotopbindung}

Die Verteilung der Kalyptorhynchia-Arten auf die verschiedenen Strandtypen auf Sylt, Amrum, Rømø und Helgoland ist in Tabelle 1 zusammengefaßt.

Aus dieser sind einige Angaben zur Biotopbildung zu entnehmen. Von den 85 Arten, die für die Deutsche Bucht nachgewiesen sind, ist das Gros Sandbewohner (73). Sieben Species können als Schlickbewohner bezeichnet werden, und nur fünf Arten sind als Phytalformen zu betrachten.

Die 85 Species lassen sich nach Gruppen (I-VII) gliedern. G r u p e I umfaßt 


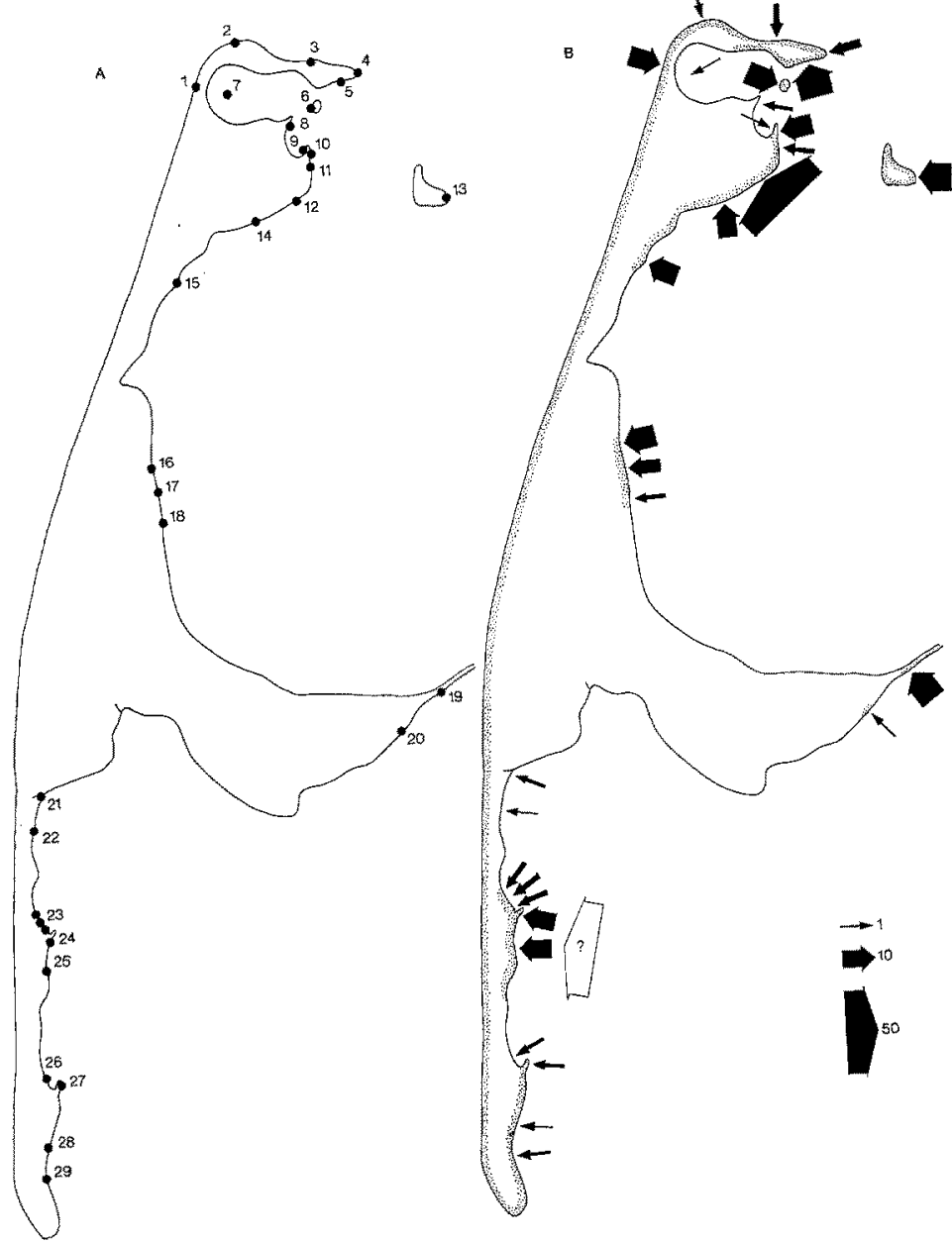

Abb. 1: Nordseeinsel Sylt (Maßstab 1:90 000). A Lage der Stationen: 1 Ellenbogen, West-. strand; 2 Ellenbogen, Westleuchtturm; 3 Ellenbogen, Bucht an der Nordseite; 4 Ellenbogen, Ostspitze; 5 Ellenbogen, Alte Anstalt; 6 Königshafen, Sandbänke; 7 Königshafen, Salzwiese; 8 Halbinsel Uthörn, Ostseite; 9 Halbinsel Lister Haken, Westseite; 10 Halbinsel Lister Haken, Ostseite und sog. „Filmwatt"; 11 List, nördlich Ablaufbahn; 12 List, Litoralstation der Biologischen Anstalt Helgoland; 13 List, Sandbank im Wattenmeer östlich List; 14 Buhne List-Süd; 15 Blidsel-Bucht; 16 Braderup; 17 Braderup, weißes Kliff; 18 Munkmarsch; 19 Hindenburgdamm, Südseite, ca. $100 \mathrm{~m}$ östlich Salzwiesenabbruchskante; 20 siidlich Morsum; 21 Rantum, Deich; 22 Rantum, Salzwiese; 23 nördlich Gr. Fli.; 24 Waarding-Deel Bucht; 25 Puan Klent; 26 nördlich Hörnum Hafen, hinter Strandwall; 27 nördlich Hörnum Hafen, vor Strandwall; 28 südlich Hörnum Hafen; 29 südlich Hörnum Hafen. $B$ Die Anzahl der Arten, die an jeder Station festgestellt wird, ist durch Pfeile veranschaulicht (Pfeilstärken siehe rechts unten); bei den Stationen 24, 25 ist eine ähnlich hohe Artenzahl zu erwarten wie bei Station 12; Sandstellen sind punktiert, negative Probennahme nicht eingetragen; Ende der Untersuchungen April 1968 
mit 15 Arten die Vertreter ausgesprochen lotischer Sandhänge. Gruppe II (8 Arten) ist durch Arten gekennzeichnet, die sowohl an stark lotischen Sandhängen als auch an mittellotischen Sandhängen sowie an schwach lotischen Sandhängen bzw. den vorgelagerten Wattflächen existieren können. Die bevorzugten Lebensräume bilden mittellotische Sandhänge bzw. deren Watten. Gruppe I I (26 Arten): hierin sind Arten zusammengefaßt, die nur an mittellotischen Biotopen nachgewiesen sind. Gru p p e I V umfaßt ganz ähnlich wie Gruppe II stärker eurytope Species, deren

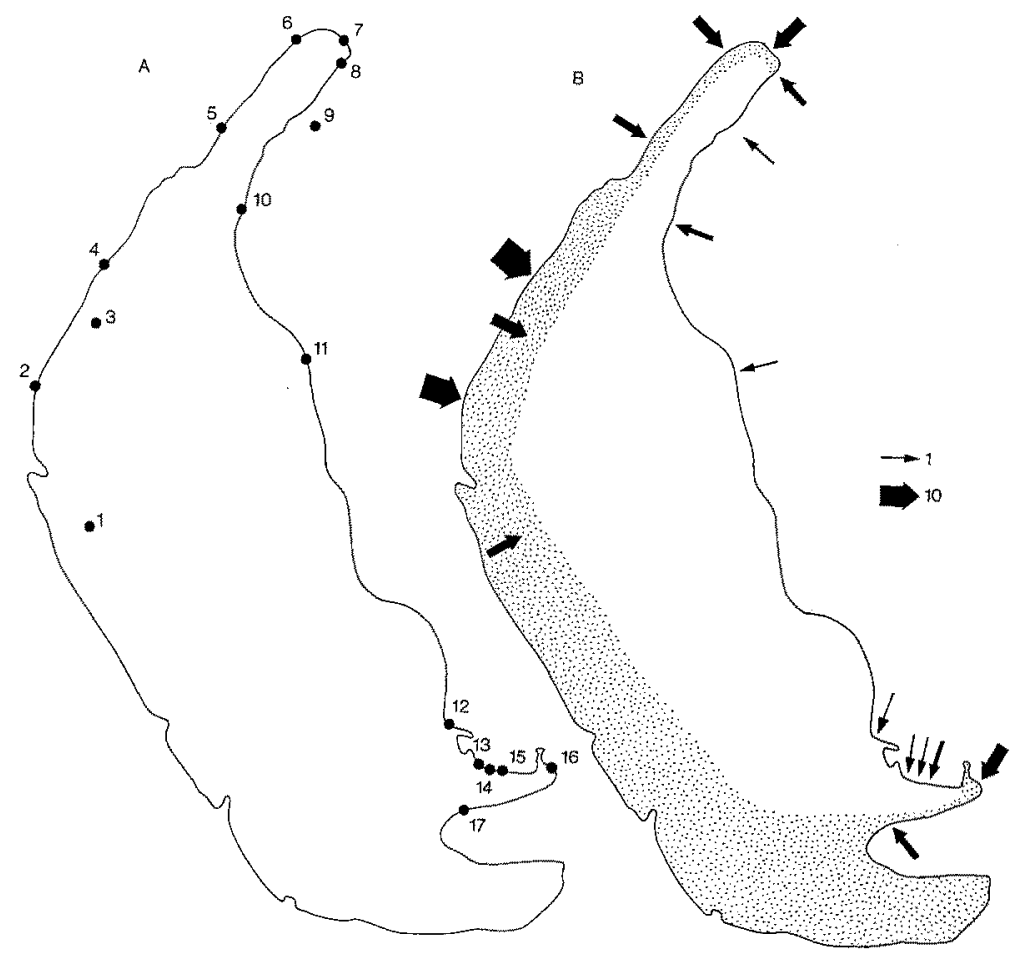

Abb. 2: Nordseeinsel Amrum (Maßstab 1:50000). A Lage der Stationen: 1 FarbstreifenSandwatt südlich Quermarkenfeuer; 2 Kniepsand, Weststrand; 3 Farbstreifen-Sandwatt, Muschelsand, bei Norddorf; 4 Kniepsand, Weststrand; 5 und 6 Kniepsand, Odde, Weststrand; 7 Odde, Nordspitze; 8 Odde, Ostseite; 9 Odde, Wattwandererschild; 10 Odde, Hospiz; 11 Nebel; 12 Steenodde; 13, 14 und 15 westlich Wittdün, Anlegebrücke; 16 östlich Wittdün, Anlegebrücke; 17 Farbstreifen-Sandwatt und Verlandungsgebiet südwestlich Wittdün. $B$ vgl. Abb. 1

größte Abundanz im schwach lotischen Bereich liegt (7 Arten). Gruppe V beinhaltet mit seinen 10 Arten Bewohner des mittel- und schwach lotischen Bereichs. Gru p p e VI (14 Species) umfaßt die Vertreter schwach lotischer Sandhänge bzw. ausgesprochene Schlickbewohner; die Arten sind teilweise stark eurytop. Grup pe V I I (5 Arten): Hierzu sind die wenigen Phytalformen zu zählen.

Als $U$ biq $\mathrm{u}$ iste n müssen wir die folgenden Arten bezeichnen: Prognatborbynchus stilofer, Placorbynchus octaculeatus octaculeatus, Diascorbynchus rubrus, Ptyalorbynchus coecus und Neopolycystis tridentata. 
Tabelle 1

Verteilung der Kalyptorhynchia-Arten auf Sylt, Amrum, Rømø und Helgoland

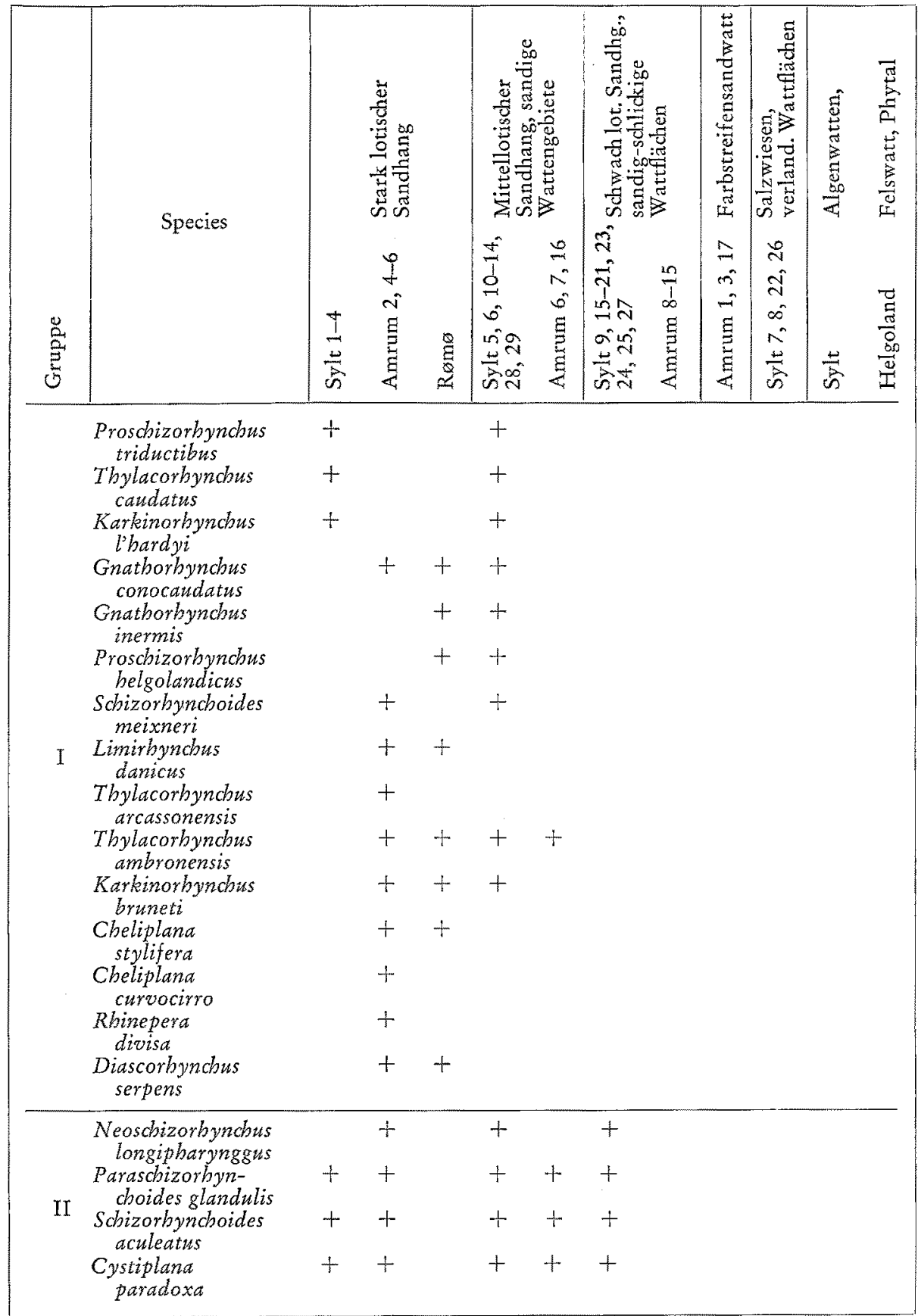


Kalyptorhynchia der deutschen Nordseeküste

Tabelle 1 (Fortsetzung)

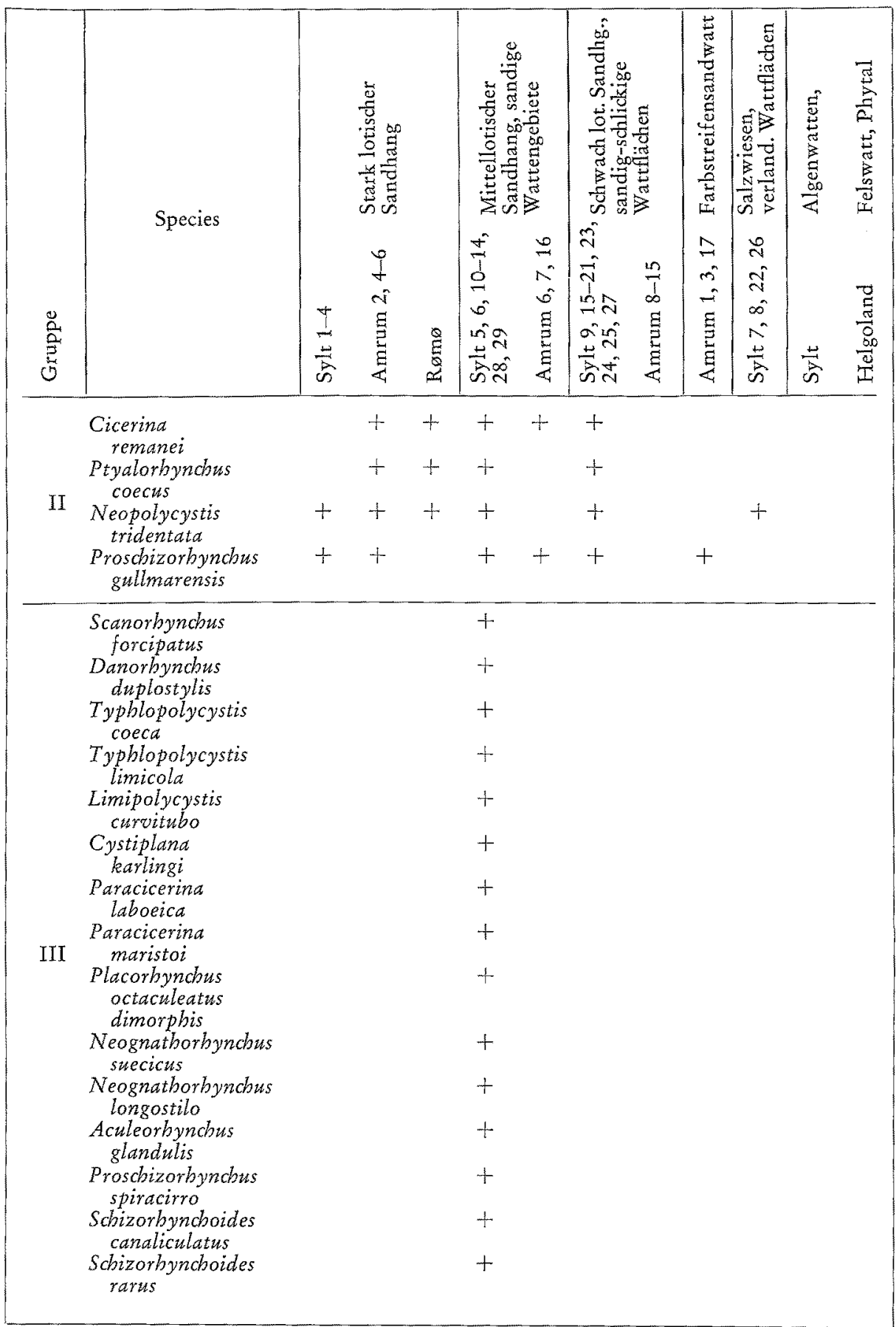


Tabelle 1 (Fortsetzung)

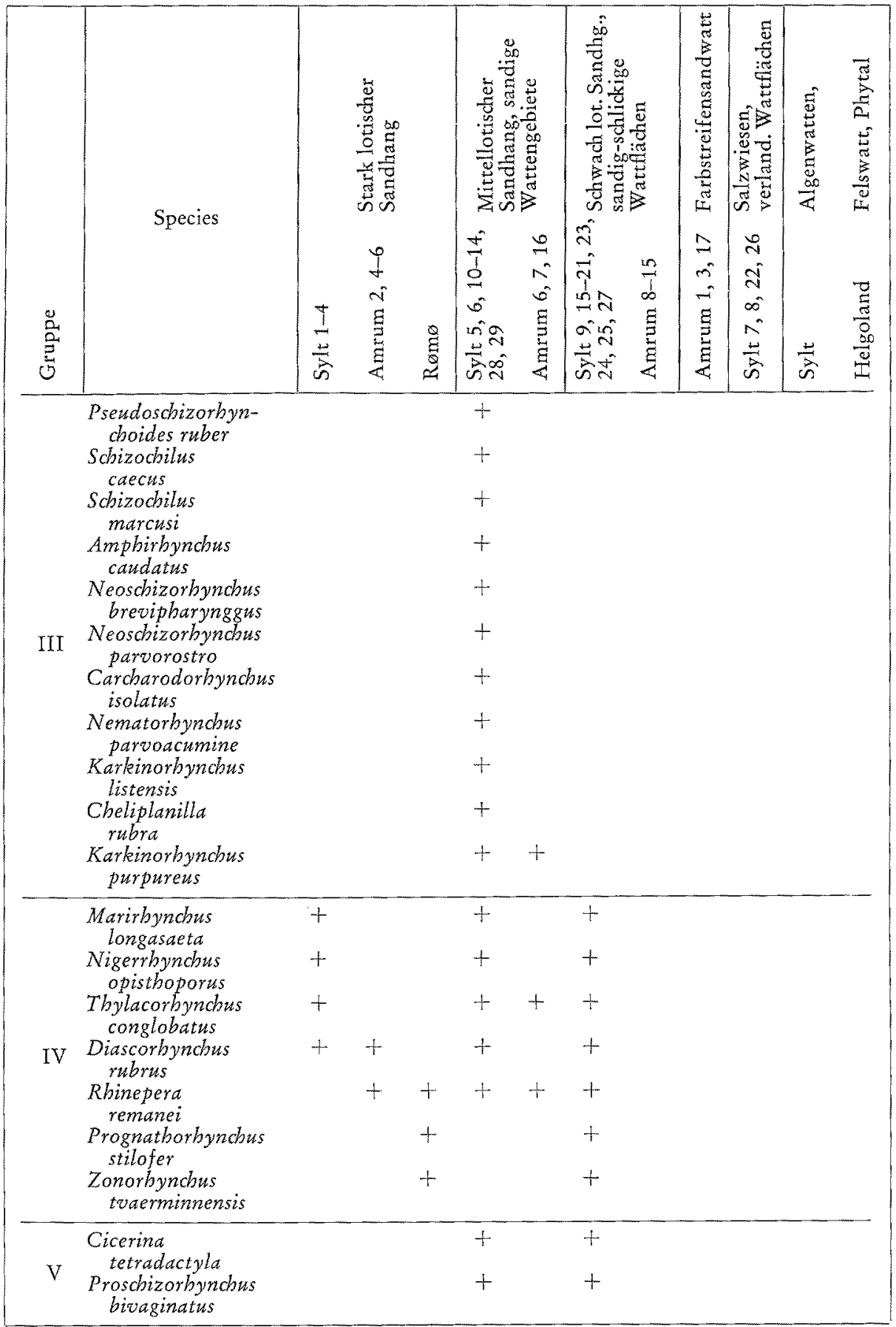


Tabelle 1 (Fortsetzung)

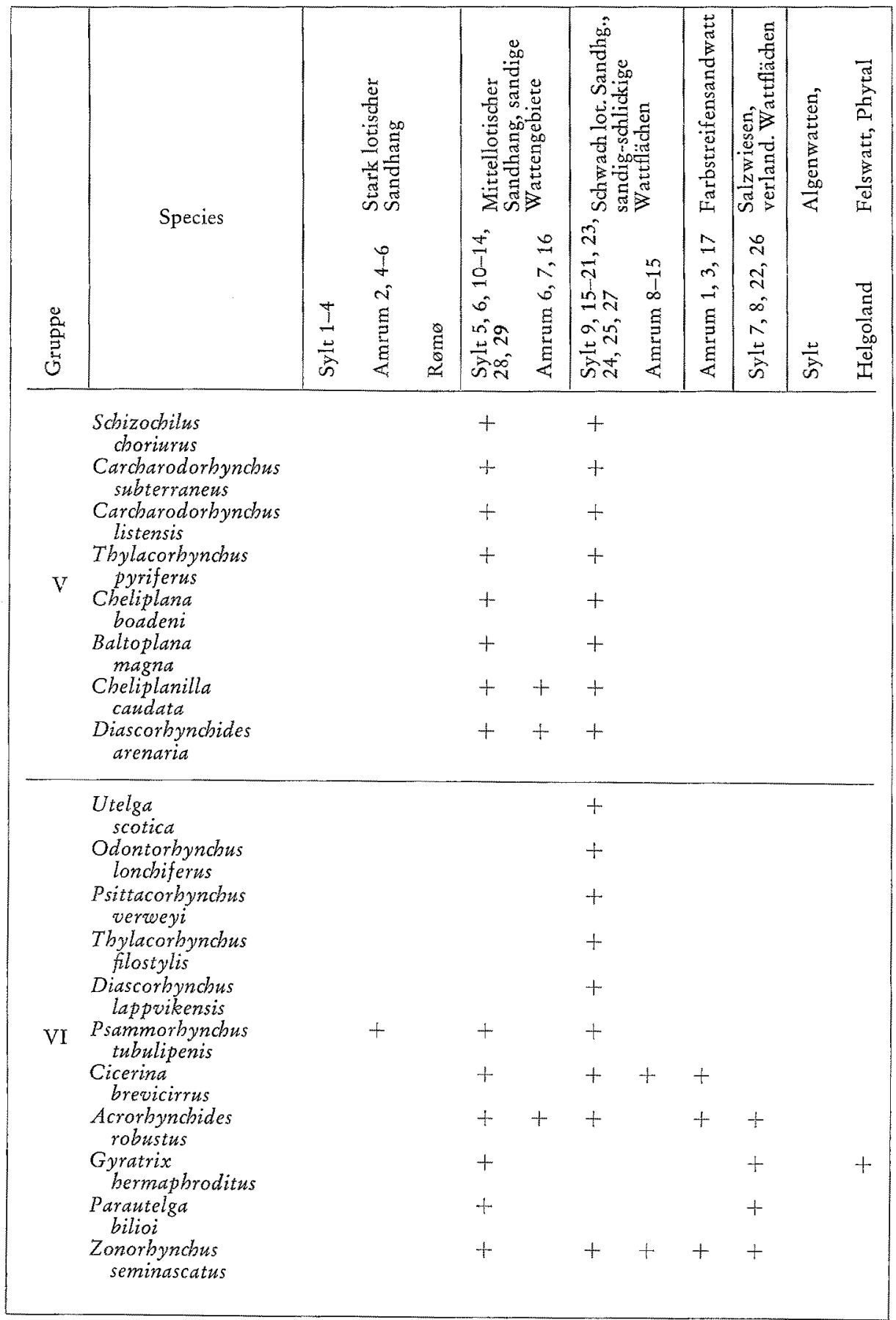


Tabelle 1 (Fortsetzung)

\begin{tabular}{|c|c|c|c|c|c|c|c|c|c|c|c|c|}
\hline 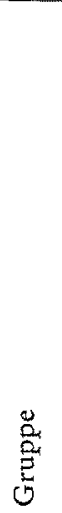 & Species & $\frac{I}{\frac{I}{2}}$ & 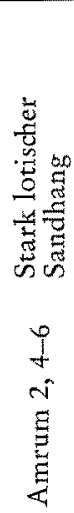 & gू & \multicolumn{2}{|c|}{ 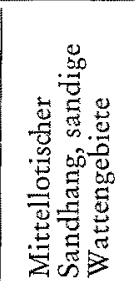 } & \multicolumn{2}{|c|}{ 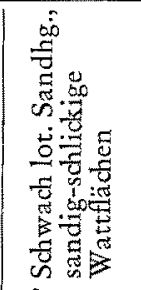 } & 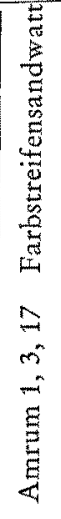 & 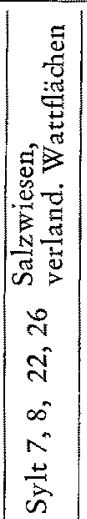 & 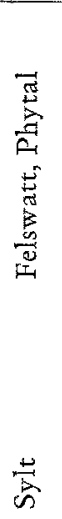 & 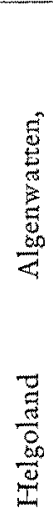 \\
\hline $\mathrm{VI}$ & $\begin{array}{l}\text { Placorbynchus } \\
\text { octaculeatus } \\
\text { octaculeatus } \\
\text { Uncinorbynchus } \\
\text { flavidus } \\
\text { Carcharodorbynchus } \\
\text { ambronensis }\end{array}$ & & + & & + & + & $\begin{array}{l}+ \\
+\end{array}$ & + & + & + & & \\
\hline VII & $\begin{array}{l}\text { Phonorbynchus } \\
\text { belgolandicus } \\
\text { Acrorbynchides } \\
\text { caledonicus } \\
\text { Gyratricella } \\
\text { attemsi } \\
\text { Polycystis } \\
\text { crocea } \\
\text { Utelga } \\
\text { beinckei }\end{array}$ & & & & & & & & & & + & $\begin{array}{l}+ \\
+ \\
+\end{array}$ \\
\hline
\end{tabular}

\section{MORPHOLOGIE UND SYSTEMATIK}

\section{Vorbemerkungen}

Es wurden nur Fundorte von der deutschen Nordseeküste sowie eigene Funde aus der Kieler Bucht aufgenommen. Dabei wurden die Arbeiten von AtTEMs, Ax, Meixner, Karling, soweit sie sich auf die deutsche Nordsceküste beziehen, durchgesehen. Ferner standen Fundortangaben von Hoxнold zur Verfügung.

Die Stationen sind auf Sylt und Amrum durchnummeriert. Die Lage der Stationen geht aus den Karten 1 und 2 hervor. Bei den Fundorten bedeuten: sh $=$ Sandhang, $s w=$ Sandwatt, $\mathrm{q}=$ Quellhorizont, $\mathrm{k}=$ Knick, Strandknick (Kennzeichnung der Strandabschnitte bei ScHMTDT 1968).

In das Artenverzeichnis wurde Karkinorbynchus primitivus (Kieler Bucht, Bülk = KB) aufgenommen, obwohl diese Art bisher nicht an der deutschen Nordseeküste 
nachgewiesen ist. Für die morphologisch-systematischen Untersuchungen war die Einbeziehung der Art notwendig.

Die Tierzeichnungen (Habitus, Organisation) sind schematisch angelegt. Die Abmessungen der Organe sind aus Einzelmessungen berechnet. Da diese Kalyptorhynchia proterandrische Zwitter sind, müssen Zeichnungen, die beide Geschlechtsapparate vereinigt darstellen, notwendig schematisch gehalten sein. Die Angaben zur Körperfarbe beziehen sich auf Durchlicht.

\section{Eukalyptorhynchia}

Familie Polycystidae GrafF 1905, sensu KarLING 1955, 1964

Acrorbynchides robustus KARLING 1931

F und o r te : Sylt: $6,10 \mathrm{sw}, 12 \mathrm{sw}, 16,19 \mathrm{sw}, 20 \mathrm{sw}, 22 \mathrm{sh} \mathrm{sw}, 26 ;$ Amrum: 16, $17 \mathrm{sw}$, sh; Ostsee: Kieler Förde, Bottsand.

Acrorbynchides caledonicus (CLApARÈde 1861)

Fu n d or t: Helgoland: Westseite (Atrems 1897)

Gyratrix bermaphroditus EHRENBERG 1831

Fundorte: Sylt: $5 \mathrm{sw}, 6,12 \mathrm{sw}, 22 \mathrm{sw}$; Helgoland (Atrems 1897): Amphioxus-Sand (MeIXner 1938)

\section{Gyratricella attemsi (GRAFF 1913)}

Fund ot t: Helgoland (AtTems 1897)

Scanorbynchus forcipatus KARLING 1955

(Abb. 3)

Fund or te: Sylt: 12 sw (leg. Hoxhold), 13 sw.

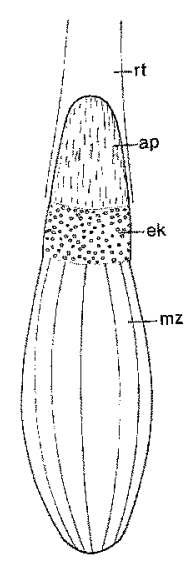

Abb. 3: Scanorhynchus forcipatus. Rüssel (Quetschpräparat) 
Materia l: Lebendbeobachtungen an zwei Exemplaren.

Beschreibung: Die Körperlänge erreicht im gestreckten Zustand $0,8 \mathrm{~mm}$ (KARLING 1955), bei kontrahierten Tieren 0,4 mm. Das Vorderende kann spitz ausge-streckt werden, das Hinterende ist abgerundet. Die Färbung ist bräunlich-marmoriert. Der kleine Rüssel erreicht $64 \mu \mathrm{m}$ (KARLING: $68 \mu \mathrm{m}$ ). Bei einem Exemplar liegen zwei Hoden zwischen Gehirn und Pharynx, wogegen KarLING nur eine Hodenblase nennt. Der Kulikularapparat wird 49-52 $\mu \mathrm{m}$ lang (KarLing: 48-60 $\mu \mathrm{m}$ ). Der Basaltrichter erreicht $15 \mu \mathrm{m}$, das Stilett $24 \mu \mathrm{m}$ (1 Expl.). Die Samenblase mißt 80-105 $\mu \mathrm{m}$, der kontrahierte Ductus spermaticus $68 \mu \mathrm{m}$ (KARLING: etwa $80 \mu \mathrm{m}$ ).

\section{Danorbynchus duplostylis KaRLING 1955}

Fundorte: Sylt: $12 \mathrm{sw}$ (leg. Hoxhold); Amrum: feinsandiger Prallhang (KARLING 1955).

\section{Neopolycystis tridentata KARLING 1955}

(Abb. 4, 9)

Fundorte: Sylt: $1 \mathrm{sh}, 5 \mathrm{sh}, 7 \mathrm{sh}, 11 \mathrm{sh}, 12 \mathrm{sh}$ sw, $27 \mathrm{sh}$; Amrum: $4 \mathrm{sh}, 5 \mathrm{sh}$; Prallhang von Sylt und Amrum (KARLING 1955); Rømø: Lakolk, Weststrand, Sandhang.

M a te ria l: Lebendbeobachtungen, ein Dauerpräparat. In der Population von Sylt und Amrum erreicht die Art nur 0,5-0,8 mm. Die Tiere schwimmen sehr schnell zwischen Sandkörnern umher, aber auch durch freies Wasser (Salzwiese), wobei sie
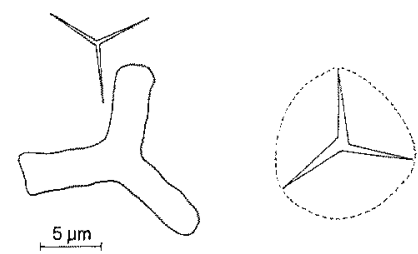

Abb. 4: Neopolycystis tridentata. Einschlüsse (Quetschpräparat)

sich ständig um ihre Längsachse drehen können. Bei Beunruhigung können sich die schlanken Tiere zu einer Kugel kontrahieren. Die hellgraue Art besitzt caudal mehrere lange Tasthaare. Im Parenchym können stark lichtbrechende Einschlüsse in Form eines dreizackigen Sterns auftreten. Die Länge einer Zacke beträgt 5-8 $\mu \mathrm{m}$. Zuweilen ist der Stern von einer sehr schwachen kreisförmigen Figur umgeben. Ein Exemplar enthielt etwa 20 derartige Einschlüsse. Bei Zusatz von verdünnter $\mathrm{HCl}$ lösen sich nur die Einschlüsse sofort auf. Ich deute sie als Exkretionskristalle.

WeSTBLAD (1942) hat bei dem Acoel Paraphanostoma trianguliferum Exkretionskristalle gefunden, denen jene von Neopolycystis tridentata recht ähnlich sind (vgl. DörJEs 1966, p. 191 und Fig. 158, 159).

Die Rüssellänge beträgt 70-100 $\mu \mathrm{m}$. Die Länge des Pharynx erreicht 30-70 $\mu \mathrm{m}$. Die Länge der Samenblase ist 40-85 $\mu \mathrm{m}$. Die Länge des Nebenstiletts beträgt 48 bis 
$51 \mu \mathrm{m}$, bei zwei Exemplaren nur 38 bzw. $41 \mu \mathrm{m}$. Das Stilett erreicht bei einem Exemplar $37 \mu \mathrm{m}$.

Die Art wird von Sporozoen parasitiert.

Polycystis crocea (O. FeBr. 1826)

F u n d ort: Helgoland: Felswatt (leg. Stecher); Helgoland (Mrixner 1925).

Phonorbynchus helgolandicus (MECZNIKOFF 1865)

F u n d o r te : Sylt: List, Ablaufbahn (S 11) unter NW-Linie, Phytal (leg. HoxHOLD); Puan Klent, in Algen (leg. HoxhoLD); Helgoland (AtTems 1897).

Die Körperlänge beträgt $1,3 \mathrm{~mm}$. Die Länge des Kutikularorgans liegt bei $54 \mu \mathrm{m}$. Das Kutikularstilett ist $90 \mu \mathrm{m}$ lang (vgl. Merxner 1925, p. 315). Die Art fehlt nach Meixner (1929, p. 765, 766) im Sande und kommt nur in der „Zone des Küstenbewuchses" vor.

Typhlopolycystis coeca KarLing 1956

Fund or te: Sylt: 5 sh, 12 sh sw; List: Prallhang (Karling 1956).

Typhlopolycystis limicola nov. spec.

(Abb. 5)

Fund or t: Sylt: 5 sh (Locus typicus), S 12.

Material: Lebendbeobachtungen an zwei Exemplaren.

Beschreibung: Der etwa 0,8 mm lange Körper ist vorne und hinten gleichmäßig abgerundet. Die Körperfarbe ist grau, undurchsichtig. Im Vorderende sind
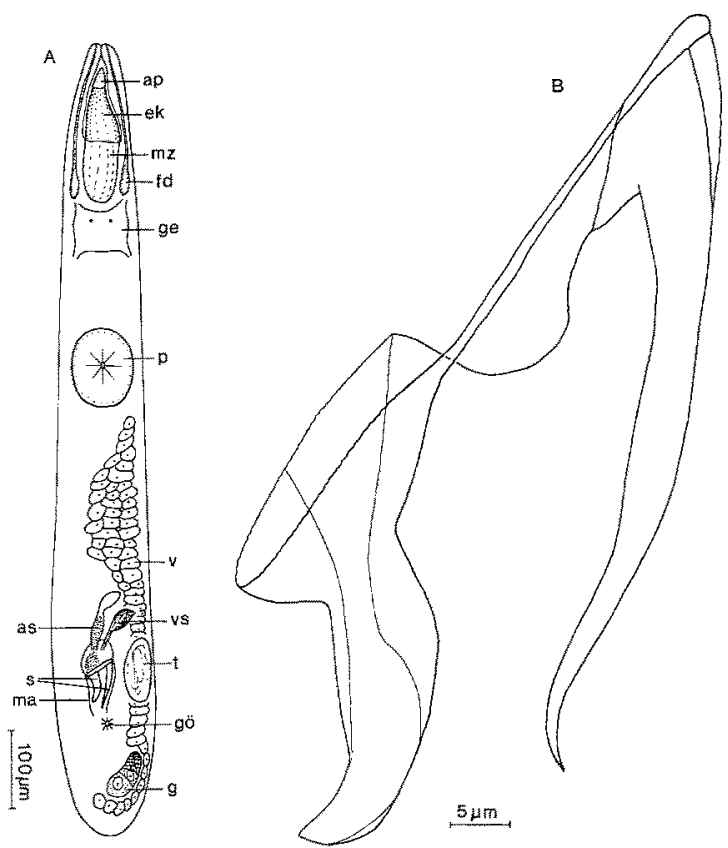

Abb. 5: Typblopolycystis limicola. A Organisation; B Stilette (Quetschpräparat) 
neben dem Rüssel Frontaldrüsen zu erkennen, im Hinterende liegen mehrere Schwanzdrüsen. Das Gehirn enthält zwei Augen. Der Pharynx rosulatus ( $p$ ) liegt vor der Körpermitte.

Der Rüssel besteht aus einem kleinen spitzen Apex, einem recht langen Endkegel mit einer sehr auffällig granulierten Oberfläche und einem rundlichen Muskelzapfen.

Die Geschlechtsorgane sind unpaar, auf den hinteren Körperabschnitt konzentriert. Die gemeinsame Geschlechtsöffnung (gö) ist bei etwa ${ }^{5 / 6}$ der Körperlänge. Der Hoden $(t)$ liegt links, ein wenig vor der Geschlechtsöffnung. Die langgestreckte, spindelförmige Samenblase ( $v s$ ) verjüngt sich caudad und tritt in den Bulbus des männlichen Kopulationsorgans $(k)$ ein. Ferner mündet ein accessorisches Drüsenorgan. Dem Bulbus sind zwei proximal verbundene Stilette angeschlossen. Das kürzere Stilett (45 $\mu \mathrm{m})$ ist sichelförmig gebogen, rinnenförmig. Das längere, ebenfalls hohle Stilett $(61 \mu \mathrm{m})$ endet in einer scharfen, gebogenen Spitze. Beide Stilette sind frontal erweitert. Die Vorderränder sind durch einen sehr feinen, kutikularen Membranteil zu einem Ring verbunden.

Die Stilette ragen weit in das lange, umfangreiche männliche Atrium, das mit einer sehr deutlichen Quermuskelhülle versehen ist.

Das Germar $(g)$ befindet sich caudal von der Geschlechtsöffnung auf der linken Seite. Es ist nicht mit dem Vitellar (v) verwachsen, das sich vom Pharynx bis ins äuBerste Hinterende erstreckt.

Diskussion: Die Gattung Typhlopolycystis ist durch ein Seminalstilett, ein accessorisches Drüsenorgan mit einem zweiten Stilett, einen Bulbus (für den Ductus ejaculatorius und die Kornsekretblase), eine subterminale Geschlechtsöffnung und durch unpaare Gonaden charakterisiert (KARLING 1956). Die Stilette anderer Gattungen, die sich ebenfalls in diese Merkmalskombination einfügen, zeigen spezifische Unterschiede gegen das Stilett unserer Art im Zusammenhalt und Form. Im Gegensatz zu $T$. mediterranea hat $T$. limicola einen schwächeren proximalen Ring und ein zugespitztes, gebogenes Ende des längeren Stiletts (BRUNET 1965).

\section{Limipolycystis nov. gen.}

Gattungsdiagnose: Geschlechtsorgane unpaarig; Samenblase mündet proximal in den männlichen Genitalkanal; Kornsekretblase mit distalem Blindsack; ein Kutikularstilett in männlichen Genitalkanal; in und neben dem Stilett Kornsekret; Germar mit Bursahohlorgan verbunden; Geschlechtsöffnung subterminal.

Typart: L. curvitubo nov. spec.

\section{Limipolycystis curvitubo nov. spec.}

(Abb. 6)

Fun dort: Sylt: 12 sw (Locus typicus).

Materia 1 : Lebendbeobachtungen (ein Exemplar), drei Schnittserien, (Holotypus eine Querschnittserie).

B e s chreibung: Die Art erreicht knapp $1 \mathrm{~mm}$ Länge, ist vorne etwas zugespitzt, hinten einfach abgerundet. Im Hinterende liegen einige Schwanzdrüsen. Haftapparate fehlen. Die Epidermis ist mit kleinen Vakuolen durchsetzt.

Ein besonderes Farbmerkmal bieten rotgefärbte Drüsen im Vorderkörper. 
Das Gehirn enthält zwei Augen. Vor der Körpermitte liegt der Pharynx rosulatus $(p)$. Die Pharynxtasche ist mittels eines Sphinkters verschließbar und von zahlreichen Ring- und Längsmuskeln umgeben. Schräg nach vorne gerichtet, sehr kontraktil, führt sie zu dem abwärts orientierten Bulbus, der einen kräftigen ventralen Greifwulst und dorsale kutikulare Buckel besitzt. Am Darmeingang münden sehr große Körnerkolben. Der einfache Rüssel besteht aus Apex, Endkegel und Muskelzapfen.

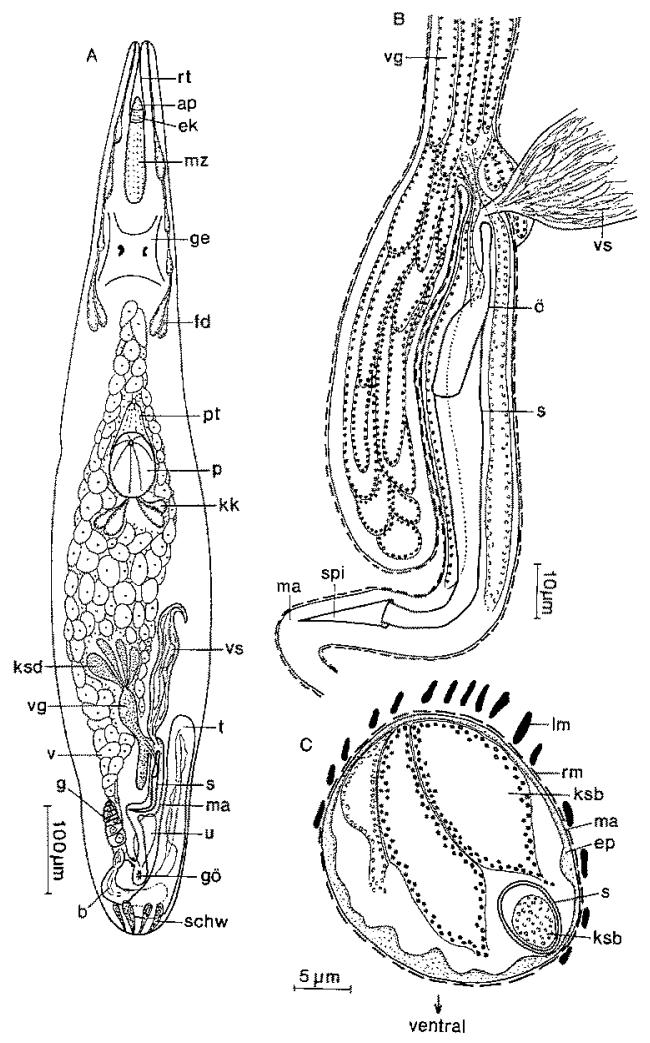

Abb. 6: Limipolycystis curvitubo. A Organisation (kombiniert); B männliches Kopulationsorgan (kombiniert aus Quetschpräparat und Schnittserie); $C$ schräger Querschnitt durch das männliche Genitalatrium mit Stilett

Die Geschlechtsorgane sind unpaarig angelegt. Die einzige Geschlechtsöffnung liegt ventral, median, kurz vor dem Hinterende.

Der Hoden $(t)$ liegt lateral im Hinterende. Die Samenblase (vs) erreicht etwa $150 \mu \mathrm{m}$ Länge, verjüngt sich caudad und mündet neben dem Stilett proximal in den männlichen Genitalkanal. Die muskulöse Vesicula granulorum (vg) teilt sich unmittelbar vor dem Stilett in einen auffälligen Blindsack, der den Genitalkanal bis zur Hälfte begleitet und in einen engeren Kanal, der proximal neben der Samenblase in den Genitalkanal einmündet. Ein Teil des Kornsekrets tritt in das Stilett ein. Ein anderer Teil liegt strangförmig neben dem Stilett im Genitalkanal. 
Das Stilett ist ein L-förmig gebogenes Hohlrohr. Es besteht aus einer etwa $32 \mu \mathrm{m}$ langen, schiefen, löffelartigen Offnung, einem geraden Rohrteil $(41 \mu \mathrm{m})$ und einem um $90^{\circ}$ abgeknickten Endabschnitt $(32 \mu \mathrm{m})$ mit einer Tüte. Diese ist dem Rohr fest aufgeschoben. Im Querschnitt ist das Stilett rund.

Der lange männliche Genitalkanal ist von Ringmuskeln, dorsal auch von kräftigeren Längsmuskeln umgeben. In dem Genitalkanal liegen das Stilett und die Kornsekretstränge. Das Sekret umfaßt feinkörnige, eosinophile und basophile Elemente. Ein Kanal für das Sperma fehlt; es wird vermutlich durch die Lücken zwischen dem Stilett und dem Sekret ausgeleitet. Weder im Genitalkanal noch im Stilett habe ich jedoch Sperma gefunden.

Der männliche Genitalkanal mündet in das gemeinsame Genitalatrium vor der Geschlechtsöffnung aus.

Das Germar ( $g$ ) liegt dorsal zum männlichen Genitalkanal bzw. der Kornsekretblase. Caudal ist der größten Oocyte ein kleines Bursahohlorgan (b) direkt angeschlossen, das Sperma enthalten kann. Eine Bursa resorbiens liegt weiter hinten neben und hinter der Geschlechtsöffnung. Beide Bursateile sind miteinander verbunden.

Der Ovidukt mündet von dorsal in das gemeinsame Atrium.

Das Vitellar $(v)$ reicht vom Gehirn zum Germar.

Ventral von dem männlichen Genitalkanal liegt der Uterus ( $u$ ), der einen schmalen Ausfuhrgang ventral in das gemeinsame Atrium unmittelbar vor der Geschlechtsöffnung hat.

Diskus s ion: Für die Verwandtschaftsbeziehungen innerhalb der Polycystidae muß die Struktur des Stiletts herangezogen werden. Wenn wir von dem einzigen Stilett und den unpaaren Geschlechtsorganen ausgehen, kommt lediglich die Gattung Gyratrix in Betracht. Der Feinbau der männlichen Organe (Kornsekretblase) schließt jedoch eine enge Verwandtschaft aus.

Das Stilett von Danorbynchus gosoensis ist dem von Limipolycystis recht ähnlich, besteht aber aus zwei Teilen. Obgleich Parachrorbynchus, Annulorbynchus und Mesorbynchus sich in ihrer Organisation tiefgreifend von Limipolycystis unterscheiden, erwähne ich gleiche Merkmale des männlichen Genitalkanals.

Die Errichtung einer neuen Gattung gründet sich damit vor allem auf die unpaaren Geschlechtsorgane, auf die Ausprägung des Stiletts und die abgesetzte Kornsekretblase.

Familie Koinocystidae MEIXNER 1925

Utelga scotica Karing 1954

Fund ort: Sylt: $16 \mathrm{sw}$, sh.

Utelga beinckei (ATTEMs 1897)

Fu n d o r : Helgoland: Phytal (Atrems 1897).

Parautelga bilioi KarLING 1964

F u n dor t : Sylt: 22 (leg. Ax), 12 sh (leg. Hoxhold). 
Marirbynchus longasaeta nov. spec.

Gat tu ngs diag nos e: Rüssel mit Apex; Geschlechtsorgane unpaarig; männliches Kopulationsorgan mit zentralem Ductus ejaculatorius und Stilett; langes, gemeinsames Atrium; Germar von Bursa umgeben, die das Hinterende ausfüllt; Geschlechtsöffnung terminal.

Typart: $M$. longasaeta nov. spec.

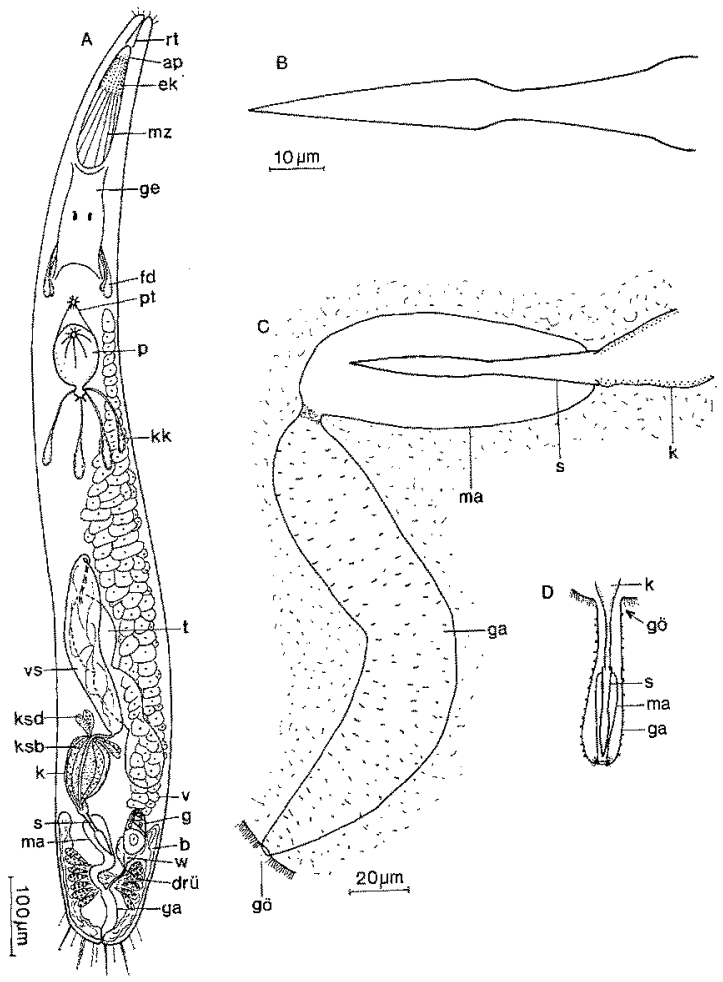

Abb. 7: Marirbyncbus longasaeta. A Organisation (kombiniert); $B$ Stilett (Quetschpräparat); $C$ männliches und gemeinsames Genitalatrium mit Stilett (Quetschpräparat); $D$ beide Atrien ausgestülpt (Quetschpräparat)

\section{Marirbynchus longasaeta nov. spec.}

(Abb. 7,9)

Fund ort: Sylt: $1 \mathrm{sh}, 3 \mathrm{sh}, 4 \mathrm{sh}, 5 \mathrm{sh}, 10 \mathrm{sw} \mathrm{q}, 11 \mathrm{sh}, 12 \mathrm{sw} s \mathrm{sh}, 25 \mathrm{q}, 29 \mathrm{q}$ (Locus typicus).

M a te ria 1 : Lebendbeobachtungen, sechs Schnittserien, ein Dauerpräparat (Holotypus).

B e schreibung: Bei 1,2-1,5 mm Länge ähnelt der Körper dem von Gyratrix; er ist torpedoförmig und hat keine seitlichen Auswüchse, Lappen oder Haftapparate. Das mit langen, radial angeordneten Tasthaaren versehene Vorderende ist etwas verjüngt. Vor dem Hinterende kann sich das Tier zuweilen ganz leicht einschnü- 
ren, ist aber meist abgerundet. Hier inserieren sehr lange Tasthaare, die teilweise zu Bündeln zusammengefaßt sind.

Die Art kann sich kugelförmig kontrahieren. Ungestört schwimmen die Tiere sehr lebhaft. Die Epidermis enthält überall kleine, weißliche Vakuolen.

Die Tiere sind dunkelgrau bis schwärzlich gefärbt. Das umfangreiche Gehirn enthält zwei Augen; hinter ihm sind mehrere Frontaldrüsen zu erkennen.

Der Pharynx liegt am Anfang des 2. Körperdrittels, der Bulbus und die lange Tasche sind schräg nach vorne gerichtet. Im Bulbus $(\phi 100-140 \mu \mathrm{m})$ lassen sich drei verschiedene Drüsensekrete unterscheiden. Der ventrale Greifwulst ist gut entwickelt. Ein dorsaler Greifwulst fehlt oder ist nur sehr klein; kutikulare Buckel fehlen ebenfalls. Dem Bulbus schließt sich ein kleiner, muskulöser, mit langen Drüsen versehener Oesophagus an.

Der Rüssel ist 160-240 $\mu \mathrm{m}$ lang. Der rundliche oder stumpfe Apex sitzt dem Endkegel auf, der eine granulierte Oberfläche hat. Der Muskelzapfen ist etwa so lang wie die beiden ersten Abschnitte zusammen.

Die unpaaren Geschlechtsorgane sind auf die Region caudal des Pharynx beschränkt. Die Geschlechtsöffnung ( gö) liegt terminal.

Der Hoden $(t)$ befindet sich in der 2. Körperhälfte. Er kann fast den gesamten Querschnitt ausfüllen und ist in lappige Abschnitte unterteilt, die zuweilen wie einzelne Follikel aussehen. Ein kurzes Vas deferens führt zu der sehr umfangreichen, langen Samenblase (vs; 220-240 $\mu \mathrm{m}$ ). Von einer Quermuskelhülle umgeben, verjüngt sie sich caudad in einen feinen Seminalkanal, der frontal in den kugelförmigen Bulbus des männlichen Kopulationsorgans $(k)$ mündet. Wenige Kornsekretdrüsen sezernieren zweierlei Sekrete. Das Kopulationsorgan besteht aus einem birnförmigen Bulbus (Länge 200-240 $\mu \mathrm{m}$ ) und dem Stilett. Das Organ kann sich beim Ausführen des Stiletts beträchtlich verlängern und verjüingen, sieht dann etwa flaschenförmig aus (Abb. 7C, D). Der Bulbus besitzt eine kräftige Quermuskelhülle. Innen schließen sich die grobkörnigen, basophilen Kornsekrete an, während um den Ductus ejaculatorius feinkörnige, eosinophile Sekrete liegen. Das Stilett $(s)$ ist proximal mit der Außenhülle des Bulbus verwachsen und ragt weit in das männliche Atrium. Es erreicht 71 bis $83 \mu \mathrm{m}$ Länge und ist wie eine Speerspitze gebaut. Im Quetschpräparat ist der Austritt von Kornsekret und Sperma aus der schrägen Stilettöffnung zu beobachten.

Das lange männliche Atrium ( $m a$ ) ist von zwei konzentrischen Kreisen radial angeordneter Längsmuskeln umgeben. Es mündet in das gemeinsame, sackförmige Genitalatrium ein. Direkt daneben beginnt der Ductus communis. Dieser führt rostrad zum Germar $(g)$. Das vorne lappige, zum Teil sehr umfangreiche Vitellar (v) reicht vom Pharynx bis zum Germar. Die Bursa (b) liegt als umfangreicher, unscharf abgesetzter Schlauch innen dem. Hautmuskelschlauch des Hinterendes an. Ein Teil der Bursa dringt bis zum Germar vor und umhällt dieses zumindestens teilweise. Öberall in der Bursa sind regellos verteilte Spermien und Vakuolen anzutreffen. Ein sehr auffälliges Artmerkmal bilden zwei laterale, basophile Drüsengruppen im Hinterende.

$\mathrm{D}$ is $\mathrm{k}$ us s i o n: Die Eingruppierung von Marirbynchus longasaeta in eine Familie der Eukalyptorhynchia stößt auf Schwierigkeiten (vgl. KARLING 1964, p. 180). Da kutikulare Buckel am Pharynx fehlen und der Bulbus des Kopulationsorgans den Ductus ejaculatorius und die Kornsekretblasen umgibt, muß eine nähere Verwandt- 
schaft mit den Polycystidae ausgeschlossen werden. Die Unpaarigkeit der Gonaden und das Vorhandensein eines Stiletts trennt die Art von den Cystiplanidae, Cytocystidae, Koinocystidae, Psammorhynchidae. Auch gegen die Cicerinidae ist die Art vor allem wegen der fehlenden Ampullen an der Junktur abzugrenzen.

Obwohl mir eine engere Beziehung zu einer Gruppe der Eukalyptorhynchia zu fehlen scheint, möchte ich doch darauf verzichten, die Art in den Rang einer Familie zu erheben, bevor nicht eine exakte histologische Analyse des Rüssels und der Atrialorgane vorliegt.

Marirbynchus longasaeta wird mit Vorbehalt zu den Koinocystidae gestellt. Hierfür sprechen das Vorhandensein eines Apex, der Bau des Kopulationsorgans und die Form des Pharynx.

\section{Familie Cystiplanidae KarLING 1964}

Die Familiendiagnose (KarLING, p. 180) muß wegen der nicht vakuolisierten Epidermis von Nigerrbynchus geändert werden und enthält den Zusatz: „Epidermis hoch, stark, vakuolisiert oder flach, nicht vakuolisiert."

Die bisher monotypische Gattung Cystiplana existiert mit zwei eng verwandten Arten im Sandhang von Sylt. Diese beiden Arten werden von HoxHoLD eingehend bearbeitet; im folgenden sind nur die Fundorte genannt.

\section{Cystiplana paradoxa KARLING 1964}

F un d or te : Sylt: $1 \mathrm{sh}, 3 \mathrm{sh}, 4 \mathrm{sh}, 5 \mathrm{sh}$ sw, $12 \mathrm{sh}$ sw, $16 \mathrm{sh}, 17 \mathrm{sh}, 24 \mathrm{sh}$; Ellenbogen, im Prallhang (KarLING 1964); Amrum: $4 \mathrm{sh}, 16 \mathrm{sw}$.

\section{Cystiplana karlingi HoxHoLd n. n.}

Fund o r t : Sylt: 12 sh (leg. HoxHoLd)

Nigerrbynchus nov. gen.

Gattungsdiagnose: Apex frontal mit kreisförmiger Struktur; geschlechtsorgane paarig; Geschlechtsöffnung terminal; etwa fünf Hodenfollikel; langes, männliches Kopulationsorgan mit intrakapsulärer Kornsekretblase; Germarien miteinander verwachsen.

Typart: N. opisthoporus nov. spec.

Nigerrbynchus opisthoporus nov. spec.

(Abb. 8, 9)

Fu n d o r t : Sylt: $1 \mathrm{sh}, 2 \mathrm{sh}, 4,5 \mathrm{sh}, 6,12 \mathrm{sw}$ sh (Locus typicus), $14 \mathrm{sw}, 25 \mathrm{sw}$. $\mathrm{M}$ a te $\mathrm{r}$ a 1 : Lebendbeobachtungen.

B es chreibung: Die Art erreicht 1,5-1,8 mm Länge. Das Vorderende läuf spitz zu. Das Hinterende ist konisch oder einfach abgerundet. Die Art kontrahiert sich kugelförmig. Haftapparate fehlen. Die Epidermis ist mit kleinen, grünlichen, runden Rhabditen bedeckt. Die Körperfarbe ist mit Ausnahme des äußersten Vorderund Hinterendes braunschwarz, undurchsichtig. Hinter dem Rüssel ist ein umfangreiches, langgestrecktes, augenloses Gehirn entwickelt, dem sich mehrere Frontaldrüsen anschließen. 
Der Pharynx rosulatus $(p)$ liegt kurz hinter dem Beginn des zweiten Körperviertels. Der Bulbus ist 175-320 $\mu \mathrm{m}$ lang. Am Oesophagus und Darmeingang befinden sich einige Körnerkolben.

Der sehr kurze Rüssel ist aus Apex, Endkegel und Muskelzapfen aufgebaut (Länge 120-140 $\mu \mathrm{m}$; entspricht $1 / 13$ Körperlänge). Apex und Endkegel allein erreichen etwa $45 \mu \mathrm{m}$. Der Apex sitzt als winziges Käppchen vorne dem Endkegel auf, ist durchsichtig und hat zentral an seiner Spitze eine kreisförmige Struktur (Porus?).

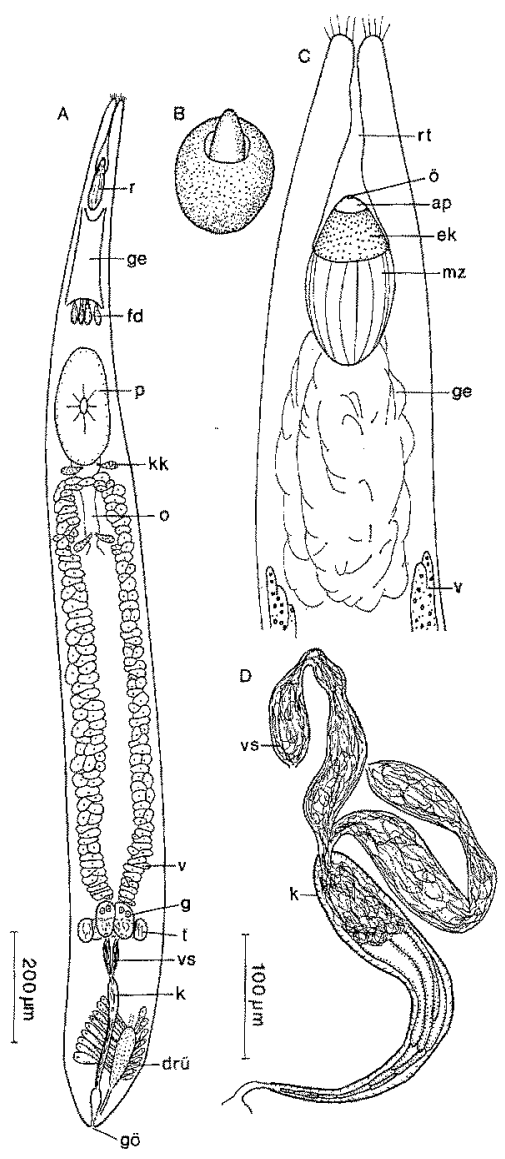

Abb. 8: Nigerrbyncbus opisthoporus. A Organisation (kombiniert); $B$ kontrahiertes Exemplar; $C$ Vorderende mit Rüssel (Quetschpräparat); $D$ männliches Kopulationsorgan (Quetschpräparat)

Der Endkegel unterscheidet sich scharf vom Apex durch seine gekörnte Oberfläche, an der Sekrete austreten. Der Endkegel ist andererseits durch dunklere Färbung von dem weißen, rundlichen Muskelzapfen abgesetzt, der proximal mit der Rüsseltasche verwachsen ist, die so lang wie der Rüssel wird. Die paarigen Geschlechtsorgane befinden sich hinter dem Pharynx. Die einzige Geschlechtsöffnung (gö) liegt terminal. Die Hoden ( $t$ ) bilden eine mehr oder weniger zusammenhängende Gruppe 

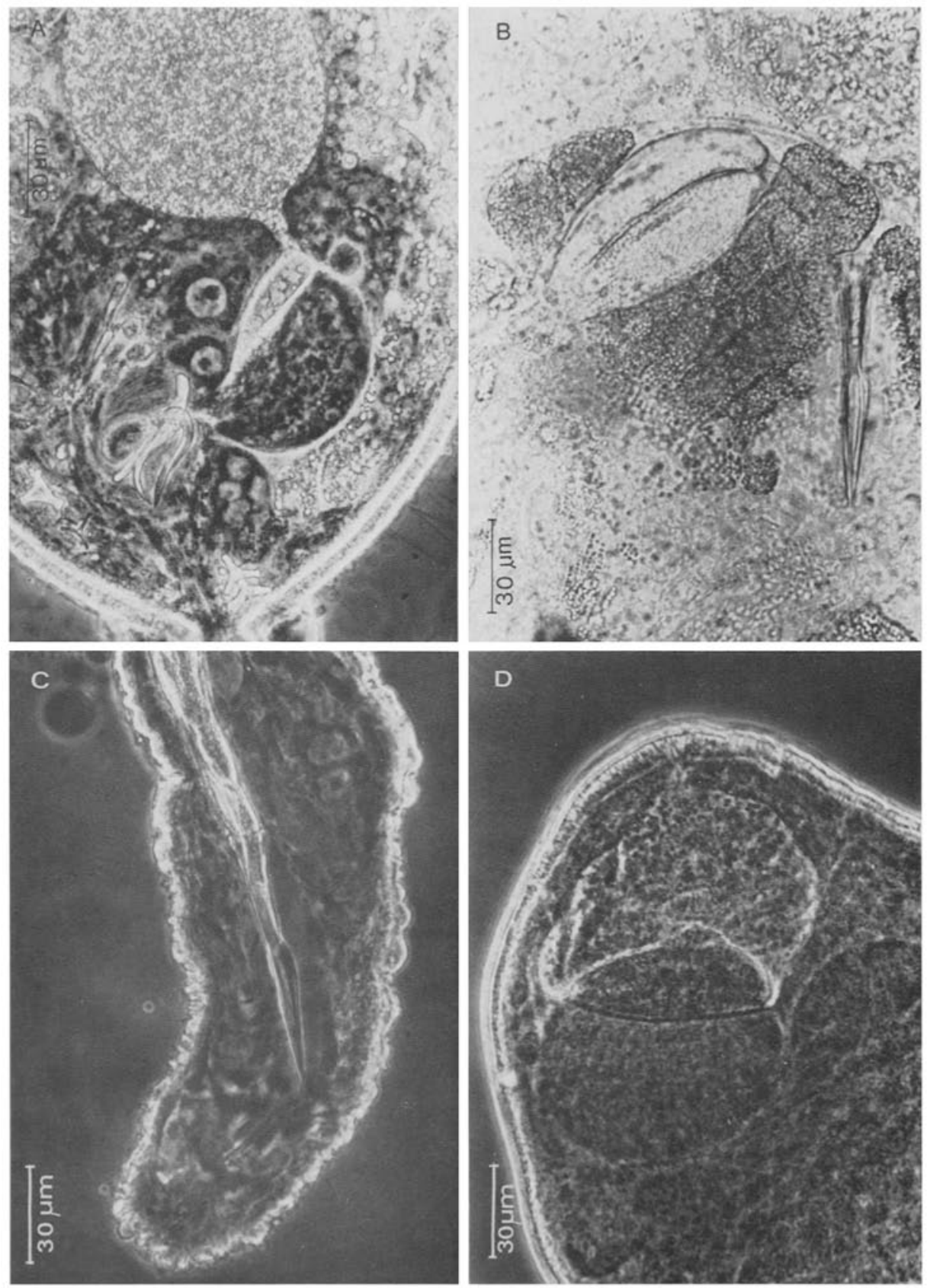

Abb. 9: A Neopolycystis tridentata. Hinterende mit Einschlüssen; $B$ Marirbynchus longasaeta. Männliches Kopulationsorgan mit Stilett; $C$ Marirbyncbus longasaeta. Stilett im ausgestülpten männlichen Atrium; $D$ Nigerrbynchtss opisthoportus. Rüssel 
von etwa fünf Follikeln am Beginn des letzten Körperviertels. Sie liegen bei einigen Tieren nebeneinander, bei anderen hintereinander gestaffelt. Die paarigen Samenblasen $(v s)$ in Form langer, schmaler Schläuche (160-320 $\mu \mathrm{m})$, münden frontal in das männliche Kopulationsorgan $(k)$. Dieses ist ein langgestreckter Schlauch (190 bis $400 \mu \mathrm{m}$ ), dem jegliche Bewaffnung, Kutikularisierung oder Zonierung fehlt. Das Kopulationsorgan ist von einer proximal kräftigen, distal schwächeren Spiralmuskelhülle umgeben. In seinem Innern ist ein breiter Ductus ejaculatorius zu erkennen, neben und in dem die Kornsekrete in länglichen Paketen liegen. Freie Kornsekretdrüsen fehlen. In der proximalen Anschwellung liegen Spermien.

Das Kopulationsorgan geht in ein kurzes, muskulöses Genitalatrium über. Die beiden Germarien $(g)$ liegen in Höhe der Hoden und sind miteinander verbunden. Sie enthalten bei einem Exemplar je 10-15 etwa gleichgroße Oozyten, die nicht serial angeordnet sind.

Die beiden Vitellarien $(v)$ bilden sehr umfangreiche, laterale Schläuche, die sich hinter dem Pharynx vereinigen. Im Hinterende der Tiere liegt neben dem Kopulationsorgan ein elliptisches Organ mit unbekannter Funktion. Es ist in sehr umfangreiche Drüsen eingebettet, die das Hinterende fast ausfüllen und bei einigen der Tiere in zwei Bündeln angeordnet sind. Von diesem Organ zieht ein Kanal zur Geschlechtsöffnung.

D iskus ion: Nigerrbynchus opisthoporns wird der Familie Cystiplanidae zugeordnet. Grundsätzliche Obereinstimmungen erstrecken sich auf das Kopulationsorgan, den Apex, die paarigen Geschlechtsorgane, die Hoden, die Lage der Vitellarien, den Oesophagus, den Pharynx, den Darm, die Lage der Geschlechtsöffnung (vgl. Karling 1964, p. 164-172, p. 179, p. 180; BRunet 1965, p. 182 f.). Nigerrhynchus unterscheidet sich von Cystiplana, Cystiplex und Cystirete durch paarige Samenblasen und den Bau des Kopulationsorgans.

\section{Familie Psammorhynchidae KarLing 1956}

\section{Psammorbynchus tubulipenis MeIXNer 1938}

F u n d orte : Sylt: $5 \mathrm{sh}$ sw, $12 \mathrm{sw}, 16 \mathrm{sw}, 25 \mathrm{sw}$ k. Amrum: $1,2 \mathrm{sh}$, Sylt und Amrum: Prallhang (KarLING 1956).

Material: Lebendbeobachtungen.

Beschreibung: Da bislang nur Habitus, Organtopographie und männliche Atrialorgane bekannt sind, mache ich ergänzende Angaben. Die Exemplare von Sylt und Amrum (Länge $1 \mathrm{~mm}$ ) sind dunkelgrau bis braun gefärbt und völlig undurchsichtig. Das zugespitzte Vorderende trägt einige lange Tasthaare, das von großen Schwanzdrüsen ausgefüllte Hinterende ist stets abgerundet. Bei Beunruhigung kontrahieren sich die Tiere kugelförmig. Die Epidermis ist mit kleinen, punktförmigen Wärzchen bedeckt (Rhabditen?). Das auffällig zweilappige Gehirn enthält zwei Augen.

Der Pharynx (80-130 $\mu \mathrm{m})$ liegt am Ende des vorderen Körperdrittels.

Der Rüssel ist nur 40-80 $\mu \mathrm{m}$ lang und durch einen fein längsgestreiften Endkegel ausgezeichnet.

Die Geschlechtsorgane sind unpaarig. Der Hoden nimmt etwa auf der Hälfte 
zwischen Pharynx und Hinterende die linke Körperseite ein. Die Samenblase erreicht 140-190 $\mu \mathrm{m}$ Länge, während das Kopulationsorgan 70-130 $\mu \mathrm{m}$ lang ist.

Das charakteristische Drüsenorgan im Atrium ist immer deutlich. Die gemeinsame Geschlechtsöffnung liegt ventral, unmittelbar vor dem Hinterende.

Das Germar ist auf der rechten Seite entwickelt. Das Vitellar reicht proximal bis neben den Pharynx. Es kann in voller weiblicher Reife mit seinen breiten Vitellocyten den mittleren Körperabschnitt nahezu ausfüllen. Vor der Geschlechtsöffnung ist der weite, sackförmige Uterus angelegt, in dessen mittleren und caudalen Teil zahlreiche Drüsen ausmünden.

\section{Familie Cicerinidae MeIXNer 1938}

\section{Cicerina brevicirrus MEIXNER 1928}

Fund or te : Sylt: 5, $10 \mathrm{sw}, 12 \mathrm{sw}, 15 \mathrm{sw}, 16 \mathrm{sw}, 19,23 \mathrm{sh} \mathrm{k,} 24 \mathrm{sw}$ k; Sylt: Ostufer von List (Karling 1952); Amrum: 1, 8, $12 \mathrm{k}$; b. Amrum (Karling 1952); Amrum-Sylt: Farbstreifensandwatt (MeIXNer 1938); Ostsee: Kieler Förde, Strande, sw; Helgoland (KARLING 1952).

\section{Cicerina remanei MeIXNER 1928}

Fund or te: Sylt: $12 \mathrm{sw}, 13 \mathrm{sw}, 18 \mathrm{k}, 25 \mathrm{sw}$; Ostufer von List, ArenicolaSandwatt (KARLING 1952), Amrum: 5 sh, 7 sw, 4 sh; Rømø: Lakolk, Weststrand. Helgoland: Nordostseite der Düne (MeIXNer 1938).

\section{Cicerina tetradactyla GiARD 1904}

F u n d o r t e : Sylt: $12 \mathrm{sw}, 15 \mathrm{sw}$; Ostsee: Kieler Förde, Strande; Heiligenhafen, Graswarder, Sandhang.

\section{Paracicerina laboeica MeIXner 1928}

F und orte : Sylt: 12 sh sw, 14 sw; List, Ostufer, Prallhang (Karling 1952); Ostsee: Kieler Förde, Strande.

Paracicerina maristoi KARLING 1952

Fu n d or t: Sylt: 10 sh k, 13 .

\section{Ptyalorbynchus coecus MerXner in Ax 1951}

(Abb. 10, 15)

Fund or te : Sylt: 5 sh, $12 \mathrm{sw} \mathrm{k,} \mathrm{13,} 16$ sw, $25 \mathrm{sw}$; Amrum: 4 sh; Rømø: Lakolk, Weststrand, Sandhang; Ostsee: Kieler Förde, Strande.

$\mathrm{M}$ a t e r i a 1 : Lebendbeobachtungen.

Beschreibung: Ptyalorbynchus coecus MeTXNer $1938 \mathrm{n} . \mathrm{n}$. wurde von Ax (1951) kurz gekennzeichnet. KarLING (1952) stellt einen Bestimmungsschlüssel der Zonorhynchidae auf und weist die Art mit Vorbehalt in die Unterfamilie der Cicerinidae ein. 
Die Art erreicht 1,6-1,8 mm Länge. Das abgerundete Vorderende trägt mehrere Tasthaare. Die Art besitzt - ganz ähnlich wie Cicerina - 6-8 serial angeordnete Kränze mit jeweils etwa vier Haftpapillen. Kurz vor dem abgerundeten, zuweilen abgestutzten Hinterende befindet sich ein besonders kräftiger Papillenkranz. Allein mit seiner Hilfe können sich die Tiere fest am Substrat anheften.

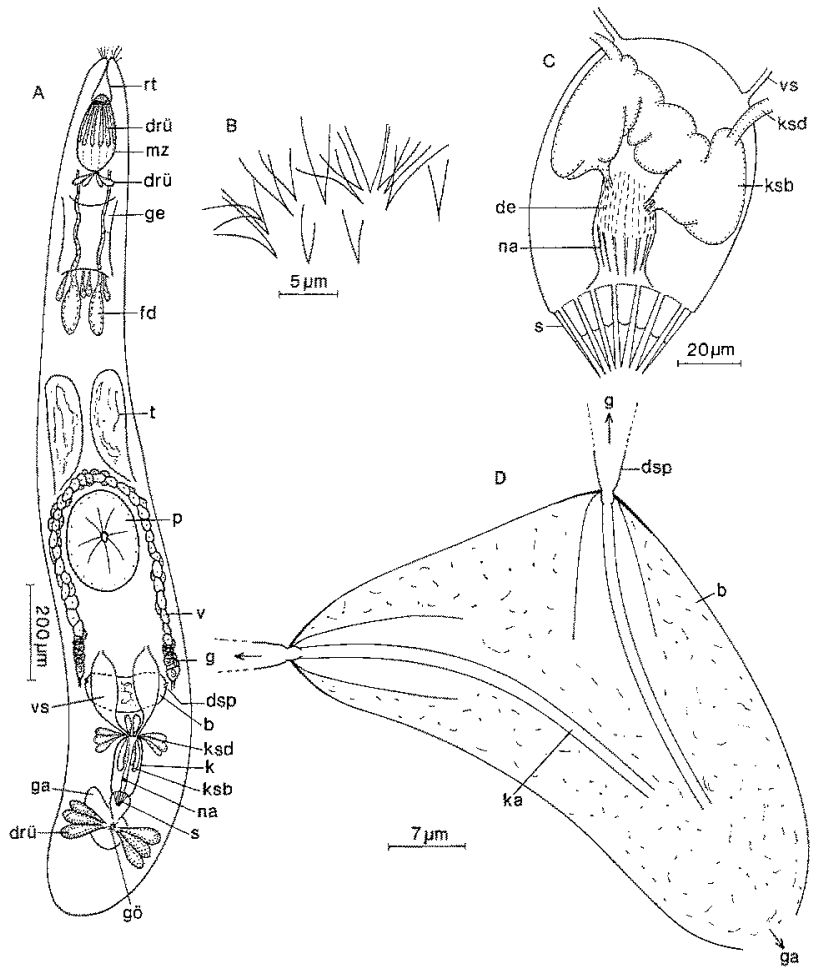

Abb. 10: Ptyalorbynchus coecus. A Organisation (kombiniert); B proximaler Häkchenkranz vor dem Stilett (Quetschpräparat); $C$ männliches Kopulationsorgan mit Stilett (Quetschpräparat); $D$ Ductus spermatici (Quetschpräparat)

Die Epidermis ist auch im gestreckten 'Tier nicht glatt, sondern ganz leicht wellig. Bei einem Exemplar von Amrum sieht sie grünlich gekörnt aus (Rhabditen).

Hellgrau gefärbt, sind die Tiere bis auf das Hinterende ziemlich durchsichtig. Der tiefschwarze Endkegel des Rüssels, der zur Namensgebung herangezogen worden ist, hebt sich als unübersehbares, spezifisches Artmerkmal stets sehr kräftig ab.

Das augenlose, umfangreiche Gehirn liegt vor zahlreichen Frontaldrüsen, von denen zwei besonders groß sind. Unmittelbar hinter dem Rüssel befindet sich eine traubige Frontaldrüsengruppe, deren Sekrete caudal in den Muskelzapfen gelangen.

Der Pharynx rosulatus ( $p$ ) liegt kurz hinter der Körpermitte und ist senkrecht zur Körperlängsachse aufgerichtet $(160-220 \mu \mathrm{m})$.

Der biegsame Rüssel (140-260 $\mu \mathrm{m})$ beginnt mit dem Endkegel, der fein gekörnt, kappenförmig ist. Hinter ihm beginnt ein kürzerer Drüsenkranz, dessen kleine, schlitz- 
förmige, radial angeordnete Drüsenzellen besonders dunkel gefärbt sind. Sie heben sich dadurch von den etwas weniger dunklen Drüsenzellen eines langen Drüsenkranzes deutlich $a b$. Dieser reicht bis mindestens zur Hältte, meistens bis etwa $2 / 3$ der Rüssellänge.

Zwei große elliptische oder keulenförmige Hoden ( $t$ ) liegen vor dem Pharynx. Die beiden Samenblasen (vs) schwellen hinter dem Pharynx an, sind gestreckt oder auch kugelig (Länge daher 130-360 $\mu \mathrm{m}$ ) und verjüngen sich caudad zu mehr oder weniger langen Seminalkanälen. Sie münden frontal neben den Ausfubrgängen mehrerer traubig entwickelter Kornsekretdrüsen in das männliche Kopulationsorgan ein. Dieses ist ein etwa 140-160 $\mu \mathrm{m}$ langer, elliptischer bis zapfenförmiger, muskulöser Schlauch $(k)$. In den vorderen $2 / 3$ liegt in ihm die Kornsekretblase. Der Ductus ejaculatorius besitzt Längsmuskeln, er ist in der Mitte und am Ende mit zwei Nadel-kränzen bewaffnet. Der vordere umfaßt etwa 15-20 (30) konische Nadeln (6 bis $8 \mu \mathrm{m})$. In dem hinteren Nadelkranz sind etwa 24 Nadeln $(24-35 \mu \mathrm{m})$ eng nebeneinander gestaffelt. Jede Nadel besteht aus zwei Abschnitten. Mehrere Nadeln werden zu Stacheln zusammengelegt, die dann distal auseinanderweichen und eine kronenförmige, zylindrische Figur ergeben.

Neben dem Nadelkranz setzt am Hinterende des Kopulationsorgans das kurze männliche Genitalatrium an. Die Geschlechtsöffnung (gö) liegt etwa bei $5 / 6$ der Körperlänge und leitet in das gemeinsame Genitalatrium. Die paarigen Germarien $(g)$ liegen lateral ein wenig vor dem Kopulationsorgan. Im gequetschten Tier können sie bis in das Hinterende verschoben werden. Frontal sind sie je mit einem schlauchförmigen, unverästelten Vitellar (v) verbunden. Die Vitellarien können vor dem Pharynx anastomosieren.

Hinter den Germarien liegt eine hohle Bursa (b), die mit den Germarien durch je einen Ductus spermaticus ( $d s p$ ) verbunden (Länge 5-7 $\mu \mathrm{m}$ ) ist. Er besteht aus zwei zusammengesetzten Trichtern, von denen der germarseitige enger und der bursaseitige weiter ist. In der Bursa sind zwei feine Kanäle in Fortsetzung der Ductus differenziert und auf das Atrium ausgerichtet. Neben der Geschlechtsöffnung liegen weibliche Genitaldrüsen.

Ptyalorbynchus coecus frißt Nematoden, die das $11 / 2$ fache der eigenen Länge erreichen können. Als Parasiten wurden mehrfach Sporozoen gefunden. In einem Exemplar waren vor dem Pharynx etwa zehn Ciliaten.

Diskussion: Der Nachweis von Ductus spermatici nähert Ptyalorbynchus der Gattung Cicerina, die ganz ähnliche Kanäle besitzt. Sie als „Bursamundstücke zu bezeichnen, ist $\mathrm{m}$. E. irreführend, da sie Sperma aus der Bursa zum Germar leiten.

Uber dieses Merkmal wird die Zuordnung von Ptyalorbynchus in die Familie Cicerinidae gestïtzt. Sie ist allerdings im Gegensatz zu den übrigen Cicerina-Arten (Karling 1952, p.4) durch die Lage des Pharynx hinter der Körpermitte ausgezeichnet.

Ahnlich gebaute männliche Kulikularapparate hat Didiadema picardi BrUNET 1965.

\section{Zonorbynchus seminascatus KARLING 1956}

Fund orte: Sylt: 6, 8, 9, $12 \mathrm{sw}, 15 \mathrm{sw}, 16 \mathrm{sw}, 19,21 \mathrm{sh} \mathrm{k}, 24 \mathrm{sw}$; Amrum: 1, 9 sw, $14 \mathrm{sh}$; Westerhever Sand: Eulitoral im Sandwatt (KARLING 1956). 
Zonorbynchus tvaerminnensis (KARLING 1931)

Fund or te : Sylt: 19; Rømø: Lakolk, Weststrand.

Familie Placorhynchidae (Meixner 1938 n. n.) KarLing 1947

Placorbyncbus octaculeatus octaculeatus KARLING 1931

Fund or te : Sylt: $8,10 \mathrm{sh}, 12 \mathrm{sw}, 15 \mathrm{sh} \mathrm{sw}, 19 \mathrm{k}, 21 \mathrm{sh}, 25 \mathrm{sw}, 26$; Sylt-Amrum: Farbstreifensandwatt (MeIXNer 1938), Amrum: 1, 2, 4 sh, 13-15 sw, 17; Ostsee: Kieler Förde, Strande.

Placorbynchus octaculeatus dimorphis KaRLING 1947

Fund or $t:$ Sylt: 12 (leg. Hoxhold)

\section{Familie Gnathorhynchidae MeIXNER 1929}

Gnatborbynchus conocaudatus MeIXNer 1929

Fund orte: Sylt: 13, 12 sw; Ostufer von List, Sandhang (Ax 1952), Amrum: 4 sh. Rømø: Lakolk, Weststrand.

Die Exemplare von der Sandbank östlich List sind augenlos. Die Frage, ob es sich um eine eigene Art handelt, bleibt offen.

Gnathorbynchus inermis nov. spec.

(Abb. 11, 15)

Fund orte : Sylt: $5 \mathrm{sw}, 12 \mathrm{sw}$ (Locus typicus), Rømø: Lakolk, Weststrand.

$\mathrm{M}$ a te ria $1:$ Lebendbeobachtungen.

B es ch reibung: Die Art erreicht $0,9 \mathrm{~mm}$ Länge, ist vorne zugespitzt, hinten abgerundet. Bei der Kontraktion setzt sich das Hinterende konisch ab. Die Art kann lebhaft schwimmen; sie ist vorne und hinten hellgrau gefärbt, während die Körpermitte schwärzlich oder graugrün aussieht. Das umfangreiche Gehirn enthält zwei nierenförmige Augen $(\phi 6-10 \mu \mathrm{m})$.

Etwa bei $2 / 3$ der Körperlänge liegt der Pharynx rosulatus $(\phi$ ca. $50 \times 80 \mu \mathrm{m}$ ). Die Pharynxtasche ist senkrecht zur Körperlängsachse aufgestellt.

Die Ritsselhaken bestehen aus einer Spitze und zwei zarten Platten.

Die nach median gebogene Spitze $(10-12 \mu \mathrm{m})$ ist dreikantig und läuft hinten in die äußere Basalplatte aus.

An dieser und an der inneren Platte inserieren Muskeln, die das Offnen bzw. das Einschlagen der Haken bewirken.

Der Muskelzapfen $(34-46 \mu \mathrm{m})$ enthält dorsal und ventral zwei Muskelwülste, die durch eine Membran von dem übrigen Gewebe abgetrennt sind.

Der frei in die Rüsseltasche ragende Endkegel ist sehr lang, kontrahiert sich aber im Quetschpräparat auf 14-17 $\mu \mathrm{m}$. Die gesamte Rüssellänge beträgt somit 48 bis $63 \mu \mathrm{m}$.

Die unpaaren Geschlechtsorgane sind mit Ausnahme des Vitellars auf das hintere 
Körperdrittel konzentriert. Der sackförmige Hoden $(t)$ ist meistens hinter, zuweilen auch neben und vor dem Pharynx zu erkennen. Der keulenförmigen Samenblase (vs) schließt sich ein schmaler, kürzerer Seminalkanal an (Länge mit Samenblase 120 bis $200, \mu \mathrm{m}$ ). Mehrere Kornsekretdrüsen liegen neben dem Seminalkanal. Das unbewaffnete Kopulationsorgan $(k)$ ist ein proximal kugelig, distal zapfenförmig gestalteter Schlauch $(42-48 \mu \mathrm{m})$. Das Organ birgt im vorderen Teil die längliche Kornsekretblase. Im hinteren Teil ist eine zylindrische Seminalpapille mit zentralem Ductus ejaculatorius.

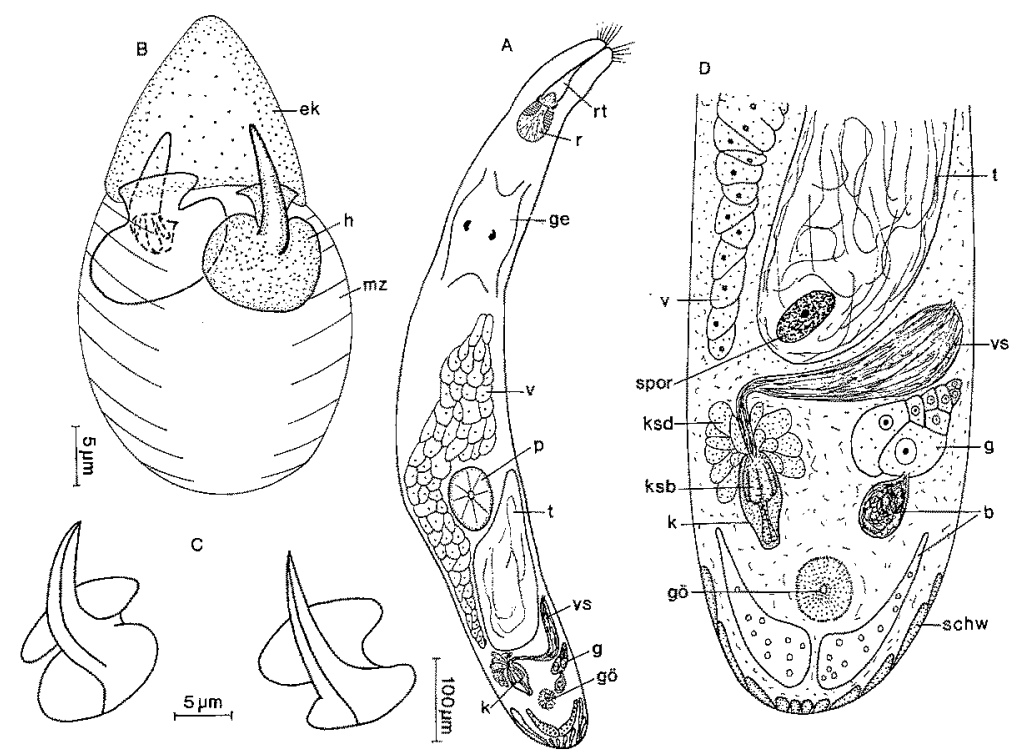

Abb. 11: Gnathorbyncbus inermis. A Organisation (kombiniert); $B$ Rüssel (Quetschpräparat); $C$ Rüsselhaken (Quetschpräparat); $D$ Hinterende (Quetschpräparat)

Die gemeinsame Geschlechtsöffnung (gö) liegt an der Ventralseite kurz vor dem Körperende. Sie ist durch ein großes, rundes Drüsenfeld markiert. Vor der Geschlechtsoffnung ist neben dem Kopulationsorgan das länglich-dreieckige Germar (g) entwikkelt. Das Vitellar ( $v$ ) kann zum Gehirn reichen, die letzten Follikel schließen auf der Höhe des Germars ab. Es ist als breiter Schlauch entwickelt oder in einzelne lappige Aste aufgespalten.

Die Bursa $(b)$ ist mit dem Germar durch einen nicht kutikularisierten Kanal verbunden. Hinter der Geschlechtsöffnung liegt ein weiterer Bursaabschnitt nierenförmig dem Körperende an, eine Bursa resorbiens. Sie enthält zahlreiche kugelige Vakuolen und ist median zweigeteilt.

Die Art wird von Sporozoen parasitiert.

Diskussion: Die Zuordnung von Gnathorbynchus inermis in die Gattung Gnathorhynchus begründe ich, obwohl die Struktur des Rüsselmuskelzapfens und des Kopulationsorgans ungenau bekannt sind, mit folgenden Merkmalen (vgl. KARLING 1947, DEN HARTOG 1968): zylindrische Muskelwiilste, unbewaffnetes Kopula- 
tionsorgan, Pharynx hinter der Körpermitte, Geschlechtsöffnung subterminal. (Die Lage des Hodens und den Besitz von Augen übergehe ich, da dies schwache Merkmale sind; vgl. DEN HARTOG 1968). Gegen eine Zuweisung wäre lediglich die nicht schwimmfußähnliche Basalplatte des Hakens anzuführen. Dies Merkmal kann m. E. nach nicht gegen die Einstellung in die Gattung Gnathorbynchus sprechen, denn es handelt sich um verschieden skulpturierte, aber stets einfache, konkave Basalscheiben.

Der Besitz einer Bursa, die bislang nur bei Odontorbynchus nachgewiesen wurde, erscheint von nebengeordneter Bedeutung. Es werden in vorliegender Arbeit weitere Gnathorhynchidae mit Bursa beschrieben, die deutlich von Gnatborbynchus inermis unterschieden sind.

Innerhalb der Gattung Gnathorbynchus bestehen enge Beziehungen zu G. krogeni KARLING 1947. Die differentialdiagnostischen Unterschiede liegen in der Hakenlänge, der Form der Basalplatten, in den Dimensionen und im Bau des Kopulationsorgans.

\section{Odontorbynchus lonchiferus KARLING 1947}

Fund orte : Sylt: $17 \mathrm{sw}$ sh, 19 sh; Ostsee: Heiligenhafen, Graswarder, Sandhang.

\section{Uncinorbynchus flavidus KARLING 1947}

Fundorte: Sylt: $12 \mathrm{sw}, 13,16 \mathrm{sw}$ sh, 19, $23 \mathrm{sh} \mathrm{k}, 24 \mathrm{k}$; Amrum: $11 \mathrm{sh}$; Ostsee: Kieler Förde, Strande.

\section{Psittacorbynchus verweyi DEN HARTOG 1968}

(Abb. 12)

Fu n d or t : Sylt: 19 sw sh.

Material: Lebendbeobachtungen.

Bes chreibung: Die Art erreicht auf Sylt 1,5 mm Länge. Das Vorderende ist konisch zugespitzt, das Hinterende ist verjüngt, abgerundet und hat keine Haftapparate. Die Epidermis ist dicht mit kleinen punktförmigen Wärzchen bedeckt (Rhabditen). Die Tiere schwimmen schnell, können sich aber auch fast kugelförmig kontrahieren. Die Körperfarbe ist gelblich-weiß. Das Tier kann aber auch in den beiden hinteren Dritteln durch das Vitellar und den Darm dunkel gefärbt sein und ist dann völlig undurchsichtig. Das Gehirn enthält zwei Augen.

Der Pharynx rosulatus ist in der Körpermitte angelegt ( $\phi 110-130 \mu \mathrm{m})$.

Der Muskelzapfen des Rüssels erreicht 60-68 $\mu \mathrm{m}$ Länge (Sylt) und enthält dorsal bzw. ventral je einen Muskelwulst. Die Frage, ob dieser "disc-shaped“ (DEN HARTOG) oder zylindrisch ist, muß eine Querschnittuntersuchung zeigen.

Der Endkegel ist bei den Exemplaren von Sylt $24 \mu \mathrm{m}$ lang und besitzt ein scharf zulaufendes Ende.

Die Rüsselhaken sind in Spitze, Zwischenstück mit Vorderplatte und Basalplatte gegliedert, sie erreichen 26-31 $\mu \mathrm{m}$ Gesamtlänge (Sylt). Die drehrunde Spitze ist etwa $12 \mu \mathrm{m}$ lang, hohl, nach innen gebogen. Sie setzt auf dem $Z$ wischenstück frontal an und ist hier gerieft (vgl. DEN HARTOG 1968, p. 342, fig. 2e). Dieses verjüngt sich ganz wenig caudad und ist etwa zylindrisch gebaut. Nach innen geht von ihm die sichelförmige Vorderplatte aus. Die runde Basalplatte ist duch eine Einschnürung abgesetzt. Die Basalplatten sitzen den Muskelwülsten auf, während die Vorderplatten 
mit Längsmuskeln verbunden sind, die den Muskelzapfen durchziehen und das Einschlagen bewirken.

Die Geschlechtsorgane sind unpaarig angelegt. Die gemeinsame Geschlechtsöffnung (gö) liegt terî̀inal. Der Hoden ( $t$ ) ist langgestreckt, beginnt hinter dem Gehirn und reicht bis hinter den Pharynx. Die keulenförmige Samenblase (vs) liegt hinter

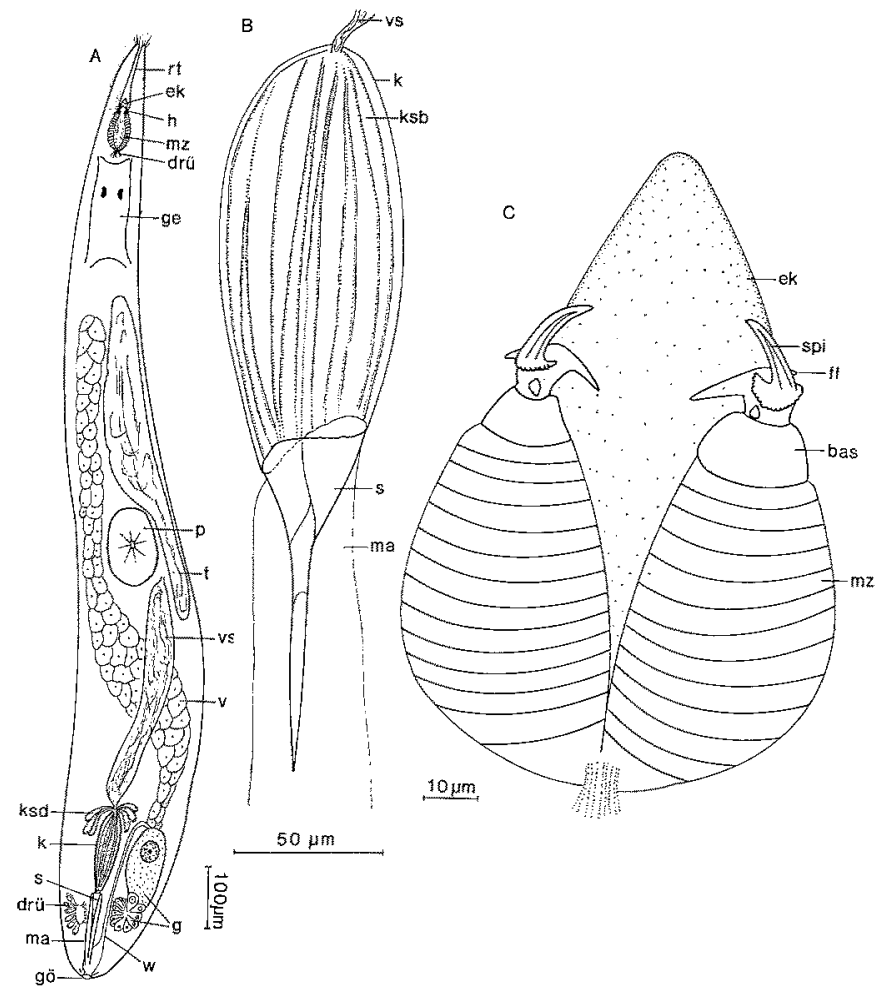

Abb. 12: Psittacorbynchus verweyi. A Organisation; $B$ Kopulationsorgan; $C$ Rüssel (Quetschpräparate)

dem Pharynx, erreicht $400 \mu \mathrm{m}$ Länge und verjüngt sich in einen ganz kurzen Seminalkanal. Er mündet zusammen mit mehreren, länglichen Kornsekretdrüsen frontal in das männliche Kopulationsorgan $(k)$ ein. Dieses ist ein dickwandiger, elliptischer, muskulöser Schlauch, der $140 \mu \mathrm{m}$ Länge erreicht (Sylt). Zentral durchzieht ihn ein feiner Ductus ejaculatorius, der von der Kornsekretblase kreisförmig umgeben ist. Die Mischung von Sperma und Kornsekret erfolgt im vorderen Teil des Stiletts (DEN HARTOG 1968). Der Ductus mündet frontal in das $112 \mu \mathrm{m}$ lange, trichterförmige Stilett ein (Sylt). Der Vorderrand des Stiletts ist gezähnt; hier greifen Muskeln an.

Am Hinterende des Organs setzt kreisförmig ein langes männliches Genitalatrium (ma) an, das eine kräftige Spiralmuskelhülle hat.

Das Germar ( $g$ ) liegt auf der Höhe des männlichen Kopulationsorgans und ist abweichend von den mir bekannten Kalyptorhynchiern - kreisförmig aufgerollt. Die 
größte Oocyte liegt frontal, die folgenden Eizellen sind im Uhrzeigersinn, konstant kleiner werdend, angeordnet. Das breite, unverästelte Vitellar ( $v)$ kann bis hinter das Gehirn reichen. Am Vorderende des Germars beginnt der Ductus communis, der in das terminale, sphärische gemeinsame Atrium ausmündet (DEN Hartog 1968). Der Uterus liegt vor dem Hinterende und ist von mehreren Drüsen umgeben.

D is k us s i o n : Die Sylter Exemplare besitzen eine Samenblase, der m. E. nach die von den Hartog (1968, Plate I, A, B) abgebildete Struktur entspricht. Mit dem Nachweis einer Samenblase entfällt das wesentliche Merkmal, das zur Errichtung der neuen Gattung Psittacorbynchus durch DEN HARTOG führte. Da Schnittserien fehlen, die eine mögliche Sonderstellung der Art erweisen könnten, wird auf systematische Konsequenzen zunächst verzichtet. Durch die Form der Rüsselhaken bestehen enge Beziehungen zu der Gattung Prognathorbynchus.

Neognathorbynchus suecicus KaRLING 1956

Fund or te : Sylt: 10 sw (2 juv. Expl.); 12 sw (leg. Hoxhold); Ostsee: Heiligenhafen, Graswarder, Sandhang (1 Expl.).

Neognathorbynchus longostilo nov. spec.

(Abb. 13-16)

Fund or t : Sylt: $12 \mathrm{sw}$ (Locus typicus).

$\mathrm{M}$ a t e r i a 1 : Lebendbeobachtungen.

Beschreibung: Die Art erreicht 0,6-0,7 mm Länge. Der drehrunde Körper ist vorne etwas zugespitzt, hinten schmal, abgerundet und kann leicht konisch verlängert werden. Die Art ist durch den Darm und das Vitellar im mittleren Körperteil graugrün gefärbt und undurchsichtig.

Der kleine Pharynx rosulatus ( $p$ ) liegt kurz hinter der Körpermitte. Der Bulbus ist senkrecht zur Körperlängsachse aufgerichtet und sehr drüsenreich.

Der schmale, langgestreckte Muskelzapfen des Rüssels erreicht 50-60 $\mu \mathrm{m}$ Länge und enthält zwei Muskelwülste oder Muskelplatten, die bis an das Hinterende des Zapfens reichen, wo sie einander tangieren. In jedem Muskelwulst ist ein sekretführender, zentraler Kanal eingeschlossen. Produktionsstätten und Zuleitung der Sekrete sind unbekannt.

Dem Muskelzapfen sitzt frontal ein Endkegel von 18-20 $\mu \mathrm{m}$ Länge auf. Am Endkegel treten Drüsensekrete aus.

Die Rüsselhaken (Gesamtlänge 21-24 $\mu \mathrm{m}$ ) bestehen aus einer Spitze, einem Hohlzylinder und zwei lateral bzw. median gelegenen Platten. Die hohle Spitze ( 9 bis $12 \mu \mathrm{m}$ ) ist nach innen gebogen. Der Hohlzylinder (bas) verjüngt sich nach hinten konisch. Bei starkem Druck weichen die Wände caudal auseinander. Der Hohlzylinder ist die direkte Fortsetzung des sekretführenden Kanals, Ausleitung von Sekreten wird allerdings nicht beobachtet. Die Spitze verbreitert sich an ihrem Hinterende ausschwingend zu den flügelförmigen Platten $(f l)$. Die Hinterlänge der Flügel beträgt $11 \mu \mathrm{m}$. Die Vorderlänge der Flügel, also die größte Breite des Hakens, erreicht $16 \mu \mathrm{m}$.

Die Geschlechtsorgane sind unpaarig angelegt.

Neben dem Pharynx ist ein Hoden ( $t$ ) zu erkennen. Hinter dem Pharynx beginnt eine keulenförmige, 65-100 $\mu \mathrm{m}$ lange Samenblase ( $v s$ ). 
Das männliche Kopulationsorgan $(k)$ besteht aus einem schlauchartigen Vorderabschnitt und dem Stilett, erreicht etwa $54 \mu \mathrm{m}$ Länge, enthält einen Ductus ejaculatorius, der proximal kolbig angeschwollen sein kann und dann hier Sperma ent-
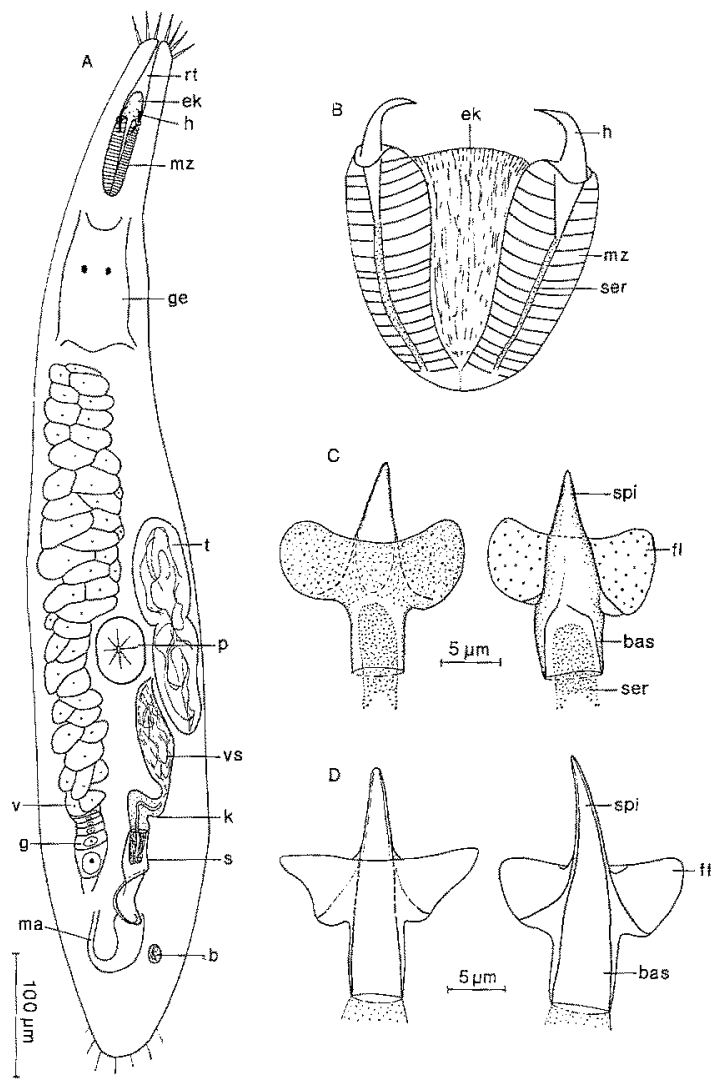

Abb. 13: Neognathorhynchus longostilo. A Organisation (kombiniert); B Rüssel (Quetschpräparat); $C$ Rüsselhaken (Quetschpräparat); $D$ Rüsselhaken eines anderen Exemplars (Quetschpräparat)

hält. Das Stilett (s) ist 63-66 $\mu \mathrm{m}$ lang, hat einen proximalen Durchmesser von $24 \mu \mathrm{m}$ und distal einen Durchmesser von $19 \mu \mathrm{m}$. Es ist mit einem Stiefel vergleichbar und sowohl in dem engen inneren "Schaft" als auch in der weitgeschwungenen, äußeren "Sohle" spiralisiert.

Die Kornsekretblase ragt in das Stilett hinein und ist einer vorderen und einer hinteren Gruppe zuzuordnen.

Hinter dem Stilett ist ein breites männliches Genitalatrium zu erkennen.

Neben dem männlichen Kopulationsorgan ist das schlauchartige Germar (g) angelegt, das Vitellar ( $v$ ) bildet die frontale Fortsetzung des Germars und erreicht unverästelt und breit ausladend das Gehirn. 
Hinter dem Stilett ist seitlich eine kleine, längliche Bursablase (b) zu erkennen, die bewegliche Spermien enthält.

Disk us ion: Ein spezifisches Sondermerkmal von Neognatborbynchus longostilo liefert der komplizierte Aufbau des Stiletts. Alle bisher bekannten Gnathorhynchidae haben allenfalls einfache dolchförmige Stilette.

Infolge des Mangels histologischer Untersuchungen gründet sich die vorläufige Einordnung in die Gattung Neognathorbynchus auf die Form der Rüsselhaken. Nur

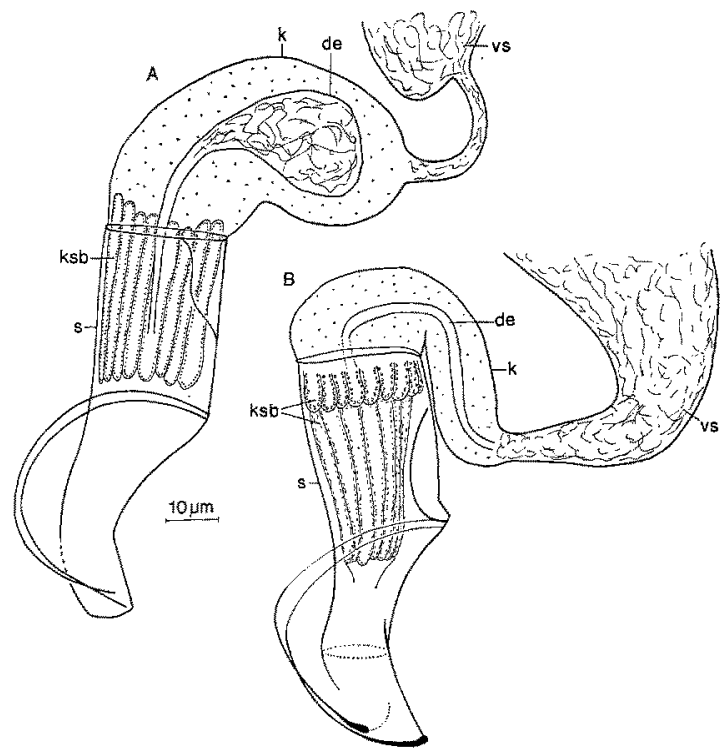

Abb. 14: $A, B$ Neognathorbyncbus longostilo. Männliche Kopulationsorgane zweier Exemplare

in dieser Gattung sind flügelförmige Lateralplatten entwickelt (Ax 1952, KARLING 1956). Das Vorhandensein eines basalen Hohlzylinders kann vielleicht als wichtiges Unterscheidungsmerkmal verwendet werden. Denn es gibt bei den Gnathorhynchidae Haken, die nur oberflächlich dem Zapfen aufsitzen und eine konkave Platte haben. Andererseits dringen bei einigen Arten - wie bei N. longostilo - die Haken in den Muskelzapfen ein (Sekretkanal; "obtuse axial outgrowth", nach DEN HARTOG 1968).

\section{Prognatborbynchus stilofer nov. spec.}

(Abb. 17, 18)

Fund orte: Sylt: $12 \mathrm{sw}$ (leg. HoxHold), $19 \mathrm{sh}$ (sw) Locus typicus, 24 sh; Romø: Lakolk, Weststrand, Sandhang; Ostsee: Heiligenhafen, Sandhang.

M a teria 1: Lebendbeobachtungen.

B e s chreibung: Die Körperlänge beträgt bei den Exemplaren von Sylt und Heiligenhafen 1-1,2 mm. Ein in Rømø gefundenes Tier erreicht 1,8 mm Länge. Das Vorderende ist etwas verschmälert, das Hinterende ist meistens einfach abgerundet, 

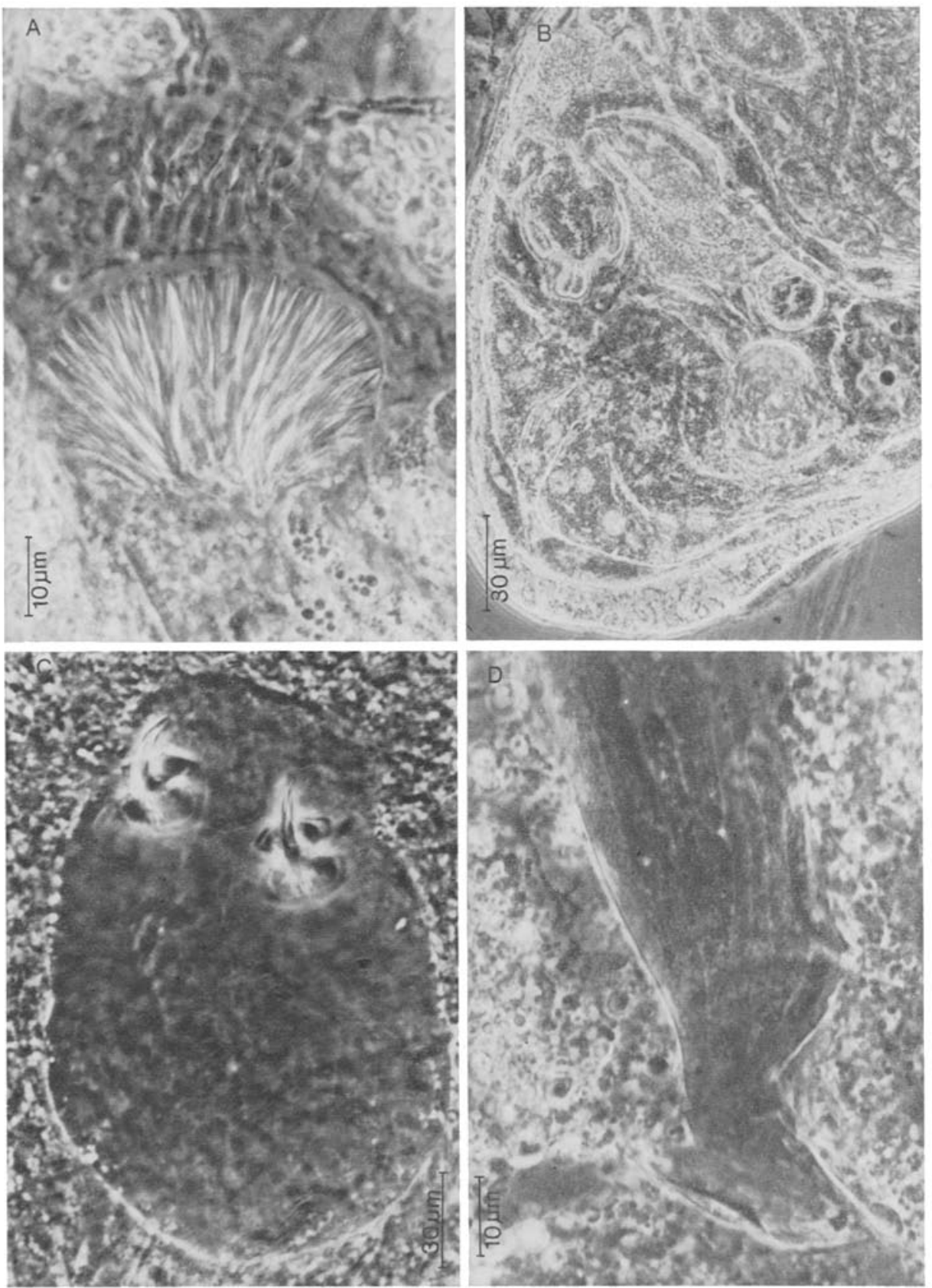

Abb. 15: A Ptyalorbynchus coecus. Stilett; B Gnathorbynchus inermis. Hinterende (vgl. Abb. $7 D$ ); $C$ wie $B$ : Rüssel; $D$ Neognathorhynchus longostilo. Stilett 
kann aber auch spitz gestreckt werden. Die Art schlängelt sich ständig, ist in ihren Bewegungen sehr lebhaft und schnell. Die Körperfarbe ist schwarzbraun, das Vorderende heller. Das Gehirn ist augenlos. Dahinter sind zwei sehr große, kugelige Frontaldrüsen entwickelt, die im Vorderende ausmünden. Thre Sekrete sind stäbchenförmig und erinnern an die der Typhloplanoida.

Der Pharynx rosulatus liegt hinter $3 / 4$ der Körperlänge. Der Rüssel (Länge 65 bis $100 \mu \mathrm{m})$ ist mit zwei komplizierten Haken, sowie zwei häkchenbesetzten Platten versehen.

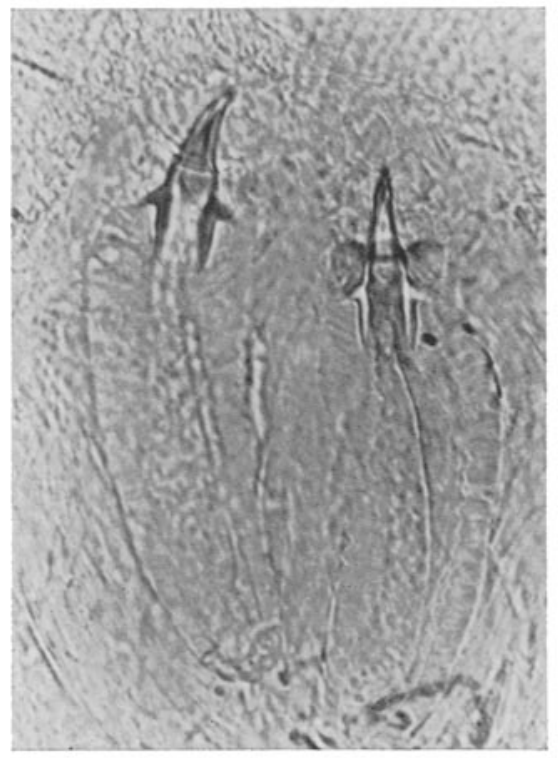

Abb. 16: Neognathorhynchus longostilo. Rüssel. Die Hakenlänge beträgt 21-24 $\mu \mathrm{m}$

Der Bulbus beginnt mit einem gekörnten Endkegel, der sich scharf von dem schneeweißen Muskelzapfen abhebt.

Die Rüsselhaken sind 21-22 $\mu \mathrm{m}$ lang und bestehen aus einer gebogenen Spitze $(14 \mu \mathrm{m})$ und einem geraden Basalstück $(7-8 \mu \mathrm{m})$. Das Basalstück ist lateral löffelartig verbreitert und hat median ein kantig abgesetztes, stärkeres Mittelstück. Zwischen Spitze und Basalstück inserieren Flügel $(\ell)$, die geknickt sind und am Ende scharf zulaufen. An diesen Flügeln sitzen Occlusoren, die sich ins Innere des Muskelzapfens verfolgen lassen. Für das Spreizen der Haken sind Muskeln verantwortlich zu machen, die hinten an den Basalstücken angreifen.

Hinter jedem Haken endet ein sekreterfüllter Kanal, der den Muskelzapfen durchzieht. Die Produktionsstätte der Sekrete ist unbekannt.

Vor dem Haken ist jeweils eine viereckige, 8-10 $\mu \mathrm{m}$ lange, häkchenbesetzte Platte ( $b \ddot{a}$ ), zu erkennen. Am Vorderrand der Platte sind ca. 32 Häkchen aufgestellt.

Zum Beutefang werden vermutlich die Haken um ein Objekt geschlagen, drücken dies gegen die ein wenig eingezogenen Platten, die als rutschfestes Widerlager dienen. 
Die Rüsseltasche ist ungewöhnlich lang und biegsam. Sie wird von kräftigen Längsmuskeln begleitet. Unmittelbar vor den Häkchenplatten sind bis etwa zur Hälfte der Tasche zahlreiche kleine Drüsen oder Ausfuhrkanäle von Drüsen zu erkennen.

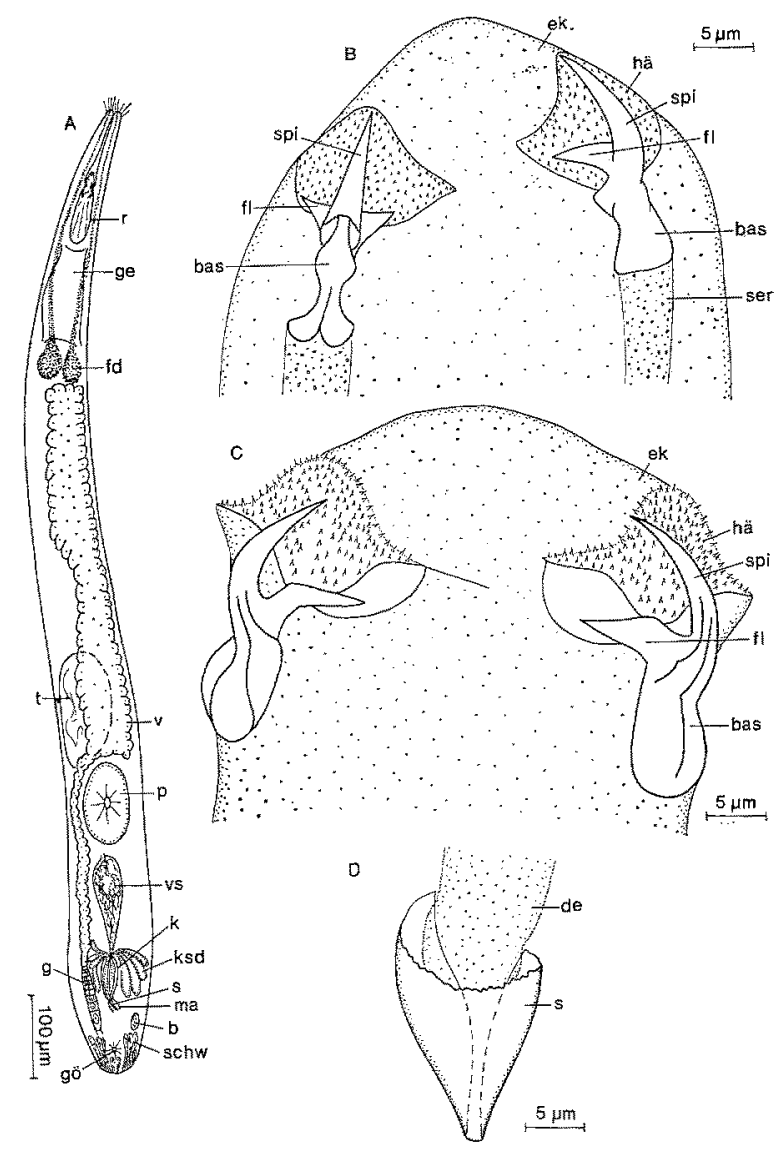

Abb. 17: Prognatborbyncbus stilofer. A Organisation (kombiniert); $B$ Rüsselhaken (Quetschpräparar); $C$ Rüsselhaken eines anderen Exemplars (Quetschpräparat); $D$ Stilett (Quetschpräparat)

Der kleine, spindelförmige Hoden $(t)$ ist bei einigen Exemplaren dicht hinter dem Pharynx zu erkennen, bei anderen liegt er vor diesem. Die spindelförmige Samenblase verjüngt sich caudad in einen dicken Seminalkanal. Neben und vor dem Kopulationsorgan sind mehrere große Kornsekretdrüsen angelegt.

Das dünnwandige Kopulationsorgan ( $k$ ) ist gestreckt keulig, kontrahiert kugelig. Der Ductus ejaculatorius ist proximal erweitert.

Das Stilett (s) ist $19 \mu \mathrm{m}$ lang und proximal $8 \mu \mathrm{m}$ breit. Seine Form ist mit einem 3/4 geschlossenen Rohr zu vergleichen. Das Stilett ähnelt demjenigen von Prognathorbyncbus canaliculatus. Der Vorderrand des Stiletts ist gezähnt und dient als An- 

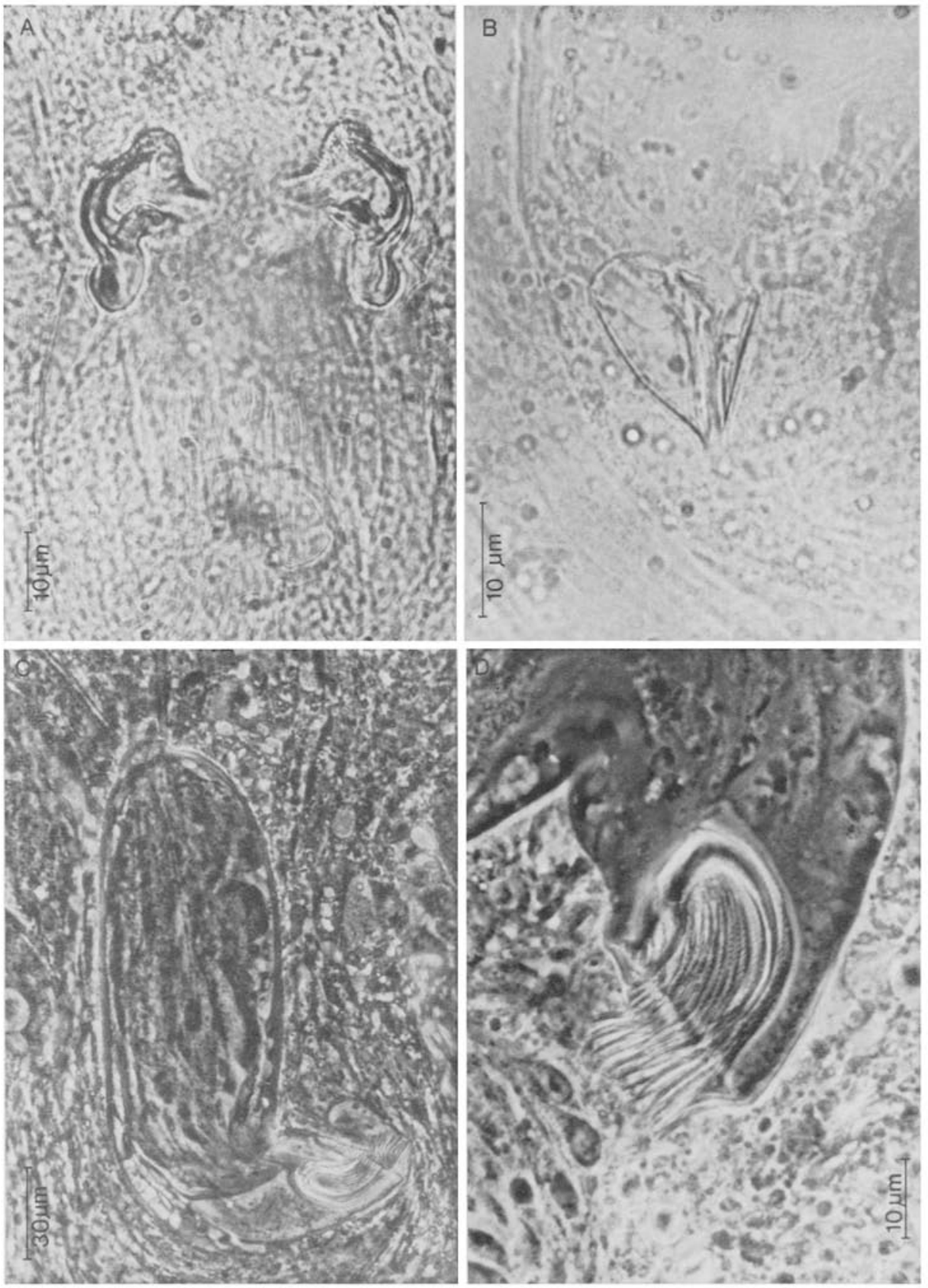

Abb. 18: A Prognathorhynchus stilofer. Rüssel; $B$ wie $A$ : Stilett; $C$ Proschizorbynchus triductibus. Männliches Kopulationsorgan; $D$ wie $C$ : Kutikularorgan 
satzpunkt von Muskeln. Sperma und Kornsekret werden miteinander noch im Stilett vermischt, denn unmittelbar vor diesem sind einzelne, schlauchartige Kornsekretpapillen neben dem Ductus zu erkennen.

Das Stilett ragt frei in das männliche Atrium (ma), das kreisförmig am Hinterrand des Kopulationsorgans ansetzt. Die gemeinsame Geschlechtsöffnung (gö) liegt ventral, unmittelbar vor dem Hinterende. Das lange, dünne Germar $(g)$ kann sich auf der Höhe der Samenblase oder vor der Geschlechtsöffnung befinden. Es ist frontal mit dem Vitellar $(v)$ verbunden, das als mehr oder weniger breiter, nicht verästelter Schlauch bis hinter das Gehirn reicht. wickelt.

Neben oder hinter dem Kopulationsorgan ist eine kleine, hohle Bursa $(b)$ ent-

D is k u s s i on: Sondermerkmale von Prognatborbynchus stilofer sind die häkchenbesetzten Platten vor den Rüsselhaken. Mit dem Nachweis dieser Strukturen können wir eine konvergente Entwicklung zu den Häkchen bei Carcharodorbyndous feststellen.

Nach den Untersuchungen an Quetschpräparaten ergeben sich lediglich zur Gattung Prognathorbynchus nähere Beziehungen, die auf der Ahnlichkeit der Rüsselhaken basieren (vgl. Ax 1952a, Fig. 1f, Ax 1952b, Tafel 23c, Den Hartog 1968).

Familie Aculeorhynchidae SchiLk 1969

Aculeorbynchus glandulis SCHILKe 1969

Fund or t: Sylt: 12 sh sw.

\section{Schizorhynchia}

Die Rüsselapparate folgender Arten werden in einer anderen Arbeit dargestellt (SCHILKE 1970). Ebenso werden bestimmte Organisationszüge des Genitalsystems darin behandelt. Es handelt sich um folgende Species: Neoscbizorbynchus longipharynggus, N. brevipharynggus, N. parvorostro, Amphirbynchus caudatus, Paraschizorbynchoides glandulis, Pseudoschizorbynchoides ruber, Proschizorbynchus triductibus, Carcharodorbynchus subterraneus, C. ambronensis, C. listensis, C. isolatus, Karkinorbynchus purpureus, $K$. listensis, K. l'bardyi, K. bruneti, $K$. primitivus, K. tetragnatbus, Rbinepera divisa, Cheliplana boadeni, Diascorbynchus rubrus, Diascorbynchides arenaria.

Familie Schizorhynchidae GrafF 1905, sensu KarLING 1950

Die Familiendiagnose (Karling 1950) muß wegen des Pharynx von Neoschizorbynchus longipharynggus geändert werden; sie erhält den Zusatz: „Pharynxtasche kurz, senkrecht oder lang, waagerecht orientiert; Pharynxbulbus tonnen- oder kugelförmig“. 


\section{Gattung Proschizorbynchus*}

2 Synapomorphien der Gattung Proschizorbynchus sind die Längsmuskelhülle um das Kopulationsorgan und die Kanalzellen („cellules bordantes“; L'HARDY 1965). Innerhalb der artenreichen Gattung existieren jedoch 2 Gruppen mit verschiedenen Typen von Kopulationsorganen. Daher wird eine Gliederung in zwei Untergattungen vorgenommen.

Proscbizorbynchus Proschizorbynchus nov. subgen.

Diag n ose : männliches Kulikularorgan kompliziert, mit Innen- und Außenhülle und mit einem Stilett.

Typart des Subgenus: P. (Proschizorbynchus) gullmarensis Karling 1950. Weitere Arten: P. (Proschizorbynchus) anophthalmus L'HARd 1965, P. (Proschizorbynchus) pectinatus L'Hardy 1965, P. (Proschizorbyndbus) triductibus nov. spec., P. (Proschizorbynchus) arenarius DE BeAuchamp 1927.

\section{Proscbizorbynchus gullmarensis KARLING 1950}

F und or te : Sylt: 1 sh, 5 sh, $10 \mathrm{k}, 12 \mathrm{sh}, 15 \mathrm{sh}, 17 \mathrm{sh}, 19,24 \mathrm{sh}, 25 \mathrm{sh}$; Amrum: 4, 5-6 sh, 16, 17; Ostsee: Kieler Förde, Strande.

Das Bursamundstück zeigt bei einem Exemplar zwei hintereinander gelegene Trichter in Richtung der Bursa.

\section{Proscbizorbynchus triductibus nov. spec.}

(Abb. 18-21)

F u n d o r t : Sylt: 1, $5 \mathrm{sw}, 6 \mathrm{sw}, 12 \mathrm{sw}$ (Locus typicus), $13 \mathrm{sw}, 14 \mathrm{sw}$.

Material: Lebendbeobachtungen, mehrere Schnittserien (Holotypus: eine Sagittalschnittserie).

Beschreibung: Die Art erreicht 3-4 mm Länge. Es sind drei Haftgürtel vorhanden (Abb. 19B).

Im Hinterende liegen umfangreiche Schwanzdrüsen; neben den sich mit Haidenhain/Eosin hellgrau anfärbenden Sekreten ist an der Ventralseite eine Drüsengruppe mit gelblichem Sekret vorhanden.

In der Epidermis sind helle, länglich-runde Flecken zu erkennen. Die Körperfarbe ist hellbraun.

Hinter dem umfangreichen, augenlosen Gehirn liegen zahlreiche, größere Frontaldrüsen, deren Sekret grobkörnig, basophil ist. Ihre Ausfuhrkanäle begleiten kreisförmig den Rüssel. Ein Septum zwischen Gehirn und dem Darm fehlt.

Der Pharynx liegt auf der Grenze vom 1. zum 2. Körperdrittel. Die Mundöffnung ist leicht nach vorne gerichtet. Die Pharynxtasche ist kurz. Die Greifwülste sind deutlich entwickelt. Der hintere, obere 'Teil des Pharynxkörpers weist bei einigen Exemplaren eine kleine caudale Auswölbung auf, in der ein basophiles, grobkörniges

* Während der Drucklegung dieser Arbeit erschien die Studie von Evoonin (1969), der 3 verschiedene phylogenetische Richtungen innerhalb der Gattung Proschizorbynchus unterscheidet. Die Untergattung P. Proschizorbynchus entspricht einer der von Evoonin dargestellten Richtungen. 
Sekret produziert wird. Ein derartiger Drüsenbeutel ist bereits bei Proschizorbynchus gullmarensis bekannt (KARLING 1950, p. 20). Der Oesophagus ist kurz, muskelschwach und mit Körnerkolben versehen.

Der Rüssel ist 300-350 $\mu \mathrm{m}$ lang, hat paarige laterale Drüsensäcke und eine caudale Nodaldrüse.

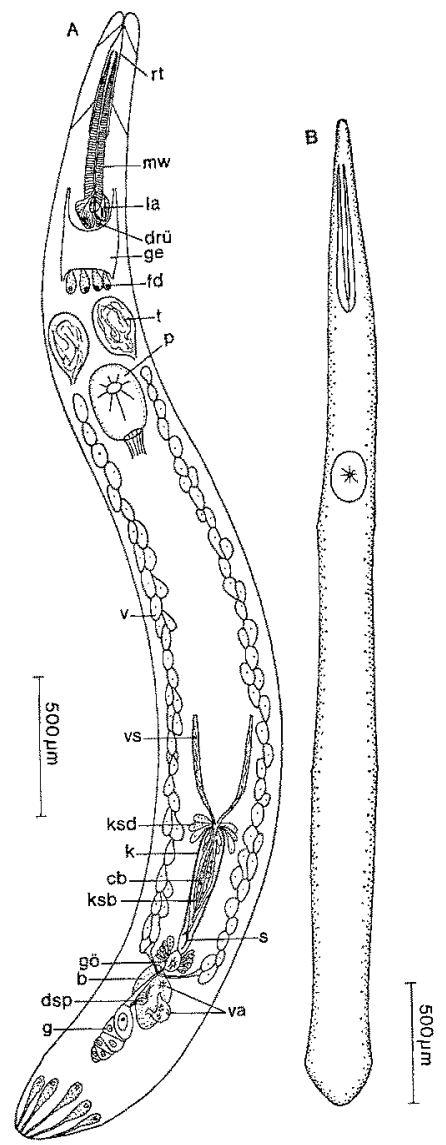

Abb. 19: Proschizorhynchus triductibus. A Organisation (kombiniert); $B$ Habitus

Zwei umfangreiche Hoden ( $t$ ) liegen im 1. Körperdrittel zwischen Gehirn und Pharynx. Die feinen Samenblasen (vs) haben eine kräftige Längsmuskelhülle. Die langen Seminalkanäle sind schwach kutikularisiert. Die umfangreichen Kornsekretdrüsen ( $k s d$ ) erstrecken sich frontal um das Kopulationsorgan herum und produzieren nur ein grobkörniges Sekret.

Das männliche Kopulationsorgan ( $k$ ) ist ein langer Schlauch von $160 \mu \mathrm{m}$ Länge mit einer kräftigen Längsmuskelhülle (Abb. $20 \mathrm{~B}$ ). Die Kornsekretblase (ksb) mündet kurz vor dem Stilett in den hier ampullenförmigen Ductus ejaculatorius.

Die Kanalzellen ( „cellules bordantes“) ragen $z$ wischen die Blase $(c b)$. 
Die Längsmuskeln, die das Kutikularorgan bewegen, sind etwas spiralig angeordnet. Zwischen ihnen und der muskulösen Hülle des Kopulationsorgans ist ein parenchymartiges Gewebe ausgespannt. Unmittelbar vor dem Stilett liegt ein sehr großer Zellkern. Das Kutikularorgan (s) ist höher als breit (Abb. 21). Es besteht aus einer äußeren zylindrischen Hülle $\left(s_{n}\right)$ und einem inneren Kanal $\left(s_{i}\right)$. Die schwach kulikularisierte Hülle und der gleichlange Kanal sind miteinander in einer gemeinsamen, langen Offnung verwachsen. Zwischen beiden Teilen ist bis auf ein schmales Epithel (ep), welches sich außen dem inneren Kanal anlegt, ein Hohlraum vorhanden.

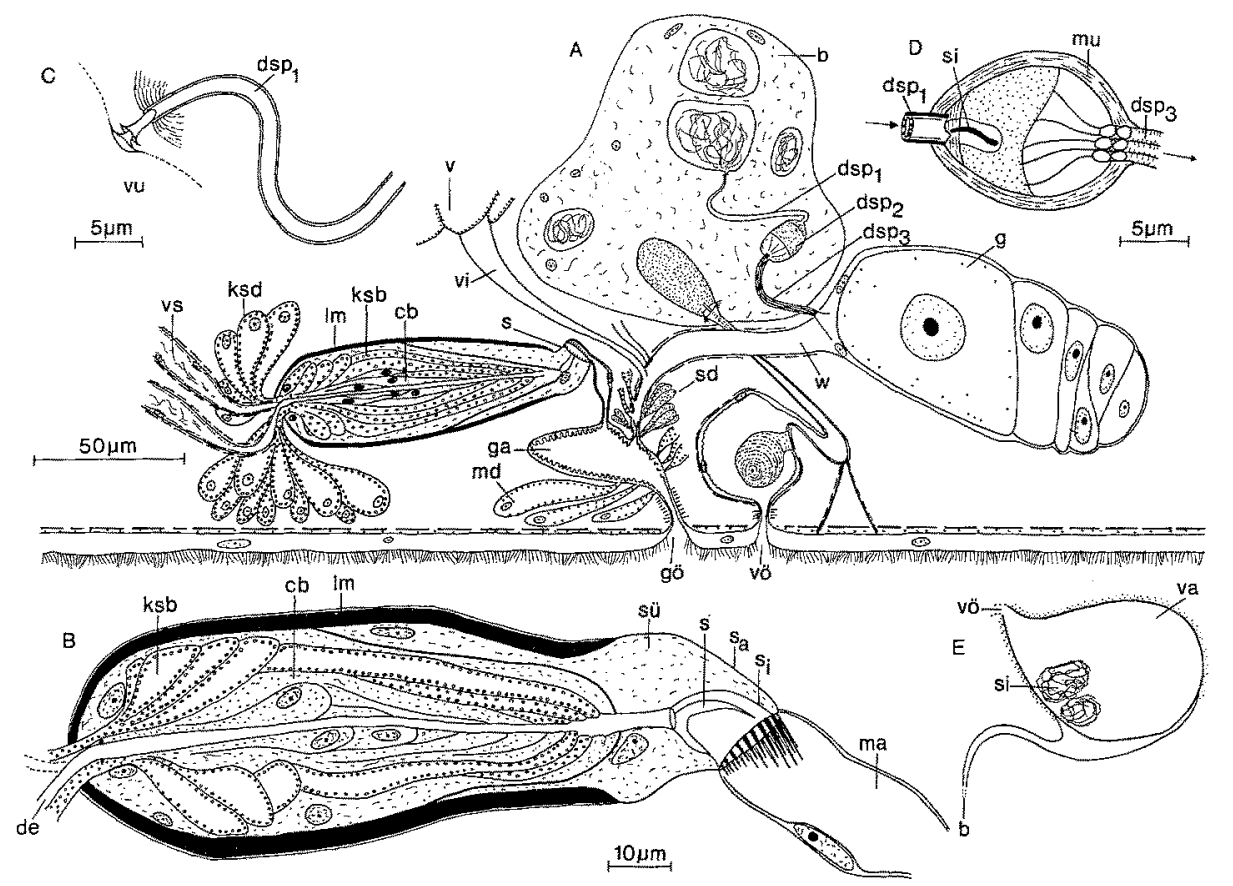

Abb. 20: Proschizorbynchus triductibus. A Sagittalschnittrekonstruktion der Atrialorgane; $B$ Sagittalschnittrekonstruktion des männlichen Kopulationsorgans; $C$ Ductus spermaticus, 1. Abschnitt, vgl. A (Schnittserie); D Ductus spermaticus, 2. Abschnitt, Bläschen (Schnittserie); $E$ Vagina externa (Quetschpräparat)

Frontal tritt in den inneren Kanal der Ductus ejaculatorius ein. Er verschmälert sich anschließend ein wenig, um caudad wieder im Durchmesser zuzunehmen. Die Innenseite des Kanals ist durch ca. 40 spiralig angeordnete Längsleisten (l) auffällig gegliedert. (Beim Quetschpräparat entsteht durch das Übereinanderfallen der Spirallinien der Eindruck, als seien die Längsleisten mit Zähnchen oder Buckeln versehen.) Aus diesen Längsleisten wachsen an der Offnung zwischen innerem Kanal und äußerer Hülle ca. 40 Stacheln (na) hervor, die einerseits mit den Leisten zusammenhängen, andererseits außen an der Hülle inserieren. Die Stacheln sind ca. 8-11 $\mu \mathrm{m}$ lang, am längsten sind sie am Hinterende der Offnung. Im inneren Kanal liegt ein feines Stilett (s). Auf Fotos und im Quetschpräparat ist es mehr oder weniger deutlich sichtbar, im Schnitt- 
präparat dagegen kaum zu erkennen. Vermutlich sind der vordere Kanalteil und der vordere Stiletteil miteinander verwachsen, so daß nur eine kleine Spitze frei im inneren Kanal liegt.

Nach dem Einstich der Nadeln in den Partner wird vermutlich das Stilett um seinen Drehpunkt ausgeschwenkt und ebenfalls eingestochen (Beobachtung bei $P$. gullmarensis).

Das schmale männliche Atrium ( $m a$ ) setzt breit am Hinterrand der äußeren Hülle an. In der Mitte liegt in einer Erweiterung des Epithels ein größerer Zellkern.

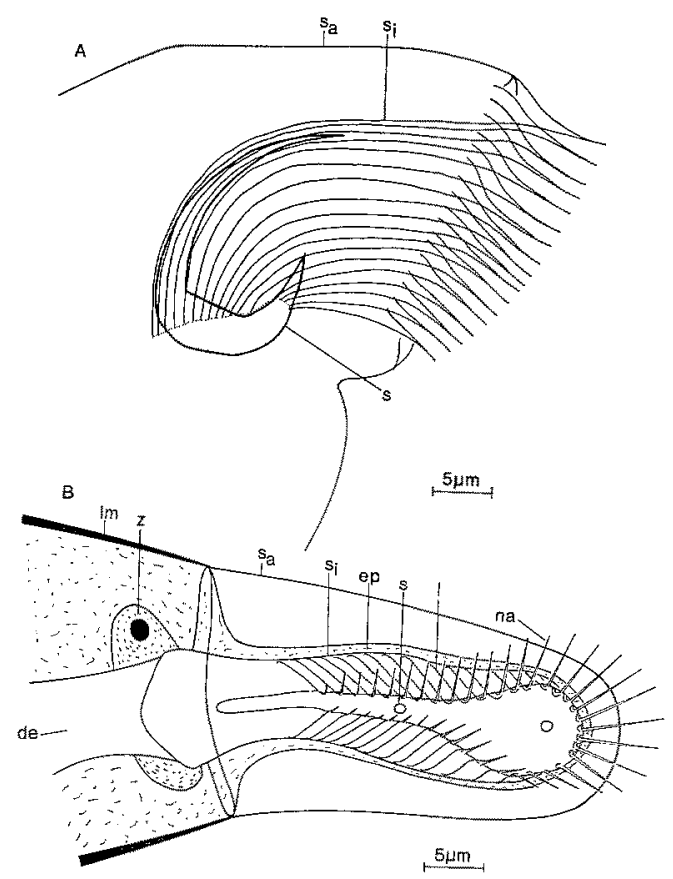

Abb. 21: Proschizorhynchus triductibus. A Kutikularorgan (Quetschpräparat); $B$ Rekonstruktion des Kutikularorgans (Schnittserien)

Die gemeinsame Geschlechtsöffnung liegt etwas hinter $4 / 5$ der Körperlänge. Der Genitalkanal leitet in ein kleines gemeinsames Atrium $(g a)$. Frontal hat das gemeinsame Atrium eine kleine Aussackung, die nicht durch einen Sphinkter verschlossen ist. Caudal und dorsal öffnet sich der Ovidukt $(w)$, der vor dem Germar $(g$ ) einen großen Vorraum bildet, der im Epithel Zellkerne und faserige Strukturen enthält. Das Germar liegt links im Hinterende des Tieres. Die paarigen Vitellarien (v) reichen von den Hoden bis zum Kopulationsorgan. Die Vitellodukte führen in den vorderen Teil des Ovidukts. Kurz hinter der gemeinsamen Geschlechtsöffnung befinder sich die Offnung der Vagina externa (vö). Die Vagina liegt rechts vor dem Germar und sieht wie eine Phiole aus. Denn sie besteht aus einer runden, weitlumigen Blase und aus einem gebogenen, ausleitenden Kanal. Beide Teile sind etwas spiralig aufgedreht, was sich an 
den kutikularisierten Wänden zeigt. Besonders auffällig ist in der Blase ein in deren Mitte vorspringender, dunkel-schwärzlicher Zapfen. In seiner Wand läßt sich eine konzentrische Struktur erkennen. Im Quetschpräparat sind Spermaballen in der Vaginablase zu erkennen. Die Vagina hat ein ziemlich hohes Epithel mit mehreren kleinen Zellkernen. Außen liegen ihrer Wand mehrere feine Längsmuskeln an.

Der Kanal wendet sich zunächst nach schräg unten und wird hier durch kräftige Muskeln, die zur Ventralseite ziehen, in seiner Lage fixiert. In diesem Punkt biegt der Kanal um nahezu $180^{\circ} \mathrm{um}$, führt also nun nach schräg vorn oben. Er verjüngt sich beträchtlich und mündet in einem, dann wieder breiteren Trichter in die Bursa.

Die Bursa $(b)$ ist eine große, komplexe Struktur und dient der Leitung, Aufbewahrung und Resorbtion von Sperma. Sie liegt dorsal etwa in der Körpermitte und erstreckt sich im Schnittbild vom Hinterende des Kopulationsorgans bis zum Vorderende des Germars. Die Wände sind überwiegend geschlossen; lediglich in einem kleinen Abschnitt der Hinterwand ist eine Verbindung zum Darm zu vermuten.

Die Vagina endet innerhalb des Trichters in einem feinen Röhrchen $(\phi \quad 0,8$ bis $1,2 \mu \mathrm{m}$ ), dem Bursamundstïck. Die Bursa bildet an dieser Stelle eine elliptische, umfangreiche Blase, deren Inhalt feinkörnig ist und sich mittels Haidenhain/Eosin und H./E. charakteristisch hellgrau anfärbt.

Aus der Bursa leitet ein dreiteiliger Ductus spermaticus zum Germar. Mehr oder weniger weit von der Blase entfernt öffnet sich ein feiner Trichter (Weite der Offnung: 2,8 $\mu \mathrm{m}$ ), der den 1. Teil des Ductus spermaticus ( $\left.d s p_{1}\right)$ darstellt (Abb. 20 C). Seine Position innerhalb der Bursa ist je nach deren Füllungszustand verschieden. Er hat anfangs einen Innendurchmesser von ca. 0,8-1,2 $\mu \mathrm{m}$. Seine Wände sind mit kräftigen Längsmuskelsträngen versehen und dunkel angefärbt. Er durchzieht die Bursa in einer weiten Schlinge, nimmt plötzlich im Durchmesser zu (Außendurchmesser ca. 2,8 bis $3 \mu \mathrm{m})$ und mündet nach kurzer Strecke von hinten in den 2. Abschnitt des Ductus spermaticus $\left(d s p_{2}\right)$ ein. Dieser ist eine elliptische Blase $(\phi 13,5 \times 16 \mu \mathrm{m})$.

Der feinkörnige Inhalt dieser Struktur ist von einer festen Hülle umgeben. Ein zentraler Kanal ist vermutlich vorhanden. Zuweilen ist aufgeknäultes Sperma in der Blase zu finden. Zum Germar führt der dritte Abschnitt des Ductus spermaticus ( $\left.d s p_{3}\right)$. Er beginnt mit kleinen Vakuolen in der Blase. Aus diesen führen sechs eng aneinanderliegende Kanäle kabelartig in völlig parallelem Verlauf zum Germar (Länge ca. 40 bis $45 \mu \mathrm{m})$. Sie sind 3,2-4 $\mu \mathrm{m}$ im Gesamtdurchmesser stark, jedes einzelne Röhrchen hat einen Durchmesser von ca. $1 \mu \mathrm{m}$. Die Einmündungsstelle am Germar ist dorsal und frontal neben dem Ovidukt. Im vorderen Teil der Bursa befinden sich kleine, festwandige, schalenartige Einschlüsse, die sich rotbraun anfärben. Im oberen Teil der Bursa sind Spermien in Vakuolen teilweise in Resorbtion begriffen, auch wird die Bursa von zahllosen, sehr feinen Kanälchen und Längsmuskeln durchzogen.

Die umfangreichen basophilen Drüsen $(m d)$ befinden sich lateral vom ventralen Teil des gemeinsamen Atriums und nahe am Anfangsteil des Ovidukts. Die eosinophilen Drïsen ( $s d$ ) liegen um den oberen Teil des gemeinsamen Atriums.

Diskussion: Proschizorbynchus triductibus unterscheidet sich von den anderen Arten der Gattung durch den Besitz eines sehr kurzen Stiletts in einer lang-bestachelten Hülle (Karling 1960, p. 16f; Sternböck 1931, p. 13; De Beauchamp 1927, p. 3f.; L'HARdy 1965, p. 157). Ein wesentliches Artmerkmal ist ferner der in- 
trabursale (dreiteilige) Ductus spermaticus. In diesem Merkmal und im Bau des Rüssels ergibt sich eine Analogie zu P. oculatus (Merxner 1928, p. 239f., Fig. 6-8; 1938, p. 65, Fig. 66). Soweit aus der knappen Beschreibung der Art ersichtlich, ist der Ductus spermaticus nicht dreiteilig, sondern einfach röhrenförmig.

Proschizorbynchus Proschizorbynchella nov. subgen. Stilette.

Diagnose: männliches Kutikularorgan einfach, cirrusförmig oder paarige

Typus des Subgenus: P. (Proschizorbynchella) belgolandicus L'HARDY 1965. Weitere Arten: P. (Proschizorbynchella) echinulatus L'HArdy 1965, P. (Proschizorbynchella) faroeensis STEINBöck 1931, P. (Proschizorbynchella) bivaginatus nov. spec., $P$. (Proscbizorbynchella) spiracirro nov, spec.

\section{Proschizorbynchus belgolandicus L'HARd 1965}

F und orte: Sylt: 12 (leg. Hoxhold); Helgoland: Nordstrand, Sandhang, Nordostseite der Düne (Merxner 1938); Rømø: Lakolk, Weststrand, Sandhang.

\section{Proschizorbynchus bivaginatus nov. spec.}

(Abb. 22-24, 28)

Fund o r t : Sylt: $12 \mathrm{sw}$ (Locus typicus), $13 \mathrm{sw}, 16 \mathrm{sw}$.

Materia 1: Lebendbeobachtungen, mehrere Schnittserien (Holotypus $1 \mathrm{Sa}$ gittalschnittserie).

Beschreibung: Die Art erreicht 2,5 mm Länge. Das abgerundete Hinterende zeigt angeheftet einen Haftgürtel mit ca. acht Papillen. Das Vorderende ist stumpf-konisch. Exemplare in männlicher Geschlechtsreife erreichen nur etwa $1,5 \mathrm{~mm}$ Länge, sind schmal, hellgrau gefärbt, haben ein Schwänzchen. In weiblicher Reife ist die Art dick, undurchsichtig, dunkelgrün gefärbt, ohne Schwänzchen.

Das rundliche, kleine Gehirn (ge) enthält vorne winzige Augenflecke. Hinter ihm liegen Frontaldrüsen, deren Ausfuhrgänge ganz im Vorderende ausmünden.

Der Pharynx $(p)$ liegt im ersten Körperdrittel $(\phi 225 \mu \mathrm{m})$. Die Mundöffnung ist mit einem starken Sphinkter verschließbar. Die Pharynxtasche steht senkrecht zur Körperlängsachse. Die Innenwand des Bulbus ist mit zahlreichen Papillen besetzt, die zum Oesophagus hin an Länge und Zahl so stark zunehmen, daß dieser ein verschlungenes, faltiges Aussehen erhält. Mehrere große Zellkerne liegen im Epithel. Innere Ringmuskeln, innere Längs- und Radiärmuskeln sind im Bulbus vorhanden. Umfangreiche Körnerkolben hängen teilweise bis weit in das Pharynxlumen herab. Der Oesophagus ist zum Darm hin mit einem Sphinkter versehen.

Dem Pharynx hängt median und caudal ein auffälliger Drüsensack (drï) von sehr variabler Größe und Form an. Meist ist er lang, schmal und etwas gebogen. Die Drüsen in ihm haben winzige Zellkerne und produzieren ein basophiles und ein eosinophiles Sekret. Um den Drüsensack herum liegt eine starke Längsmuskelschicht. Die Sekrete treten am ventralen Greifwulst aus. Neben diesem Drüsensack sind zahlreiche andere Drüsen im Bulbus vorhanden. Eine zusätzliche Produktion von Sekreten im Drüsensack ist bei dieser Art mit einer muskelschwachen Pharynxtasche kombiniert (vgl. KarLing 1950, p. 20). 
Der große Rüssel $(r)$ erreicht $300 \mu \mathrm{m}$ Länge ( schmalen Muskelwülste sind in feine, biegsame Spitzen ausgezogen. In der Rüsseltasche liegen lateral mehrere Zellkerne. Vor dem Nodus öffnen sich zwischen den Wülsten die Ausfuhrgänge zweier kurzer, keuliger lateraler Drüsensäcke. Sie enthalten ein grobscholliges Sekret (Quetschpräparat) und mehrere Zellkerne. Einige kräftige Muskeln setzen am Ende der Drüsensäcke an. Ein Septum zwischen Gehirn und Darm fehlt.

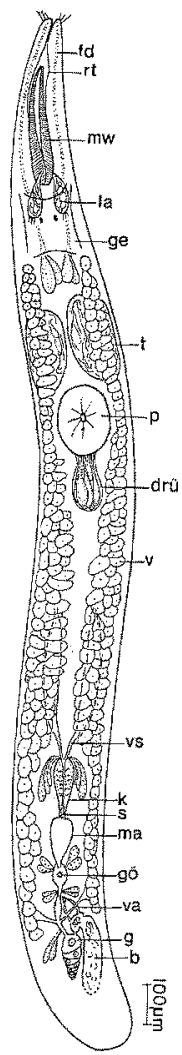

Abb. 22: Proschizorhynchus bivaginatus. Organisation (kombiniert)

Zwei umfangreiche Hoden ( $t$ ) liegen in 1. Körperdrittel zwischen Gehirn und Pharynx. Zwei keulige Samenblasen ( $v s$ ) befinden sich etwa zu Beginn des letzten Körperdrittels (220-350 $\mu \mathrm{m}$ Länge). Die starke äußere Längsmuskulatur ist aus einzelnen, breiten Fasern aufgebaut. Das deutliche Epithel enthält mehrere langgestreckte Kerne. Ein Teil der Kornsekretdrüsen ( $k s d$ ) produziert ein eosinophiles, feinkörniges $\left(k s b_{2}\right.$ ), ein anderer Teil ein basophiles, grobkörniges ( $\left.k s b_{1}\right)$ Sekret.

Das männliche Kopulationsorgan (k) ist ein gestreckter, vorne weiter, nach hinten regelmäßig enger werdender Schlauch (Länge [100]-150-[190] $\mu \mathrm{m}$ ). Es ist von einer proximal starken Längsmuskelhülle umgeben. Zentral befindet sich ein weitlumiger 
Ductus ejaculatorius, der von einem lockeren, parenchymähnlichen Gewebe ( $c b$ ) umgeben ist. In ihm münden an zwei weit voneinander getrennten Abschnitten die beiden Arten Kornsekret $\left(k s b_{1}, k s b_{2}\right)$ aus. $4-5$ basophile Ausfuhrkanäle $\left(k s b_{1}\right)$ sind senkrecht zu dem Ductus ejaculatorius orientiert. Die basophilen Gänge $\left(k s b_{1}\right)$ reichen distal bis zur Außenwand, während die eosinophilen Kanäle $\left(k s b_{2}\right)$ der Mitte genähert anzutreffen sind.

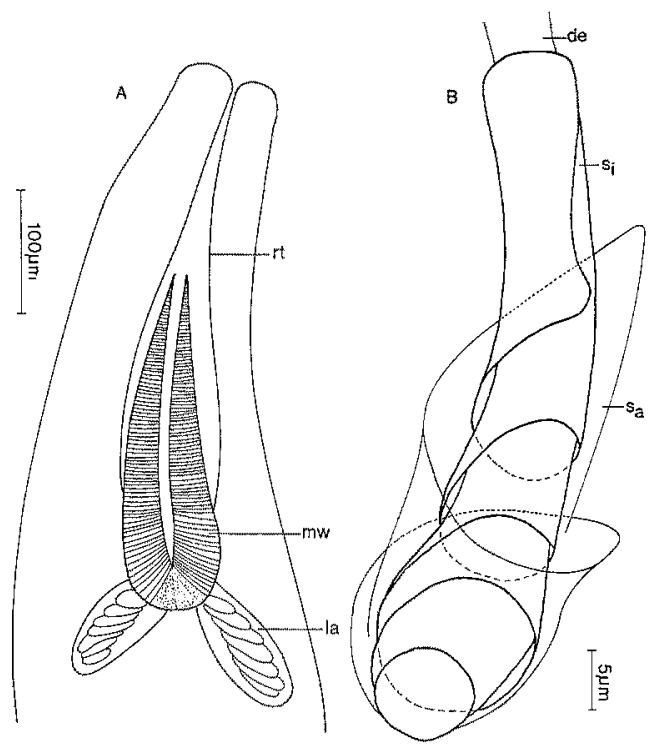

Abb. 23: Proschizorbynchus bivaginatus. A Rüssel (Quetschpräparat); $B$ Rekonstruktion des Stiletts (kombiniert nach Quetschpräparat und Schnittserie)

Das Kopulationsorgan ist caudal mit einem federähnlichen Stilett (s) versehen (Abb. $23 \mathrm{~B})$. Dieses besteht im Prinzip aus einer inneren Spirale $\left(s_{i}\right)$ und einer sie einschließenden äußeren Spirale $\left(s_{a}\right)$. Die Innenspirale ist (35)-42-(48) $\mu \mathrm{m}$ lang, nach links eingerollt und weist 3-4 Umgänge auf. Die Innenspirale ist mit sehr dicht stehenden Stachelreihen versehen (Stachellänge $2,5-3 \mu \mathrm{m}$ ). Die äußere Spirale ist rechtsgewunden und zeigt lediglich $1 \frac{1}{2}$ Windungen. Den Hinterrand der Außenspirale bildet ebenfalls die kreisförmige Offnung der Innenspirale, d. h. die Außenspirale kann als umgeschlagener Teil der Innenspirale aufgefaßt werden. Zwischen beiden Teilen des Stiletts ist vermutlich ein Hohlraum; an die Außenwand der Innenspirale legt sich ein schwaches, eosinophiles Epithel.

Die Außenwand des Kopulationsorgans umgibt das Stilett und ist hier nur noch wenig muskulös.

Das männliche Genitalatrium ( $m a$ ) ist mit einem Sphinkter versehen.

Die gemeinsame Geschlechtsöffnung (gö) liegt bei 4/5 der Körperlänge. Dorsal vom Genitalkanal ( $g k$ ) beginnt ein kleines gemeinsames Genitalatrium ( $g a$ ). Das gemeinsame Genitalatrium hat frontal eine kleine Ausbuchtung, die nicht durch einen Schließmuskel abgetrennt ist. Der weibliche Genitalkanal (w) hat einen Sphinkter, er- 
weitert sich caudalwärts zu einem weitlumigen, muskulösen Kanal. Das große Germar (g) ist von einer Tunica umgeben. Kurz hinter der Geschlechtsöffnung befindet sich die unpaare, trichterartige Offnung der paarigen Vaginae externae (va). Zwei lange Vaginae führen von hier zu der dorsolateral vom Germar gelegenen zweigeteilten Bursa (b). Der Durchmesser beträgt ventral 3-4 $\mu \mathrm{m}$, nahe der Bursa 5-7 $\mu \mathrm{m}$.

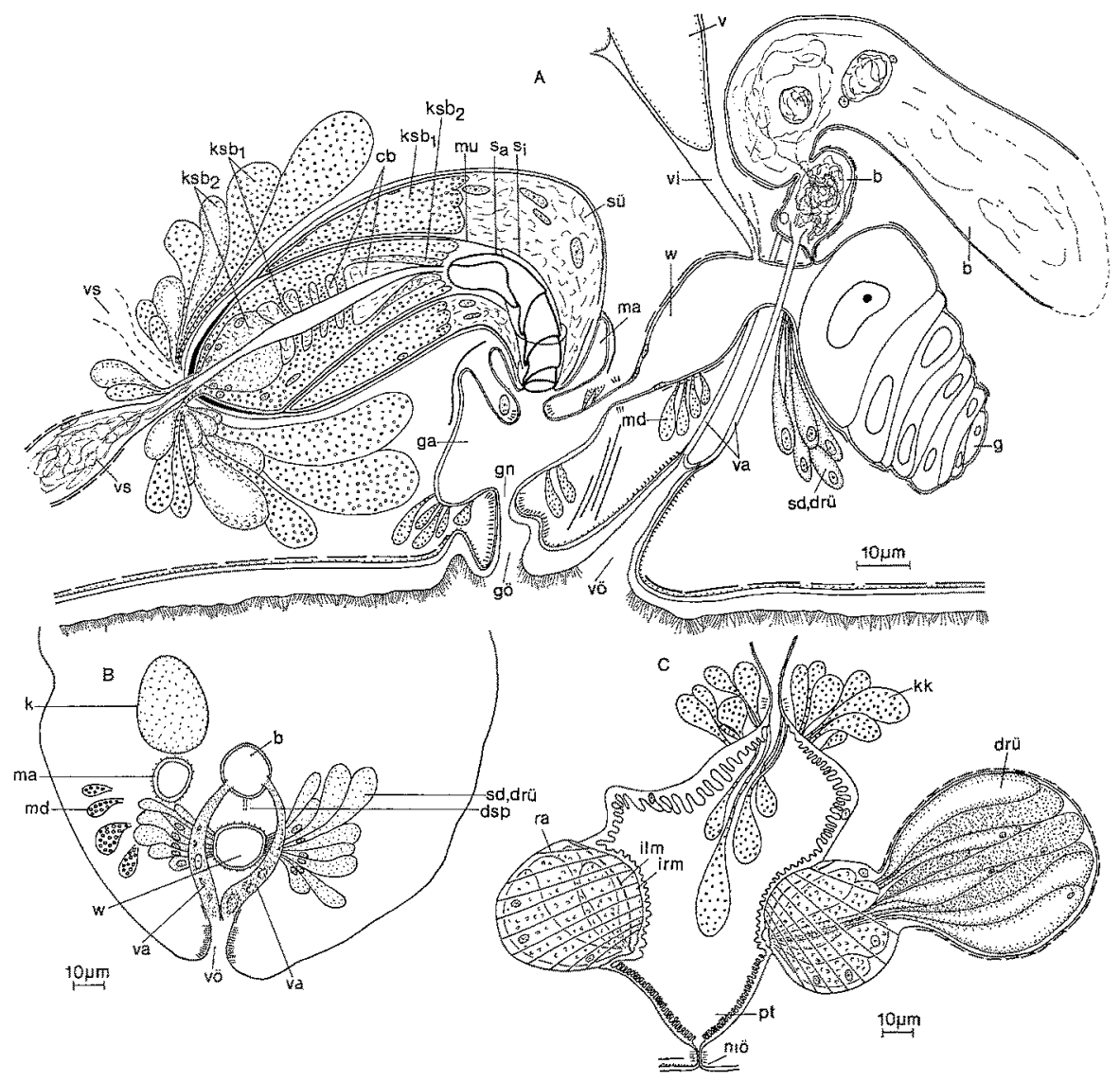

Abb. 24: Proschizorbynchus bivaginatus. A Sagittalschnittrekonstruktion der Atrialorgane; $B$ ventraler Teil eines Querschnittes durch den Hinterkörper, paarige Vaginae externae; C Sagittalschnittrekonstruktion des Pharynx

Während die trichterartige Offnung mit starken Ringmuskeln und wenigen starken Längsmuskeln umgeben ist, sind an den Vaginae nur deutliche Längsmuskeln nachzuweisen. Die Vaginae sind mit eosinophilen Sekreten gefüllt, die von Drüsen produziert werden, die in unmittelbarer Nähe liegen und in die Kanäle einmünden ( $s d, d r i i)$. In dieser Region liegen jedoch auch eosinophile Genitaldrüsen. Zwischen beiden Drüsentypen kann kein Unterschied herausgestellt werden (s. u.).

Nahe dem Germar liegt der kleinere Abschnitt der Bursa, der aktive Spermien 
speichert. Er hat dicke, muskulöse Wände mit mehreren Zellkernen. Ein feiner, nicht kutikularisierter Kanal führt in den Ovidukt unmittelbar vor dem Germar. An seiner Wand sind kräftige Längsmuskeln zu finden.

Der kleinere Abschnitt der Bursa wird von einem größeren Abschnitt durch eine Einschnürung getrennt. Im frontalen Teil sind noch mehr oder weniger deutliche Spermien vorhanden. Im caudalen Teil findet dagegen eine Resorption statt. Die Wand dieses Bursaabschnittes ist dünn und muskelfrei. Im hintersten Abschnitt läßt sie sich nicht mehr deutlich nachweisen. Hier findet ein Ubergang zum Darmgewebe statt. Zwei laterale Vitellarien ( $v$ ) reichen vom Gehirn bis ins Hinterende.

Umfangreiche, eosinophile Genitaldrüsen ( $s d$ ) befinden sich rechts und links vom Germar und vom caudalen Teil des Ovidukts und münden in diesen. Die basophilen Drüsen ( $m d$ ) liegen etwas weiter zum gemeinsamen Genitalatrium hin, sind z. T. sogar vor der gemeinsamen Geschlechtsöffnung zu finden. Ein Uterus fehlt.

Diskussion: Spezifische Artmerkmale von Proschizorbynchus bivaginatus sind die kernlosen, von der Kornsekretblase serial durchbrochenen Kanalzellen („cellules bordantes"), das stahlfederartige Stilett und die paarigen Vaginae.

\section{Proschizorbynchus spiracirro nov. spec.}

(Abb. 25, 26, 28)

Fund ort: Sylt: $12 \mathrm{sw}$ (Locus typicus).

Material: Lebendbeobachtungen, 1 Sagittalschnittserie (Holotypus).

Beschreibung: Die Art wird $2 \mathrm{~mm}$ lang, ist beim Schwimmen vorne und hinten zugespitzt, kontrahiert hinten abgerundet. Das Vorderende trägt lange, feine Tasthaare. Haftgürtel fehlen. Die Körperfarbe ist grau-durchsichtig. Das Gehirn enthält keine Augen. Der Pharynx (p) liegt etwas vor der Körpermitte und ist senkrecht zur Körperlängsachse orientiert. Er ist durch sehr lange, feine Epithelpapillen charakterisiert, die weit in das Lumen ragen. Auch der umfangreiche Oesophagus ist mit derartigen Papillen dicht bedeckt.

Ein typischer Spaltrüssel liegt im Vorderende. Die beiden Wülste haben feine, vorne umschlagbare Spitzen (Länge $310 \mu \mathrm{m} ; 1 / 5$ der Körperlänge). Hinter dem Rüssel liegen zwei etwa $70 \mu \mathrm{m}$ lange Drüsenbeutel.

Die Geschlechtsorgane sind paarig angelegt. Zwei umfangreiche Hoden $(t)$ liegen im 1. Körperdrittel zwischen Gehirn und Pharynx. Die schmalen, 100-120 $\mu \mathrm{m}$ langen Samenblasen (vs) beginnen hinter dem Pharynx. Die Seminalkanäle $(80 \mu \mathrm{m})$ münden voneinander entfernt in das männliche Kopulationsorgan. Die Kornsekretdrüsen ( $k s d)$ produzieren ein grobkörniges, basophiles Sekret.

Das männliche Kopulationsorgan $(k)$ ist außen von einer starken Längsmuskelhülle umgeben (Länge 120-160 $\mathrm{m}$ ). Proximal enthält es die kugelige, umfangreiche Kornsekretblase $(k s b)$ und mehrere undeutliche Kanalzellen. Der weite Ductus ejaculatoris endet in einem 48-51 $\mu \mathrm{m}$ langen Cirrus (c); (Schnittpräparat: $36 \mu \mathrm{m}$ lang). Der Cirrus wird frontal durch zahlreiche, kräftige Muskeln festgehalten, die das Kopulationsorgan schräg durchziehen. Er besteht aus einer inneren Spirale $\left(c_{i}\right)$ und einer äußeren Hülle $\left(c_{a}\right)$. Die Spirale setzt vorne kreisförmig am Ductus ejaculatorius (de) mit einer kleineren Windung an und erweitert sich in etwa 3-4 Windungen auf einen konstanten Durchmesser. Insgesamt sind 21-23 Windungen der 
Innenspirale vorhanden, die feine, gebogene Lamellen entsenden. Die Lamellen werden durch radial angeordnete Versteifungsleisten gestützt, die an der Spirale an knotig verdickten Stellen inserieren. Diese Stellen sind in einem konstanten Winkel gegeneinander versetzt.

Die äußere Hülle des Cirrus inseriert am Hinterende der Spirale zugleich mit dem männlichen Genitalatrium. Sie bildet einen Zylinder um die Spirale und ist bis
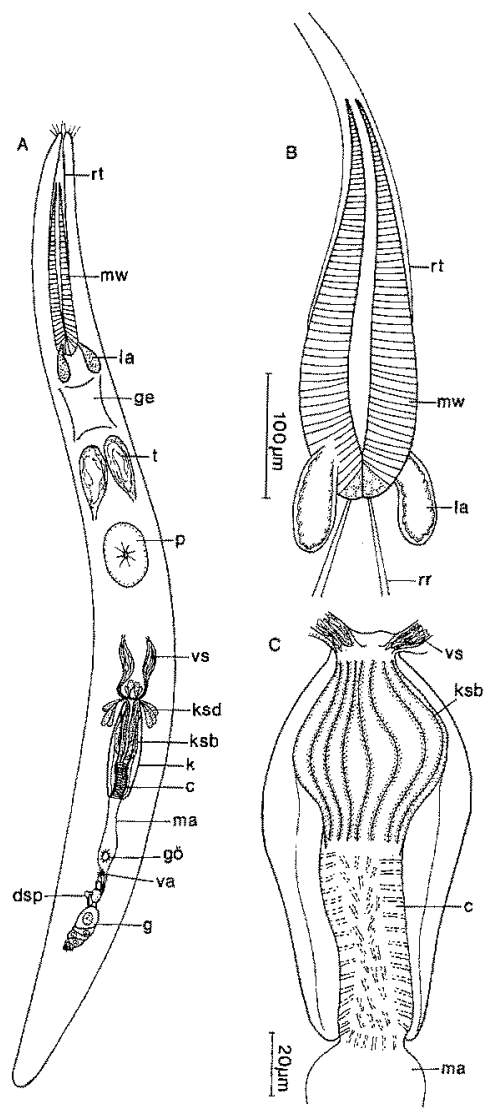

Abb. 25: Proscbizorbynchus spiracirro. A Organisation (kombiniert); $B$ Rüssel (Quetschpräparat); $C$ männliches Kopulationsorgan (Quetschpräparat)

zum Hinterende der Kornsekretblase nachzuweisen. Sie kann als „umgeschlagener Teil" des Cirrus angesehen werden. Der Raum zwischen der äußeren Hülle und der Spirale ist mit körnigen Zellen angefüllt.

Zwischen dem Cirrus und der Muskelhülle des Kopulationsorgans befindet sich ein lockeres, kernhaltiges Stützgewebe.

Die gemeinsame Geschlechtsöffnung (gö) liegt etwa bei $4 / 5$ der Körperlänge. Der Genitalkanal ( $g n$ ) erweitert sich dorsal zu einem kleinen gemeinsamen Atrium ( $g a$ ), das 
mit einer kräftigen Ringmuskulatur versehen ist. Ventral öffnet sich caudad der lange, weite, muskulöse Ovidukt ( $w)$.

Das Germar ( $g$ ) liegt wcit vor dem Hinterende, der Dorsalseite des Körpers genähert und ist von einer schmalen Tunica umgeben.
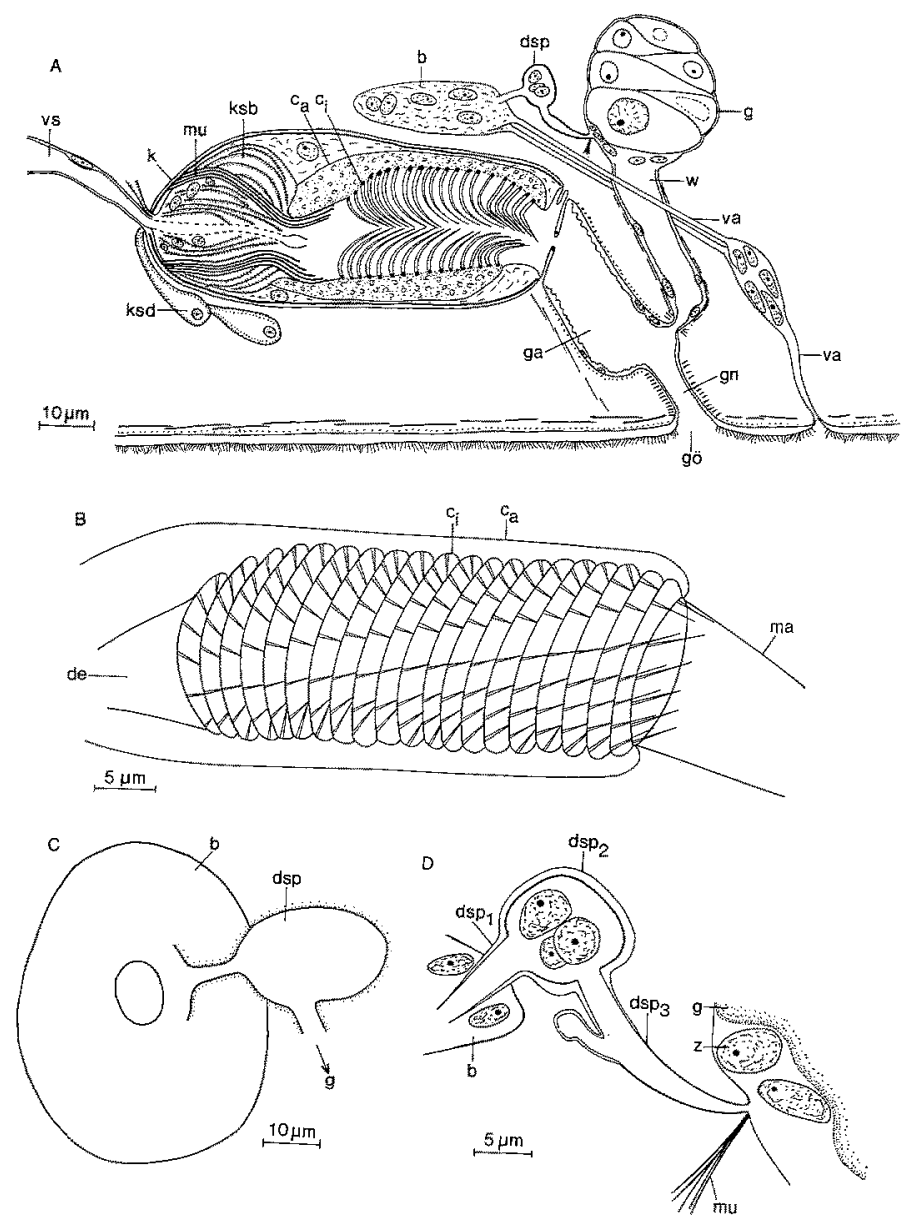

Abb. 26: Proscbizorbynchus spiracirro. A Sagittalschnittrekonstruktion der Atrialorgane; $B$ Sagittalschnittrekonstruktion des Kutikularorgans; C Ductus spermaticus (Quetschpräparat); $D$ Ductus spermaticus: Sagittalschnittrekonstruktion

Kurz hinter der Geschlechtsöffnung liegt die Öffnung der Vagina externa (va). Sie besteht anfänglich aus einem $16 \mu \mathrm{m}$ langen, ganz leicht gebogenen, feinen Kanal ( $\$ 2-3 \mu \mathrm{m}$ ). Der Kanal erweitert sich zu einem etwa elliptischen Bläschen (Länge $16 \mu \mathrm{m})$. Beide Teile haben durch Verdickung der Basalmembran entstandene, versteifte Wände. Das Bläschen enthält etwa fünf große Kerne. Aus ihm zweigen nach vorn oben zwei Vaginae (va) ab, die lateral am Ovidukt vorbeilaufen und in der 
Bursa (b) enden. Die Vaginae haben eine Länge von $48-60 \mu \mathrm{m}$ und einen mittleren Durchmesser von $2,4 \mu \mathrm{m}$.

Die kleine Bursa liegt dorsal vor dem Germar; sie enthält zahlreiche große Zellkerne.

Ein dreiteiliger Ductus spermaticus ( $d s p$ ) verbindet Bursa und Germar. Ein Trichter $\left(d s p_{1}\right)$ führt in ein kugeliges bis elliptisches Bläschen $\left(d s p_{2}\right)$. Der Kanal und das Bläschen sind im Quetschpräparat $37 \mu \mathrm{m}$ lang, das Bläschen hat einen Durchmesser von $15 \mu \mathrm{m}$. Es hat versteifte Wände und enthält mindestens drei Zellkerne. Aus dem Bläschen führt - im rechten Winkel gegen den 1. Abschnitt abgeknickt - ein etwa $16 \mu \mathrm{m}$ langer Kanal ( $\left.d s p_{3}\right)$ zum Germar $(\varnothing 3 \mu \mathrm{m}-1,5 \mu \mathrm{m})$. Die Wände dieses 3. Abschnittes sind im schmaleren 'Teil kutikularisiert. Neben der trichterförmigen Einmündung in das Germar inseriert an diesem ein auffällig dicker Muskel ( $m u$ ).

Vitellarien sind vermutlich paarig angelegt. Ein Uterus fehlt.

D is k us sion: Proschizorbynchus spiracirro ist wegen des gewundenen Cirrus und des dreiteiligen Ductus spermaticus klar von den übrigen Arten der Gattung zu unterscheiden. Ein weiteres wichtiges Artmerkmal ist in der Paarigkeit der Vaginae zu sehen.

\section{Schizorbynchoides MEIXNer 1928}

Die artenreiche Gattung ist mit vier Formen im Untersuchungsgebiet vertreten.

\section{Schizorbynchus aculeatus L'HARDY 1963}

Fund or te: Sylt: 1, 3, 5 sh, 12 sh k, 24 sh, $28 \mathrm{k}$; Amrum: 4, 7 (leg. Ax), $16 \mathrm{sw} \mathrm{k.}$

Die Muskelwülste des Rüssels sind (90)-160 $\mu \mathrm{m}$ lang. Die Art besitzt einen abgewinkelten, mit einem Bläschen versehenen Ductus spermaticus ( $\phi$ ca. $15 \mu \mathrm{m})$. Als Parasiten sind Sporozoen zu nennen.

\section{Schizorbynchoides meixneri BOADEN 1963}

Fu nd or te : Sylt: 5 sw, 13 sw; Amrum: 4 sh.

\section{Schizorbynchoides canaliculatus L'HARDY 1963}

(Abb. 27, 28, 33)

Fundorte: Sylt: $12 \mathrm{sw}$ sh, $5 \mathrm{sh}$.

Material: Lebendbeobachtungen.

Be s ch r e ib ung: Die Art erreicht 1,2 mm Länge. Der schmale, langgestreckte Körper ist vorne leicht zugespitzt und mit mehreren Tasthaaren besetzt. Das runde Hinterende ist mit einem Haftgürtel aus etwa 6 einzelnen Papillen versehen und läuft in einen (150)-170-(250) $\mu \mathrm{m}$ langen Schwanz aus. Der Schwanz ist sehr kontraktil und durch ein Septum von dem Körperparenchym abgetrennt. Die Tiere können sehr lebhaf $z$ wischen Sandkörnern umherschwimmen. Rhabditen fehlen. Die Körperfarbe ist hellgrau.

Ein Septum ist hinter den umfangreichen Frontaldrüsen ausgespannt.

Der Pharynx rosulatus ist bei $2 / 3$ der Körperlänge senkrecht zur Körperlängsachse orientiert ( $\phi 100-140 \mu \mathrm{m})$. 
Die Muskelwülste sind zugespitzt und langgestreckt (140-160 $\mu \mathrm{m})$. Hinter ihnen sind zwei längliche laterale Drüsensäcke (ca. 80-90 $\mu \mathrm{m}$ ) zu erkennen.

Die Art besitzt vier elliptische Hoden $(t)$ vor dem Pharynx. Die keuligen Samenblasen $(v s)$ sind $100-180 \mu \mathrm{m}$ lang. Das männliche Kopulationsorgan $(k)$ ist ein pro-

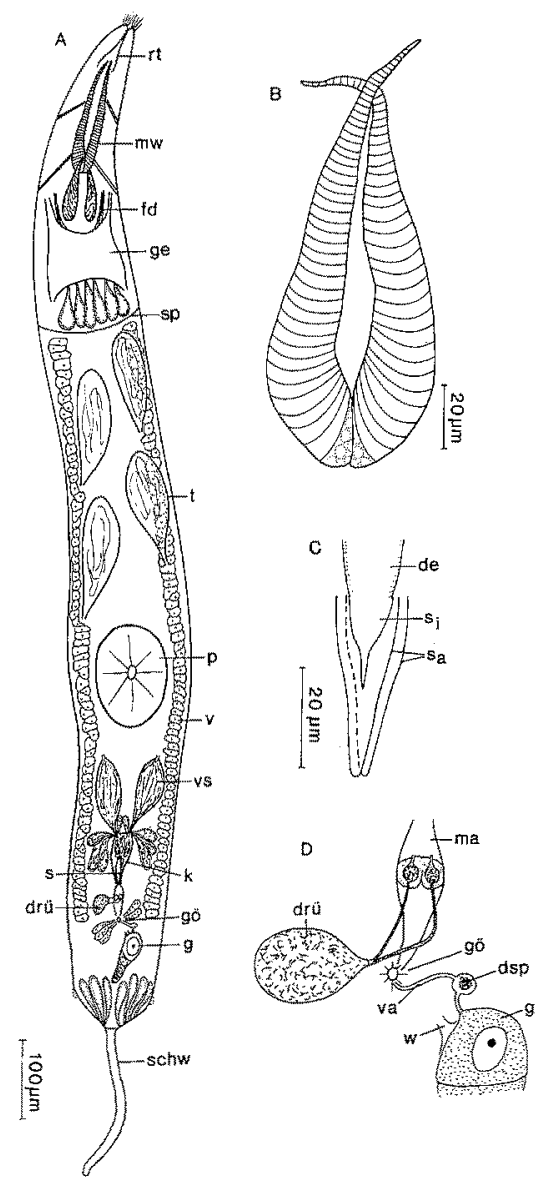

Abb. 27: Schizorbynchoides canaliculatus. A Organisation (kombiniert); B Rüssel (Quetschpräparat); $C$ Stilett (Quetschpräparat); $D$ männliches Atrium mit Drüsenorgan; Ductus spermaticus (Quetschpräparat)

ximal kugeliger, distal langgestreckter, muskulöser Schlauch $(70-110 \mu \mathrm{m})$. Das Kopulationsorgan enthält vorne die Kornsekretblase. Das dreiteilige Stilett besteht aus zwei $30-40 \mu \mathrm{m}$ langen Klappen $\left(s_{a}\right)$, die sich gegenüberstehen, sich caudad verjüngen und hier abgerundet sind. Beide Klappen können gegeneinander verschoben werden. In den Hohlraum zwischen den Klappen ragt ein kurzer Stachel $\left(s_{i}\right)$ als Fortsetzung des Ductus ejaculatorius $(20 \mu \mathrm{m})$. Das männliche Genitalatrium (ma) ist lang und muskulös. In dies Atrium mündet ein Drüsenorgan (drü) ein. Von einer ellipti- 

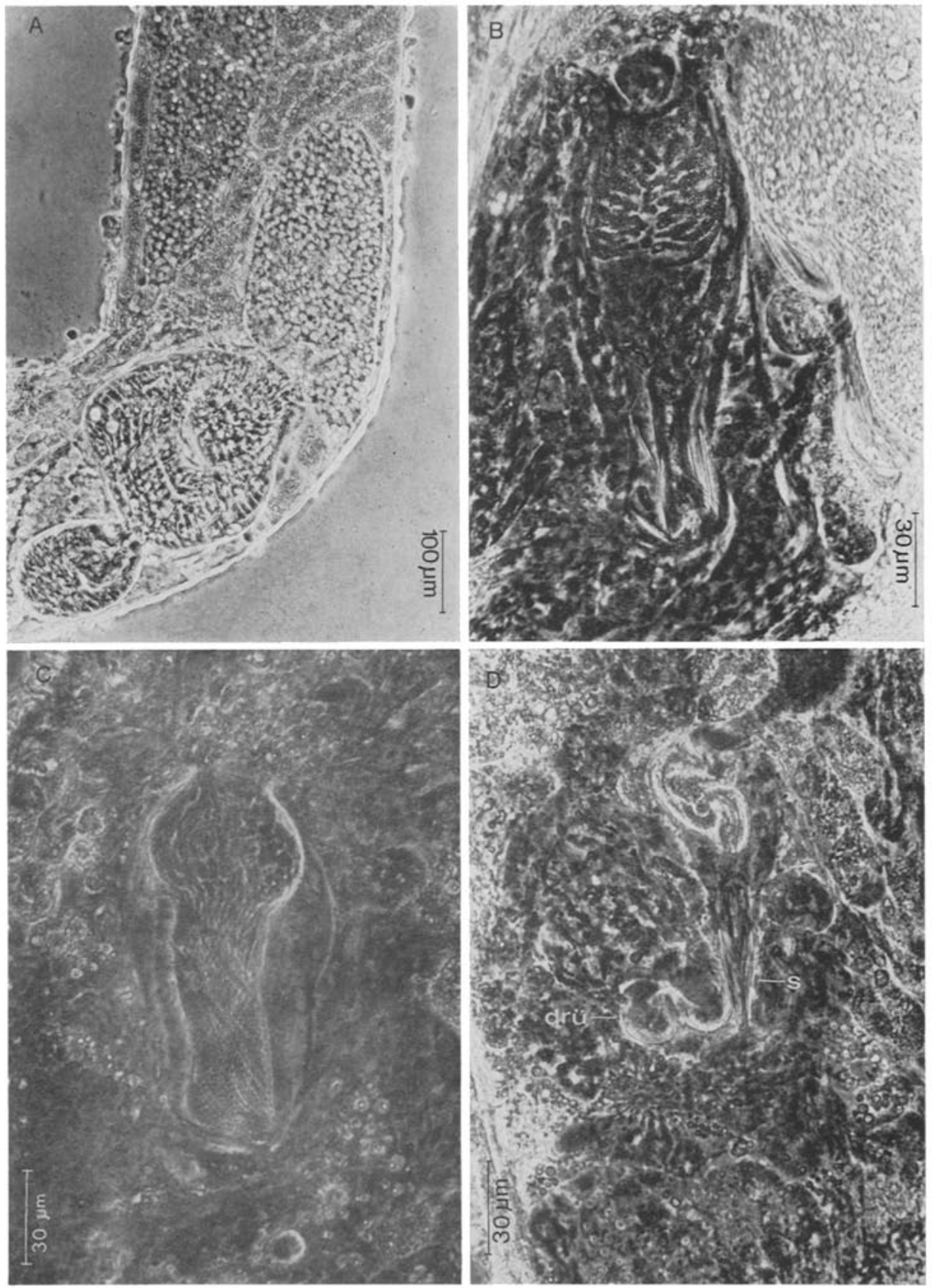

Abb. 28: A Proschizorbyncbus bivaginatus. Pharynx; $B$ wie $A$ : männliches Kopulationsorgan; $C$ Proschizorbynchus spiracirro. Männliches Kopulationsorgan; $D$ Schizorhynchoides canaliculatus. Männliches Kopulationsorgan 
schen Blase entspringen zwei feine, sekretführende Kanäle und münden in zwei kugelige Bläschen, die innerhalb des Atriums liegen und von einer gemeinsamen Hülle umgeben sind. Sie besitzen diinne Verbindungskanäle zum Innern des Atriums.

Die Frage, ob es sich um einen Uterus, einen Bursateil oder ein accessorisches männliches Organ handelt, kann nur an Schnittserien entschieden werden.

Hinter der Geschlechtsöffnung ist eine sehr feine Vagina interna (va) entwickelt, die zu einem Ductus spermaticus ( $d s p$ ) führt. Das kleine Bläschen enthält Spermaballen, ein weiterer Gang führt zum Germar.

Das Germar ( $g$ ) ist langgestreckt. Die paarigen Vitellarien $(v)$ erreichen vorne das Septum und schließen caudal etwa auf der Höhe des Germars ab. Neben der Geschlechtsöffnung liegen zahlreiche weibliche Drüsen.

Diskussion: Trotz der Unterschiede in Längenangaben des Körpers und anderer Organe wird die Art mit Scbizorbynchiodes canaliculatus identifiziert. L'HARDY hat in brieflicher Mitteilung meine Beobachtungen über den dreiteiligen Stilettbau bestätigt.

Schizorbynchoides rarus Ax 1951

Fund or t: Sylt: 12 (leg. Hoxhold).

\section{Paraschizorbynchoides nov, gen.}

D i a g n o s e : Laterale Drüsensäcke mit kompliziertem, muskulösem Beutel verwachsen, dieser caudal mit Drüsen; Frontaldrüsen münden in den Rüssel, Ausfuhrkanäle lateral an den Muskelwülsten; Rüsseltasche reicht bis zum Nodus; Pharynxbulbus kugelförmig; vier Hoden vor dem Pharynx; männliches Kopulationsorgan mit Ringmuskelhülle und Stilett; Germar in Bursa eingeschlossen; Ductus spermaticus vorhanden, nicht kutikularisiert; Uterus, Vagina fehlen; unpaare Geschlechtsöffnung.

Typart: $P$. glandulis nov. spec.

Paraschizorbynchoides glandulis nov. spec.

(Abb. 29, 33)

Fund or te: Sylt: $1 \mathrm{sh}$ (Locus typicus), $12 \mathrm{sw} \mathrm{sh}, 27 \mathrm{sh}$; Amrum: $4 \mathrm{sh}, 5 \mathrm{sh}$, $7 \mathrm{q}$.

Material: Lebendbeobachtungen, mehrere Schnittserien (Holotyp: 1 Sagittalschnittserie).

B e sch re ibung: Die Art erreicht 2-3 mm, ist vorne etwas zugespitzt, hinten gleichmäßig gerundet. Deutliche Haftapparate fehlen. Die Epidermis zeigt im Quetschpräparat und im histologischen Schnitt übereinstimmend flaschen- oder keulenförmige Bläschen (Abb. 29 B). Sie sitzen sehr dicht nebeneinander und sind mit eosinophilen Sekreten erfüllt.

Die Basalmembran ist recht dick und in ein regelmäßiges Maschenwerk mit rechteckigem Muster aufgeteilt. Ring- und Längs-Muskelschicht sind sehr kräftig entwikkelt. Im Parenchym fallen in zwei Schnittserien kleine ( $\phi 2-3 \mu \mathrm{m})$, kugelige Einschlüsse unbekannter Natur auf. Sie haben meist eine eosinophile Hülle, die zuweilen eingebuchtet ist. Innen kann sich eine schwarze körnige Masse befinden. Nahe der Ba- 
salmembran ist die Masse ohne Hüllen anzutreffen. Ein dicker Klumpen (20 $\mu \mathrm{m} \phi)$ derartiger Einschlüsse liegt bei einem Exemplar im Hinterende.

Das Gehirn der dunkelgrauen Tiere enthält zwei kleine Augen (Länge $8 \mu \mathrm{m}$ ). Hinter und neben dem Gehirn liegen mehrere Frontaldrüsen.

Der Pharynx $(p)$ liegt vor der Körpermitte $(\phi 120-180 \mu \mathrm{m})$. Die kurze Pharynxtasche ist senkrecht orientiert. Der ventrale Greifwulst ist sehr kräftig entwickelt.

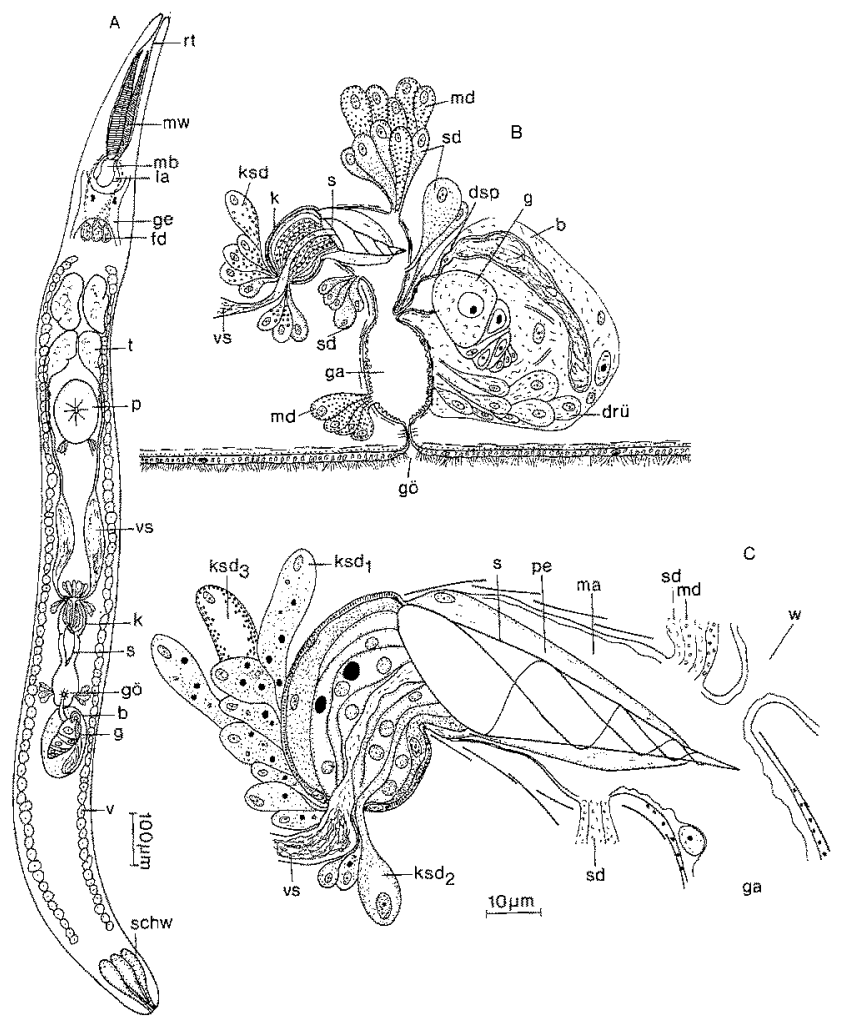

Abb. 29: Paraschizorbynchoides glandulis. A Organisation (kombiniert); $B$ Sagittalschnittrekonstruktion der Atrialorgane; $C$ Sagittalrekonstruktion des männlichen Kopulationsorgans

Im Bulbus werden basophile und eosinophile Sekrete produziert; sie sind auch im Darm nachzuweisen, der vom Gehirn bis in das äußerste Hinterende reicht.

Der Spaltrüssel ist $240 \mu \mathrm{m}$ lang.

Vier umfangreiche Hoden $(t)$ liegen vor dem Pharynx.

Die keuligen Samenblasen (vs) sind $80-130 \mu \mathrm{m}$ lang. Einzelne, mittelgroße Kornsekretdrïsen ( $k s d_{1-3}$ ) sezernieren drei Arten Kornsekret.

Das männliche Kopulationsorgan $(k)$ ist ein vorne kugeliges, hinten zungenförmig gestrecktes Organ $(100-120 \mu \mathrm{m})$ mit einer kräftigen Ringmuskelhülle. Die Kornsekretblase liegt proximal, während distal eine Papille (pe) das komplizierte Kutiku- 
larorgan umschließt. Die Papille hat außen eine schwach gekörnte Oberfläche und innen längsstreifiges Plasma, sie ragt in das männliche Atrium (ma).

Das Stilett (s) ist (55)-60-(65) $\mu \mathrm{m}$ lang, proximal $18 \mu \mathrm{m}$ breit und läuft nach hinten sehr scharf spitz zu. Diese Spitze ist streifig-faserig.

Das Stilett ist eine vierfach gewundene Spirale, deren Windungen caudal teleskopartig auseinandergeschoben sind. Innen liegt dem Stilett, zumindest in seinem proximalen Teil, ein feines Epithel an. Die Kornsekretblase ragt von vorne fingerförmig weit in das schräg ansetzende Stilett hinein und ist hierin ebenfalls mehrfach eingewunden.

Die gemeinsame Geschlechtsöffnung ( $g \ddot{o}$ ) liegt etwa bei $2 / 3$ der Körperlänge. Das kanalartige gemeinsame Atrium ( $g a$ ) ist mit einem papillösen Epithel ausgekleidet und wird von sehr kräftigen Längsmuskeln begleitet.

Der kurze Ovidukt (w) führt zu dem kleinen Germar $(g)$, das von der Bursa $(b)$ eingeschlossen ist. Der feine, kurze Ductus spermaticus $(d s p)$ erweitert sich zu einem Bläschen. Beide Abschnitte sind nicht kutikularisiert. In dem Bläschen sind bewegliche Spermien zu sehen; diese haben hier keine dicke eosinophile Hülle wie in den Samenblasen. Das Bläschen öffnet sich in eine langgestreckte Vakuole innerhalb der Bursa. In der Bursa liegen viele feine Kanälchen, resorbierte Spermien und teilweise sehr große Kerne. Auffällig sind tiefrote Drüsen (drii) mit schwarzen Sekreten unbekannter Funktion, die ventral fast die ganze Bursa anfüllen. Die eosinophilen, feinkörnigen Drüsen $(s d)$ und die basophilen, grobkörnigen Drüsen $(m d)$ münden an verschiedenen Stellen in das Atrium aus (Abb. 29 B).

Uterus und Vagina fehlen. Die Vitellarien (v) bilden paarige Follikelstränge vom Gehirn bis in das Hinterende.

Mehrfach wurden als Parasiten Sporozoen beobachtet.

D iskussion: Wesentliche Autapomorphien der neuen Gattung Paraschizorbynchoides ergeben sich aus dem Bau des Rüssels (ScHnLk 1970). Innerhalb der Schizorhynchidae sind nur bei dieser Form die Frontaldrüsen in den Rüssel einbezogen. Ferner ist der enge Zusammenhalt der lateralen Drüsensäcke mit dem komplizierten muskulösen Beutel hervorzuheben. Im übrigen sprechen folgende Merkmale für eine enge Verwandtschaft mit Schizorbynchoides: Ringmuskelhülle um das Kopulationsorgan, keine Kanalzellen („cellules bordantes“), Zahl der Testes, Rüssellänge.

Pseudoschizorbynchoides nov. gen.

D i a g n o s e : Spaltrüssel mit sehr langen, dreigliedrigen Rüsseldrüsen; Bulbus senkrecht orientiert; männliches Kopulationsorgan mit Längsmuskelhülle und spiralgewundenem Stilett aus Nadeln; zweigeteilte Bursa.

Typart: Pseudoschizorbynchoides ruber nov. spec.

Pseudoschizorbynchoides ruber nov. spec.

(Abb. 30)

Fund or t: Sylt: $12 \mathrm{sw}$ (leg. HoxHoLd; Locus typicus).

M a t e r i a 1: Lebendbeobachtungen, 3 Sagittal- und Querschnittserien (Holotypus 1 Sagittalschnittserie). 
B esch reibung: Die Körperlänge beträgt $1,5 \mathrm{~mm}$. Das Tier ist schmal, fadenförmig. Das Vorderende ist stumpf. Am Hinterende sind zwei lappig ausziehbare Haftlappen. Die Körperfarbe ist intensiv tiefrot. Unter der Längsmuskelschicht liegen im ganzen Körper umfangreiche, basophile Vakuolen. Hierin ist vermutlich die rote Körperfarbe fixiert. Augen fehlen.

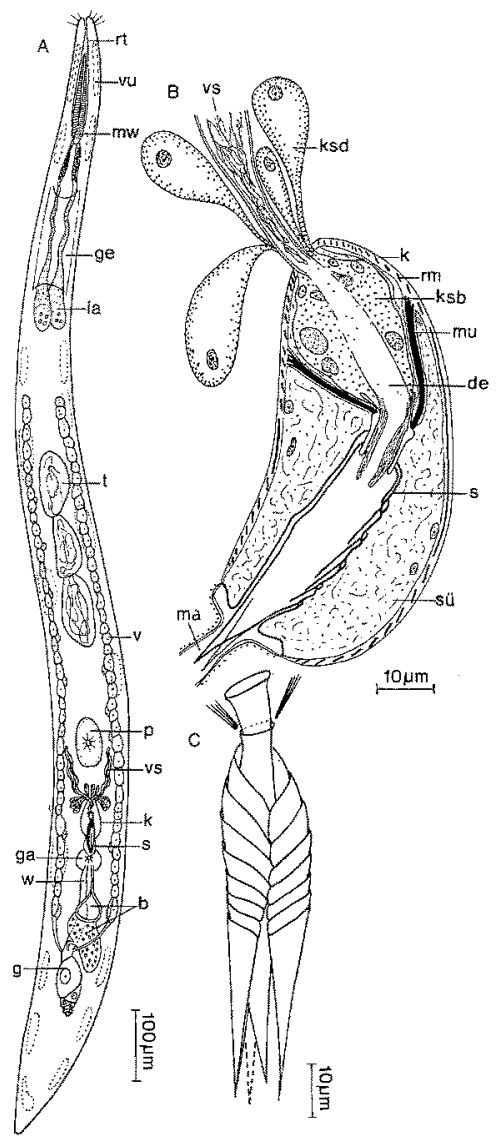

Abb. 30: Pseudoschizorbynchoides ruber. $A$ Organisation (kombiniert); $B$ Sagittalschnittrekonstruktion des männlichen Kopulationsorgans; C Stilett (Quetschpräparat)

Der kleine Pharynx liegt bei $2 / 3$ der Körperlänge. Das Epithel des Pharynxkörpers ist in einzelne Papillen ausgezogetz. Die Radiärmuskeln sind sehr fein, die inneren Ring- und Längsmuskeln deutlicher. Im Pharynx werden basophile und eosinophile Sekrete sezerniert. Die kurze Pharynxtasche ist senkrecht aufgerichtet.

Die Hoden $(t)$ liegen etwa in der Körpermitte zwischen Gehirn und Pharynx. Die Samenblasen (vs) sind lang und gewunden. Wenige große Kornsekretdrüsen (ksd) produzieren grobkörnige, basophile Sekrete.

Das männliche Kopulationsorgan ( $k$ ) ist ein etwa $90 \mu \mathrm{m}$ langer Schlauch. Unter 
der Längsmuskelhülle liegt proximal und zentral die Kornsekretblase ( $k s b$ ), die ungefähr das 1. Drittel einnimmt. Kanalzellen fehlen.

Das Stilett $(s, 65 \mu \mathrm{m})$, ist mit sehr kräftigen, radiär stehenden Längsmuskelsträngen ( $m u$ ) verbunden, die an der Außenwand des Kopulationsorgans inserieren. Es besteht aus einem proximalen Trichter und einer distalen Stachelgruppe. Der Trichter hat eine Länge von $7-8 \mu \mathrm{m}$, die Offnung ist $8 \mu \mathrm{m}$ weit. An den Trichter schließt sich in einem verstärkten Ring ein Übergangsteil von $12 \mu \mathrm{m}$ Länge und $8 \mu \mathrm{m}$ Durchmesser an. Der Stachelteil besteht aus 3-4 etwa $45 \mu \mathrm{m}$ langen Stacheln. Um das Stilett liegt ein lockeres, kernhaltiges Stützgewebe (sü). Es schließt sich proximal dicht der Kornsekretblase an und füllt über die Hälfte des Kopulationsorgans aus.

Das männliche Atrium ( $m a$ ) setzt kreisförmig an dem Kopulationsorgan und an einem umgebogenen Stiletteil an.

Die gemeinsame Geschlechtsöffnung (gö) liegt bei etwa $4 / 5$ der Körperlänge. An den kurzen, senkrechten Genitalkanal schließt sich dorsal ein kleines gemeinsames Atrium ( $g a$ ) an, welches sich frontal ein wenig erweitert. Caudal öffnet sich etwas mehr dorsal eine Vagina interna. Ventral mündet der außerordentlich lange, muskulöse Ovidukt, und führt za dem großen Germar $(g)$. Die umfangreiche zweigeteilte Bursa (b) füllt dorsal vom Germar fast den ganzen Körperquerschnitt aus. Die Wände der Bursa sind bis zum dorsalen, hinteren Abschnitt deutlich sichtbar; hier ist ein Ubergang in den Darm gegeben. Der vordere Abschnitt ist ein Hohlorgan, welches ein faseriges Epithel und eine Längsmuskelhülle hat. Der hintere Abschnitt der Bursa wird von einem geschlossenen, dichten Gewebe mit zahlreichen Kernen und feinen Kanälchen eingenommen. Die Bursa hat einen ventralen Fortsatz, der in unmittelbarer Nähe des Ovidukres oder des vorderen Teiles des Germars führt.

Die feinkörnigen, eosinophilen Drüsen und die grobkörnigen, basophilen Drüsen münden in das gemeinsame Atrium aus. Die paarigen Vitellarien (v) entsenden lange Vitelloducte kurz vor dem Germar in den Ovidukt.

D is k u s s i o n: Durch das gemeinsame Vorhandensein überlanger, gegliederter Drüsensäcke des Rüssels und einer Längsmuskelhülle um das Kopulationsorgan ist Pseudoschizorbynchoides von den übrigen Gattungen der Schizorhynchidae isoliert.

\section{Schizochilus BOADEN 1963}

Die Gattung Schizochilus kommt mit drei Arten im Untersuchungsgebiet vor. $S$. choriurus und $S$. choriurus caecus, die von HoxHold in den Rang einer selbständigen Art erhoben wird, werden von diesem bearbeitet.

\section{Schizochilus choriurus BOADEN 1963}

Fundorte: Sylt: $5 \mathrm{sw} \mathrm{k,} 6 \mathrm{sw}, 11 \mathrm{sh}, 12 \mathrm{sw}$ sh, $13 \mathrm{sw}, 17 \mathrm{sh}, 19$ sh., 24 sh, $25 \mathrm{sw}$.

Schizochilus caecus L'Hardy 1963

Fundort: Sylt: 12 (leg. Hoxhold).

Schizochilus marcusi BOADEN 1963

Fundort: Sylt: 12 sh sw. 
Amphirbynchus nov. gen.

Di a g n o s e : Langer, konischer Schwanz; um die Radiärmuskeln in den Muskelwülsten feine Hüllen; senkrechter Pharynx hinter der Körpermitte; vier Hoden in einer Reihe vor dem Pharynx; männliches Kopulationsorgan mit Längsmuskelhülle; in den Ductus ejaculatorius mündet proximal ein Teil der Kornsekretdrüsen; Stilett aus Nadeln, mit Innenrohr; Ductus spermaticus und Vagina externa vorhanden.

Typart: Amphirbynchus caudatus nov. spec.

\section{Amphirbynchus caudatus nov. spec.}

(Abb. 31-33)

Fundort: Sylt: 12 sw (Locus typicus).

Materia 1: Lebendbeobachtungen, mehrere Schnittserien (Holotypus 1 Sagittalschnittserie).

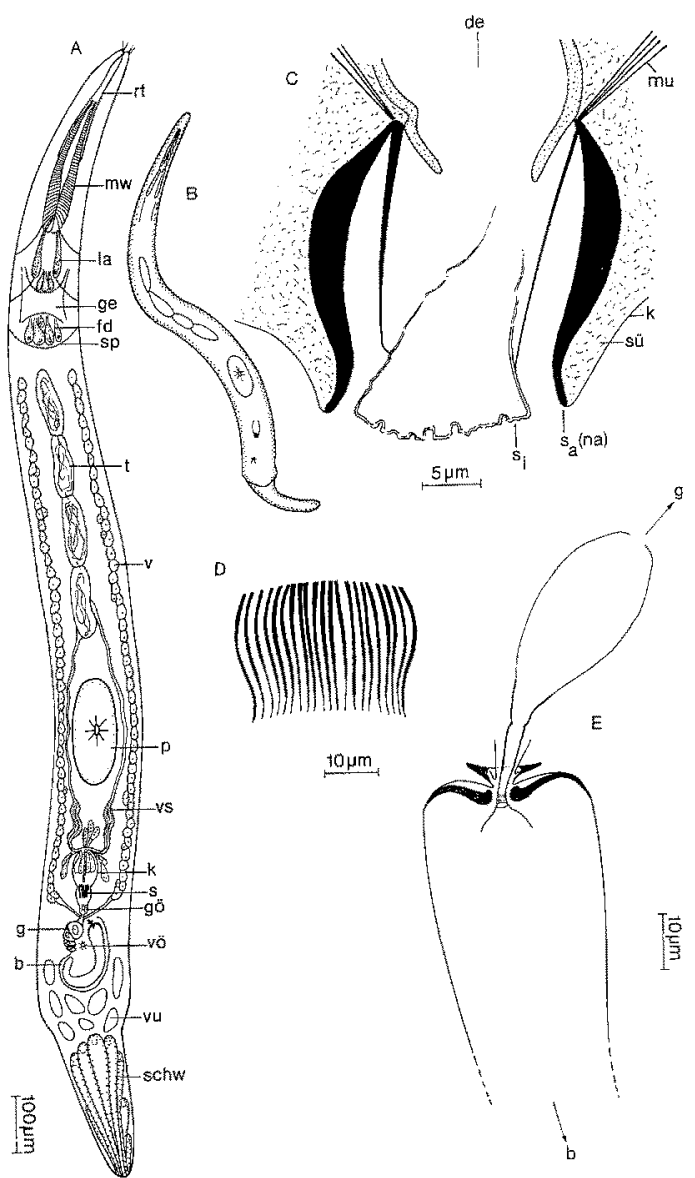

Abb. 31: Amphirhynchus caudatus. A Organisation (kombiniert); $B$ Habitus; $C$ Kutikularorgan (Schnittserie); D Kutikularorgan (Quetschpräparat); E Ductus spermaticus (Quetschpräparat) 
Beschreibung: Die Körperlänge beträgt 1,8-2 mm. Beim sehr lebhaften Umherschwimmen bewegen sich die Tiere mit den ersten zwei Körperdritteln schlängelnd. Das dritte Körperdrittel wird dagegen in charakteristischer Weise leicht angewinkelt hinterhergeschleppt; es ist viel unbeweglicher. Die Tiere besitzen einen langen, konisch zulaufenden Schwanz (schw), er ist stets steif. Bei zwei Exemplaren ist er $170 \mu \mathrm{m}$; bei einem Exemplar $300 \mu \mathrm{m}$ lang. Bei Beunruhigung wird mit dem Hinterende zuweilen nach hinten gestoßen, vielleicht stellt es ein Bohrorgan dar. Der Inhalt des Schwanzes ist feinkörnig, homogen und wird in mehreren Schwanzdrüsen produziert.

Kurz vor dem Schwanzansatz liegt ein Haftring. Durch alternierendes Anheften des Hinterendes und Kontrahieren des Vorderendes kann Amphirbynchus caudatus rückwärts kriechen. Vor den Schwanzdrüsen befindet sich ein vakuolisiertes Gewebe.

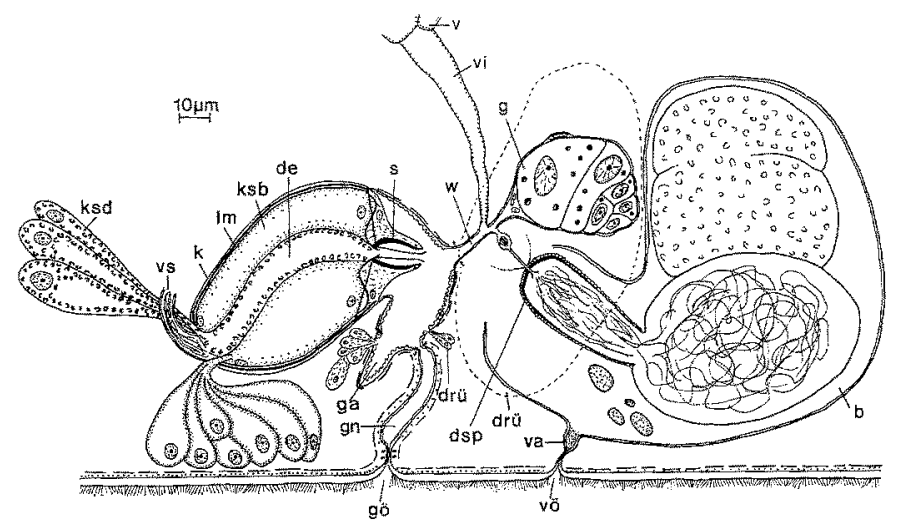

Abb. 32: Ampbirbyncbus caudatus. Sagittalschnittrekonstruktion der Atrialorgane

Die Körperfarbe ist grünlich-grau. Hinter dem augenlosen Gehirn und zwischen den Rüsseldrüsen liegen ansehnliche Frontaldrüsen. Ein schwaches Septum ( $s p)$ umgibt die Frontaldrüsen. Der Pharynx ( $p$ ) liegt hinter der Körpermitte $(\phi[130]-160$ bis [220] $\mu \mathrm{m}$ ). Das Epithel der kurzen Pharynxtasche und des Bulbus ist in sehr lange Papillen ausgezogen. Im Pharynx werden basophile und eosinophile Sekrete produziert. Der ventrale Greifwulst ist sehr stark entwickelt.

Als Parasiten kommen Sporozoen und Mesozoen vor.

Die Muskelwülste sind 160-230 $\mu \mathrm{m}$ lang. Um die Radiärmuskeln liegen Hüllen. Die lateralen Drüsensäcke haben Längsmuskeln.

Im vorderen Körperabschnitt nehmen vier Hoden ( $t$ ) etwa die Medianlinie ein. Die aufgewundenen Samenblasen (vs) verjüngen sich zu Seminalkanälen, die miteinander verwachsen.

Das kugelige bis elliptische Kopulationsorgan $(k)$ ist 70-100 $\mu \mathrm{m}$ lang, außen von einer schwachen Hülle aus einzelnen Längsmuskelfasern $(\mathrm{lm})$ umgeben. Der Innenraum wird von der Kornsekretblase in einer bemerkenswerten Anordnung ausgefüllt. Die Kanäle mit eosinophilem Sekret $(k s b)$ liegen radial um einen zentralen Kanal 
mit basophilem Sekret (de). Dieser Kanal vereinigt sich proximal aus Kornsekretdrüsen $(k s d)$. Offensichtlich entspricht dieser Kanal dem Ductus ejaculatorius.

Der Kornsekretblase schließt sich ein Stützgewebe (sï) an. Das Stilett (s) ist 22 bis $24 \mu \mathrm{m}$ lang, bei einem größten Durchmesser von $25 \mu \mathrm{m}$ und besteht im Prinzip aus einem äußeren Kreis von Nadeln $\left(s_{a}\right)$ und einem inneren, stempelartigen Hohlzylinder $\left(s_{i}\right)$. Der äußere Kreis sieht im Quetschpräparat wie eine Lyra aus. Insgesamt sind (40)-48 Nadeln vorhanden. Jede Nadel hat einen knaufartigen Ansatz, verbreitet sich stark und läuft dann spitz zu. Der innere Hohlzylinder ist mit den Nadeln proximal verwachsen. Die dünne, faltige Wand ist leicht spiralisiert. Das gemeinsame Genitalatrium ist mit der äußeren Muskelhülle des Kopulationsorgans verwachsen.

Die gemeinsame Geschlechtsöffnung ( $g \ddot{o}$ ) liegt etwa bei ${ }^{4 / 5}$ der Körperlänge. Dorsal rom Genitalkanal $(g k)$ öffnet sich das gemeinsame Genitalatrium ( $g a)$ mit einer kleinen frontalen Aussackung.

Caudal beginnt der kurze Ovidukt (w), an dessen Ende links das Germar ( $g$ ) liegt. Es hat eine kernhaltige, schmale Tunica.

Beträchtlich weit hinter der gemeinsamen Geschledhtsöffnung zeigt sich eine schmale Vagina externa (vö). Sie führt nach einem kurzen, bewimperten Anfangsteil sogleich in eine blasen- oder trichterartige Erweiterung, die stets mit einem feinkörnigen Sekret ausgefüllt ist. Hieran schließt sich die sehr umfangreiche Bursa (b) an. Sie hat dorsal meist einen resorbierenden Abschnitt. Ventral befindet sich häufig eine Ansammlung elliptischer oder kugeliger, eosinophiler Einschlüsse. Ist Sperma vorhanden, so ballt es sich zu einem umfangreichen Haufen zusammen oder liegt in einem gewundenen Schlauch. Aus dieser Spermaansammlung führt nach vorn oben ein Kanal zu einem sehr auffälligen Ductus spermaticus. Die Stärke der Basalmembran nimmt in dem Kanal nach vorne hin zu. Außen legt sich um den Kanal eine dicke Ringmuskelschicht. Der Ductus spermaticus $(42 \mu \mathrm{m}$ ) beginnt innerhalb des Kanals mit einem etwa $14 \mu \mathrm{m}$ weiten Trichter, verjüngt sich zu einem $20 \mu \mathrm{m}$ langen, etwa $3 \mu \mathrm{m}$ weiten, konstant starken Röhrchen, um sich kurz vor der Einmündung in den mittleren Teil des Ovidukts zu einer Blase mit Kernen zu erweitern. Frontal vom Kanal legt sich um das Röhrchen eine trichterartige oder kragenartige Versteifung. Die Spermien in der Blase haben keine eosinophilen Hüllen, während sie in Hoden, in den Samenblasen und teilweise auch in der Bursa von einer dicken, roten Hülle umschlossen sind. Die Vorderwand der Bursa ist nicht eindeutig zu bestimmen; zwischen ihr und dem Genitalatrium liegen umfangreiche, eosinophile Strukturen (drï) mit dunklem, körnigem Inhalt.

Die paarigen Vitellarien ( $v$ ) entsenden Vitellodukte $(v i)$ in den mittleren Teil des Oviduktes. In das Atrium münden mehrere, sich mit Haidenhain/Eosin grauocker anfärbende Drüsen (drï), die streifige Sekrete produzieren. Ein Uterus fehlt.

D is kus ion: Spezifische Autapomorphien von Amphirbynchus sind die von Hüllen umgebenen Radiärmuskeln in den Wülsten, die Längsmuskeln an den lateralen Drüsensäcken, die Längsmuskelhülle um das Kopulationsorgan kombiniert mit proximal mündenden Kornsekretdrüsen und die Konstruktion des Schwanzes. Im Unter-

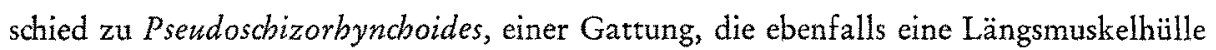
um das Kopulationsorgan hat, besitzt Amphirbynchus keine langen, gegliederten Drüsensäcke. 

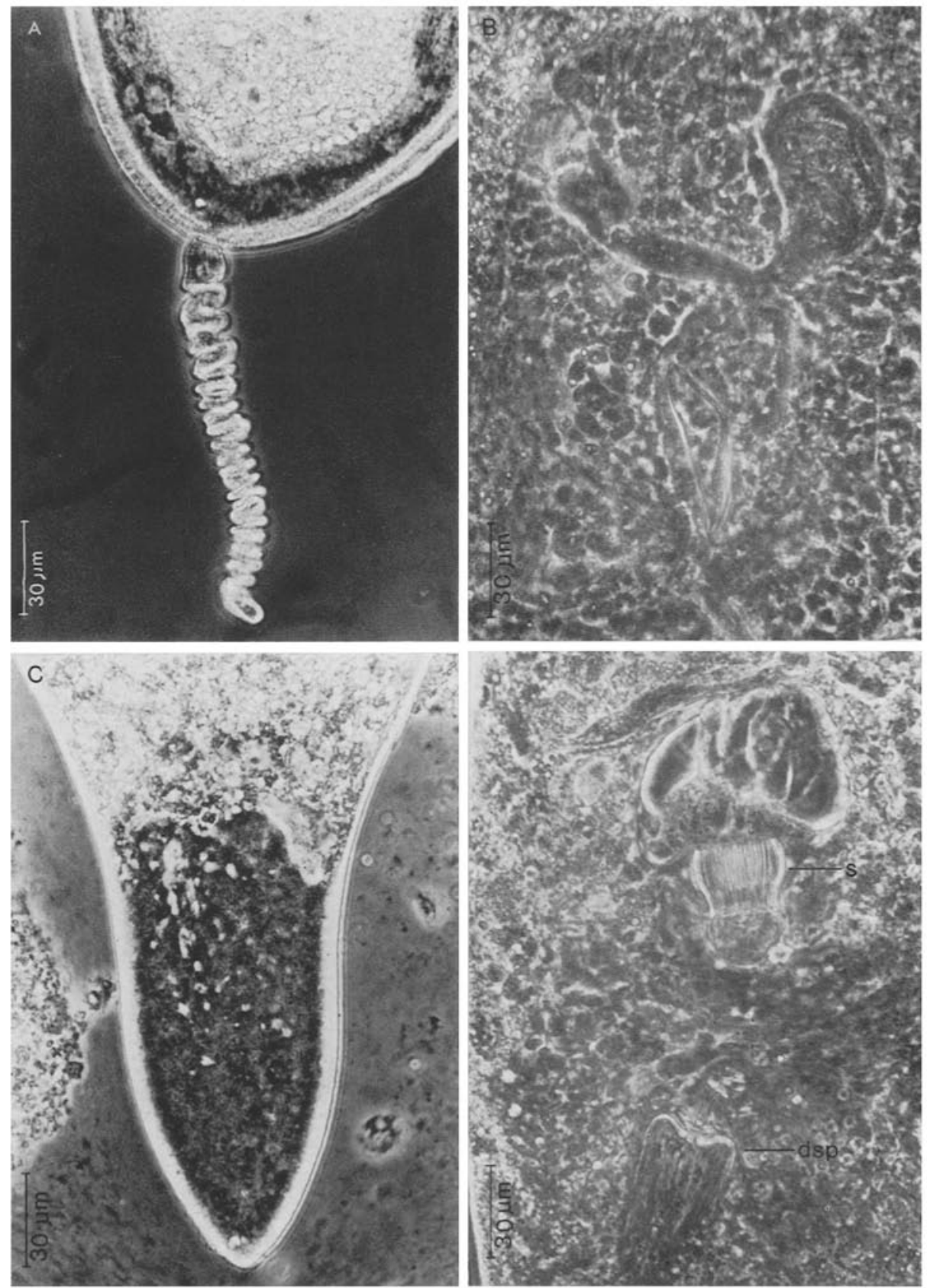

Abb. 33: A Schizorhynchoides canaliculatus. Schwänzchen; B Paraschizorbynchoides glandulis. Männliches Kopulationsorgan; $C$ Amphirbyncbus candatus. Schwanz; $D$ Amphirbynchus caudatus. Kopulationsorgan und Ductus spermaticus 
Limirbynchus nov. gen.

D i a g n o s e: Senkrechter Pharynx kurz hinter der Körpermitte; zwei Hoden; männliches Kopulationsorgan mit rohrförmigem Stilett; Germar vor der gemeinsamen Geschlechtsöffnung; Vitellarien paarig.

Typart: Limirbynchus danicus nov. spec.

Limirbyncbus danicus nov. spec.

(Abb. 34, 35, 41)

Fundorte: Amrum: 4 sh (Locus typicus); Westerhever: (leg. Ax 1951); Rømø: Lakolk, Weststrand, verschiedene Stellen.

M a t eria l: Lebendbeobachtungen, Zeichnungen von Ax (2 Expl.).

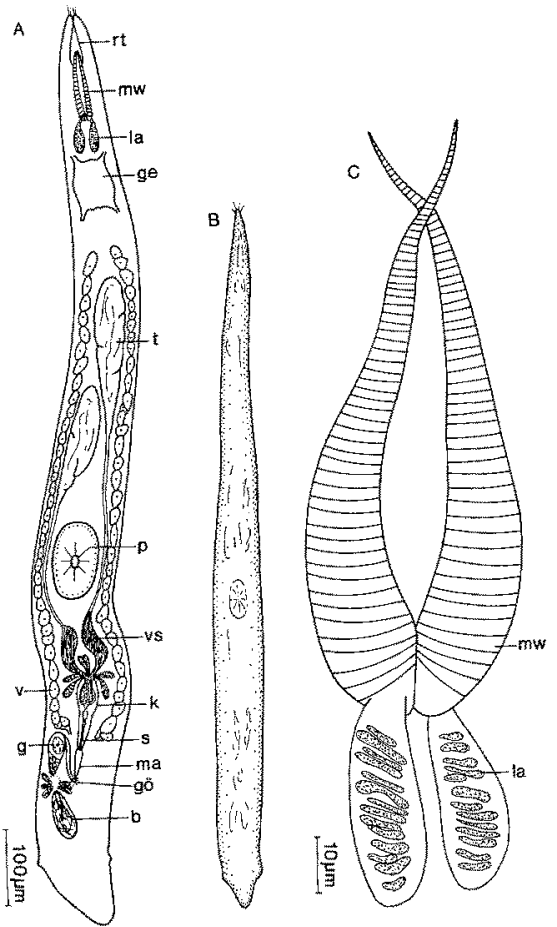

Abb. 34: Limirhynchus danicus. A Organisation (kombiniert); $B$ Habitus; C Rüssel (Quetschpräparat)

B es chreibung : Die Körperlänge beträgt 1-1,2 mm. Die Art ähnelt im Habitus der Gattung Cheliplana. Das Vorderende läuft spitz zu, das Hinterende ist abgerundet und hat einen Haftring.

Die Körperfarbe ist gelblichweiß. Augen fehlen.

Der zarte Spaltrüssel (75)-90-(100) hat zwei laterale Drüsenbeutel (ca. $25 \mu \mathrm{m})$. 
Der Pharynx rosulatus $(\phi 100 \mu \mathrm{m})$ befindet sich knapp hinter der Körpermitte. Die Pharynxtasche öffnet sich senkrecht zur Körperlängsachse.

Die Geschlechtsorgane sind parig angelegt. Zwei umfangreiche Hoden ( $t$ ) liegen gegeneinander versetzt $z$ wischen dem Gehirn und dem Pharynx. Die keulenförmigen Samenblasen $(v s$, Länge $70-85 \mu \mathrm{m})$ enthalten feine Spermien, wodurch sie beinahe gleichmäßig gefärbt und strukturiert erscheinen. Das Kopulationsorgan $(k)$ ist $90 \mu \mathrm{m}$ lang und hat die Form einer ovoiden Blase, an der hinten ein langer, schlanker Schlauch hängt. Das Hinterende des Kopulationsorgans ist ganz schwach kurikularisiert. Der vordere Teil nimmt die schwach entwickelte Kornsekretblase auf. Der Ductus ejaculatorius mündet in ein einfach gebautes Stilett (s). Von seinem trichterförmigen Vorderende $a b$ verschmälert es sich zu einem feinen, biegsamen Rohr (Länge [39]-44 bis [48] $\mu \mathrm{m})$.

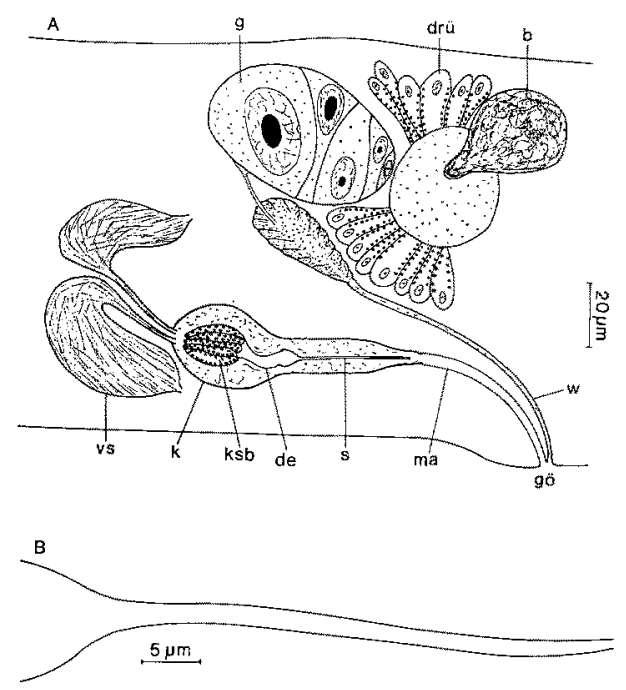

Abb. 35: Limirbynchus danicus. A Atrialorgane (Quetschpräparat); B Stilett (Quetschpräparat)

Das lange männliche Genitalatrium ist mit dem Kopulationsorgan verwachsen.

Die gemeinsame Geschlechtsöffinung (gö) liegt bei etwa $4 / 5$ der Körperlänge. Das Germar $(g)$ befindet sich auf der Höhe des männlichen Atriums und damit vor der Geschlechtsöffnung. Es ist mit dieser durch einen sehr langen und dünnen Ovidukt verbunden. Unmittelbar vor dem Germar ist der Ovidukt von mehreren Drüsen umgeben. Dem Germar schließt sich hinten eine etwa gleich große Bursa (b) an; zwischen beiden liegen zahlreiche Drüsen mit grobkörnigen Sekreten. Die beiden Vitellarien (v) erstrecken sich vom Gehirn bis zum Germar.

Diskussion: Obwohl nur Lebendbeobachtungen vorliegen, sprechen folgende Merkmale für die Errichtung einer neuen Gattung. Das Germar liegt vor der Geschlechtsöffnung; es sind nur zwei Hoden vorhanden; Kanalzellen fehlen im Kopulationsorgan; der Habitus ähnelt den Cheliplanidae. 


\section{Neoschizorbynchus nov, gen.}

Zwei Arten der Gattung werden beschrieben. Eine weitere Species wird nur mit Fundortangaben aufgenommen und an anderer Stelle von Heller publiziert.

D i a g n o se : Kurzer Spaltrüssel 1/18 bis ca. 1/50 körperlang; Pharynxtasche lang, waagerecht, Bulbus tonnenförmig oder Pharynxtasche kurz, senkrecht, Bulbus kugelförmig; zwei oder vier Hoden vor dem Pharynx; männliches Kopulationsorgan mit Längsmuskelhülle und Cirrus, in dem ein Stilett vorhanden sein kann; eine Geschlechtsöffnung vor dem Hinterende, ventral; Germar unpaar; Vitellar paarig.

Typart: Neoschizorbynchus longipharynggus nov. spec.

\section{Neoschizorbynchus longipharynggus nov. spec.}

(Abb. 36, 37, 41)

Fundorte: Sylt: $12 \mathrm{sw}$ (Locus typicus), $25 \mathrm{sw}$; Amrum: $4 \mathrm{sh}$.

$\mathrm{M}$ a teria l: Lebendbeobachtungen, mehrere Schnittserien (Holotyp: 1 Sagittalschnittserie).

Beschreibung: Der Körper ist 1,2-1,4 mm lang. Das verjüngte Vorderende hat zwei Bündel von sehr langen Tasthaaren. Am gesamten Körper stehen einzelne Tasthaare. Vor dem abgerundeten Hinterende liegt ein Haftring. Der vordere Haftring liegt etwa bei $3 / 5$ der Körperlänge. Das Tier ist graugrün gefärbt.

Das Gehirn (ge) trägt zwei nierenförmige Augen $(\phi 14 \mu \mathrm{m})$.

Der tonnenförmige Pharynx $(p)$ ist waagerecht orientiert. Die ungewöhnlich lange Pharynxtasche $(110 \mu \mathrm{m})$ reicht bis hinter das Gehirn. Die Muskulatur der sehr kontraktilen Pharynxtasche ( $p t)$ besteht aus sehr kräftigen Ringmuskeln und Längsmuskelfasern (Abb. 41). Der Bulbus (100-150 $\mu \mathrm{m})$ enthält eine kräftige innere (irm) und cine schwächere äußere Ringmuskulatur (äturm). Außen um diese liegt eine kräftige Längsmuskulatur. Die inneren Längsmuskeln (ilm) sind stark entwickelt. 14-15 Radiärmuskeln $(\mathrm{ra})$ sind vorhanden. Der Pharynx besitzt einen kräftigen ventralen und einen ebenso kräftigen dorsalen Sphinkter. Der Rüssel ist $70 \mu \mathrm{m}$ lang.

Die beiden kleinen Hoden $(t)$ liegen zwischen Gehirn und Pharynx. Die Samenblasen (vs) sind kurz und gedrungen $(135 \mu \mathrm{m})$. Die umfangreichen Kornsekretdrüsen $(k s d)$ liegen ventral und ventrolateral. Die Kornsekretblase $(k s b)$ bildet eine Schlinge in der vorderen Hälfte des schlauchförmigen Kopulationsorgans (Länge [170]-210 bis [270] $\mu \mathrm{m}$ ) und mündet proximal in den Cirrus ein. Einige kleinere Teile der Kornsekretblase liegen aber auch neben dem Cirrus und münden erst in seinen distalen Teil aus. Der Ductus ejaculatorius (de) mündet in das Stilett (s). Lediglich am proximalen Teil des Kopulationsorgans ist eine schwache Verdickung der Längsmuskelhülle ( $m u$ ) festzustellen.

Das Kutikularorgan besteht aus einem langen Stilett $(140 \mu \mathrm{m})$ und einem etwa gleichlangen, bestachelten Cirrus. Das Stilett ist ein feines, biegsames Rohr mit einer Trichteröffnung ( $\phi$ proximal 6-7 $\mu \mathrm{m}$, distal 1-1,2 $\mu \mathrm{m}$ ). An diesen setzen einige sehr kräftige Muskeln $(m u)$ an, die mit der Außenwand des Kopulationsorgans verwachsen sind.

Der Cirrus (c) umgibt das Stilett, und der proximale Teil ist nur schwach entwickelt. Die Innen- und Außenwand sind durch querstehende Muskelfasern getrennt. 
Diese dienen vermutlich zur Bewegung der Stacheln $(5-8 \mu \mathrm{m})$, die nach etwa $1 / 3$ der Stilettlänge auftreten. An den Ansatzstellen der Stacheln liegen kleine Grana. Ein großer Zellkern liegt im Cirrus neben dem Anfangsteil des Stiletts.

Der Cirrus wird von einem lockeren Gewebe (sï) des Kopulationsorgans mit kleinen Zellkernen umgeben. Ein großer Zellkern liegt am Ende des Kopulationsor-

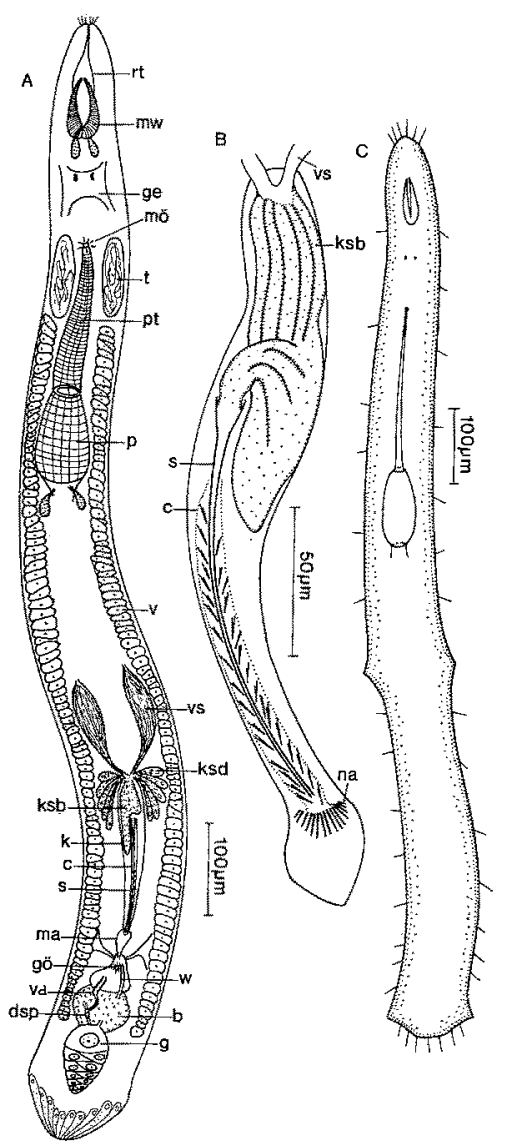

Abb. 36: Neoscbizorbynchus longipharynggus. A Organisation (kombiniert); $B$ männliches Kopulationsorgan (Quetschpräparat); $C$ Habitus

gans. Hier befindet sich ein Kranz von etwa 20-30 radial um das Stilettende gestellten, kräftigen Nadeln $(8 \mu \mathrm{m})$, die in einer kleinen Tasche befestigt sind. Die Cirruswand endet papillenförmig im männlichen Atrium ( $m a$ ), das kurz und muskulös ist.

Die gemeinsame Geschlechtsöffnung (gö) liegt etwa bei $4 / 5$ der Körperlänge. Der lange, schmale Genitalkanal ( $g n$ ) führt in das weite Atrium ( $g a$ ). Aus dem oberen, hinteren Teil entspringt das gewundene weibliche Atrium (wa). An seinem Ende liegen fünf kleine Zellkerne. Hier beginnt die gewundene Vagina interna (va) mit einer Längsmuskelhülle (Innendurchmesser $1 \mu \mathrm{m}$ ). Die Vagina interna führt zum Ductus 
spermaticus ( $d s p)$. Ich habe in zwei Schnittserien die direkte Einmündung feststellen können; in sieben Schnittserien endet die Vagina in unmittelbarer Nähe.

Der Ductus spermaticus (15 $\mu \mathrm{m}$ Länge) ist nicht kutikularisiert. Er beginnt mit einem zur Bursa offenen Bläschen, das zuweilen Spermaknäuel enthält. Der mittlere Teil des Ductus spermaticus ist von einer starken Muskelhülle umgeben. In diesen

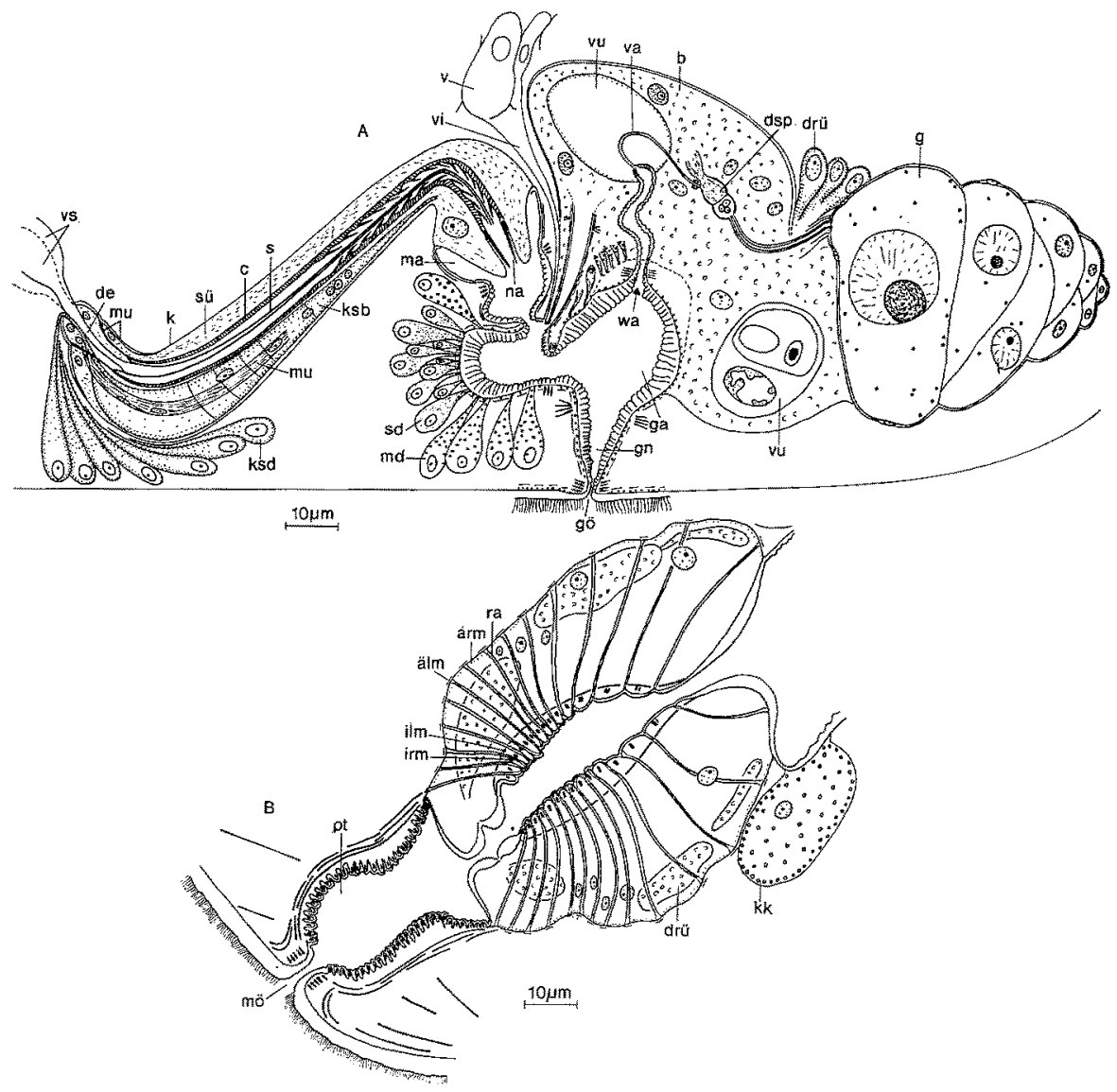

Abb. 37: Neoschizorhynchus longipharynggus. A Sagittalschnittrekonstruktion der Atrialorgane; $B$ Sagittalschnittrekonstruktion des Pharynx

Teil führt gegenüber der Vagina ein sehr feiner Kanal, der mit einer Vakuole in der Bursa in Verbindung steht. Der bläschenförmige Endteil des Ductus spermaticus enthält drei Kerne und ist durch ein Septum abgetrennt. Zwei feine, kutikularisierte Röhrchen führen in völlig parallelem Verlauf zum vordersten Zipfel des Germars. Beide haben eine sehr schwache Muskelhülle und einen Innendurchmesser von $1 \mu \mathrm{m}$.

Das umfangreiche Germar $(g)$ nimmt im Hinterende über die Hälfte des Körperquerschnittes ein. Das Germar ist von einer feinen, kernhaltigen Tunica umgeben. 
Ein typischer Ovidukt fehlt. Neben und vor dem Germar liegt an einer Seite ein drüsiges Anhangsorgan (drü), welches sich wie das Germar anfärbt.

Die Bursa (b) zeigt im Quetschpräparat und in Schnittserien ein ungemein variables Bild. Sie ist vorne mit dem gemeinsamen Atrium, caudal mit dem Germar bzw. mit dem drüsigen Anhangsorgan verwachsen. Im Innern befinden sich neben zahlreichen Vakuolen auch Zellkerne. In konstanter Anordnung liegen mehrere Kerne um den Ductus spermaticus. In vielen Schnittserien liegen zwei große, ellipsoide Einschlüsse (vu) in der Bursa. Diese sind entweder homogen cosinophil oder sie enthalten basophile Reste von Spermien. In einer Schnittserie konnte ich eine kleine Oocyte (in Resorption?) feststellen. Außerdem befinden sich in ihnen stark färbbare Kristalle.

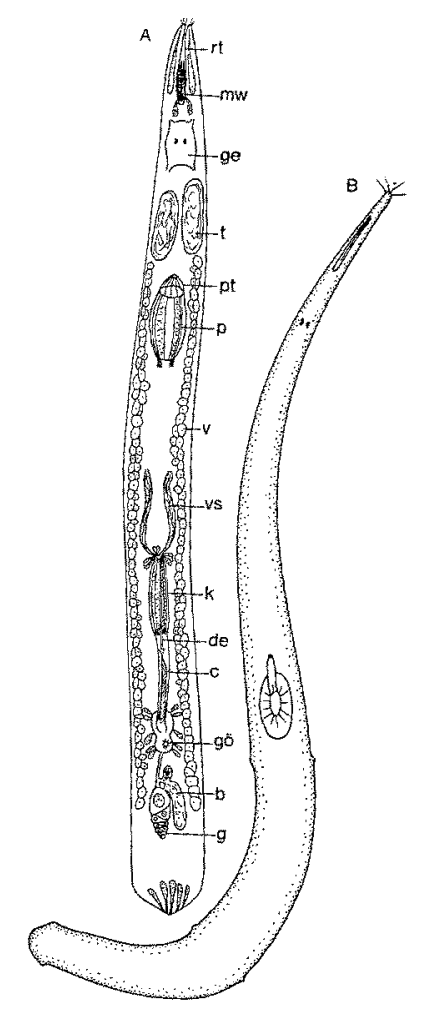

Abb. 38: Neoschizorbynchus brevipharynggus. A Organisation (kombiniert); B Habitus

Homogen eosinophil angefärbte Einschlüsse können aber auch als accessorische „Schalendrüsen"bildung aufgefaßt werden.

Die Bursa stellt vermutlich ein Leitungsorgan für reife Oocyten dar, die durch schwache, kanalartige Bahnen aus dem Germar in sie gelangen und sie durch das ebenso feine, am Vorderende gelegene Ausleitungsteil verlassen.

In die proximale Auswölbung des Atriums münden zahlreiche eosinophile Drüsen (sd). Zwei weitere derartige Drüsen sind neben dem Endteil des Oviduktes festzu- 
stellen. Die basophilen Drüsen ( $m d$ ) liegen in zwei sehr großen, lateralen Gruppen neben dem gemeinsamen Atrium und münden in dessen gesamten frontalen Teil aus.

Zwei Vitellarien $(v)$ entsenden schwache Vitellodukte $(v i)$ in die proximale Auswölbung des gemeinsamen Atriums.

Neoschizorbynchus brevipharynggus nov. spec.

(Abb. 38-41)

Fund or te: Sylt: $12 \mathrm{sw}$ (Locus typicus), $14 \mathrm{sw}, 13 \mathrm{sw}$.

Materia 1: Lebendbeobachtungen, mehrere Schnittserien (Holotypus: 1 Sagittalschnittserie).

Beschreibung: Die fadenförmige Art erreicht 1,2-1,4 mm Länge. Das Vorderende trägt wenige Tasthaare. Das Hinterende ist drehrund, angeheftet dreieckig. Die Art hat drei Hatringe (Abb. $38 \mathrm{~B}$ ). Die Farbe ist hellgrau bis grüngrau. Das Gehirn enthält zwei Augen, vor ihm liegen umfangreiche Frontaldrüsen. In der Epidermis treten helle Einschlüsse auf.

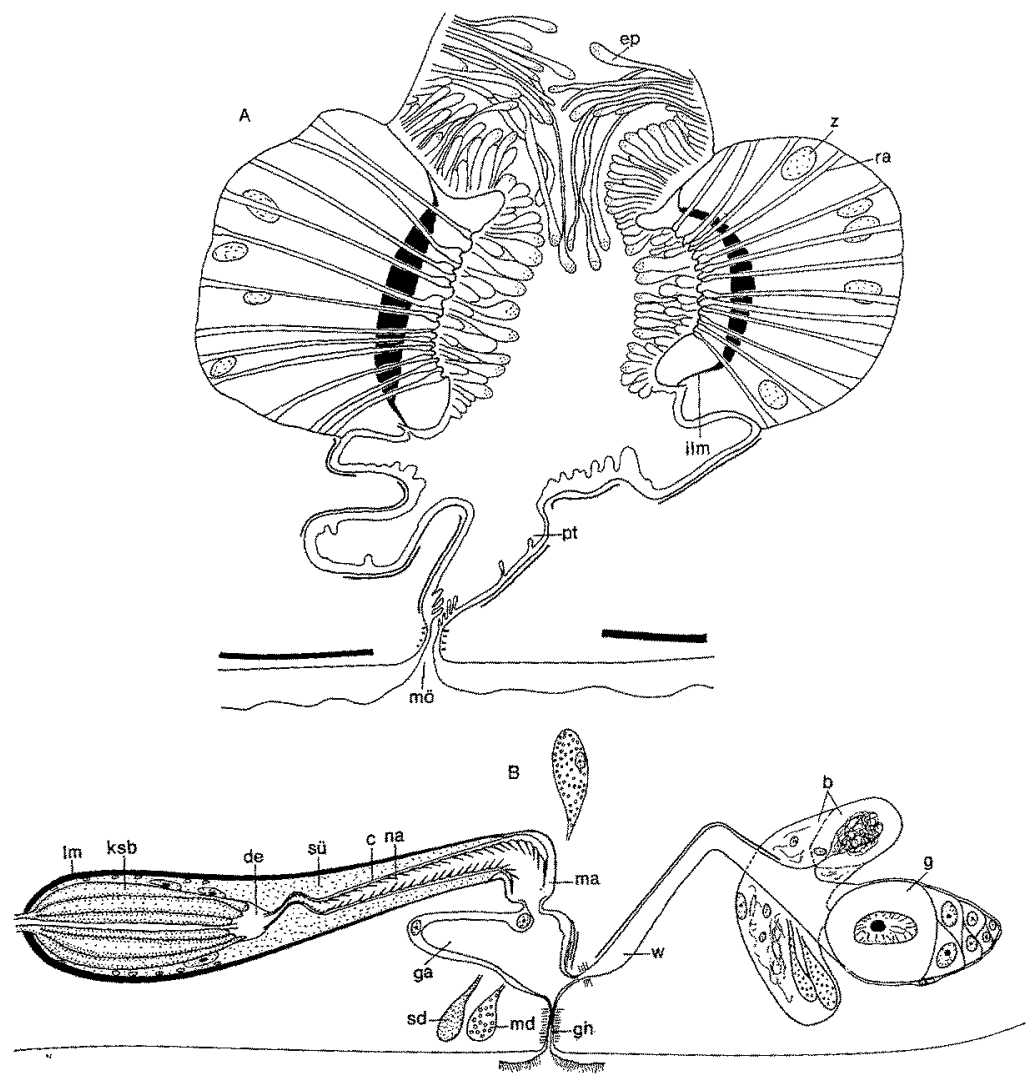

Abb. 39: Neoschizorbynchus brevipharynggus. A Sagittalschnittrekonstruktion des Pharynx; $B$ Sagittalschnittrekonstruktion der Atrialorgane (Lage des Vitellodukts unbekannt) 
Der stark erweiterungsfähige Pharynx liegt zwischen $1 / 3$ der Körperlänge und der Körpermitte. Im Schnittpräparat ist er (ohne Pharynxtasche) $20-40 \mu \mathrm{m}$, Im Quetschpräparat 80-140 $\mathrm{m}$ lang. Die kurze Pharynxtasche hat schwache Längsmuskeln.

Der Bulbus ist durch sehr kräftige Längsmuskeln charakterisiert. Drïsen sind in ihm kaum sichtbar. Der proximale und der distale Sphinkter sind nur schwach entwickelt. Das Epithel des Bulbus ist in eine Vielzahl von Papillen ausgezogen, die insgesamt einen dichten, zottenartigen Besatz bilden. Die keulenförmigen Enden sind mit dunklen, kleinen Einschlüssen versehen (Drüsensekrete?). Besonders lange Papillen befinden sich im Oesophagus.

Der Spaltrüssel erreicht $65 \mu \mathrm{m}$ Länge.

Zwei kleine Hoden ( $t$ ) liegen zwischen Gehirn und Pharynx. Die Samenblasen (vs) sind leicht gewunden (Länge etwa $120 \mu \mathrm{m}$ ). Eosinophile und basophile Kornsekretdrüsen liegen an der Ventralseite.

Das männliche Kopulationsorgan (Länge [160]-230-[300] $\mu \mathrm{m}$ ) ist ein langer Schlauch mit einer Längsmuskelhülle und enthält einen bestachelten Cirrus (c). An der Einmündung des Ductus ejaculatorius endet die Kornsekretblase (Abb. 40 A, G). Hier liegen lateral zwei weitere große Kerne. Am Cirrus fehlen Kerne. Lediglich am Ansatz des Atriums am männlichen Kopulationsorgan befindet sich ein großer Zellkern.

Der Cirrus hat einen komplizierten Anfangsteil (Abb. 40). Im Quetschpräparat zeigt sich dieser als feines, kutikularisiertes Röhrchen (Abb. 41). Der histologische Schnitt erklärt dieses als eine u-förmige Einbuchtung des weiter hinten drehrunden

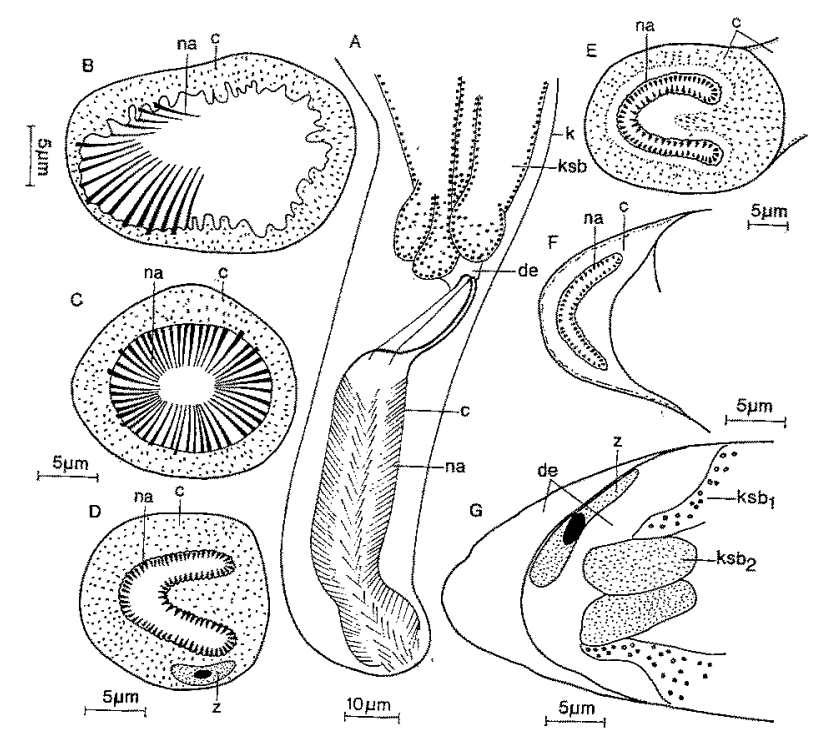

Abb. 40: Neoschizorhynchus brevipharynggus. A Hinterende des Kopulationsorgans mit Cirrus (Quetschpräparat), am Cirrus vorne eine u-förmige Einbuchtung; $B$ Querschnitt durch den Cirrus, kurz vor dessen Hinterende; $C$ wie $B:$ mittlerer Teil des Cirrus; $D$ wie $B:$ Beginn der u-förmigen Einbuchtung; $E$ wie $B$ : vollständige Einbuchtung; $F$ wie $B$ : Vorderende des hier sehr feinen Cirrus; $G$ wie $B$; Ductus ejaculatorius mündet in den Cirrus 

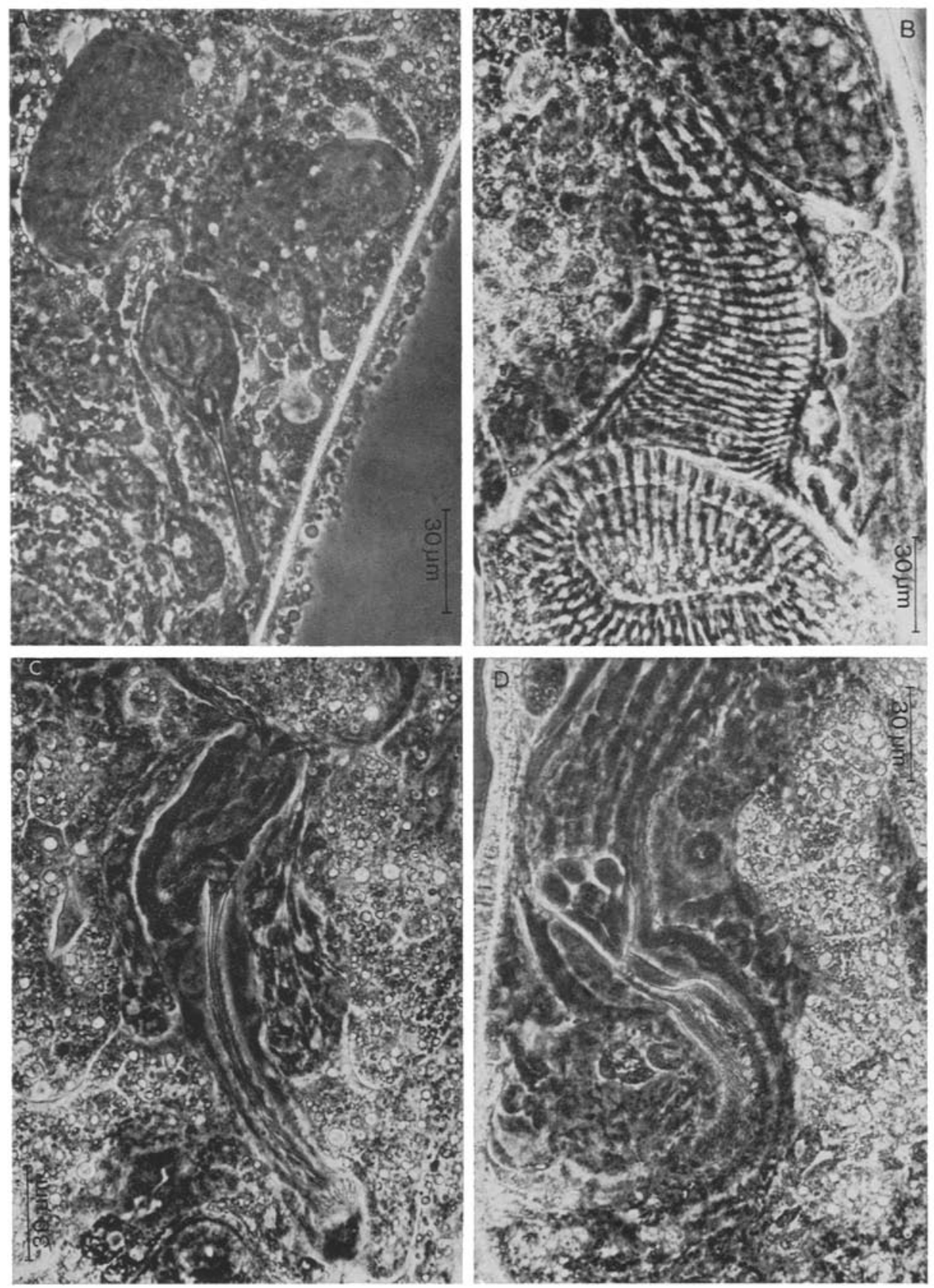

Abb. 41: A Limirhynchus danicus. Kopulationsorgan; B Neoschizorhynchus longipharynggus. Pharynxtasche, stark kontrahiert; C Neoschizorbynchus longipharynggus. Kopulationsorgan; D Neoschizorhynchus brevipharynggus. Kopulationsorgan 
Cirrus (Abb. 40 D-E). In diesem Anfangsteil sind nur kurze Stacheln vorhanden. Dagegen sind lange Stacheln $(3 \mu \mathrm{m})$ in seinem Hauptteil vorhanden. Zwischen der Innen- und der Außenwand des Cirrus liegen Muskeln. Der Cirrus wird durch ein lockeres Gewebe (sii) im Kopulationsorgan fixiert.

Die gemeinsame Geschlechtsöffnung (gö) liegt bei $4 / 5$ der Körperlänge. Der Genitalkanal $(\mathrm{g} n)$ führt in das gemeinsame Atrium ( $\mathrm{g} a$ ), das frontal einen durch einen schwachen Sphinkter verschließbaren Uterus hat. Der weibliche Genitalkanal (w) führt in leicht gebogenem Verlauf zum Germar. Dorsal begleitet ihn auf ganzer Länge ein starker Längsmuskel.

Kurz vor dem Germar $(g)$ zeigt sich am dorsalen Rand des weiblichen Genitalkanals eine schwache Auswölbung, in der ein feiner Kanal beginnt. Dieser fuihrt in die $z$ weiteilige Bursa (b). Der vordere Bursaabschnitt ist dickwandig und enthält nur Spermien. Er liegt im Quetschpräparat etwas seitlich vor dem Germar. Der hintere, größere Bursaabschnitt ist dünnwandiger und enthält neben Spermien noch Sekrete. Die Abschnitte der Bursa sind durch ein Septum voneinander getrennt und stehen durch einen Kanal in Verbindung.

Die paarigen Vitellarien (v) beginnen hinter den Hoden und reichen bis hinter die Geschlechtsöffnung. Die wenigen, eosinophilen Drüsen (sd) münden in den Vorderteil des gemeinsamen Atriums. Die umfangreicheren, basophilen Drüsen (md) münden teilweise ebenfalls an dieser Stelle, zum anderen sind sie aber an verschiedenen Stellen um das Atrium anzutreffen.

Neoschizorbynchus parvorostro (HELLER 1970)

Fund ort: Sylt: $12 \mathrm{sw}$ (leg. Heller).

Diskus sion: Spezifische Merkmale der drei in der Gattung Neoschizorbynchus vereinigten Species sind eine Längsmuskelhülle um das Kopulationsorgan und ein Cirrus. Weiterhin nenne ich den tonnenförmigen Pharynx, vor dem zwei oder vier Hoden liegen.

$N$. longipharynggus zeigt im Aufbau des Kopulationsorgans gemeinsame Züge mit Schizorbynchus tartaricus (GRAFF). Leider ist diese Art unvollständig bekannt. Die Angaben GRAFrs über paarige Germarien verbieten bis zur Nachuntersuchung der Art eine Identifizierung.

\section{Carcharodorbynchus MeIXNER 1938}

Nachdem die Gattung Carcharodorbynchus lange Zeit nur durch die unvollkommen bekannte Art $C$. subterraneus vertreten war, wurde erst in den letzten Jahren die Existenz mehrerer Arten mit Häkchenreihen auf dem Rüssel bekannt. Bereits KaRLING (1963) verweist auf die Uneinheitlichkeit des von ihm noch als C. subterraneus zusammengefaßten Materials. Nachdem L'Hardy (1963) die neue Art C. polyorchis und BrunET (1967) C. flavidus fanden, können wir neben C. subterraneus drei weitere neue Arten nachweisen. Die artspezifischen, subtilen Merkmale des Rüsselorgans sind bei ScHmKe (1970) dargestellt.

Di a g n o s e : Körper langgestredkt, fadenförmig; am Hinterende meistens ein Haftring; keine Augen; symmetrischer oder asymmetrischer Spaltrüssel mit zwei meistens u-förmigen lateralen Häkchenreihen bewaffnet; einfache laterale Drüsen- 
säcke; Pharynx rosulatus $z$ wischen $1 / 2$ und $2 / 3$ der Körperlänge; Geschlechtsorgane paarig; 1-6 Paar Hoden vor dem Pharynx; männliches Kopulationsorgan mit Cirrus oder Stilett, dieser (s) mit oder ohne Außenhülle; Germarien und Vitellarien paarig; Uterus und Bursa vorhanden; einzige Geschlechtsöffnung ventral, median, zwischen $4 / 5$ und $5 / 6$ der Körperlänge.

\section{Bestimmungsschlüssel}

1. Männliches Genitalatrium mit kräftiger, auffälliger Ringmuskulatur

C. listensis

- Männliches Genitalatrium ohne diese

\section{2.}

2. Zwei Hoden

C. subterraneus

- mehr als zwei Hoden

3. Asymmetrischer Spaltrüssel mit ungleich langen Wuilsten und nicht identischen Häkchenreihen, Häkchen basal bis $15 \mu \mathrm{m}$ C. isolatus - symmetrischer Spaltrüssel, Häkchen 1-2 $\mu$ m hoch

4. Basal auf den Muskelwülsten keine Häkchen

- U-förmige Zuordnung der Häkchenreihen

5. Cirrus mit Nadeln, bis acht Paar Hoden, ohne Haftring

- Cirrus ohne Nadeln, zwei Paar Hoden, mit Haftring

C. ambronensis

\section{Carcharodorbynchus subterraneus MEIXNER 1938}

(Abb. 42, 43)

F und or te : Sylt: 12 sh (leg. Schmid ), 15 sh; Ostsee: Kieler Bucht, Strande, Sandhang; Hohwachter Bucht, Weissenhaus, Sandhang.

$\mathrm{M}$ a te rial : Lebendbeobachtungen.

Beschreibung: Der 1-1,2 mm lange Körper verjüngt sich zu dem spitzen Vorderende und dem etwas verschmälerten Hinterende. Caudal liegt ein Haftring. Die Tiere sind dunkelgrau gefärbt. Das Exemplar von Weissenhaus ist ganz hell. Augen fehlen. Der Pharynx rosulatus ( $p$ ) liegt hinter der Körpermitte und hat einen senkrechten Bulbus $(\phi 50-60 \mu \mathrm{m}$ ). Der asymmetrische Spaltrüssel ist $60-80 \mu \mathrm{m}$ lang. Er hat 3 (4) Häkchenreihen auf dem längeren Wulst und 1-2 Häkchenreihen auf dem kürzeren Wulst.

Die beiden großen Hoden ( $t$ ) sind etwas verschoben oder liegen hintereinander. Die einfachen Samenblasen ( $v s$ ) münden durch feine Seminalkanäle in das elliptische männliche Kopulationsorgan ( $k$ ) ein. Dieses ist nur etwa $40 \mu \mathrm{m}$ lang und enthält drei hintereinander angeordnete Gruppen von Kornsekretgängen verschiedenen Inhalts. Der Cirrus (s) ist nur durch subtile Merkmale von dem von $C$. listensis zu unterscheiden. Er besteht aus einem inneren und einem äußeren Rohr. Ersteres ist 8-10 $\mu \mathrm{m}$ lang, rund, in der Mitte tailliert. Winzige Häkchen sind an der Innenseite in spiralig verlaufenden Reihen angeordnet. Sie können auch völlig fehlen. Das Innenrohr ist caudal mit dem Außenrohr verwachsen. Dieses ist nur etwa einfach spiralisiert, sehr fein und unbewaffnet. Die muskulöse Hülle des Kopulationsorgans und die Wand des männlichen Genitalatriums setzen am Vorderrand der Außenhïlle an. Das Atrium 
(ma) ist wenig länger als das Kopulationsorgan und hat eine schwache Ringmuskelhïlle. Es verjüngt sich caudad und führt $z u$ der zwischen $4 / 5$ und $5 / 6$ der Körperlänge befindlichen, drüsenumstellten Geschlechtsöffnung ( $g \ddot{o}$ ).

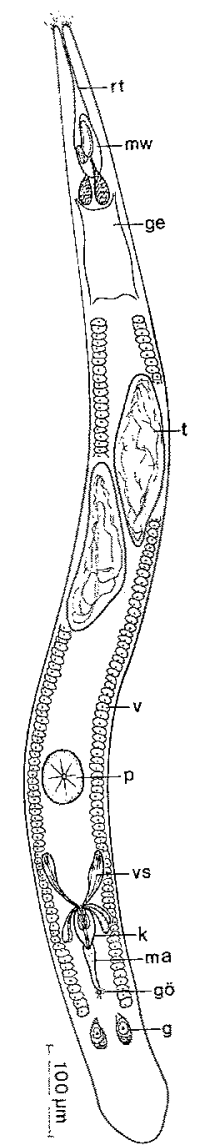

Abb. 42: Carcharodorbynchus subterraneus. Organisation (kombiniert)

Hinter dieser sind zwei nebeneinander liegende Germarien $(g)$ zu erkennen. Die Vitellarien $(v)$ beginnen hinter dem Gehirn und enden vor den Germarien.

\section{Carcharodorbynchus listensis nov. spec.}

$$
\text { (Abb. 44, 52) }
$$

Fund orte: Sylt: 5, $12 \mathrm{sw}$ sh (leg. Ax; eigene Funde; Locus typicus), $15 \mathrm{sw}$, $16,29$.

M a te ria 1: Lebendbeobachtungen, mehrere Zeichnungen von $A x(1951,1963)$, 2 Dauerpräparate (1 juv., 1 adult).

Beschreibung: In der heterogenen Beschreibung von Karling (1963) beziehen sich Angaben über die Tiere (Fig. 88) auf C. listensis nov. spec. 
Die (1,5) 1,6-1,8 mm langen Tiere sind schmal und fadenförmig. Das Hinterende ist beim schnellen, lebhaften Umherschwimmen einfach abgerundet oder dorsoventral abgeplattet. Ein subterminaler schwacher Haftring ist vorhanden; zum anderen kann das Hinterende auch platt dem Substrat angepreßt und dabei vom übrigen Körper scharf dreieckig abgesetzt werden.

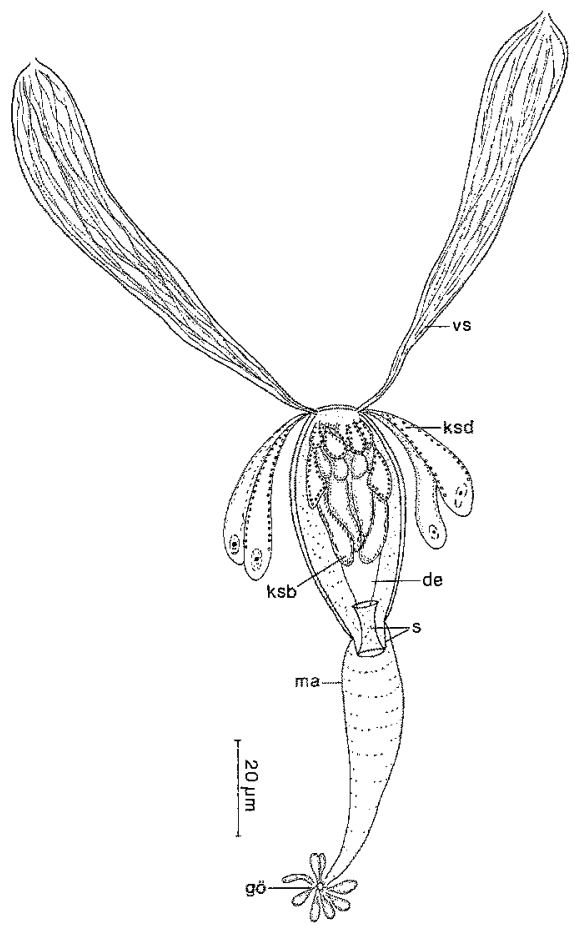

Abb. 43: Carcharodorbynchus subterraneus. Männliches Kopulationsorgan

In der Epidermis fehlen Rhabditen. Die Tiere sind vorne hellgelblich, vom 2. Drittel ab dunkelgrün gefärbt. Hinter dem Gehirn liegen Frontaldrüsen.

Der Pharynx rosulatus $(\varnothing 110 \times 160 \mu \mathrm{m})$ ist senkrecht aufgerichtet. Der Bulbus beginnt mit einem krättigen Greifwulst. Der asymmetrische Rüssel hat max. 9-10 Häkchenreihen auf dem dorsalen und 5-6 Häkchenreihen auf dem ventralen Wulst (mw).

Die männliche und weibliche Phase sind streng getrennt. Die Organisationszeichnung ist kombiniert. In männlicher Reife werden zwischen Gehirn und Pharynx ventral bis zu sechs Paar Hoden ( $t$ ) in zwei parallelen Reihen angelegt. Die Follikel sind meist deutlich voneinander abgeschnürt und of isoliert anzutreffen. Die schmalen, langgestreckten Samenblasen (vs) verjüngen sich zu Genitalkanälen. Das männliche Kopulationsorgan $(k)$ ist elliptisch, 80-110 $\mu \mathrm{m}$ lang und hat seinen größten Durchmesser etwas vor der Mitte ( $36 \mu \mathrm{m}$, Dauerpräparat). Drei Gruppen von Kornsekretblasen liegen hintereinander, die sich an ihren verschiedenen Sekreten unterscheiden 
lassen. Thnen schließt sich ein kompliziertes Stilett (s) an (Abb. 44 E). Ein benadeltes, spiralisiertes, inneres Rohr $\left(s_{i}\right)$ ist von einem etwas kürzeren, unbewaffneten, spiralisierten Rohr $\left(s_{a}\right)$ umgeben. Beide sind hinten miteinander kreisförmig verwachsen.

Das innere Rohr wird 14-15 $\mu \mathrm{m}$ lang und hat vorne und hinten einen Durchmesser von $8 \mathrm{bzw}$. von $10 \mu \mathrm{m}$, im mittleren Teil erreicht es jedoch nur $5 \mu \mathrm{m}$, ist also
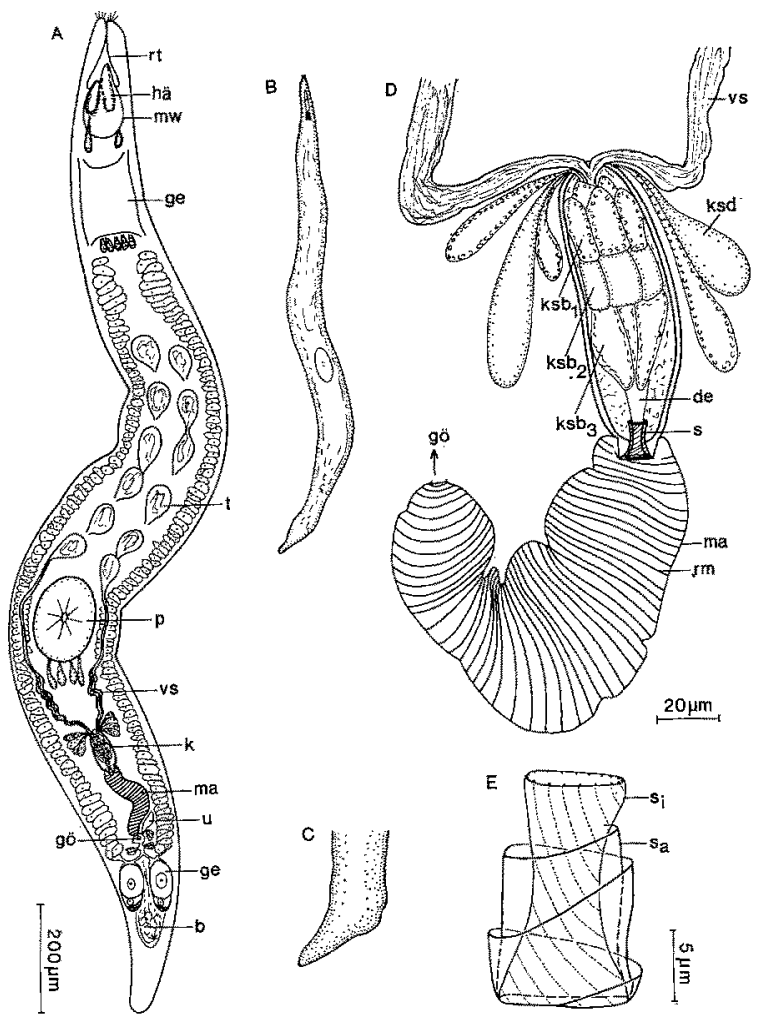

Abb. 44: Carcharodorbynchus listensis. A Organisation (kombiniert); $B$ Habitus, Hinterende in Dorsalansicht; $C$ Hinterende in Seitenansicht; $D$ männliches Kopulationsorgan mit Atrium; E Rekonstruktion des Stiletts (kombiniert)

deutlich tailliert. Da es stark kontraktil ist, kann es sich auf eine Form verkürzen, in der Länge und Breite gleich, also loxlo $\mu \mathrm{m}$ werden. In seinem Innern sind sehr kurze Nadeln in spiralig verlaufenden Längsreihen angeordnet.

Das äußere, nicht kontraktile Rohr ist 8-10 $\mu \mathrm{m}$ lang, ein- bis zweifach spiralisiert und hat glatte Wände. Sein Durchmesser ist konstant und etwas größer als der caudale Durchmesser des Innenrohres, also etwa $11 \mu \mathrm{m}$. Am frontalen Rand des Außenrohres setzt die dicke Muskelhülle des Kopulationsorgans und zugleich das männliche Genitalatrium ( $m a$ ) an, das den Durchmesser des Kopulationsorgans erreicht oder ihn sogar übertrifft und länger als dieses wird. Das Atrium ist durch eine sehr kräftige, regelmäßig gebaute Ringmuskelhülle ausgezeichnet. 
Die gemeinsame Geschlechtsöffnung (gö) liegt bei $5 / 6$ der Körperlänge. In den Genitalkanal mündet von vorne der Uterus $(u)$, von dorsal das männliche Atrium und von caudal der weibliche Genitalkanal. Letzterer erweitert sich zu einem kleinen Hohlraum, in dem die Ovovitellodukte der beiden Germarien bzw. Vitellarien zusammentreffen. Hier hinein gelangen auch die Sekrete einiger eosinophiler, feinkörniger Drüsen. Die Vitellodukte münden kurz vor jedem Gernar in die Ovidukte aus.

Die elliptischen Germarien $(g)$ enthalten stets nur 3-4 Oocyten. Die Vitellarien (v) reichen frontal bis zum Gehirn und caudal bis zu den Germarien und können in weiblicher Reife sehr umfangreich sein. Im Hinterende befindet sich eine Bursa (b), in der neben Spermien zahlreiche Vakuolen und Zellkerne anzutreffen sind. Die Bursa reicht sehr nahe an die Germarien heran.

\section{Carcharodorbynchus ambronensis nov. spec.}

(Abb. 45)

F und or te : Sylt: $12 \mathrm{sw}, 25 \mathrm{sw}$ sh; Amrum: 1, 2, 4 (Locus typicus), $16 \mathrm{sw}$, 7 sw; Amrum: Kniepsand, Farbstreifensandwatt (Schutz 1939; vermutlich ist die neue Art identisch mit Carcharodorbynchus subterraneus von ScHulz).

$\mathrm{Mate}$ ria 1: Lebendbeobachtungen.

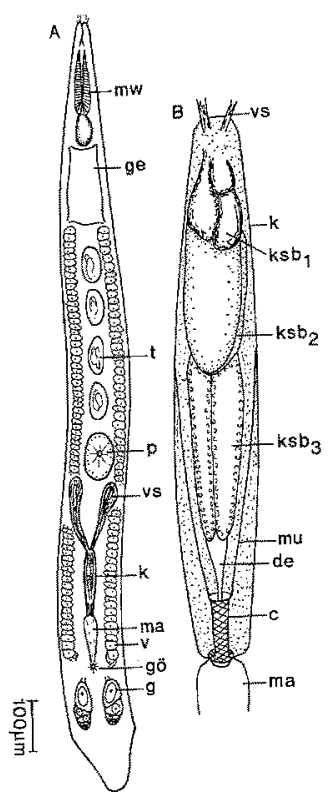

Abb. 45: Carcbarodorbynchus ambronensis. A Organisation (kombiniert); $B$ männliches Kopulationsorgan (Quetschpräparat)

Beschreibung: Die Art wird 1,5 mm lang. Das mit etwa 10 langen Tasthaaren besetzte Vorderende ist leicht zugespitzt. Das dreieckige Hinterende ist mit einem rotbraunen, deutlich abgesetzten Haftring versehen, damit ähnlich dem von 
Cheliplana. Die Körperfarbe ist intensiv grüngelb. Augen fehlen. Der Pharynx $(p)$ liegt bei $2 / 3$ der Körperlänge ( $\phi 90 \mu \mathrm{m})$. Der symmetrische Spaltrüssel ist (70)-100 bis (120) $\mu \mathrm{m}$ lang. Die Häkchen liegen basal in (3)-4-6 Reihen, davor in 2-1 Reihe.

$Z$ wischen dem Gehirn und dem Pharynx liegen vier Hoden $(t)$ median hintereinander. Die Samenblasen (vs) sind gewunden oder kugelig. Das elliptische männliche Kopulationsorgan $(50-75 \mu \mathrm{m})$ ist kontraktil und enthält hintereinander drei Gruppen von Kornsekretblasen $\left(k s b_{1-3}\right)$. Es endet in einem (8)-13-(15) $\mu \mathrm{m}$ langen Cirrus $(c)$. Dieses einfache gerade Rohr ist proximal und distal mit einem kleinen Trichter versehen. Die Wände zeigen Spirallinien. Nadeln fehlen. Das kurze, männliche Genitalatrium $(m a)$ hat keine auffällige Ringmuskeln. Hinter der gemeinsamen Geschlechtsöffnung ( $g \ddot{o})$, die sich bei $4 / 5$ bis $5 / 6$ der Körperlänge befindet, liegen zwei Germarien (g). Die Vitellarien $(v)$ reichen frontal bis hinter das Gehirn und caudal bis zu der Geschlechtsöffnung.

\section{Carcharodorbynchus isolatus nov. spec.}

(Abb. 46)

Fund orte : Sylt: $13 \mathrm{sw}$ (Locus typicus), $12 \mathrm{sw}$ (leg. Hoxhold).

Materia 1: Lebendbeobachtungen.

Beschreibung: Die Art erreicht 2,2 mm Länge. Das Vorderende ist sehr spitz. Das Hinterende sieht rund aus, vor ihm liegt ein scharf abgesetzter, breiter Haftring. Die Körperoberfläche ist mit Längsreihen grünlicher Wärzchen bedeckt und erscheint daher gestreift. Die Körperfarbe ist grünbraun. Augen fehlen. Der Pharynx rosulatus $(50 \times 110 \mu \mathrm{m})$ liegt im Endabschnitt des mittleren Körperdrittels. Der Bulbus ist senkrecht zur Körperlängsachse orientiert.

Der asymmetrische Spaltrüssel hat zwei laterale Häkchenteihen mit vier bis zu $15 \mu \mathrm{m}$ langen Häkchen auf dem kürzeren Wulst. Die Hoden $(t)$ sind vor dem Pharynx entweder in zwei Reihen zu je sechs runden Follikeln angeordnet oder bilden zwei mehr oder weniger septierte Schläuche. Die Samenblasen (vs) bilden hinter dem Pharynx mäandrische Gänge. Die Seminalkanäle münden mit wenigen, kolbigen Kornsekretdrüsen getrennt in das elliptische männliche Kopulationsorgan ( $k$ ) ein (Länge $75 \mu \mathrm{m})$. Es enthält wiederum drei Gruppen von Kornsekretblasen. Der zentrale Ductus ejaculatorius ( $d e$ ) führt zu einem einfachen, rohrförmigen Cirrus (14 $\mu \mathrm{m}$ lang). Der druckempfindliche Cirrus (c) ist innen mit kräftigen, kurzen Nadeln bedeckt, die schräg caudad zeigen. Die Cirruswand geht distal in die Wand des Kopulationsorgans über, an der dicht daneben sogleich kreisförmig das männliche Genitalatrium (ma) ansetzt. Der Cirrus hat keinen äußeren Teil und ragt nicht in das Atrium. Dieses ist etwa doppelt so lang wie das Kopulationsorgan $(135-170 \mu \mathrm{m})$, sehr schmal und biegsam ohne auffällige Muskelhülle.

Die gemeinsame Geschlechtsöffnung (gö) liegt bei $4 / 5$ bis $5 / 6$ der Körperlänge. Hinter ihr sind die beiden Germarien $(g)$ mit wenigen Oocyten entwickelt. Die paarigen Vitellarien (v) reichen vom Gehirn bis zur Geschlechtsöffnung.

D is k us sion: Zur Artgliederung können im wesentlichen drei Merkmalskomplexe herangezogen werden. An erster Stelle steht die spezielle Ausprägung der Häkchenreihen auf den Muskelwülsten (Schuke 1970). Es folgen Merkmale des Kutikularorgans, wobei sich zwei Gruppen innerhalb der Gattung ergeben. Bei C, subterraneus 
und C. listensis besteht das Stilett aus Außen- und Innenrohr, es ragt frei in das männliche Atrium. Dagegen besitzen C. polyorchis, C. flavidus (BRUNET in litt; Dauerpräparat), C. ambronensis und C. isolatus nur einen einfachen, rohrförmigen Cirrus, an dessen Ende das Atrium inseriert. Schließlich erscheint auch die Muskulatur des männlichen Atriums artspezifisch verwendbar. C. listensis besitzt im Unterschied zu den anderen Arten ein sehr umfangreiches Atrium mit einer sehr kräftigen, auffälligen Quermuskelhülle.

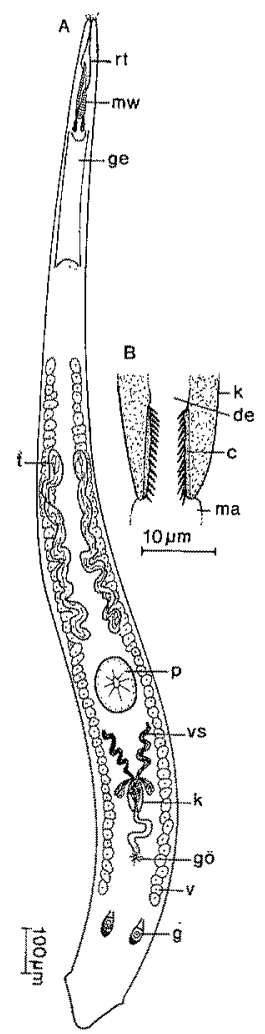

Abb. 46: Carcharodorbynchus isolatus. A Organisation (kombiniert); $B$ Cirrus (Quetschpräparat)

Die vier beschriebenen Arten kommen alle im Sandhang bzw. Sandwatt am Ostufer von List/Sylt vor. Die Unterscheidung wird durch ihre ökologische Präferenz erleichtert (einige Daten verdanke ich HoxHoLD). Carcharodorbynchus isolatus besiedelt das Sublitoral des Sandwattes und entsprechend die östlich List gelegene Sandbank. C. ambronensis ist ebenfalls im Sandwatt anzutreffen, geht aber auch in den unteren Hang. Diese Art besiedelt das Farbstreifensandwatt auf Amrum (vgl. ScHulz 1939). C. listensis lebt vorwiegend im Knidkbereich (hierzu auch Abb. 88 von Ax in KARLING 1963). C. subterraneus lebt im oberen Sandhang unmittelbar am Dünenfuß. Die Art wurde ferner in der Blidsel-Bucht und Kieler Bucht (Ostsee) nachgewiesen. 
Thylacorbynchus DE BEAUCHAMP 1927

Im Untersuchungsgebiet leben sechs Arten der Gattung Thylacorbynchus. Neben Thylacorbynchus ambronensis werden $T$. caudatus und $T$. arcassonensis, zwei bislang unvollständig bekannte Arten, eingehender behandelt.

\section{Bestimmungsschlüssel}

1. Cirrus mit innerem Stilett

T. filostylis

- Cirrus ohne dieses

2. mit Vagina externa, diese kammartig strukturiert

- ohne Vagina externa

3. Cirrus einfach rohrförmig, bestachelt oder nicht bestachelt mit Ductus spermaticus

- Cirrus kompliziert, spiralig aufgerollt, terminal mit langen Nadeln; ohne Ductus spermaticus

T. conglobatus

4. Mit deutlich abgesetztem Schwanz

T. ambronensis

-- ohne Schwanz

5. 2 Abschnitte der Cirrusbestachelung

6.

- Cirrusbestachelung einheitlich, Nadellänge nimmt nach caudal zu.

6. 2 Arten der Cirrusbestachelung; Cirrus mit etwa parallelen Wänden

7. Cirrusbestachelung einheitlich; Cirrus umgekehrt trichterförmig

\section{Thylacorbynchus arcassonensis DE BEAUCHAMP 1927}

(Abb. 47)

Fundort: Amrum: Kniepsand; Frankreich, Arcachon, Pilat-Plage (leg. Ax 1964).

Materia 1 : Lebendbeobachtungen.

Beschreibung: Die Art erreicht eine Körperlänge von 1,2 mm. Fadenartig und dünn, ist die Gestalt nicht so kräftig wie die der anderen Thylacorhynchus-Arten. Das Vorderende ist breit und rundlich.

Das Hinterende wird bei der sehr lebhaften Bewegung flach-zungenförmig gestreckt. Zwei Haftringe liegen kurz vor der Mitte und am Körperende.

Die Tiere sind gelblichweiß, und die Vitellarien schwimmen grauschwarz durch. Im Gehirn liegen zwei nierenförmige Augenbecher ( $\phi 8 \mu \mathrm{m})$.

Der Pharynx rosulatus $(\varnothing 80 \times 120 \mu \mathrm{m})$ liegt deutlich vor der Körpermitte. Pharynxtasche und Bulbus sind senkrecht abwärts gerichtet. Die Muskelplatten des Rüssels sind $200-240 \mu \mathrm{m}$ lang ( $\cong 1 / 6-1 / 5$ der Körperlänge). Jeder Muskelwulst läuft frontal in drei Spitzen oder Loben aus (KARLING 1961). Caudal von den Wülsten liegen die kugeligen, dunklen Drüsensäcke.

Die beiden Hoden ( $t$ ) liegen etwas versetzt hintereinander. Die Vasa deferentia münden kurz hinter deren Spitze in die keulenförmigen oder wenig gew undenen Samenblasen $(100-140 \mu \mathrm{m})$. Das männliche Kopulationsorgan $(k)$ ist eine $125-140 \mu \mathrm{m}$ lange Blase mit einem geschwollenen vorderen $(\phi$ ca. $48 \mu \mathrm{m})$ und einem schlauchartigen 
hinteren ( $\phi$ ca. $22-26 \mu \mathrm{m}$ ) Abschnitt. Im kontrahierten Zustand sieht das Kopulationsorgan elliptisch oder birnförmig aus. Die Kornsekretblase ist in eine zentrale Gruppe und in eine darum liegende, weniger weit nach hinten reichende Gruppe unterteilt. Der leicht gebogene, bestachelte Cirrus (c) erreicht bei dem Exemplar aus Arcachon (Pilat Plage) $50 \mu \mathrm{m}$, bei Exemplaren vom Kniepsand auf Amrum 68-71 $\mu \mathrm{m}$. Der
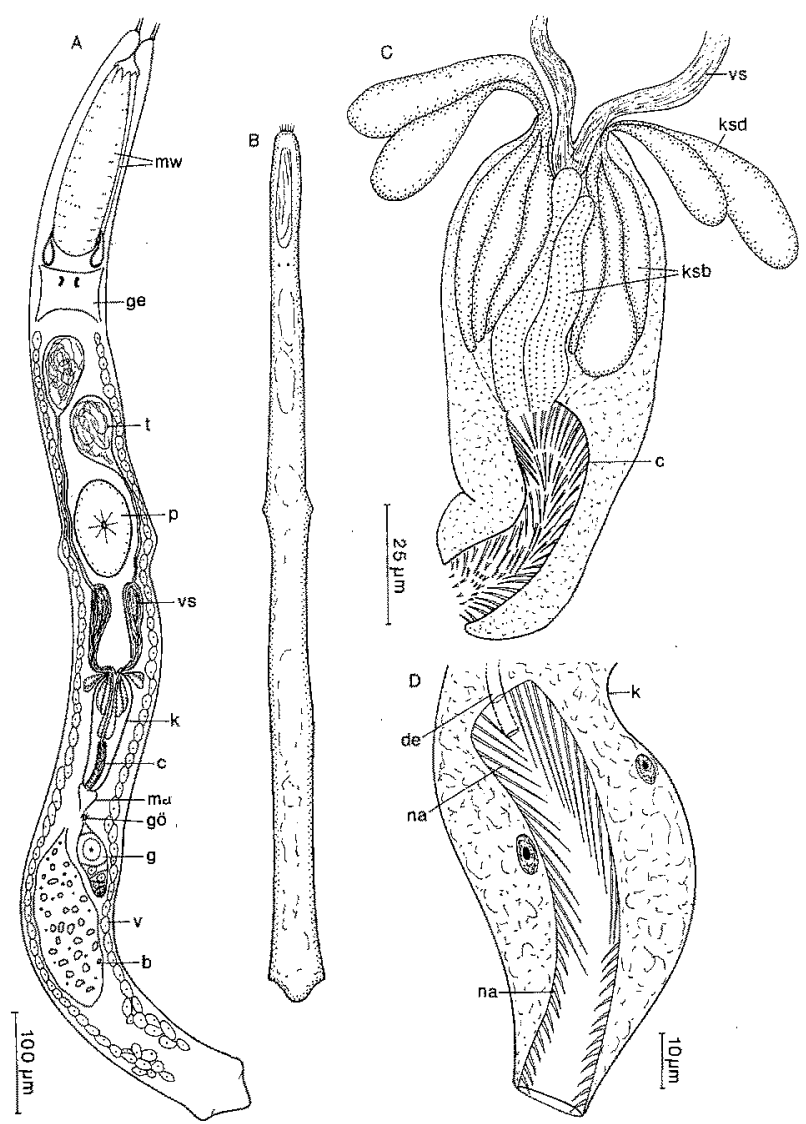

Abb. 47: Thylacorhynchus arcassonensis. (Zeichnungen $A-C$ von $\mathrm{Ax}$, Abb. $A$ etwas verändert) $A$ Organisation (kombiniert); $B$ Habitus; $C$ männliches Kopulationsorgan (Quetschpräparat); $D$ Cirrus (Quetschpräparat)

Cirrus ist proximal und distal stärker $(10-12 \mu \mathrm{m})$ als im mittleren Teil $(8-8,5 \mu \mathrm{m})$. Die Stacheln sind in folgender Weise differenziert und angeordnet. Die vordere Hälfte des Cirrus bildet lange, feine Nadeln ( $n a)$ aus. Proximal sind sie am längsten $>$ $10 \mu \mathrm{m}$ ). Hinter der Mitte des Cirrus ändert sich die Bewaffnung. Hier stehen ca. zwölf leichtgebogene Häkchen an der Cirruswand hintereinander. Die gemeinsame Geschlechtsöffnung (gö) liegt am Ende des mittleren Körperdrittels. Es folgt ein kleines Germar $(g)$ und die große, sackförmige Bursa $(b)$, die proximal schmal, distal, hinter 
dem Germar, stark angeschwollen ist. In der Bursa liegen rundliche und unregelmäßig geformte Sekrete, die glänzend, lichtbrechend und auffallend groß sind. Die paarigen Vitellarien $(v)$ reichen vom Gehirn bis ins Hinterende.

Diskussion: Trotz einiger Abweichungen in Körperlänge und Proportionen gestattet die spezielle Struktur des Cirrus die Identifizierung mit der Bearbeitung von De Beauchamp. Der von Karling (1956, Fig. 11 a) abgebildete Cirrus hat dagegen gleich lange und gleich starke Nadeln; möglicherweise handelt es sich um eine andere Art. Angaben über einen reinen Längen-Breiten-Index des Kopulationsorgans erscheinen problematisch, da der Durchmesser nicht konstant, vielmehr proximal und distal verschieden ist. Auch schwanken die Werte selbst in Meßreihen beträchtlich. Die Art der Bestachelung und die Cirruslänge liefern demgegenüber sichere Unterschiede zu der nächstverwandten Art $T$. pyriferus.

\section{Thylacorbynchus conglobatus MEIXNER 1928}

Fu nd or te : Sylt: 1, 10 q, $12 \mathrm{sw}$ sh, $13 \mathrm{sw}, 16 \mathrm{sw}, 24 \mathrm{sw}$; Amrum: $7 \mathrm{sw}$ sh, (4); Helgoland: Düne (Meixner 1938); Ostsee: Heiligenhafen, Graswarder, Sandhang.

Während BOADEN (1963) die Art ohne bestachelten Cirrus angibt, hat sie nach KarLING (1963) zuweilen doch Stachel (dänische Nordseeküste). Die von mir untersuchten Exemplare besitzen Cirrusstacheln, die meist gleich lang sind und schräg caudad zeigen.

\section{Thylacorbynchus caudatus MEIXNER 1928}

(Abb. 48)

Fund orte: Sylt: $1 \mathrm{sh}, 5 \mathrm{sh}, 10 \mathrm{sh}, 12 \mathrm{k}$ (juv.); Klappholtal (leg. Ax 1951); Westerheversand (leg. Ax 1951).

Materia 1: Lebendbeobachtungen; Zeichnungen (1 Exemplar, Ax 1951).

B eschreibung: Merxner (1928, p. 243-244) beschreibe Thylacorbynchus caudatus anhand von Schnittserien. Die beigefügten Figuren 10 und 11 gehören zu T. conglobatus (Karling 1950, p. 3). So ist eine Skizze MeIxners (1938, Fig. 11 E) die einzige bildliche Darstellung. Zur Beschreibung Merxners (vgl. auch 1929, p. 767; 1938, p. 134) fügen sich einige Angaben Karlings (1950, p. 25; 1961, p. 256, 259, 269).

Die Körperlänge beträgt bei den Exemplaren von Sylt 1,5 mm. Das von $\mathrm{Ax}$ untersuchte Exemplar von Westerhever ist $2-3 \mathrm{~mm}$ lang. Das Vorderende ist breit. Das Hinterende läuft in einen mit langen Haaren besetzten Schwanz (schw) aus, in den Körperparenchym ragt. Der Schwanz erreicht gestreckt $140 \mu \mathrm{m}$ (normale Länge 75-95 $\mu \mathrm{m}$; kontrahiert $50 \mu \mathrm{m}$ ). Neben dem Schwanz münden mehrere große Schwanzdrüsen. Die beiden Haftringe liegen in der Körpermitte und terminal. Rhabditen fehlen. Die Tiere sind grünbraun gefärbt.

Das Gehirn enthält zwei nierenförmige, dicht nebeneinander angeordnete Augen. Ein Septum trennt den Vorderkörper vom mittleren Körperabschnitt (MEIXNER).

Der Pharynx ( $\phi 130 \mu \mathrm{m}$ ) liegt vor der Körpermitte; Tasche und Bulbus sind senkrecht orientiert. Der sehr große Spaltrüssel erreicht gestreckt etwa $350 \mu \mathrm{m} \mathrm{(1/s} \mathrm{der}$ Körperlänge) kontrahiert 160-240 $\mu \mathrm{m}$. Die beiden Zungen sind fast blattförmig dünn und stark gefaltet (KarLing). Caudal und lateral von den Wülsten sind kleine, kugel- 
förmige Drüsensäcke zu erkennen (KARLING 1961, p. 259). Zwei kugelige, große Hoden (t) befinden sich vor dem Pharynx. Die gewundenen Samenblasen sind bis $160 \mu \mathrm{m}$ lang.

Das von einer dicken Muskelhülle umgebene männliche Kopulationsorgan ( $k$ ) ist schlauchförmig, vorne lang-elliptisch und hinten schmal-zylindrisch (210-280 $\mu \mathrm{m}$ Länge). Der hintere Abschnitt ist stets leicht s-förmig gebogen. Die Meßwerte für den

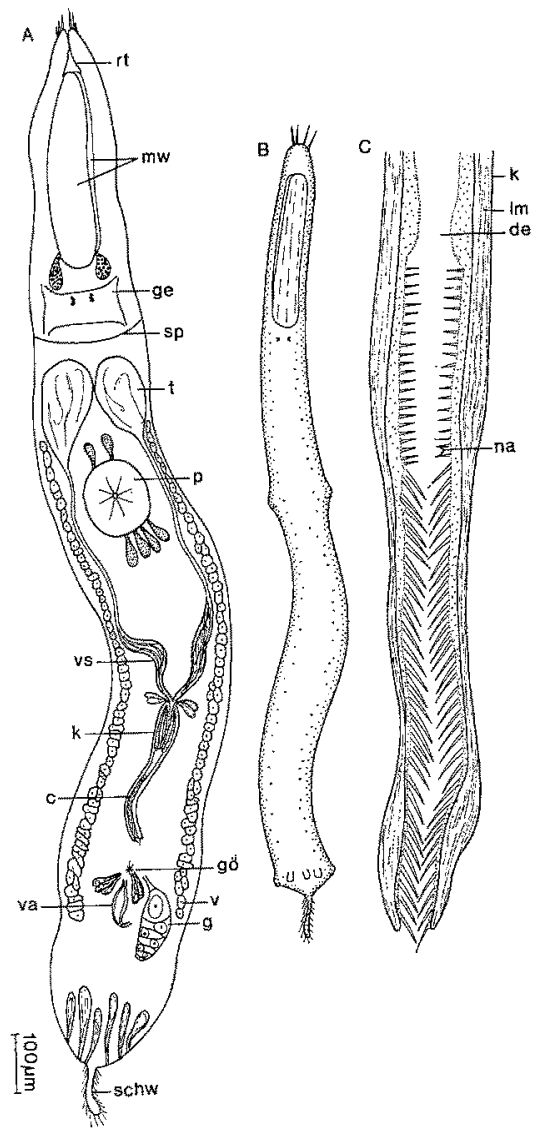

Abb. 48: Thylacorbynchus caudatus. A Organisation (kombiniert); $B$ Habitus; $C$ Cirrus (Quetschpräparat)

größten Durchmesser im elliptischen Teil schwanken zwischen 40-55 $\mu \mathrm{m}$ ( $\phi$ caudal 15-20 $\mu \mathrm{m}$ ). Das Verhältnis der Organlänge zur größten Organbreite liegt zwischen $4: 1$ und 6:1. Der lange, dünne benadelte Cirrus (c) erreicht 115-130 $\mu \mathrm{m}$ Länge. In der Bewaffnung des biegsamen, beweglichen Rohres sind zwei Abschnitte zu unterscheiden. Im 1. Drittel sind nur kurze Stacheln (na) quer zur Längsrichtung des Cirrus aufgestellt $(2,4-3,2 \mu \mathrm{m}$ Länge). Es folgen dann längere Nadeln, die schräg inserieren (4-8 $\mu \mathrm{m})$. Die Länge der Nadeln ist in jedem Abschnitt konstant. Der Cirrus kann 
hinten handschuhfingerförmig umgekrempelt werden. Die gemeinsame Geschlechtsöffnung ( $g \ddot{o}$ ) liegt bei etwa $4 / 5$ der Körperlänge. Das Germar $(g)$ besitzt einen kurzen Ovidukt. $\mathrm{Zu}$ der Geschlechtsöffnung führt eine birnförmige Vagina interna (va) (Metxner 1929, p. 767). Ein langer Ductus spermaticus ist vorhanden. Die paarigen Vitellarien ( $v$ ) reichen vom Gehirn bis in das Hinterende zur Höhe des Germars. Hinter der Geschlechtsöffnung liegen zahlreiche weibliche Drüsen.

D is k us ion: Thylacorbynchus caudatus wird auf Grund folgender Merkmale identifiziert. Die Art besitzt einen Schwanz. Sie hat einen langen, bestachelten Cirrus. Meixner gibt keinen Hinweis auf die Art der Cirrusbestachelung. Das spezifische Artmerkmal ist die Differenzierung zweier Abschnitte der Bestachelung.

Thylacorbynchus pyriferus KARLING 1950

F und or te: Sylt: $12 \mathrm{sw}, 14 \mathrm{sw}, 16 \mathrm{sw}, 23 \mathrm{sh} \mathrm{k}$.

\section{Thylacorbynchus filostylis KARLING 1956}

(Abb. 49)

Fundort: Sylt: 15 sh.

Materia l: Lebendbeobachtung an einem Exemplar in männlicher Reife.

Von dieser Art sind bislang nur Rüssel und Kopulationsorgan bekannt.

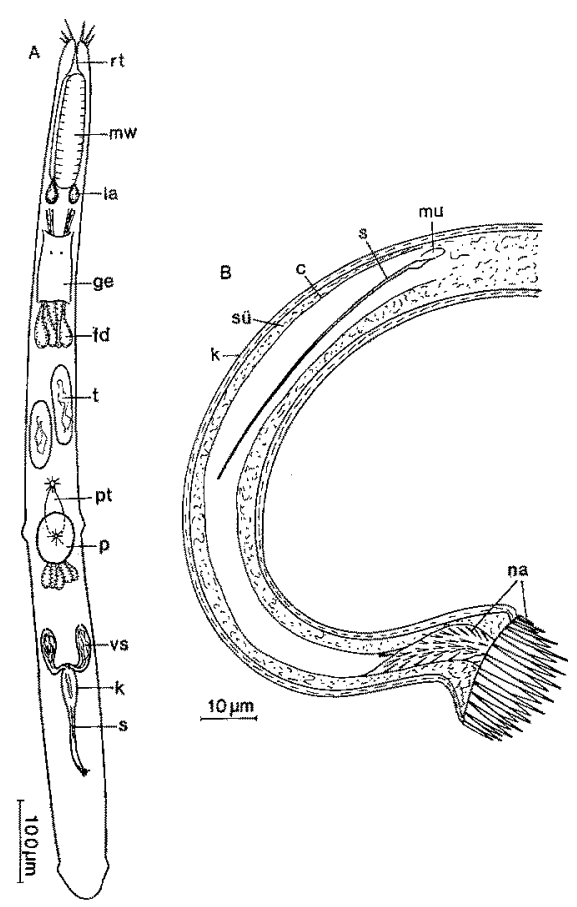

Abb. 49: Tbylacorbynchus fllostylis. A Organisation (Exemplar nur in männlicher Reife); B Cirrus mit Stilett und Nadeln (Quetschpräparat) 
B e schreibung: Die Körperlänge beträgt ca. $1 \mathrm{~mm}$. Der Körper ist vorn und hinten abgerundet. Kurz hinter der Körpermitte und caudal liegen zwei kräftige Haftringe. Der Körper ist braun-marmoriert. Das Gehirn trägt zwei winzige Augen, die jeweils nur 6-8 Pigmentkörnchen umfassen. Dem Gehirn schließen sich große Frontaldrüsen an. Der Bulbus des Pharynx rosulatus $(p)$ liegt kurz hinter der Körpermitte. Die Tasche ist schräg nach vorne abwärts gerichtet. Der Spaltrüssel (160-200 $\mu \mathrm{m}$ ) füllt das Vorderende völlig aus (ca. 1/6 der Körperlänge). Nach KARLING (1961) sind die Zungen fast blattartig dünn und stark gefaltet.

Zwei längliche Hoden $(t)$ liegen vor dem Pharynx. Die keulenförmigen Samenblasen (vs) sind ca. $110 \mu \mathrm{m}$ lang. Das langgestreckte männliche Kopulationsorgan $(220 \mu \mathrm{m})$ ist proximal elliptisch oder birnförmig, verschmälert sich distal in einen sehr langen und gebogenen Fortsatz ( $\phi 12 \mu \mathrm{m}$ ). Im vorderen, angeschwollenen Abschnitt ist die Kornsekretblase zu erkennen. Ihr schließt sich ein etwa $110 \mu \mathrm{m}$ langer, konstant starker Cirrus (c) an, der nur hinten etwas blasig aufgetrieben ist. Proximal inseriert im Cirrus ein hohles, nadelförmiges Stilett $(46 \mu \mathrm{m})$, das durch Muskeln bewegt werden kann. Distal ist der Cirrus dicht mit kurzen, caudad gerichteten Nadeln besetzt. Den Abschluß bildet eine weite, glockenförmig nach hinten offene Nadelkuppel. In ihr inserieren zentral besonders lange $\mathrm{Nadeln}(14 \mu \mathrm{m})$.

D isk us sion: Die Zuordnung des Sylter Materials zu T. filostylis ergibt sich aus der Identität im Bau des komplizierten Cirrus. Ein inneres Stilett in einem benadelten Cirrus (KaRLING 1956, p. 206) existiert parallel bei Cheliplana stylifera und Neoschizorbynchus longipharynggus.

Thylacorbynchus ambronensis nov. spec.

(Abb. 50-52)

Fund or te: Sylt: $10 \mathrm{sh}$ k, $12 \mathrm{sw}, 13 \mathrm{sw}$; Amrum: 4 sh (Locus typicus), $7 \mathrm{k}$, 16 sw; Westerhever Sand: (leg. Ax 1951); Rømø: Lakolk, Weststrand.

Materia 1: Lebendbeobachtungen, mehrere Schnittserien (Holotypus, 1 Sagittalschnittserie).

Beschreibung: Die 1,5-1,8 mm langen Tiere sind schmal und langgestreckt. Das Vorderende ist im Gegensatz zu den anderen Arten leicht zugespitzt. Das Hinterende ist abgerundet. Hinter der Körpermitte und caudal liegen zwei Haftringe.

Die blasenreiche Epidermis und der Hautmuskelschlauch sind sehr dünn. Weiblich reife Exemplare sind grünbraùn gefärbt.

Das Gehirn enthält zwei Augen $(\phi 8-14 \mu \mathrm{m})$. Mehrere Frontaldrüsen liegen vor dem Gehirn. Der Pharynx bulbosus $(\phi 100 \mu \mathrm{m}$ ) offnet sich bei etwa $2 / 5$ bis $1 / 2$ der Körperlänge. Der Bulbus setzt mit sehr feinen Greifwülsten an der muskelschwachen Tasche an. In diesen liegen einige schwache, innere Ringmuskeln. Kräftiger sind die Radiärmuskeln und die inneren Längsmuskeln (ilm) entwickelt. Außere Längsmuskeln (älm) und äußere Ringmuskeln (ärm) sind schwer zu trennen. An der äußeren Membran treten im mittleren Teil des Pharynx auch schwache Längsmuskeln auf. Hier fehlen die Ringmuskeln. Im Pharynx werden faserige, eosinophile und feinkörnige, basophile Sekrete produziert. Ein Oesophagus fehlt.

Der Spaltrüssel (300-360 $\mu \mathrm{m}$ Länge) besteht aus zwei sich plattenartig gegen- 
überliegenden lappigen Wülsten. Die Wülste haben ganz kurze, „freie Spitzen“. Die Rüsseltasche setzt an den Spitzen der Wülste an, kann ein wenig nach caudal umbiegen und dann erst nach vorne ziehen. Sie ist mit vorderen und hinteren Dilatoren versehen. Thr membranartiges Epithel verdickt sich kurz vor den Wülsten; Ringmuskeln fehlen an der Rüsseltasche.

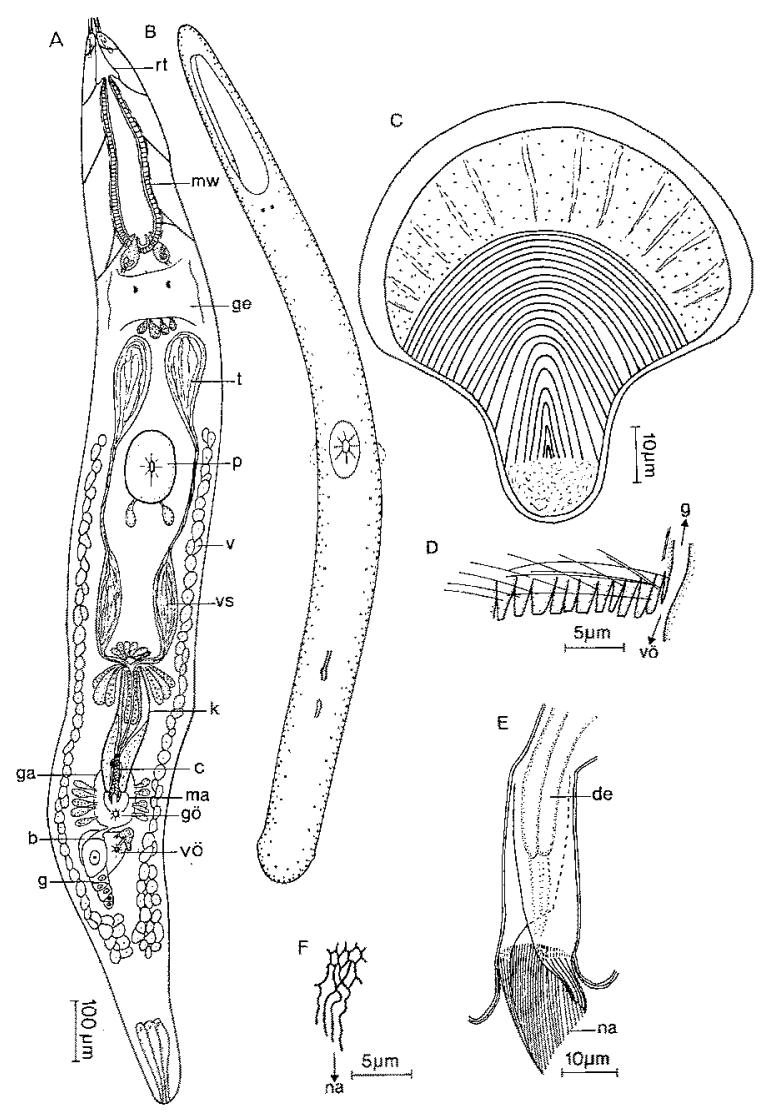

Abb. 50: Thylacorbyncbus ambronensis. A Organisation (kombiniert); $B$ Habitus; $C$ Blasenteil der Vagina externa (Quetschpräparat); $D$ Sagittalschnitt durch den dorsalen Teil der Vagina externa; $E$ Sagittalschnittrekonstruktion des Kutikularorgans, räumlich, Wabenmuster proximal weggelassen; $F$ Ausschnitt aus dem Kutikularorgan, Entstehung der caudalen Nadeln aus den frontalen Waben

Ein Ergreifen der Nahrung, wie bei anderen Schizorhynchiden, erscheint daher nicht ausgeschlossen (vgl. dagegen KarLING 1961, p. 277, Fig. 63 A, B). Die Wülste werden zusammen von einem lockeren Vakuolengewebe umgeben. Die Zellwände erscheinen auf Querschnitten deutlich, während sie auf Sagittalschnitten nur teilweise zu sehen sind und eine weite Rüsseltasche vortäuschen (MeIXner 1928, p. 243, Fig. 10). Zwei kleine, laterale Drüsensäcke sezernieren ein grobes, eosinophiles Sekret. An ihrem Ende setzen Muskeln an. 
Zwei große Hoden $(t)$ liegen im 1. Körperdrittel zwischen dem Gehirn und dem Pharynx. Die Samenblasen (vs) sind etwa $150 \mu \mathrm{m}$ lang, schmal und keulenförmig. Die Spermien in den Hoden und den Samenblasen sind korkenzieherartig gekrümmt. Eine eosinophile Hülle um die Spermien ist sehr fein oder fehlt.

Das männliche Kopulationsorgan $(k)$ ist ein 160-190 $\mu \mathrm{m}$ langer, biegsamer Schlauch. Es ist von einer sehr dicken Längsmuskelhülle umgeben. Um den Ductus ejaculatorius gruppieren sich innen proximal Kornsekretkanäle mit grobkörnigem,

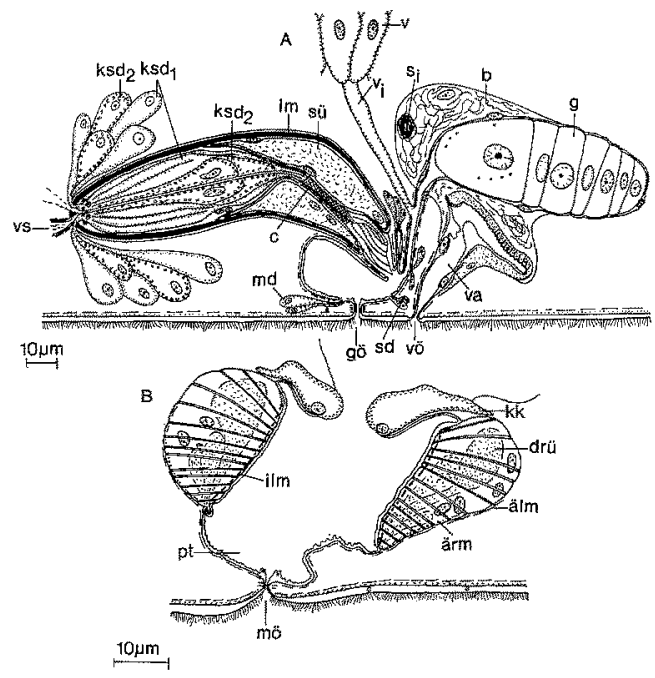

Abb. 51: Thylacorbynchus ambronensis. A Sagittalschnittrekonstruktion der Atrialorgane; $B$ Sagittalschnittrekonstruktion des Pharynx

eosinophilem bzw. basophilem Sekret $\left(k s d_{2}\right)$. Zwischen diesen Kanälen und der Außenhülle befindet sich das feinkörnige, basophile Sekret $\left(k s d_{1}\right)$, das distal ausmündet. Der Ductus ejaculatorius (de) endet in einer Penispapille. Der Cirrus (50)-56-(60) $\mu \mathrm{m}$ ist im Prinzip ein proximal etwa $1 \frac{1}{1} / 2$ fach spiralisiertes Rohr, das distalwärts auseinanderweicht (Abb. 50 E, F). Der Cirrus besteht entsprechend aus zwei Teilen, einem vorderen röhrenartigen Teil (Länge 32-36 $\mu \mathrm{m}$ ) und einem hinteren blattartigen Nadelteil (na). Die Wand des vorderen Cirrus-Teils besteht aus regelmäßigen Sechsecken (Abb. $50 \mathrm{E}, \mathrm{F}$ ) und ist mit winzigen Stacheln bedeckt. Das Wabenmuster entsteht durch kutikulare Fäden, die sich - jeweils zu $1 / 2$ Sechsecken gebogen - zu ganzen Sechsecken zusammenlegen. Etwa 18-20 Sechseckwaben liegen hintereinander $(\phi$ 0,8-1 $\mu \mathrm{m}$; Fadendicke 0,3-0,4 $\mu \mathrm{m}$ ). Am Hinterrand des vorderen Cirrusteils hören die Sechsecke auf; die kutikularen Fäden sind noch 1-2mal geschwungen und bilden von hier ab die einzelnen Nadeln. Diese Nadeln sind etwa 20-24 $\mu \mathrm{m}$ lang, leicht nach außen gebogen und hängen miteinander zusammen. Der Cirrus ist im wenig gequetschten Tier röhrenartig aufgerollt, im stark gequetschten und fixierten Tier ist dagegen der Nadelteil fächerartig nach hinten gespreizt. 
Der vordere Cirrusteil ist von einem Epithel umhüllt, in dem frontal ein großer Kern liegt. Um dieses herum ist ein lockeres Füllgewebe (sii) mit mehreren Kernen entwickelt. Das kurze männliche Atrium (ma) setzt an der Übergangsstelle beider Cirrusteile an.

Die Geschlechtsöffnung ( $3 / 4-4 / 5$ der Körperlänge) führt nach einem kurzen Genitalkanal in das geräumige gemeinsame Genitalatrium $(\mathrm{ga})$. Es ist frontal erweitert. Der lange Ovidukt führt zu dem großen, links im Hinterende angelegten Germar $(\mathrm{g})$.
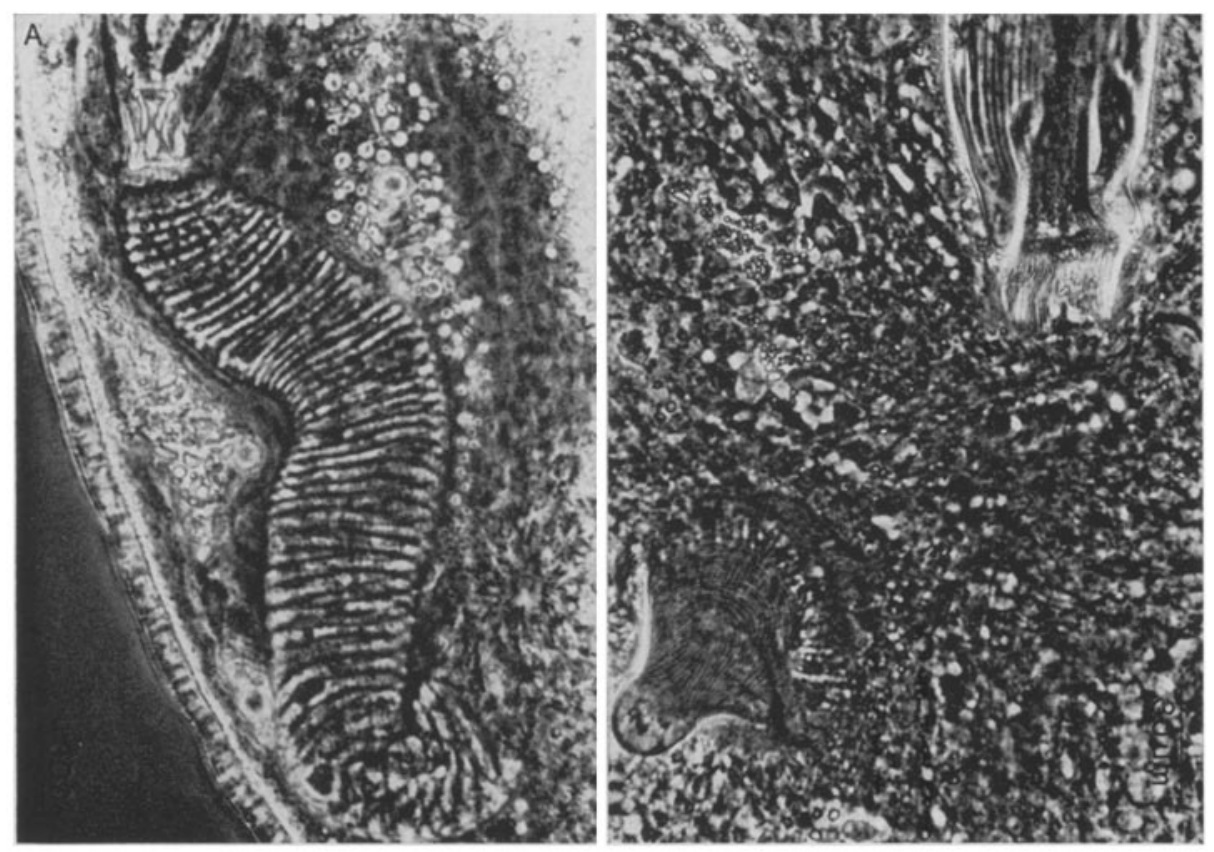

Abb. 52: A Carcharodorbynchus listensis. Stilett und männliches Atrium; B Thylacorbynchus ambronensis. Kutikularorgan und Vagina externa

Die feine Tunica enthält mehrere Kerne, von denen einer stets ventral am Hinterende der großen 1. Oocyte liegt. Direkt darunter liegt ein Kern in der Bursa. An dieser Stelle dringen vermutlich Spermien in das Germar ein.

Die etwa $24 \mu \mathrm{m}$ lange Vagina externa (va) hat ein hohes Epithel und kräftige Längsmuskeln. Das Körperepithel setzt sich etwa bis zur Hälfte in die Vagina hinein fort. Die Vagina erweitert sich zu einer birnförmigen Blase (Länge [28]-30-[42] $\mu \mathrm{m}$ ).

Im hinteren und mittleren Teil (zuweilen auch überall) ist das Hohlorgan mit einem feinkörnigen, sich grau anfärbenden Material ausgefüllt. Das lappige Epithel ist im ventralen Bereich mit Ausnahme der Mitte des Organs hoch. Der gesamte dorsale und der mittlere ventrale Teil ist frei vom Epithel. Hier ist die Basalmembran dorsal wellig bis kammförmig verdickt (Abb. 50 D).

Frontal führt aus der Vagina ein feiner, kurzer Kanal in die Bursa (b). Sie hat ein 
kaum sichtbares Epithel und kann im Innern zahlreiche Spermien, die zuweilen klumpig gehäuft sein können, aufweisen, die weder eine Hülle besitzen noch korkenzieherartig gewunden sind (s. o.). Die Bursa setzt an dem unteren Vaginakanal an und umgibt frontal das Germar so dicht, daß die Spermien eng der Tunica um die 1. Oocyte anliegen.

Die eosinophilen Drüsen liegen dorsal und caudal vom gemeinsamen Atrium. Die basophilen Drüsen $(m d)$ münden hauptsächlich im unteren Teil des Atriums aus, sind vereinzelt aber auch dorsal zu finden. Die Vitellarien $(v)$ erstrecken sich vom Pharynx $\mathrm{ab}$ bis in das Hinterende; hier sind die ersten Vitellocytenkerne und die ersten Dotterkugeln anzutreffen. Die Vitellodukte münden in den mittleren Teil des Oviduktes.

D iskussion: Spezifische Artmerkmale liefern die komplizierte Struktur des Cirrus und die dorsale Vaginablase mit verdickter Basalmembran. In der Anatomie der weiblichen Organe ergeben sich im übrigen engere Beziehungen zu $T$. conglobatus. Allerdings fehlt bei $T$. ambronensis ein Ductus spermaticus.

Familie Nematorhynchidae ScHILke 1969

Nematorbynchus parvoacumine SCHILKE 1969

Fund or t: Sylt: 12 sw.

\section{Familie Karkinorhynchidae MeIXNER 1928}

Auf Grund klarer Synapomorphien, die einerseits die Gattungen Cheliplana, Rbinepera, Cheliplanilla und Baltoplana vereinigen, andererseits die Vertreter der Gattung Karkinorbynchus charakterisieren, gliedere ich die Karkinorhynchidae in zwei Unterfamilien. Zur Begründung führe ich die Unterschiede in der Ausformung der lateralen Drüsensäcke und des Kopulationsorgans an (SCHILKE 1970).

Karkinorhynchinae nov. subfam.

D i a g n os e : laterale Drüsensäcke vorhanden; männliches Kopulationsorgan mit Ringmuskelhïlle und darunter anschließender Kornsekretblase; Kutikularorgan ein oder zwei Stilette. Typgattung und einzige Gattung: Karkinorbynchus Merxner 1928.

Karkinorbynohus MEIXNER 1928

Neben einer kurzen Darstellung der bisher ganz ungenügend bekannten 'Typart $K$. primitivus werden vier neue Arten vom Sandstrand der Nordseeküste erfaßt. Die Beschreibung einer weiteren neuen Art von der Mittelmeerküste ( $K$. tetragnatbus Ax \& SCHILKe n. n.) erfolgt an anderer Stelle. Über das reichhaltige Material wird eine Gliederung der Gattung in zwei Untergattungen notwendig.

Karkinorbynchus Karkinorbynchus nov. subgen.

Diagnose: Im Kopulationsorgan paarige, spiegelsymmetrische Stilette vorhanden.

Typart: K. (Karkinorhynchus) primitious MEXXNER 1928. 
Weitere Arten: K. (Karkinorbynchus) l'hardyi nov. spec., K. (Karkinorbynchus) bruneti nov. spec., K. (Karkinorbyncbus) listensis nov. spec.

\section{Karkinorbynchus primitivus MeIXNER 1928}

(Abb. 53)

F u n d o r t e : Der erste Fundort entspricht dem Typlokal eines juvenilen Exemplars, auf dem die Originalbeschreibung MeIXNERs basiert. Ostsee: Kieler Bucht, Bülk, $5 \mathrm{~m}$ Tiefe, 2 Exemplare (leg. Ax 1950, 1951), Flüggesand, $6 \mathrm{~m}$ Tiefe, 1 Exemplar (leg. Ax 1951).

M a teria 1: Lebendbeobachtungen $(A x)$.

Beschreibung: Die Körperlänge beträgt 2-2,5 mm. Zwei kräftige Haftringe befinden sich hinter der Körpermitte und vor dem Hinterende. Das Vorderende besitzt mehrere lange Tasthaare. Das kleine Gehirn enthält zwei nierenförmig gebogene Augen. Der horizontal gestellte, tonnenförmige Pharynx liegt am Hinterende des

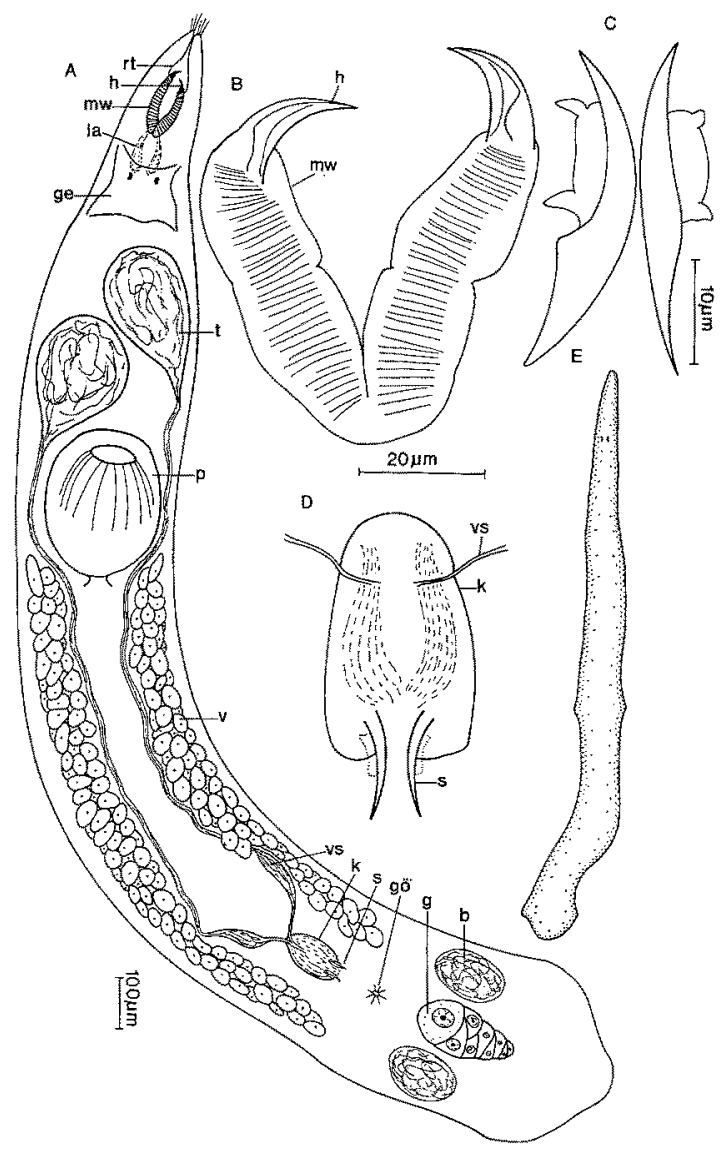

Abb. 53: Karkinorbynchus primitious. (Zeichnungen ron $\mathrm{Ax}, \mathrm{Abb} . A$ etwas verändert) $A$ Organisation; $B$ Rüssel; $C$ parige Stilette, Seitenteile schematisiert; $D$ Kopulationsorgan; E Habitus 
1. Körperdrittels. Die Rüsselhaken sind $20-22 \mu \mathrm{m}$, die Wülste $44-50 \mu \mathrm{m}$ lang. Die Pharynxtasche ist kurz. Vor dem Pharynx liegen zwei große, rundliche Hoden ( $t$ ). Die kurzen, keulenförmigen Samenblasen (vs) gehen in nicht sehr lange Seminalkanäle über. Das elliptische männliche Kopulationsorgan $(k)$ wird von der Kornsekretblase ausgefüllt und besitzt kaudal zwei spiegelsymmetrische Stilette ( $31 \mu \mathrm{m}$ lang). Es sind gekrümmte Stacheln, deren Spitzen hinten auseinanderweichen. Sie tragen lateral komplizierte Fortsätze, an deren Verlängerung die muskulöse Wand des Kopulationsorgans ansetzt. Die Stilette sind gegeneinander verschiebbar.

Die gemeinsame Geschlechtsöffnung (gö) liegt bei etwa $4 / 5$ der Körperlänge. Dahinter befindet sich das umfangreiche Germar $(g)$ und eine spermaerfüllte Bursa $(b)$. Die paarigen Vitellarien (v) reichen vom Pharynx bis etwa zum Germar.

\section{Karkinorbynchus bruneti nov. spec.}

(Abb. 54, 55)

F u n d o r te: Sylt: 12 sw k (Locus typicus), 29 sw; Amrum: 2 sh; Rømø: Lakolk, Weststrand, verschiedene Stellen.

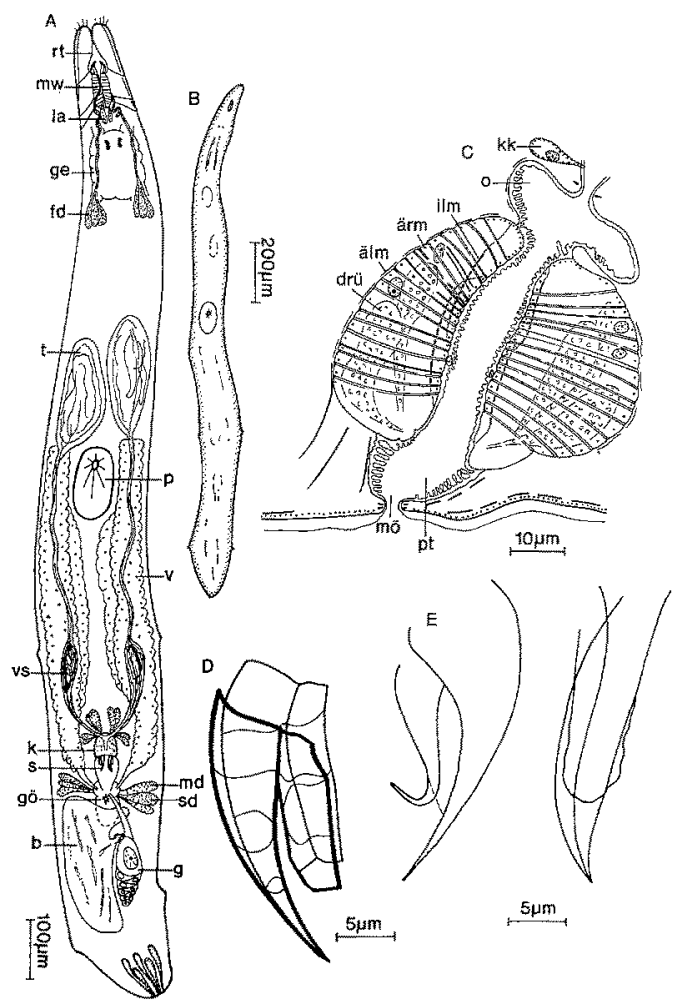

Abb. 54: Karkinorbynchus bruneti. A Organisation (kombiniert); $B$ Habitus; $C$ Sagittalschnittrekonstruktion des Pharynx; $D$ Sagittal- und Querschnittrekonstruktion eines Stiletts (vordere Linien dicker ausgezogen, 4 Querschnitte eingezeichnet); $E$ paarige Stilette (Quetschpräparat) 
Materia 1: Lebendbeobachtungen, mehrere Schnittserien (Holotypus $1 \mathrm{Sa}$ gittalschnittserie).

Beschreibung: Die Körperlänge der biegsamen Art beträgt 1,6-2 mm. Der erste Haftring liegt caudal von der Körpermitte, während der zweite (acht Papillen) terminal ist.

Die Epidermis enthält zahlreiche kleine Bläschen, die sich teilweise etwas aus thr vorwölben. Die graugrün gefärbten Tiere haben zwei Augen (16-17 $\mu \mathrm{m}$ Länge).

Der kleine Pharynx rosulatus $(p)$ ist etwas schräg nach vorne gerichtet, nicht tonnenförmig und liegt kurz vor der Körpermitte $(\phi 90-120 \mu \mathrm{m})$. Die Pharynxtasche ist kurz. Der Bulbus enthält eine kräftige innere Ring- und Längsmuskulatur (irm, ilm). Mehrere starke Muskelfasern sind vom dorsalen Teil des Bulbus schräg zur dorsolateralen Körperwand ausgespannt. Der Oesophagus ist ein kleiner Hohlraum dorsal vom Bulbus. Der Darmeingang ist mittels eines schwachen Sphinkters verschließbar. Die Rüsselhaken $(19 \mu \mathrm{m})$ haben Spitzen auf den Oberseiten. Die Muskelwülste sind ca. $50 \mathrm{~m}$ lang.

Zwei Hoden $(t)$ liegen yor dem Gehirn hintereinander. Die keulenförmigen, 100 bis $130 \mu \mathrm{m}$ langen Samenblasen ( $v s$ ) sind von breiten Längsmuskeln umgeben. Das pilzförmige männliche Kopulationsorgan $(k)$ ist kürzer als hinten breit $(40 \times 80 \mu \mathrm{m}$ Quetschpräparat) und von einer Ringmuskelhülle umgeben. Die Kornsekretblase hat verschieden gelagerte, basophile und eosinophile Sekrete $\left(k s b_{1}, k s b_{2}\right)$.

Die beiden Stilette (s) bestehen aus einer vorne offenen, hinten geschlossenen Spitze und einem vorne, außen mit ihr verwachsenen Halbrohr. Die sanft nach außen gebogene Spitze ist 25-27 $\mu \mathrm{m}$ lang, während das Halbrohr $17 \mu \mathrm{m}$ erreicht. Während in die einander zugekehrten Spitzen von vorne vermutlich der sich aufspaltende Ductus ejaculatorius einmündet, sind die Halbrohre außen mit der Wand des Kopulationsorgans verwachsen und durch deren Dehnung spreizbar.

Das lange männliche Genitalatrium (ma) setzt hinter dem männlichen Kopulationsorgan an und läßt den mittleren Teil und die Stilette frei.

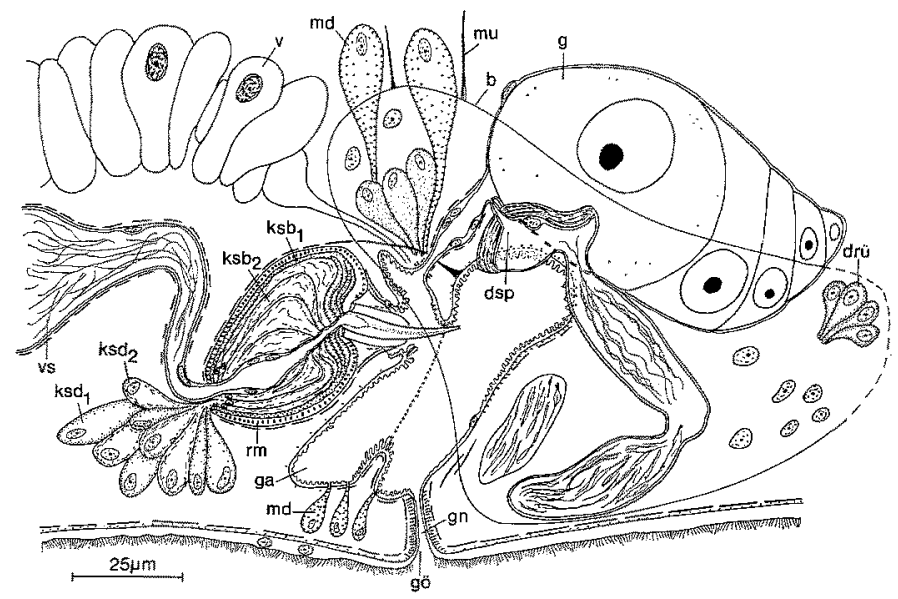

Abb. 55: Karkinorbynchus bruneti. Sagittalschnittrekonstruktion der Atrialorgane 
Die etwa bei $4 / 5$ der Körperlänge befindliche Geschlechtsöffnung ( $g$ ö) führt durch den langen Genitalkanal $(g n)$ in das umfangreiche gemeinsame Genitalatrium ( $g a$ ). Das Atrium besitzt vor allem dorsal eine deutliche Quer- und Längsmuskelhülle.

Das Atrium wird frontal durch einen Ringwulst vom männlichen Atrium getrennt. In diesem setzt in einer kleinen dorsalen Erweiterung der lange Ovidukt an. Das große Germar $(g)$ liegt rechts im Hinterende.

Neben Germar und Atrium füllt die sehr große Bursa (b) fast die linke Körperseite aus. Spermien sind in ihr zu hantelförmigen Bündeln zusammengelegt. Die rückwärtige Wand der Bursa geht in das Darmepithel über. Resorptionsvakuolen mit Spermien sind in der Bursa und im Darm anzutreffen. Hinten in der Bursa sezernieren einige Drüsen (drii) dunkle, eosinophile Sekrete. Vom frontalen Teil der Bursa führen einige kräftige Muskeln zur dorsalen Körperwand.

Der Ductus spermaticus $(d s p)$ beginnt mit einem gegen eine Vakuole offenen, dickwandigen Trichter $(\varnothing[14]-20-[22] \mu \mathrm{m})$. Ein großer Zellkern liegt dorsal in dem Trichter. Ein kurzer Kanal $(1,6 \mu \mathrm{m}$ dick, $5 \mu \mathrm{m}$ lang) führt zum Germar unmittelbar am Ansatz des Ovidukts. Eine Vagina fehlt.

Die eosinophilen $(s d)$ und basophilen ( $m d$ ) Drüsen liegen lateral neben dem männlichen Atrium. Sie sezernieren ihre Sekrete vorwiegend in dessen dorsalen Teil. Einige basophile Drüsen liegen ventral vom männlichen bzw. gemeinsamen Atrium.

Die paarigen, lateralen Vitellarien ( $v)$ reichen von den Hoden bis vor das Germar. Die feinen Vitellodukte münden entweder in den Ovidukt oder direkt daneben in das männliche Atrium aus.

Als Parasiten sind Sporozoen anzutreffen.

Karkinorhynchus l'bardyi nov. spec.

(Abb. 56, 57)

Fund o r te: Sylt: 1 sh, 12 sh k (Locus typicus).

Material: Lebendbeobachtungen, mehrere Schnittserien (Holotypus $1 \mathrm{Sa}-$ gittalschnittserie).

Beschreibung: Die Art erreicht 2,8-3 mm Länge. Die Art kann sich mit zwei Haftringen hinter der Körpermitte und terminal anheften. Die Epidermis enthält besonders im Vorderende zahlreiche rundliche bis längliche Vakuolen. Die Basalmembran ist ungewöhnlich dick.

Die Art ist schwärzlichbraun gefärbt und undurchsichtig. Das Gehirn besitzt zwei große, nierenförmige Augen ( $\varnothing 12-15, u \mathrm{~m})$.

Der tonnenförmige Pharynx $(p)$ hat eine kurze Tasche mit einem in hohe Falten gelegten Epithel, das oberflächlich membranartig kutikularisiert ist. Der Bulbus (160 bis $240 \mu \mathrm{m}$, Schnittserie) liegt fast parallel zur Körperlängsachse. Vorne und hinten hat er Greifwülste mit dicht gepackten Ringmuskeln. Ungefähr 40 Radiärmuskelfasern, innere Längsmuskeln und proximal besonders kräftige innere Ringmuskeln sind gut entwickelt. Die äußeren Ringmuskeln und die äußeren Längsmuskeln liegen innen bzw. außen der Außenseite des Bulbus an. Im Bulbus befinden sich auffällig spärliche Drüsen.

Der Oesophagus füllt hinter dem Bulbus fast den Körper aus und ist dorsal mit Muskelfasern an der Körperoberfläche befestigt. Caudal öffnet sich der drüsenum- 
stellte, verschließbare Darmeingang. Die Rüsselhaken sind 40-43 $\mu \mathrm{m}$, die Wülste 56-64 $\mu \mathrm{m}$ lang. Die Drüsensäcke sind gegliedert.

Zwei kleine Hoden $(t)$ liegen vor der Pharynxtasche. Die kurzen Samenblasen (vs) haben nur einen Durchmesser von 14-20 $\mu \mathrm{m}$. Die Samenblasen verjüngen sich zu den Seminalkanälen, deren Epithel Kerne enthält, die das Lumen fast ganz ausfüllen können.
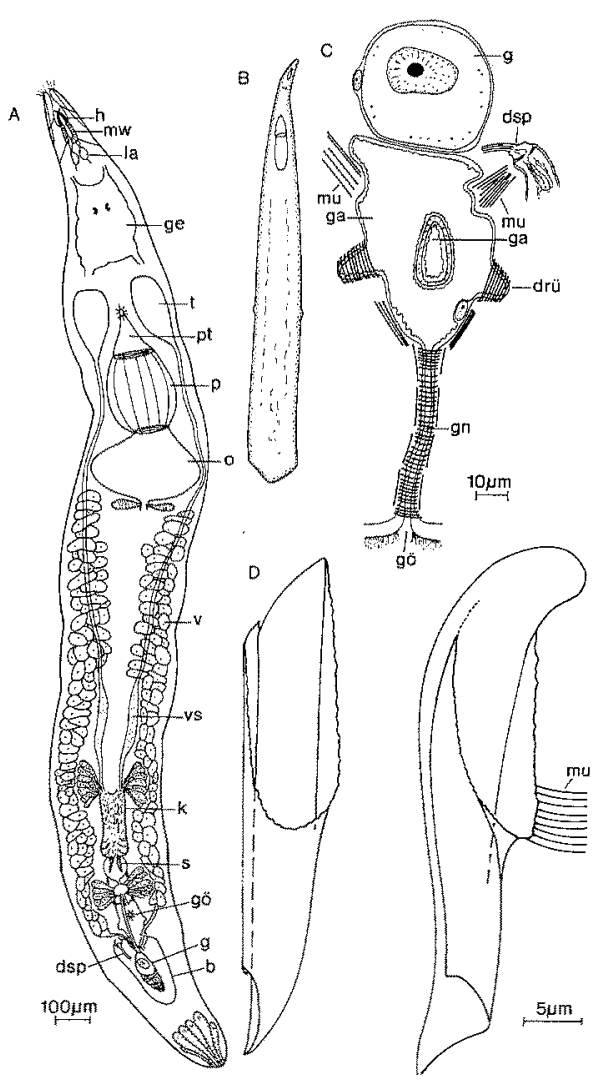

Abb. 56: Karkinorbynchus l'hardyi. A Organisation (kombiniert); $B$ Habitus; $C$ Querschnitt durch den caudalen Teil des gemeinsamen Atriums; Genitalkanal, Ductus spermaticus, Germar; D paarige Stilette (Quetschpräparat)

Das pilzförmige Kopulationsorgan ( $k$ ) krümmt sich im Schnitt stets s-förmig ein. Die kräftige Ringmuskelhülle bildet proximal einen Sphinkter. Die Kornsekretblase enthält Gänge mit eosinophilem, grobkörnigem Sekret $\left(k s b_{2}\right)$ und solche mit basophilem, feinkörnigem Sekret $\left(k s b_{1}\right)$. Beide Sekretarten münden in die Stilette aus. Drei Gruppen von Muskeln bewirken die Bewegung der Stilette. Krättige Längsmuskelfasern $(m u)$ inserieren etwa bei $1 / 3$ des Kopulationsorgans und ziehen quer zu den Sti-

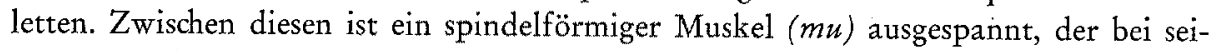
ner Kontraktion die Stilettspitzen spreizt. Schließlich liegen mehrere Muskelfasern 
hinten quer im Kopulationsorgan, die seitlich am Stilett angreifen. Die Frage, ob der Ductus ejaculatorius zumindestens hinten paarig auftritt, bleibt offen. Proximal hat er ein hohes Epithel mit einer feinen Längsmuskelhülle.

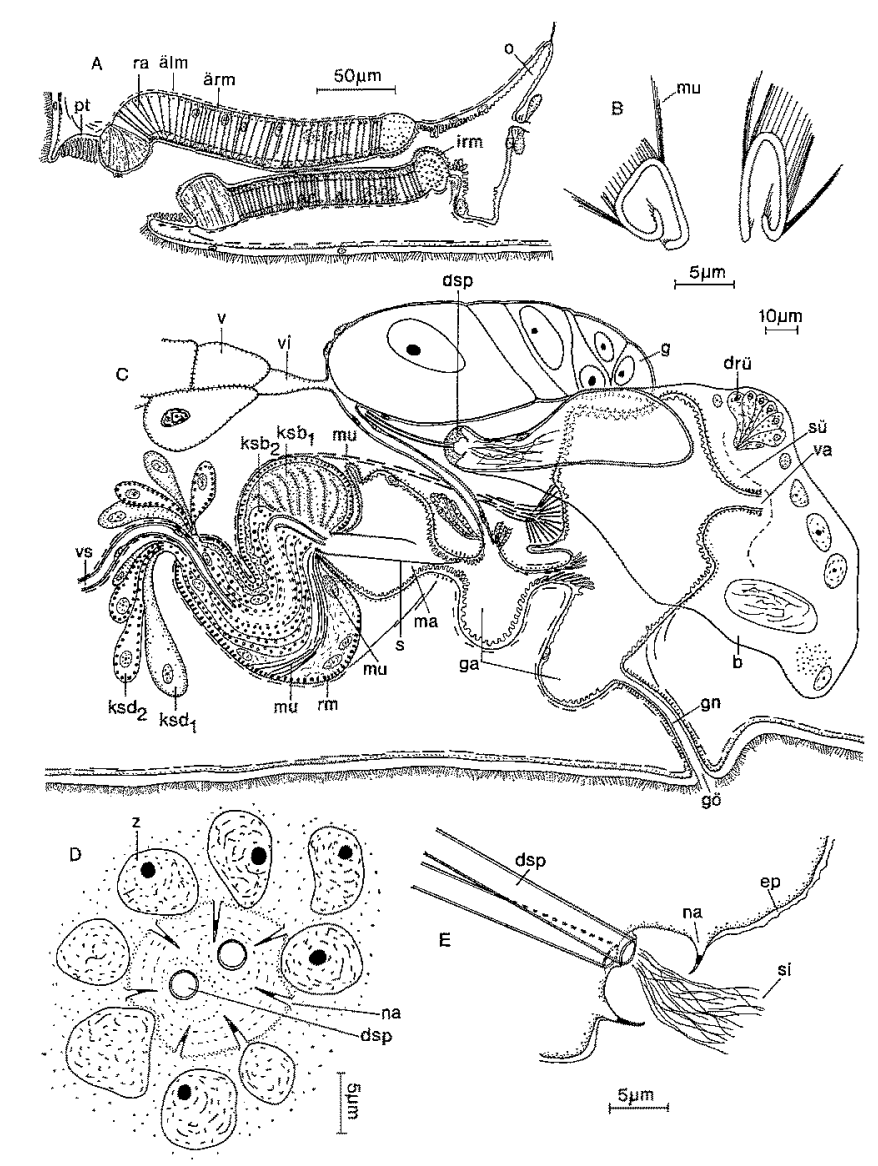

Abb. 57: Karkinorbynchus l'bardyi. A Sagittalschnittrekonstruktion des Pharynx; $B$ Querschnitt durch die parigen Stilette; $C$ Sagittalschnittrekonstruktion der Atrialorgane; $D$ Querschnitt durch den Ductus spermaticus, Zuordnung von Zellkernen und Nadeln; E Sagittalschnittrekonstruktion des Ductus spermaticus (Zellkerne weggelassen)

Die Stilette ([37-] $42 \mu \mathrm{m})$ sind $1^{1 / 2 f a c h ~ l i n k s-b z w . ~ r e c h t s g e w u n d e n e, ~ k u t i-~}$ kularisierte Spiralen. Proximal sind sie durch die genannten Muskeln befestigt und ragen fast mit ihrer ganzen Länge in das männliche Genitalatrium. Die runzelige, proximale Offnung ist schräg abgeschnitten, von hier ab verjüngen sie sich stark nach hinten, um in Spitzen auszulaufen.

Das männliche Genitalatrium (ma) läßt nur den mittleren Teil zwischen den Stiletten frei, erweitert sich stark und ist durh einen Ringwulst gegen das gemeinsame 
Atrium abgeschlossen. Zwei dorsolaterale Muskeln verbinden das Kopulationsorgan mit dem gemeinsamen Atrium.

Die gemeinsame Geschlechtsöffnung ( $g \ddot{0})$ liegt etwa bei $5 / 6$ der Körperlänge. Der lange Genitalkanal ( $g n$ ) führt in das umfangreiche gemeinsame Atrium ( $g a$ ). Es ist frontal ausgesackt. Eine Ringwulst begrenzt das Atrium vorne. Dorsolateral von ihm spalten sich die erwähnten Muskeln in radial zu der Wand des Atriums ziehende feine Fasern auf. Die beiden Ansatzstellen springen ins Lumen des Atriums vor.

Etwas weiter caudal, dem ventralen Teil des Atriums zugehörig, befinden sich zwei halbkugelige Blindsäcke (drï). Neben ihnen befinden sich Drüsen, die dem Atrium lateral anliegen und feinkörnige, basophile Sekrete herstellen. $\mathrm{sa}(b)$.

Schließlich kommuniziert das Atrium durch eine Vagina interna (va) mit der Bur-

Der lange Ovidukt beginnt in einem durch zwei Ringwülste begrenzten Atriumteil. Das median liegende Germar $(g)$ ist mit der umfangreichen Bursa durch einen kraterförmigen Ductus spermaticus $(d s p)$ verbunden ([6]-8-[12] $\mu \mathrm{m})$.

Am Kraterrand ragen sieben einwärts gekrümmte, kutikularisierte Nadeln (na) von 3,2(-4) $\mu \mathrm{m}$ Länge in das Lumen der Bursa. Sie sind in ihrer Mitte basophil, sonst hell. Am Boden des Kraters beginnen zwei parallele, ca. $23 \mu \mathrm{m}$ lange Kanäle $(\phi[1,5]$ bis $2-[2,4] \mu \mathrm{m})$, die zum Vorderende des Germars ziehen. Den Nadeln sind mehrere Zellkerne ( $z$ ) kreisförmig zugeordnet (Abb. 57 D). Die Bursa (b) liegt links und unter dem Germar. Sie enthält ein oder mehrere Hohlorgane, die Sperma speichern. Zuweilen hat die Bursa einen proximalen Teil vor dem Ductus spermaticus, in dem Resorption stattfindet. In der Bursa werden caudal und dorsal in einer Drüsengruppe eosinophile Sekrete (drï) produziert, während ventral basophile, grobkörnige Einschlüsse zu beobachten sind.

Die Vitellarien $(v)$ münden durch kurze feine Vitellodukte (vi) in den Ovidukt am Germar.

Die eosinophilen Drïsen (sd) und die basophilen Drüsen $(m d)$ liegen in umfangreichen Trauben lateral vom gemeinsamen Atrium und münden an der Ansatzstelle des Oviduktes in parallelen Kanälen aus. Mehrere basophile Drüsen öffnen sich auch im unteren, lateralen Teil des Atriums.

\section{Karkinorbynchus listensis nov. spec.}

(Abb. 58, 59, 64)

Fund ort: Sylt: $12 \mathrm{sw}$ sh (Locus typicus).

Materia 1: Lebendbeobachtungen, ein Dauerpräparat (juv.), eine Sagittalschnittserie (Holotypus).

B e schreibung: Die Art erreicht eine Länge von $2 \mathrm{~mm}$. Der langgestreckte Körper ist vorne etwas zugespitzt. Kurz hinter der Körpermitte und caudal ist stets ein Haftring zu sehen. Das Hinterende ist abgerundet. Die Körperfarbe ist gelblichweiß bis grau.

Das umfangreiche Gehirn ist augenlos. Hinter ihm sezernieren mächtige Frontaldrüsen eosinophile Sekrete, die in Drüsenschläuche des Rüssels geleitet werden. Ein Septum ist frontal vorhanden.

Der Pharynxbulbus $(p)$ und die kurze Tasche sind senkrecht aufgerichtet. Die 
Rüsselhaken (20-23 $\mu \mathrm{m})$ sitzen auf 52-65 $\mu \mathrm{m}$ langen Wülsten. Sekrete der FrontaIdrüsen werden durch den Riissel ausgeleitet. Zwischen Gehirn und Pharynx sind vier längliche Hoden $(t)$ in zwei Reihen angeordnet. Bei etwa ${ }^{2 / 3}$ der Körperlänge liegen zwei spindelförmige, lange Samenblasen ( $v s$ ).

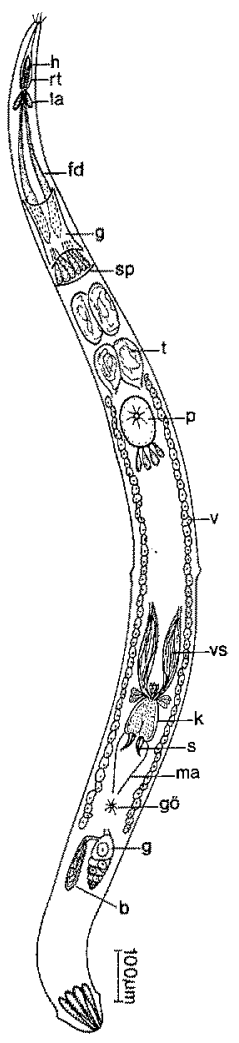

Abb. 58: Karkinorbynchus listensis. Organisation (kombiniert)

Das pilzförmige männliche Kopulationsorgan (Länge $90 \mu \mathrm{m}$ ) endet in $z$ wei spiegelsymmetrischen Stiletten $(49-51 \mu \mathrm{m})$. Diese sind proximal halbkreisförmig, distal haben sie scharfe Spitzen und sind sanft gekrümmt.

Das männliche Genitalatrium (ma) setzt kreisförmig am Hinterrand des Kopulationsorgans neben den etwas verbreiterten Stilettbasen an.

Hinter der gemeinsamen Geschlechtsöffnung ( $3 / 4-4 / 5$ der Körperlänge) sind das Germar ( $g$ ) und daneben eine voluminöse Bursa angelegt. Aus ihr führt ein Ductus spermaticus ( $d s p$ ) zum Germar, ein gerades Röhrchen von $29 \mu \mathrm{m}$ Länge.

Die paarigen, lateralen Vitellarien ( $v)$ reichen von den Hoden bis vor das Germar.

Diskussion: Spezifische Merkmale von Karkinorbynchus primitivus, $K$. l'bardyi, K. bruneti, K. listensis sind paarige, spiegelsymmetrische Stilette. Darüber hinaus münden bei $K$. listensis und $K$. bruneti Frontaldrüsen in den Rüssel. $K$. 
l'bardyi und K. bruneti sind eng durch die Form der Genitalatrien, Insertion von Atrialmuskeln, Ductus spermaticus und weibliche Genitaldrüsen verbunden.

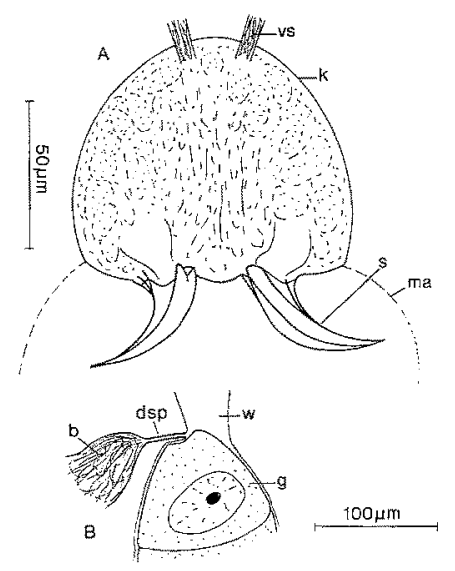

Abb. 59: Karkinorbynchus listensis. A Kopulationsorgan (Quetschpräparat); B Ductus spermaticus (Quetschpräparat)

Karkinorbynchus Karkinorbynchides nov. subgen.

$\mathrm{D}$ i a g n o s e : männliches Kopulationsorgan mit unpaarem Stilett.

Ty p a $\mathrm{t}: K$. (Karkinorbynchides) purpureus nov. spec.

We itere Arten: $K$. (Karkinorhynchides) megalopharynx L'Hardy 1966, K. (Karkinorbynchides) tetragnathus Ax \& ScHLkE n. n.

Karkinorbynchus purpureus nov. spec.

(Abb. 60, 61, 64)

F und or te: Sylt: $12 \mathrm{sw}$ (Locus typicus); Amrum: 7.

Materia l: Lebendbeobachtungen, mehrere Schnittserien (Holotypus 1 Sagittalschnittserie).

B e s c h r e ib u n : Die fadenförmige Art erreicht 1,8-2,5 mm Länge. Das Vorderende läuft spitz zu. Das Hinterende ist beim freien Schwimmen konisch und wird oft u-förmig gebogen. Ein schwacher, subterminaler Haftring besteht aus unregelmäBigen Papillen.

Die Tiere sind leuchtend purpurrot gefärbt. Die Epidermis ist scharf gelblichgrau abgesetzt. Die rote Färbung ist vermutlich in kleinen basophilen Drüsen fixiert, die unter dem Hautmuskelschlauch liegen. Augen fehlen.

Der Pharynx rosulatus ( $\varnothing 120 \mu \mathrm{m})$ steht senkrecht zur Körperlängsachse und ist nicht tonnenförmig. Die kurze Pharynxtasche ist mit einem ventral sehr hohen, faltigen Epithel ausgekleidet. Der Bulbus wird von kräftigen inneren Längs- und inneren Ringmuskeln (ilm, irm), feinen Radiärmuskeln und schwachen äußeren Längsmuskeln durchzogen (älm). Umfangreiche basophile Drüsen füllen fast den Bulbus aus. Der mit Längsmuskeln versehen Oesophagus leitet in den Darm. Die Rüsselhaken (18-19 $\mu \mathrm{m})$ 
sitzen auf $46 \mu \mathrm{m}$ langen Muskelwülsten. Sekrete der Frontaldrüsen gelangen in die Haken.

8-9 Hodenfollikel ( $t$ ) sind yor dem Pharynx hintereinander angeordnet. Die Samenblasen (bis $360 \mu \mathrm{m}$ Länge) speichern Spermien, die von einer dicken Hülle umgeben sind. Sie hat eosinophile und basophile feinkörnige Bestandteile. Das kleine

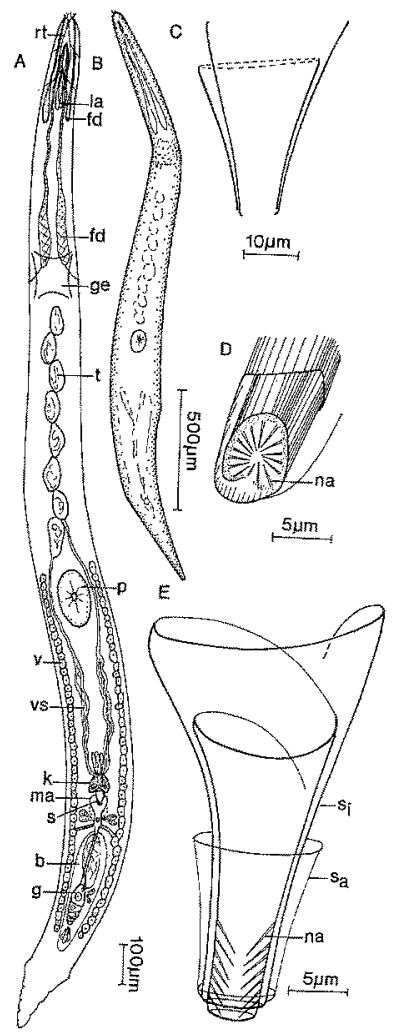

Abb. 60: Karkinorhynchus purpureus. A Organisation (kombiniert); B Habitus; C Stilett (Quetschpräparat); $D$ Querschnitt durch das caudale Ende des Stiletts; $E$ Rekonstruktion des Stiletts, räumlich (kombiniert)

männliche Kopulationsorgan ( $k$ ) erreicht ohne Stilett nur 27-39 am Länge (Schnittpräparat) und ist von einer sehr dicken Ringmuskelhülle umgeben. Die Kornsekretblase enthält zweierlei Sekret $\left(k s b_{1}, k s b_{2}\right)$. Sehr auffällig sind große Zellkerne, die yor allem frontal - dem Kornsekret kaum Platz lassen. Der Ductus ejaculatorius ragt proximal ein kurzes Stïck in das Stilett (s) hinein. Es ist 30-44 $\mu \mathrm{m}$ lang (30-33 $\mu \mathrm{m}$ im Schnittpräparat); caudal hat es einen Durchmesser von $6 \mu \mathrm{m}$ (Schnittpräparat).

Das Stilett ist im Prinzip eine 11/2-2fach gewundene Innenspirale $\left(s_{i}\right)$, die caudal von einer feinen zylindrischen Hülle $\left(s_{a}\right)$ umgeben ist. Das letzte Drittel der inneren 2. Windung ist mit langen, sehr feinen Nadeln (na) besetzt, die kreisförmig das Lumen der Spirale umgeben. Dieser benadelte Teil ist im Schnittpräparat 8-9 $\mu \mathrm{m}$ lang. 
Die zylindrische, äußere Hülle des Stiletts ist mit der Innenspirale caudal verbunden. Sie erreicht etwa die halbe Länge der 1 . Windung der Innenspirale.

Das Stilett ist auf $2 / 3$ seiner Länge von einer muskelfreien Penispapille ( $p e$ ) umgeben, an der das männliche Genitalatrium ( $m a$ ) inseriert. Das Epithel des Genitalatriums legt sich als feine Schicht außen der Penispapille an, wird danach aber hoch und lappig.

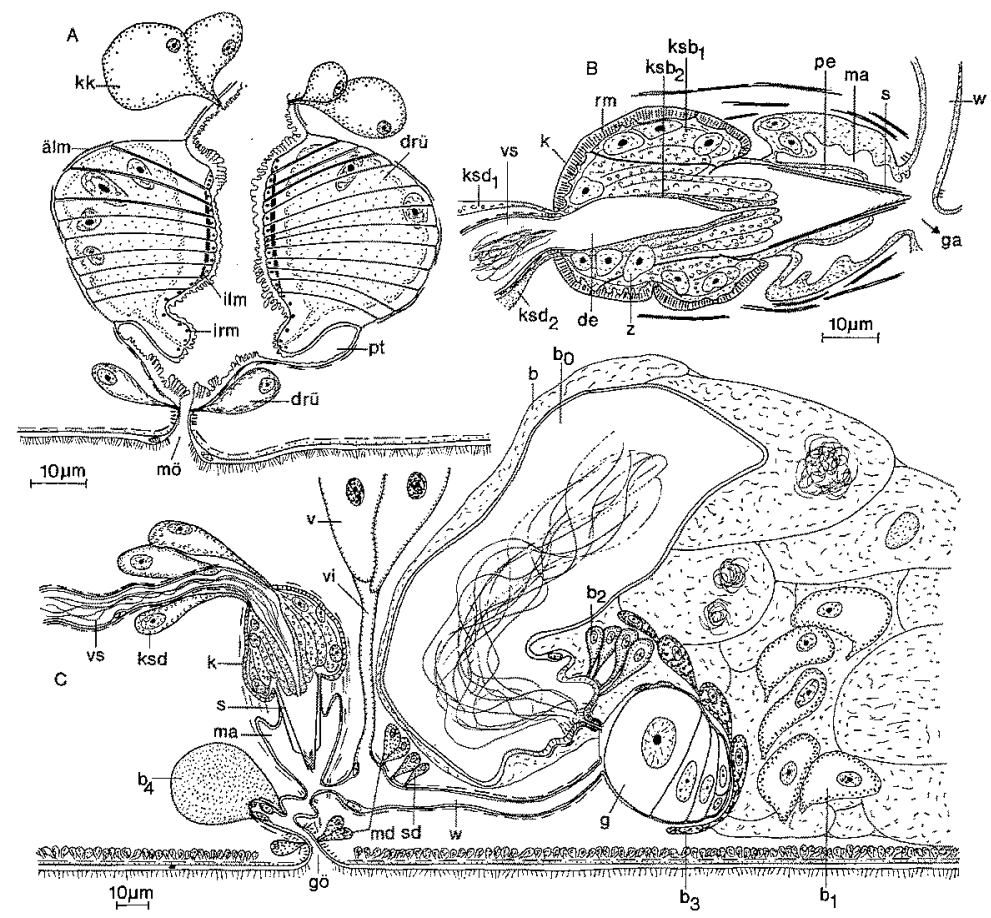

Abb. 61: Karkinorhynchus purpureus. A Sagittalschnittrekonstruktion des Pharynx; $B$ Sagittalschnittrekonstruktion des Kopulationsorgans; $C$ Sagittalschnittrekonstruktion der Atrialorgane

Die gemeinsame Geschlechtsöffnung ( $g$ ö) befindet sich bei $4 / 5$ der Körperlänge. Der Genitalkanal hat yorne einen Blindsack und führt in das gemeinsame Atrium ( $g a$ ).

Der sehr lange Ovidukt (w) entspringt aus dem männlichen Atrium und bildet proximal einen Hohlraum. Das Germar $(g)$ hat eine feine Tunica. Vor der ersten Oocyte erweitert sich eine kleine Blase, die mit einer feinkörnigen Masse angefüllt ist. Hier hinein führt von dorsal ein Ductus spermaticus (6-8 $\mu \mathrm{m}$ Länge, ca. $1 \mu \mathrm{m} \phi)$. Der Ductus verbindet das Germar mit der komplizierten, zweiteiligen Bursa $\left(b, b_{0}\right.$, $\left.b_{1-4}\right)$. Das Bursahohlorgan $\left(b_{0}\right)$ hat ein feines, membranartiges Epitel. Spermien in ihm haben keine basophilen, feinkörnigen Bestandteile in ihren Hüllen und sind dünner als in den Samenblasen. Lediglich die eosinophilen Bestandteile sind in der Hülle vorhanden. Zum Ductus spermaticus hin fehlen die Hüllen um die Spermien völlig. Vagina und Uterus fehlen. 
Die weiblichen Genitaldrüsen sind kompliziert und vielfältig. Die spärlichen eosinophilen Driisen ( $s d$ ) liegen dorsal vom frontalen Teil des Ovidukts. Die basophilen Drüsen ( $m d$ ) liegen lateral von dem gemeinsamen Genitalkanal und am Atrium, außerdem dorsal vom vorderen Teil des Ovidukts. Derartige Sekrete werden auch in einer weiteren, sehr umfangreichen Drüsengruppe $\left(b_{1}\right)$ hinter dem Germar sezerniert. Eine eosinophile Drüsengruppe $\left(b_{2}\right)$ liegt frontal und dorsal zu dem Germar. Die Sekrete ergießen sich in den Endabschnitt der Bursa.

Eine weitere basophile Drüsengruppe $\left(b_{3}\right)$ befindet sich caudal vom Germar und den Drisen $\left(b_{2}\right)$.

Frontal von dem stumpf endenden gemeinsamen Genitalkanal schwillt eine fast kugelförmige, eosinophile Blase $\left(b_{4}\right)$ an.

Diese verschiedenen Drüsen sind, mit Ausnahme der letztgenannten, von sehr großen Zellen eines zweiten Bursateiles (b) umgeben. Dieser Abschnitt umfaßt das Hohlorgan frontal mit einer dünnen Schicht, um sich dahinter bis in das äußerste Ende des Tieres mit sehr großen Zellen zu entwickeln. Hierin werden im vorderen, dorsalen Teil Spermien resorbiert, die zu Klumpen geballt sind. Der hintere Bursateil dient vermutlich der Eikapselbildung.

Zwei strangartige Teile dieser Bursa befinden sich rechts und links neben dem Hohlorgan und reichen bis zum Anfangsteil des Ovidukts. Auch in diesen Abschnitten findet Resorbierung statt.

Die paarigen Vitellarien $(v)$ entsenden Vitellodukte (vi) in den Hohlraum des frontalen Ovidukts.

Bei einem untersuchten Exemplar (Schnittserie) befindet sich ein großer Spermaballen im Darm dorsal der Samenblasen; die Spermien haben eine Hülle.

$D$ is k us sion: Das gemeinsame Merkmal von K. megalopharynx, K. tetragnathus und $K$. purpureus ist ein unpaares, röhrenförmiges Stilett. Ein Sondermerkmal an K. purpureus sind Frontaldrüsen, die in den Rüssel münden. Diese Art nimmt auf Grund einfacher Rüsselhaken, ungegliederter lateraler Drüsensäcke, wegen der Lage und Zahl der Hoden und der des Pharynx mutmaßlich eine ursprüngliche Stellung in der Gattung ein (vgl. KarLING 1961).

Cheliplaninae nov. subfam.

D i a g o s e: Bulbus postrostralis vorhanden; männliches Kopulationsorgan mit Längsmuskelhülle; axial die von einer Muskelhülle umgebende Kornsekretblase; Kulikularorgan fast stets ein Cirrus, selten ein Stilett.

Typgattung: Chelipland DE BEAUCHAMP 1927; weitere Gattungen: Rbinepera Meixner 1928, Cheliplanilla Metxner 1938, Baltoplana Karling 1949.

\section{Cheliplana de BeAuchamp 1927}

Nach Untersuchungen von Brunet (1968) umfaßt die Gattung Cheliplana elf Arten. Neben dem Nachweis von C. stylifera werden in dieser Studie zwei neue Arten beschrieben.

\section{Cheliplana stylifera KARLING 1949}

F und or te : Amrum: 2, 4 sh; Rømø: Lakolk, Weststrand, Sandhang; Westerhever Sand (Karling 1963). 
Cheliplana curvocirro nov. spec.

(Abb. 62, 64)

Fund or t: Amrum: 2 sh (Locus typicus).

Materia l: Lebendbeobachtungen.

Beschreibung: Die 0,6 bis $1 \mathrm{~mm}$ langen Tiere sind vorne fein zugespitzt. Kurz vor dem abgerundeten Hinterende liegt ein Haftring. Die weißlichgrau gefärbten Tiere haben keine Augen. Der tonnenförmige Pharynx $(p)$ besteht aus einem Bulbus (etwa $140 \mu \mathrm{m}$ lang) und einer etwa $200 \mu \mathrm{m}$ langen, schmalen Pharynxtasche.

Die Rüsselhaken sind 10-13 $\mu \mathrm{m}$ lang. Der Basalteil setzt - ähnlich wie bei Baltoplana magna - schräg vorne auf den Wuilsten an. Die Spitzen sind gleichmäßig nach innen gebogen. An ihrer Innenseite tragen sie kurz oberhalb der Basalteile eine winzige Vorwölbung. Die Muskelwülste sind 18-19 $\mu \mathrm{m}$ lang. Hinter den Wülsten beginnt ein typischer Bulbus postrostralis.

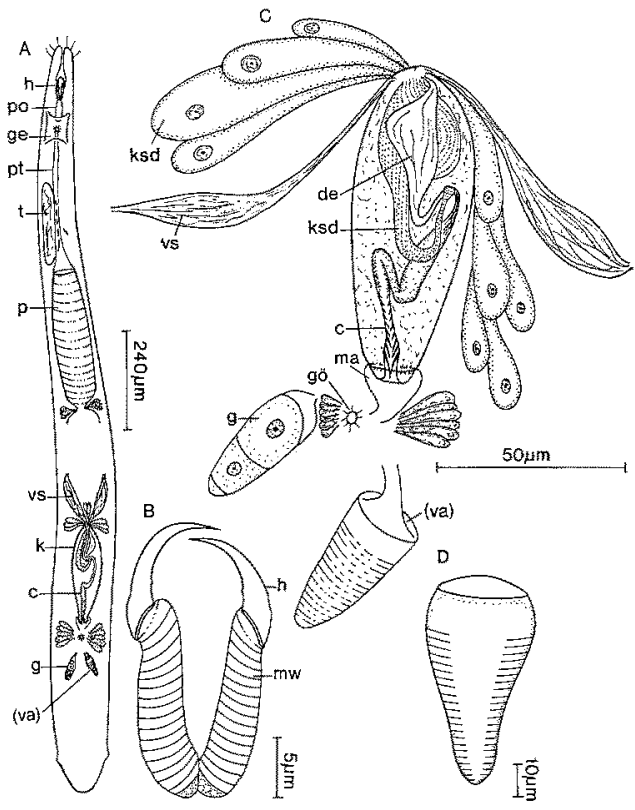

Abb. 62: Cheliplana curvocirro. $A$ Organisation; $B$ Rüssel (Quetschpräparat); $C$ Kopulationsorgan, weibliche Organe (Quetschpräparat); $D$ weibliches Hilfsorgan (Quetschpräparat)

Die Geschlechtsorgane sind mit Ausnahme der Samenblasen und der Vasa deferentia unpaar. Uber das Vitellar liegen keine Beobachtungen vor.

Der Hoden $(t)$ liegt vor oder hinter dem Pharynx. Die kurzen Samenblasen (40 $\mu \mathrm{m}$ lang) münden proximal neben einigen Kornsekretdrüsen in das elliptische männliche Kopulationsorgan (Länge 90-110 $\mu \mathrm{m}$ ). Der stellenweise weite Ductus ejaculatorius ist u-förmig gebogen und empfängt hier aus feinen, fingerförmig ausgezogenen Papillen Kornsekret. An dieser Stelle beginnt ein langer, gewundener Cirrus (etwa $70-90 \mu \mathrm{m}$ ). Im Innern ist vorne eine streifige Struktur, anschließend eine feine 
Punktierung zu erkennen. Die Frage, ob es sich dabei um Nadeln handelt, bleibt offen. Im letzten Teil sind Nadeln nachzuweisen, deren Länge zunimmt. Caudal ragen etwa $8 \mu \mathrm{m}$ lange, spitze Nadeln bündelartig nebeneinander gelegt ins Innere des Cirrus. Die Cirruswand ist hinter der Ansatzstelle der letzten Nadeln kutikularisiert; sie schlägt trichterförmig um (5-7 $\mu \mathrm{m}$ lang). An der Vorderwand des Trichters setzt die muskulöse Hülle des Kopulationsorgans und das kurze männliche Genitalatrium (ma) an.

Neben der Geschlechtsöffnung ( $3 / 4^{-4 / 5}$ der Körperlänge) liegen zahlreiche weibliche Genitaldrüsen. Das Germar $(g)$ besitzt vorne einen kurzen Ovidukt und enthält wenige Oocyten. Neben dem Germar ist ein weibliches Hilfsorgan (Vagina?) von charakteristischer Struktur sichtbar, in dem ein Spermaballen liegen kann. Das birnförmige Organ (Länge 34-36 $\mu \mathrm{m}$, vorderer $\phi 15 \mu \mathrm{m}$ ) ist von Ringmuskeln umstellt. Es erinnert an die Vagina externa von Thylacorbynchus ambronensis.

Cheliplana boadeni nov. spec.

(Abb. 63, 64)

Fund or te: Sylt: $5,12 \mathrm{sw}$ sh (Locus typicus), $14 \mathrm{sw}, 18,24 \mathrm{sh}$.

Materia 1: Lebendbeobachtungen. Die Art wurde bereits von Boaden erkannt, aber nur kurz als Rbinepera spec. charakterisiert (BOADEN 1963, p. 200, Fig. 35).

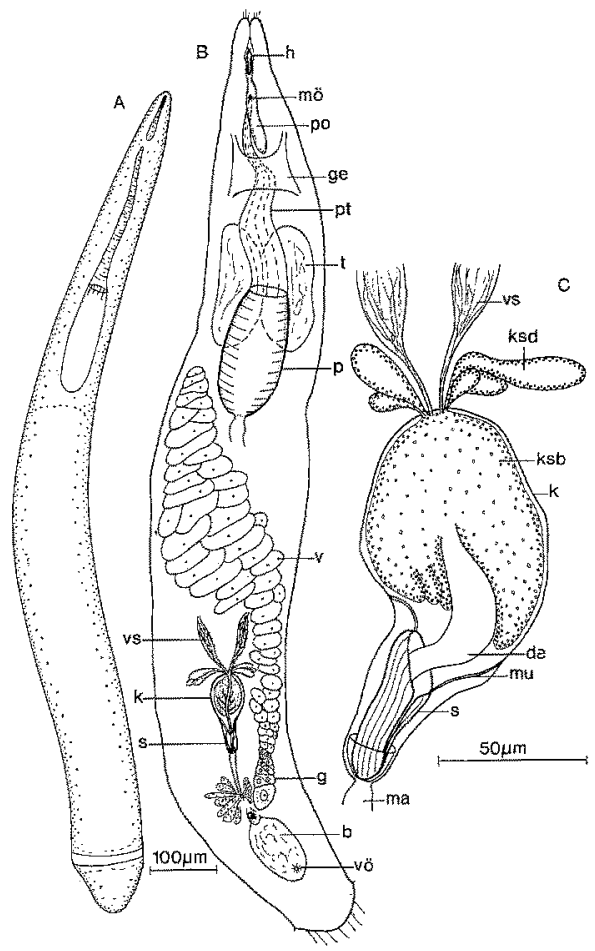

Abb. 63: Cheliplana boadeni. A Habitus; $B$ Organisation; $C$ männliches Kopulationsorgan (Quetschpräparat) 

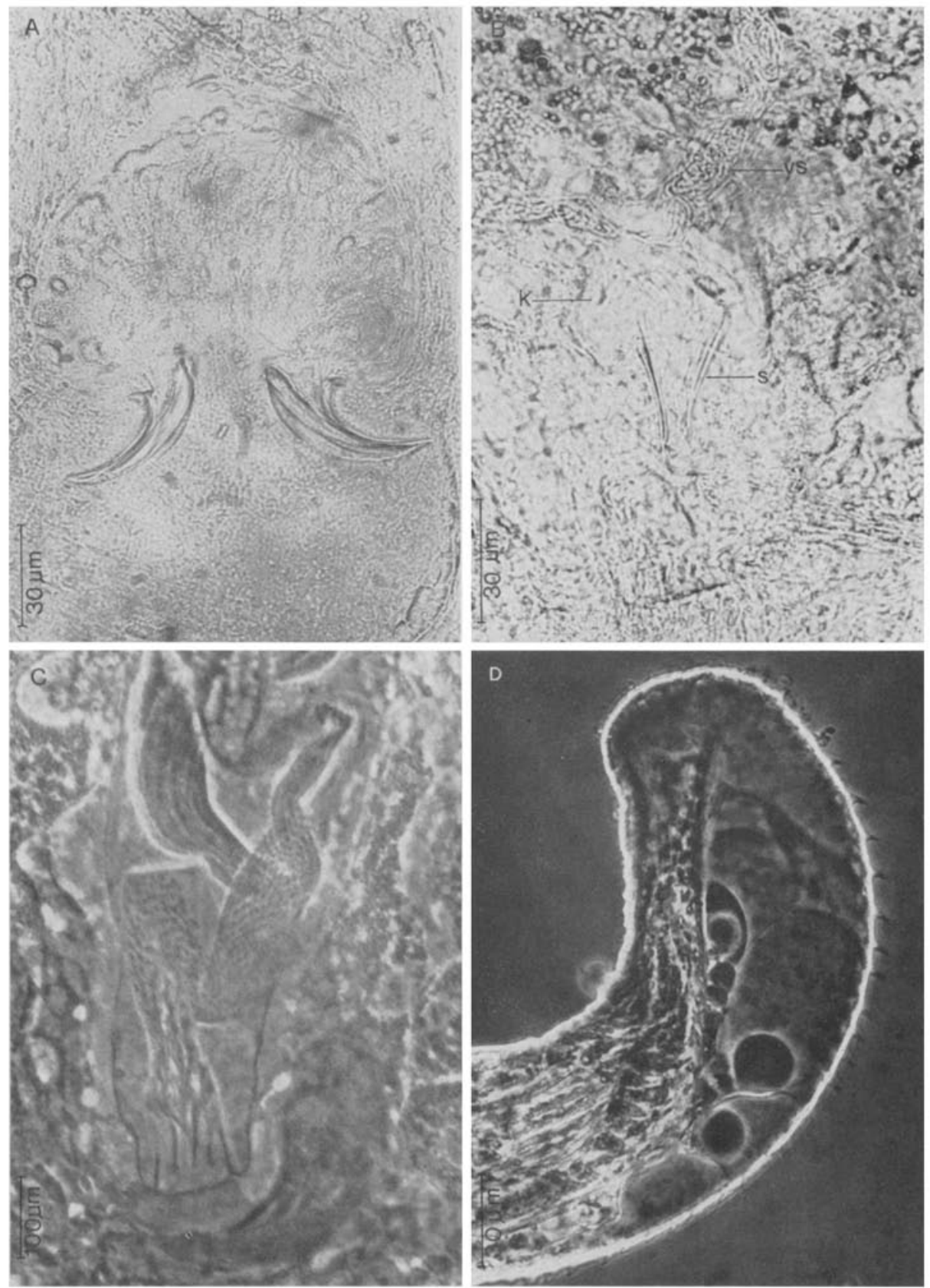

Abb. 64: A Karkinorbynchus listensis. Stilette; B Karkinorbynchus purpureus. Stilett; C Cheliplana curvocirro. Cirrus; $D$ Cheliplana boadeni. Pharynxtasche ausgestulpt mit Stacheln 
B es c b reibung: Die 1,5 mm lange Art hat ein spitz zulaufendes Vorderende und ein stumpf-kegeliges Hinterende. Caudal ist ein odkerfarbener Haftring scharf abgesetzt. Die Tiere sind hellbraun gefärbt und augenlos. Die Rüsselhaken (18-21 $\mu \mathrm{m})$ sitzen auf $23 \mu \mathrm{m}$ langen Muskelwuilsten. Die Nebenapparate erreichen etwa $24 \mu \mathrm{m}$.

Der tonnenförmige Pharynx $(p)$ besteht aus der biegsamen Pharynxtasche (270 $\mu \mathrm{m}$ Länge), die mit etwa 5 Reihen kräftiger Zähnchen besetzt ist und dem Bulbus (170 bis $190 \mu \mathrm{m})$.

Die zwei Hoden ( $t$ ) liegen vor und neben dem Pharynx und sind median, ventral von der Pharynxtasche miteinander verwachsen. Neben den keulenförmigen Samenblasen $(\mathrm{ca} .80 \mu \mathrm{m})$ liegen mehrere Kornsekretdrüsen $(k s d)$. Das männliche Kopulationsorgan $(80-130 \mu \mathrm{m})$ liegt am Beginn des letzten Körperdrittels. Der kugelförmige Anfangsteil nimmt die Kornsekretblase auf, der anschließende, zylindrische Teil enthält das Stilett (Länge [50]-54-[60] $\mu \mathrm{m}$ ). Es besteht aus einem inneren spiraligen Teil und aus einem kappenförmigen Teil, der ersteren hinten umgibt. Der innere Teil ist mit 7-9 Längsreihen feinster Nadeln besetzt. Beide Abschnitte des Stiletts stehen hinten miteinander in Verbindung. Der innere Teil kann jedoch aus dem äußeren Teil caudal herausgeschoben werden und besitzt vorne eine weite Offnung, deren einer Wandteil weit vor- und abgespreizt ist.

Am Hinterende des Kopulationsorgans inseriert neben dem Stilett das kurze, schmale, männliche Genitalatrium.

Die gemeinsame Geschlechtsöffnung (gö) liegt bei etwa $4 / 5$ der Körperlänge. Das Germar $(g)$ ist mit dem umfangreichen Vitellar $(v)$ verbunden. Caudal vom Germar befindet sich die unterteilte Bursa $(b)$. Spermien liegen in einem kleinen Bläschen gleich hinter dem Germar. In die Bursa führt subterminal die muskulöse Vagina externa (va).

Als Parasiten kommen Mesozoen vor.

\section{Rhinepera MeIXner 1928 \\ Rhinepera remanei MEIXNER 1928}

Fundorte: Sylt: $12 \mathrm{sw}, 13 \mathrm{sw}, 15 \mathrm{sw}, 16 \mathrm{sw}$; Amrum: 2, $16 \mathrm{sw}$; Rømø: Lakolk, Weststrand, Sandhang; Ostsee: Kieler Förde, Strande; Bülk (leg. Ax 1950); Heiligenhafen: Graswarder, Sandhang.

Rhinepera divisa nov. spec.

(Abb, 65)

Fund or te: Amrum: 2 sh (Locus typicus), 4 sh.

Material: Lebendbeobachtungen, 1 Horizontalschnittserie (Holotypus).

Beschreibung: Die fadenförmigen Tiere (Länge $0,7 \mu \mathrm{m}$ ) tragen vorne und hinten mehrere lange Tasthaare. Die Art ist rötlich gefärbt und augenlos. Die Mundöffnung liegt ventral von den Muskelwülsten oder kurz dahinter und führt in die lange, unbestachelte Pharynxtasche. Der tonnenförmige Bulbus (ca. $80 \mu \mathrm{m}$ ) beginnt mit zwei "Lippen" des proximalen Greifwulstes, die gegeneinander bewegt werden können und an denen Sekrete aus dem Bulbus treten.

Die Geschlechtsorgane sind unpaar. Direkt hinter dem Pharynxbulbus liegt ein einheitlicher Hoden ( $t$ ). Die gewundene Samenblase (vs) ist außen von einer kräftigen 
Spiralmuskelhülle umgeben. Das langgestreckte männliche Kopulationsorgan $(k)$ ist ein proximal kugelförmiger, distal schmalzylindrischer Schlauch mit einer Längsmuskelhülle. Der Cirrus $(27-29 \mu \mathrm{m})$ besteht aus vier Teilen (Artname). Der 1. $\left(c_{1}\right) \mathrm{Ab}-$ schnitt (17-22 $\mu \mathrm{m}$ lang, $\phi 7 \mu \mathrm{m})$ und der 3. Abschnitt $\left(c_{3}\right)$ sind mit reihig angeordneten Häkchen oder Wärzchen bedeckt. Dazwischen ist ein Nadelkranz $\left(c_{2}\right)$ eingeschoben.

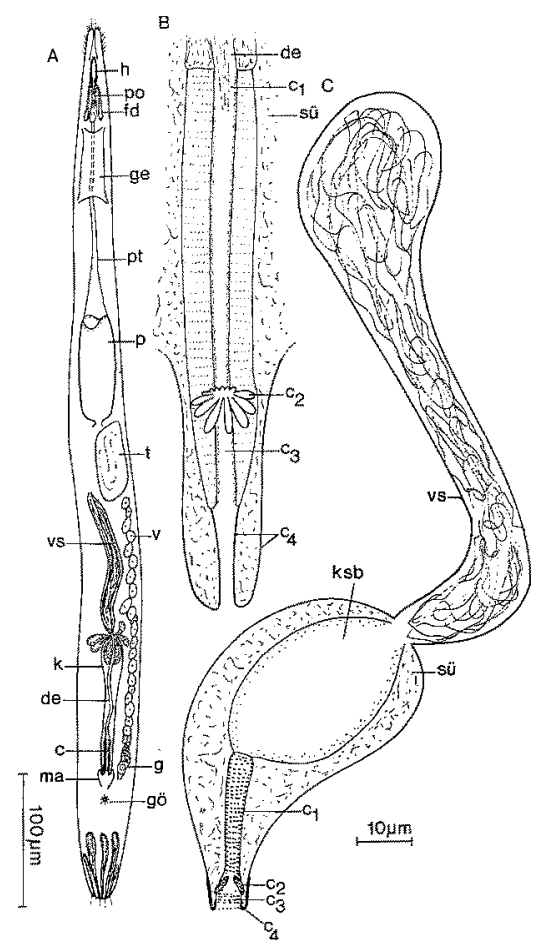

Abb. 65: Rhinepera divisa. A Organisation; $B$ Cirrus mit Abschnitten $c_{1}-c_{4}$ (Quetschpräparar); $\mathrm{C}$ Kopulationsorgan eines anderen Exemplars (Quetschpräparat)

Schließlich ist die Wand des Cirrus ( $\left.c_{4}\right)$ U-förmig umgebogen, vorne mit der Muskelhülle des Kopulationsorgans und mit dem männlichen Genitalatrium verbunden. Dieser Teil des Cirrus (7-10 $\mu \mathrm{m}$ Länge) ist kutikularisiert und ragt etwas in das Genitalatrium hinein.

Die gemeinsame Geschlechtsöffnung ( $g \ddot{o})$ liegt ventral, median, kurz vor dem Hinterende. Das Germovitellar $(g, v)$ befindet sich mit seinem Germarteil neben dem männlichen Kopulationsorgan, während der Vitellarteil bis hinter den Hoden bzw. bis hinter den Pharynx reicht.

Im Darm oder im Körperparenchym kommen Sporozoen als Parasiten vor.

$D$ is k u s i o n zu den Gattungen Cheliplana und Rbinepera: Auf die enge Verwandtschaft zwischen beiden Gattungen weist KARLING $(1949$, p. 24), hin (vgl. auch Ax 1959, p. 141).

BRUNET (1968) trennt die Gattungen auf Grund folgender Merkmale: Cheliplana hat paarige Vesiculae, Rhinepera besitzt eine unpaare Samenblase. Die Hodenzahl 
kann nach BRUNET nur bedingt zur Unterscheidung herangezogen werden, weil innerhalb Cheliplana eine Entwicklungsreihe existiert, in der Tiere mit zwei getrennten Hoden, mit verwachsenen Hoden und schließlich nur mit einem Hoden vorhanden sind.

Ich habe im Anschluß an die von Brunet vorgeschlagene Trenmung der Gattungen die Zuordnung der von mir gefundenen Species vorgenommen und weise auf einige Besonderheiten derselben hin. Die Trennung der beiden Gattungen basiert auf einem Merkmal, den Samenblasen, und erscheint daher problematisch. Da keine Gesamtrevision der Gattungen vorgenommen wird, erfolgt unter dieser Einschränkung die Verweisung von Rhinepera divisa in diese Gattung.

Cheliplana curvocirro gehört zu der Gruppe um C. enxeinos (BRUNET 1968). Sondermerkmale der neuen Art sind die im Cirrus zunehmende Nadellänge, der caudal umgeschlagene Teil des Cirrus und das birnförmige, weibliche Hilfsorgan.

Spezifisches Artmerkmal von C. boadeni ist die Ausprägung des Kulikularstiletts. Rbinepera divisa ist durch einen bislang unbekannten, in Abschnitte geteilten Cirrus und die Ausprägung von Frontaldrüsen charakterisiert; die Art ist R. marcusi in den Basalteilen der Rüsselhaken sehr ähnlich; diese Art hat allerdings kleine Nebenspitzen an den Haken.

\section{Cheliplanilla MeIXNer 1938 \\ Cheliplanilla caudata MeIXNER 1938}

F un d or te : Sylt: $10 \mathrm{sw}, 12 \mathrm{sw} \mathrm{k}, 15 \mathrm{sw}$; Amrum: $7 \mathrm{sw}$; Ostsee: Kieler Förde, Strande; Heiligenhafen: Graswarder, Sandhang.

Cheliplanilla rubra nov. spec.

(Abb. 66)

Fu nd ort: Sylt: $13 \mathrm{sw}$ (Locus typicus).

Materia 1: Lebendbeobadhtungen (Holotypus 1 Dauerpräparat).

B eschreibung: Die Art erreicht $0,5 \mathrm{~mm}$ Länge. Das Hinterende läuft in einen etwa $50 \mu \mathrm{m}$ langen, mit Tasthaaren besetzten Schwanz aus. Vor dem Hinterende liegt ein schwacher Haftring. Der Körper ist leuchtend rot gefärbt.

Die Rüsselhaken (12-14 $\mu \mathrm{m})$ haben an den Innenseiten jederseits zwei kleine Zähnchen. Die Basalteile sind nach innen abgeknickt und einander genähert. An den Muskelwülsten $(10-15 \mu \mathrm{m})$ sind Nebenapparate $(14-16 \mu \mathrm{m})$ befestigt, die vorne und hinten gegabelt sind. Die Rüsseltasche ist kurz. Dem Rüssel hängt hinten ein sehr langer, postrostraler Bulbus an. Neben dem Rüssel befinden sich die Ausfuhrgänge mehrerer Frontaldrüsen.

Die Mundöffnung führt in die lange, unbestachelte Pharynxtasche. Der tonnenförmige Pharynx ( $p$ ) liegt parallel zur Körperlängsachse (Länge $70 \mu \mathrm{m}$ ).

Der Hoden ( $t$ ) liegt im Bereich des Pharynx, neben der Pharynxtasche oder in Höhe des Darms. Das kurze gewundene Vas deferens (= Samenblase; Nomenklatur nach BOADEN 1963, p. 198) kann abschnittsweise anschwellen. Es mündet vorne in das Kopulationsorgan ( $k$. Daneben ist eine blind geschlossene Samenblase mit dem Kopulationsorgan (50-75 $\mu \mathrm{m}$ Länge) verwachsen. Der Cirrus $(28-33 \mu \mathrm{m})$ ist bestachelt und biegsam. Die Länge der Cirrusstacheln beträgt etwa $6 \mu \mathrm{m}$. 
Die gemeinsame Geschlechtsöffnung (gö) befindet sich bei etwa $4 / 5$ der Körper-länge. Neben dem Germar $(g)$ befindet sich eine kugelige Bursa (b). Das Vitellar $(v)$ beginnt hinter dem Oesophagus und ist mit dem Germar verbunden.

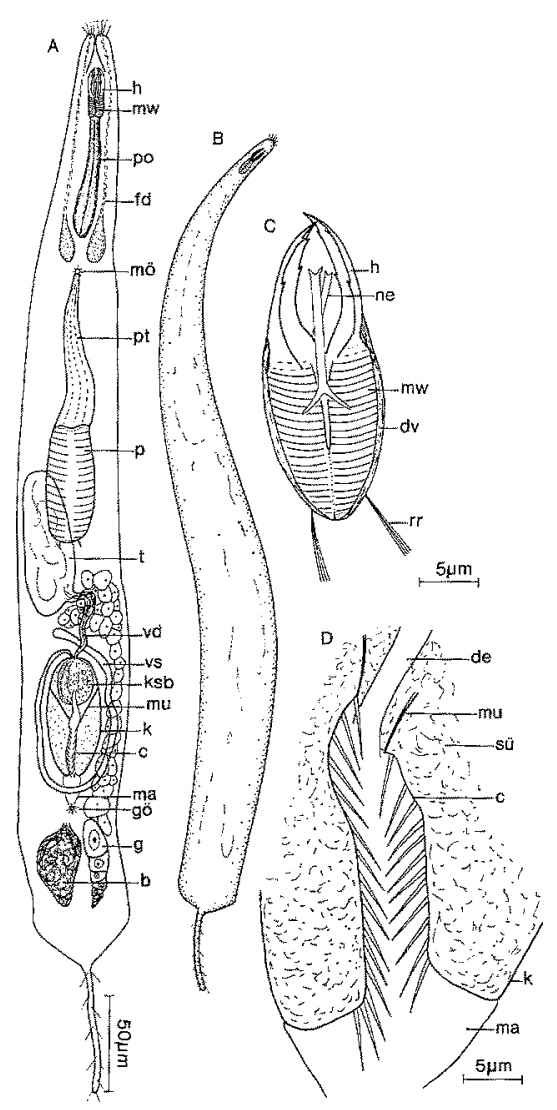

Abb. 66: Cheliplanilla rubra. A Organisation (kombiniert); B Habitus; C Rüssel (Quetschpräparat); $D$ Cirrus (Quetschpräparat)

D is k us sion: Cheliplanilla rubra gehört auf Grund spezieller Rüsselmerkmale (Rüsselhaken mit lateralen Häkchen) und Eigenheiten der männlichen Organe (zwei Typen von Samenblasen) in die Gattung Cheliplanilla. Von den bisher bekannten Arten C. caudata MeIXner 1938, C. karlingi Brunet 1968 und C. implicata BRUNET 1968 unterscheidet sie sich besonders durch Abmessungen im Rïsselorgan und die Form des Cirrus.

\section{Baltoplana KARLING 1949 \\ Baltoplana magna KARLING 1949}

Fund orte: Sylt: $12 \mathrm{sw}$ (leg. Hoxhold), $15 \mathrm{sh}, 17 \mathrm{sh}, 19 \mathrm{sh}$; Ostsee: Kieler Förde, Strande; Weißenhaus, Wasserlinie. 
Familie Diascorhynchidae MEIXNER 1928

Von der bisher einzigen Gattung Diascorbynchus existieren drei Arten an der deutschen Nordseeküste. Für eine weitere, morphologisch abweichende Form wird die neue Gattung Diascorbynchides aufgestellt. In beiden Gattungen konnten im Rüsselapparat Organisationselemente der Muskelzangen als plesiomorphe Merkmale nachgewiesen werden (SCHILKE 1970).

Diascorbynchus MeIXNER 1928

Diascorbynchus lapprikensis KARLING 1963

F u n d o r t : Sylt: 15, große Düne, Sandhang, 4-8 m.

Die Art wird auf Sylt nur in der Blidsel-Bucht gefunden. Hier besiedelt sie eine enge Zone am Strand.

Diascorbynchus serpens KARLING 1949

F u n d o r te: Sylt: $12 \mathrm{sw}$ (leg. Hoxhold); Amrum: $2 \mathrm{sh}, 4 \mathrm{sh}$; Rømø: Lakolk, Weststrand, Wasserlinie; Ostsee: Kieler Förde, Strande, Wasserlinie und Sandwatt; Heiligenhafen, Graswarder, Sandhang.

\section{Diascorbynchus rubrus BOADEN 1963}

(Abb. 67-69, 72)

Fund or te: Sylt: $1 \mathrm{k}, 5,12 \mathrm{sw}, 13 \mathrm{sw}, 14 \mathrm{sw}, 17 \mathrm{sh}, 19 \mathrm{sh}, 24 \mathrm{sw}$; Amrum: 4 sh.

Materia l: Lebendbeobachtungen, mehrere Schnittserien.

Beschreibung: Auf Grund der Struktur des Kutikularorgans ist die Sylter Population einwandfrei mit $D$. rubrus zu identifizieren. Die eingehende Analyse der Art liefert für den Rüssel (Scurkx 1970) und die Atrialorgane eine Reihe von Ergänzungen und Korrekturen zur Originalbeschreibung durch BOADEN.

Die Art erreicht 1,5-2,5 mm Länge. Der Körper ist fadenartig gestreckt. Das Habitusbild, das BOADEN (1963, Fig. 36) zeichnet, gibt kein sich normal bewegendes Tier wieder. Bei der Kontraktion zeigen sich drei Haftringe.

Die Körperfarbe ist mit Ausnahme des hellen Vorderendes intensiv rot. Jungtiere sind hellgrau, heranwachsende Exemplare hellrot. Die Farbe ist vermutlich in zwei lateralen Schläuchen eines Turgorgewebes im Parenchym konzentriert, die auf Schnitten stets deutlich sind. Die Schläuche sind hinter dem Gehirn und vor dem Hinterende besonders gut entwickelt. Hinter dem augenlosen Gehirn liegen große Frontaldrüsen. Neben den Asci sind ebenfalls große Drüsengruppen entwickelt, die das Vorderende gänzlich ausfüllen.

Am Pharynx rosulatus $(\phi \mathrm{ca} .100 \mu \mathrm{m})$ habe ich übereinstimmend mit BOADEN keinen distalen Sphinkter finden können, der proximale Sphinkter ist nur schwach entwickelt.

Normalerweise sind vier Hoden ( $t$ ) vorhanden, seltener fünf Follikel. Die Samenblasen sind in Abhängigkeit vom Füllungszustand mehr oder weniger gewunden, wogegen BOADEN sie als "not winding“ beschreibt. Die Länge liegt $z$ wischen 110 und $190 \mu \mathrm{m}$ (BOADEN $90-120 \mu \mathrm{m}$ ). Die Kornsekretdrüsen produzieren basophile, grobkörnige Sekrete. 
Das männliche Kopulationsorgan ( $k$ ) ist 35-60 (80) $\mu \mathrm{m}$ lang, von einer Ringmuskelhülle umgeben. Die Kornsekretblase ragt bis in das Stilett, wo ihre Ausfuhrkanäle radial um den Ductus ejaculatorius angeordnet sind (Abb. 68 B, 69).

Das Stilett ist 25-30 (35) $\mu \mathrm{m}$ lang (BOADEN 26,5-27,8 $\mu \mathrm{m}$ ). Es ist spiralig aufgerollt und besteht aus einem vorderen, konischen Teil und einer stiefelförmigen Spitze.

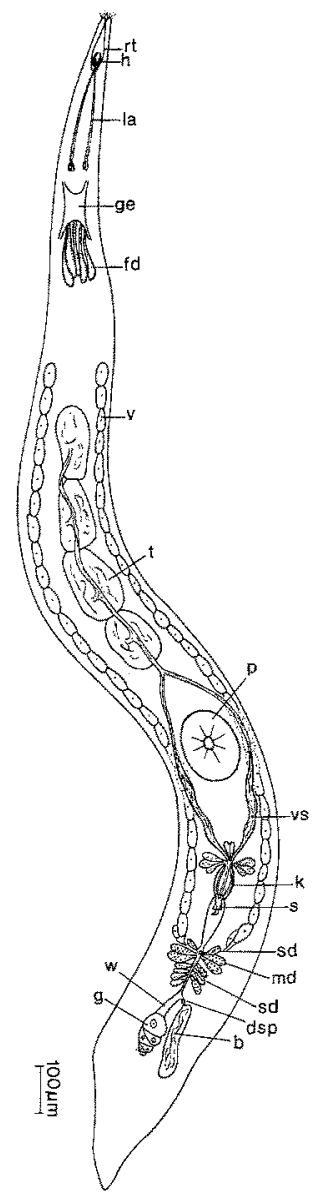

Abb. 67: Diascorbyncbus rubrus. Organisation (kombiniert)

Das männliche Genitalatrium ( $m a$ ) setzt an der muskulösen Hülle des Kopulationsorgans neben dem Stilett an. Es besitzt kräftige Ring-- und Längsmuskeln, vor dem gemeinsamen Atrium liegt ein Sphinkter.

Die gemeinsame Geschlechtsöffnung (gö) liegt etwa bei $4 / 5$ der Körperlänge. Der lange, muskelschwache Ovidukt ist sehr kontraktil und erweitert sich kurz vor dem Germar ( $g$ ) trichterartig. Hier beginnt die schmale Vagina interna, die zu dem Ductus spermaticus $(d s p$ ) führt. Die Vagina hat einen Durchmesser von $0,8-1,2 \mu \mathrm{m}$ (Schnitt- 
präparat) und enthält zuweilen Spermien. Im Gegensatz zu BOA.DEN habe ich aber keine Vagina gefunden, die zum Genitalatrium führt.

Der Ductus spermaticus liegt lateral vor dem Germar, er ist im Quetschpräparat und auf Schnitten stets deutlich durch seine dicke Muskulatur zu erkennen. Meine Beobachtungen über den Bau dieses Organs stimmen mit denen von BOADEN überein. Zuweilen erscheint der Ductus (Länge im Quetschpräparat 16-18 $\mu \mathrm{m}$, Breite $12 \mu \mathrm{m}$ ) in der Mitte zweigeteilt. Im Innern finden sich häufig Spermaknäuel. Distal führt ein

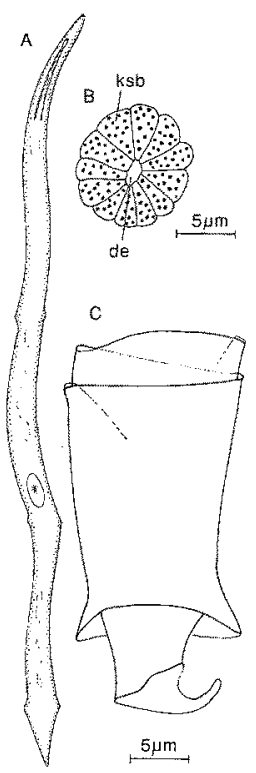

Abb. 68: Diascorhyncbus rubrus. A Habitus, 3 Haftringe; $B$ Querschnitt durch den Ductus ejaculatorius mit Kornsekretblase im Stilett C Stilett, Rekonstruktion (Quetschpräparat, Schnittserie)

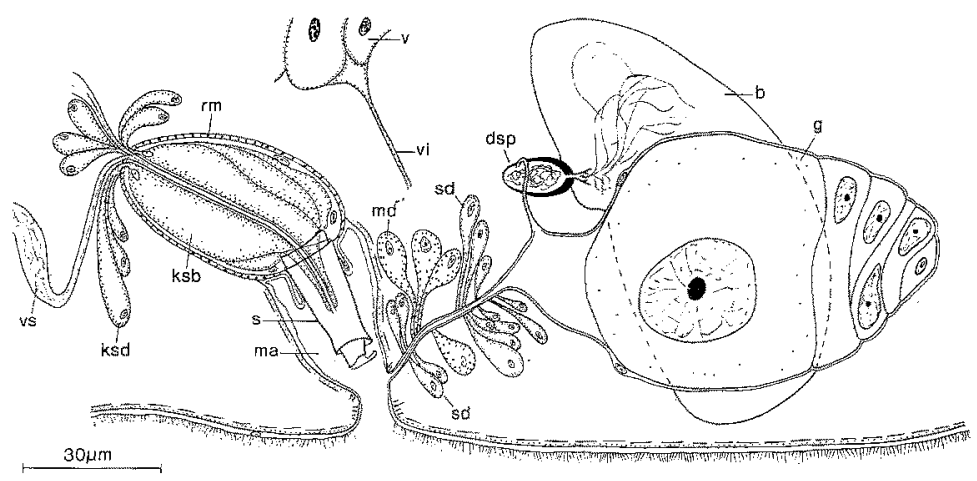

Abb. 69: Diascorbynchus rubrus. Sagitralschnittrekonstruktion der Atrialorgane. (Einmündung der Vitellodukte unbekannt) 
Kanal (Länge $2 \mu \mathrm{m}, \phi 0,8 \mu \mathrm{m}$ ) durch die dicke Muskulatur in den vorderen Teil des Bursahohlorgans (b). Er erweitert sich in der Bursa trichterförmig. Die Ausdehnung des Bursahohlorgans ist stark vom Reifezustand des Tieres abhängig. Hinter dem Hohlorgan ist ein weiterer, resorbierender Bursateil zu erkennen.

Die paarigen Vitellarien $(v)$ entlassen feine Vitellodukte in der Nähe des Ovidukts. Ein Uterus fehlt.

Die basophilen Drüsen (md) münden in zwei lateralen Gruppen am Anfang des Oviduktes aus. Die eosinophilen Drüsen ( $s d$ ) liegen sowohl vor als auch hinter ersteren am Ovidukt.

Diascorbynchides nov. gen.

G a t t u g s diag nos e : Asymmetrischer Rüsselapparat mit einem rechtwinklig gebogenen, hohlen und einem geraden, offenen Haken; hinter diesem ein Muskelwulst; 14-16 Hodenfollikel vor dem kleinen Pharynx rosulatus; männliches Kopulationsorgan mit 5-7 kreisförmig angeordneten Stilettnadeln; Bursa mit Ductus spermaticus; Vagina fehlt; bewimperter Uterus.

Typart: Diascorbynchides arenaria nov. spec.

Diascorbynchides arenaria nov. spec.

(Abb. 70-72)

F und or te: Sylt: $10 \mathrm{sw}, 12 \mathrm{sw}$ sh (Locus typicus), $14 \mathrm{sw}, 15$; Amrum: $7 \mathrm{q}$.

Materia 1: Lebendbeobachtungen, mehrere Schnittserien (Holotypus 1 Sagittalschnittserie).

Beschreibung: Die Art erreicht 3,5-4 mm Länge und hat zwei Haftringe. Die Epidermis enthält zahlreiche, dichtstehende Vakuolen (Tangentialschnitt), die ein schachbrettartiges Muster erzeugen. Im Vorderende dienen diese Vakuolen als verdickte Ausfuhrgänge von Drüsen. Sie enthalten hier Sekrete einer drüsigen Schicht, die sich im ganzen Körper unmittelbar unter der Längsmuskelschicht ausbreitet. Feine Kanälchen sind zwischen ihr und den Vakuolen sichtbar. Derartige Vakuolen im Vorderende haben eine Spitze oder Düse nach außen. Unterhalb der Drüsenzellen hat die Art ein vakuolenreiches Gewebe im peripheren Parenchym (vgl. Ax 1966, p. 285 f.). Die Vakuolen dieses Gewebes sind an der ganzen Körperperipherie vorhanden. Dorsal sind die Vakuolen kleiner als ventral, wo sie mächtige Schläuche bilden.

Die Körperfarbe ist intensiv gelb. Hinter dem augenlosen Gehirn liegen einige Frontaldrüsen. Der kleine Pharynx rosulatus ( $\varnothing 120-160 \mu \mathrm{m}$, Quetschpräparat) ist senkrecht orientiert. Die Pharynxtasche ist unter dem vorderen Teil des Bulbus etwas kürzer als unter dem hinteren und hat ein papillöses Epithel. Der Bulbus enthält Radiärmuskeln, an den Greifwülsten besonders kräftige innere Ringmuskeln (irm), sehr feine innere Längsmuskeln (ilm) und einzelne äußere Längsmuskeln (älm). In der Mitte des großen, ventralen Greifwulstes münden Drüsen aus, die überwiegend ein grobkörniges, basophiles, zum geringeren Teil aber auch ein eosinophiles Sekret sezernieren.

Die Geschlechtsorgane sind paarig. 14-16 (20) Hodenfollikel (t) liegen hinter dem Gehirn strangartig in zwei Reihen. Die langen, stark gewundenen Samenblasen (vs) haben eine schwache Längsmuskulatur. Zwei Arten Kornsekretdrüsen sind zu unterscheiden $(k s d)$. 
Das Kopulationsorgan (200-220 $\mu \mathrm{m})$ hat eine starke Ringmuskelhülle. Der Ductus ejaculatorius erweitert sich kurz vor dem Beginn des Kutikularorgans ( $s$ ) hofartig. Es besteht aus 7 Einzelstacheln $(66-70 \mu \mathrm{m})$. Sie inserieren kreisförmig, plattenartig am Ende de. -o lationsorgans, sind hohl, leicht spiralig.

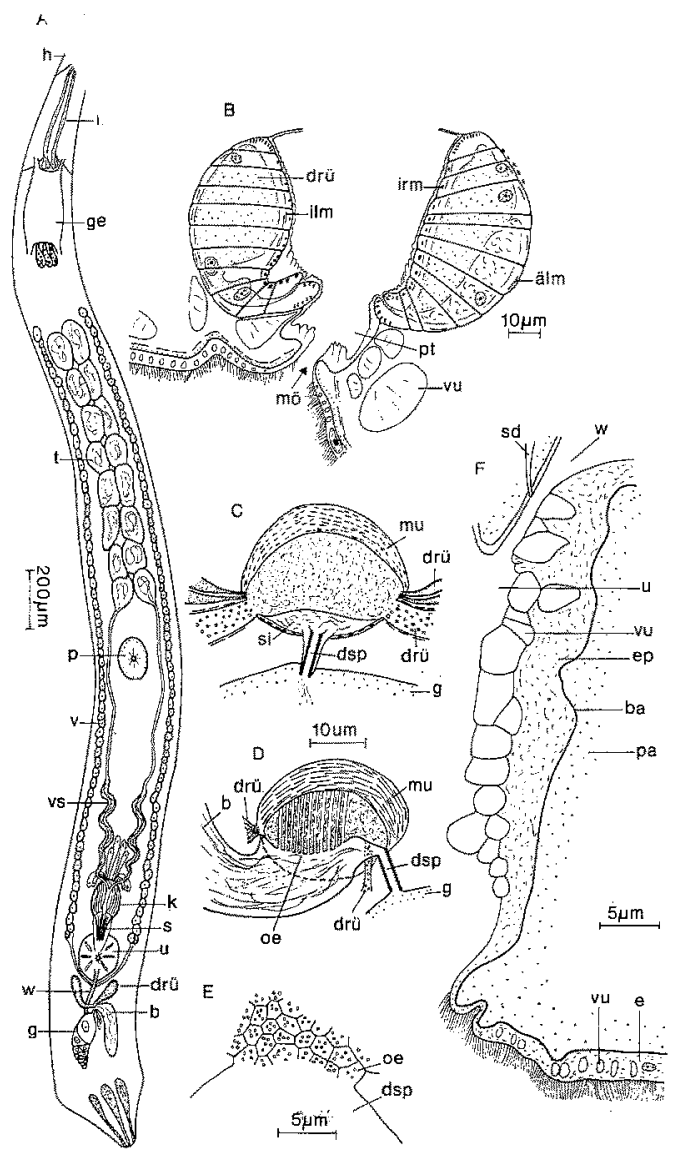

Abb. 70: Diascorhynchides arenaria. A Organisation (kombiniert); $B$ Sagittalschnittrekonstruktion des Pharynx; $C$ Querschnitt durch den Bläschenteil des Ductus spermaticus, kombiniert; $D$ Sagittalschnitt durch den Bläschenteil des Ductus spermaticus mit Offnungen; $E$ wie $D$ : Ausschnitt, Offnungen; $F$ Sagittalschnitt durch die caudale Wand des Genitalatriums, Vakuolen

Im leicht gequetschten Tier bilden die Stacheln ein geschlossenes Bündel, das sich nach hinten konisch verjüngt. Beim stärkeren Quetschen weichen die Spitzen auseinander.

Vor dem Kutikularorgan liegt ein einziger großer Kern in einem körnigen Gewebe. Die Stilettstacheln ragen in das weite männliche Atrium (ma). Die gemeinsame Geschlechtsöffnung ( $g \ddot{o}$ ) liegt etwa bei ${ }^{3 / 4}$ der Körperlänge und führt in das weite Ge- 
nitalatrium, dessen frontale Aussackung als Uterus ( $u$ ) zu bezeichnen ist. Der Uterus ist mit Längsmuskeln versehen, liegt median und nimmt ungefähr die Hälfte des Körperdurchmessers ein. Das Epithel ist mit Ausnahme des frontalen Teils überall gleich dick. Dieser vordere Teil ist schwach kutikularisiert. Alle anderen, mit einem Epithel versehenen Teile sind dicht bewimpert. In dem dorsal gelegenen Teil des Uterus sind

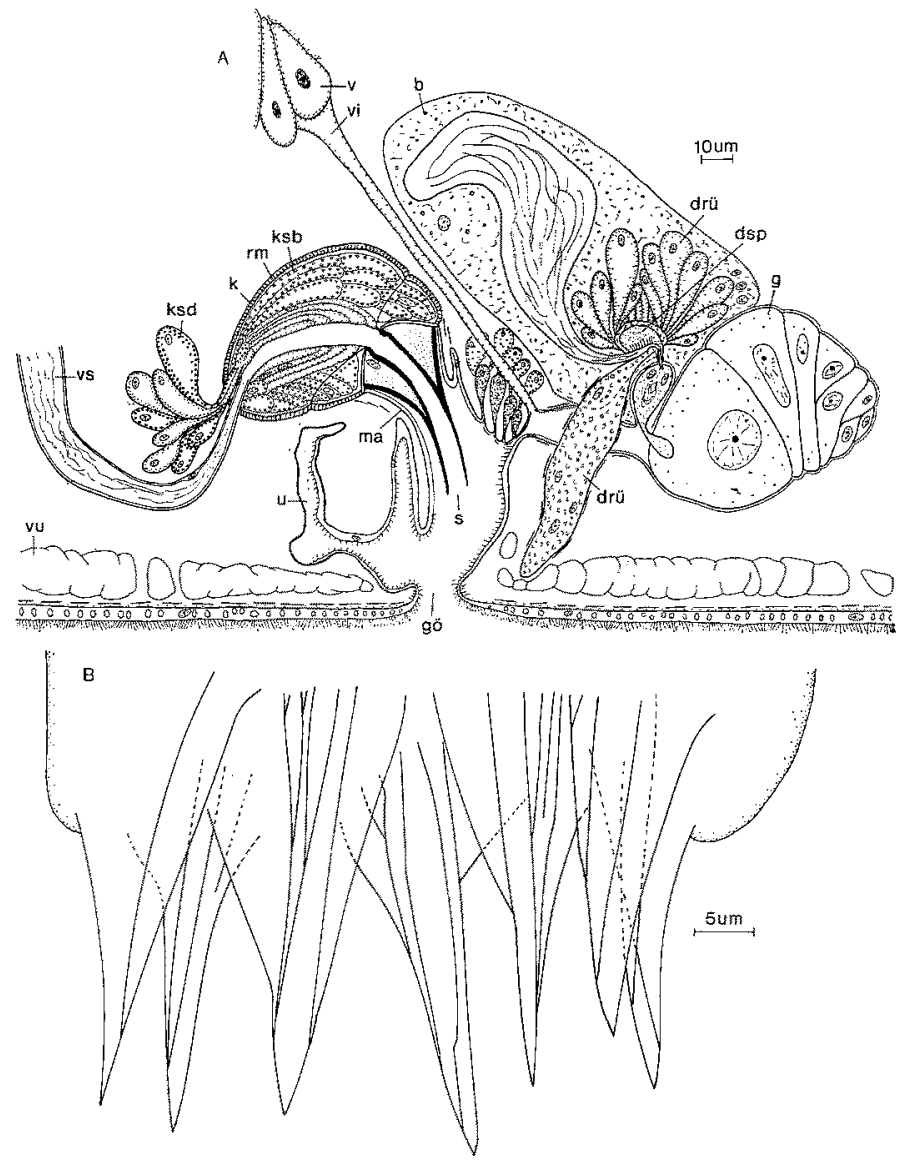

Abb. 71: Diascorbynchides arenaria. A Sagittalschnittrekonstruktion der Atrialorgane; $B$ Stilett (Quetschpräparat)

kleine quaderartige Vakuolen (3-4 $\mu \mathrm{m}^{2}$ ) vorhanden (Abb. $\left.70 \mathrm{~F}\right)$. Im ventralen Teil des Uterus, in der Nähe der Geschlechtsöffnung sind stets nur Wimpern vorhanden. Der Ovidukt erweitert sich hinten und bildet einen weitlumigen Kanal. Das umfangreiche Germar $(g)$ liegt etwas links von der Mittellinie. Die feine Tunika enthält wenige Zellkerne. In einer Schnittserie befindet sich etwas Vitellocytenmaterial unmittelbar an der ersten Oocyte. Die umfangreiche Bursa $(b)$ liegt rechts im Hinterende des Tieres. Die Abgrenzung der Bursa ist stellenweise so schwach, daß eine Unterscheidung vom 

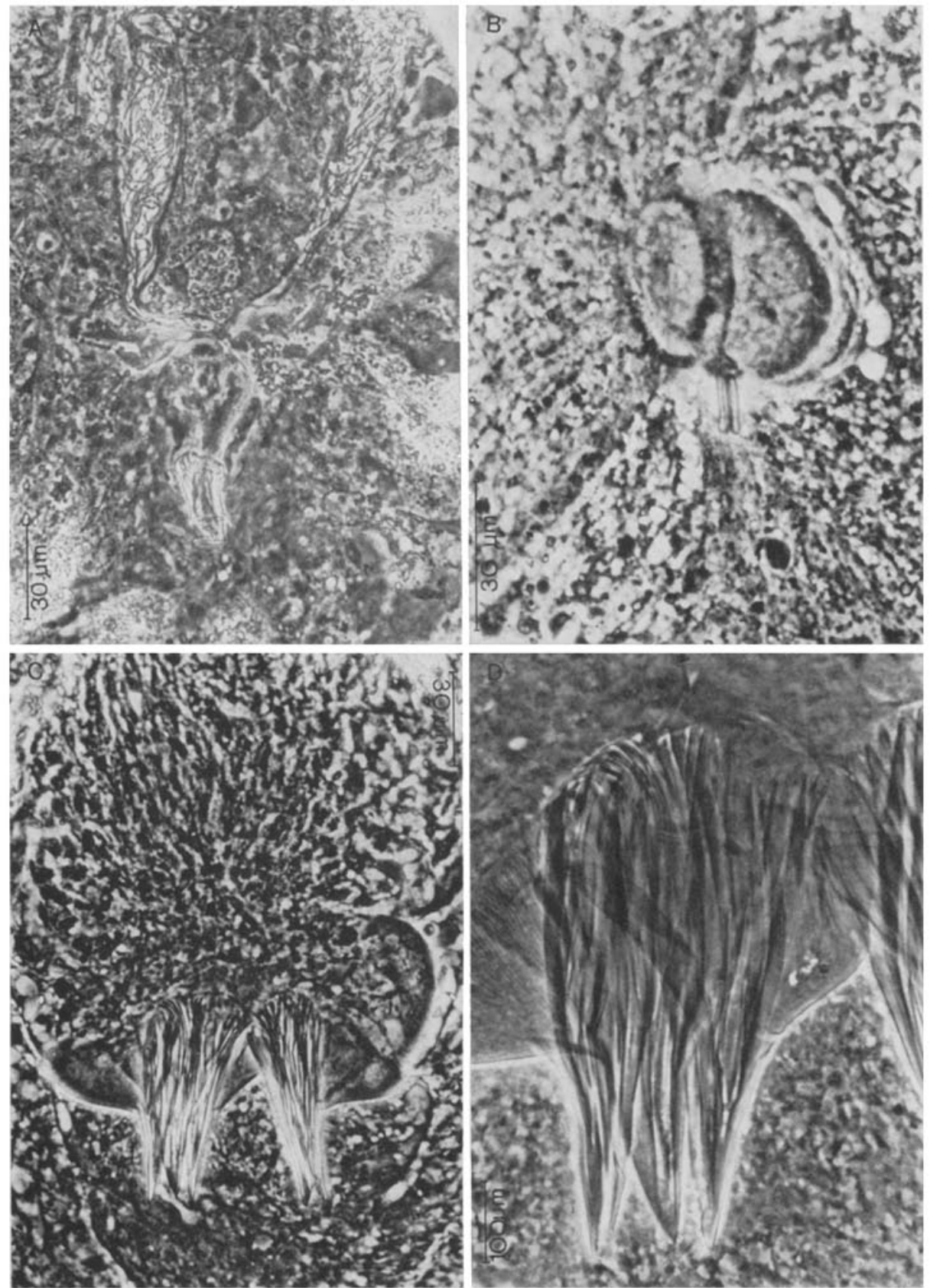

Abb. 72: A Diascorbynchus rubrus. Männliches Kopulationsorgan mit Stilett; B Diascorbynchides arenaria. Ductus spermaticus (vgl. Abb. $70 C, D, E)$; C Diascorbyncbides arenaria. Kopulationsorgan mit 5 Stilettnadeln; D Diascorbynchides arenaria. 3 Stilettnadeln 
Darmgewebe hier nur schwer möglich ist. Der mittlere Teil des Ovidukts ist dorsal mit der Bursawand verwachsen. Sperma liegt in einem Beutel, der sich nach hinten kanalartig verengt. Der Kanal ist kutikularisiert und mündet in den Ductus spermaticus (dsp). Dieser besteht aus einer Blase und einem kurikularisierten Röhrchen (10-14 $\mu \mathrm{m}$ Länge; $\phi 2-3 \mu \mathrm{m})$, das zum Germar führt. Der Ductus hat um seine Blase dorsal einen starken Muskelmantel. Die Blase ist innen eosinophil.

In die Blase des Ductus münden zwei Drüsenarten. Zwei umfangreiche, grobkörnige, eosinophile Drüsen liegen links und rechts neben dem Ovidukt, die fast die Ventralseite erreichen, mehrere Zellkerne haben und von kräftigen Längsmuskeln umgeben sind. Identische Sekrete sind auch im Ovidukt vorhanden und können ihn prall ausfüllen.

Ein dritter Komplex eosinophiler Drüsen (drii) liegt dorrsal vom Ductus spermaticus.

Die Ausfuhrgänge der drei Drüsen werden in einem Feld zusammengefaßt (ca. 50 Poren). Sie öffnen sich entweder in den spermaführenden Kanal oder in einen Hohlraum unterhalb der Blase, in welchem ein Zapfen mit drei Zellkernen hineinragt. Dieser Hohlraum steht vermutlich mit dem mittleren Teil des Ovidukts in Verbindung, so daß die Sekrete aus den drei Drüsen auch in den Ovidukt gelangen könnten.

Das Röhrchen des Ductus spermaticus ist von einem basophilen Auswuchs des Innenraumes der Blase begleitet. Er führt in einen halsartigen, dorsalen Teil des Germars, der im fixierten Zustand meist an dieses herangezogen ist. In ihm liegen drei Zellkerne. Der Inhalt dieser Struktur ist homogen feinkörnig.

Die eosinophilen $(s d)$ und basophilen ( $m d$ ) Drüsen liegen in zwei sehr umfangreichen, lateralen Trauben am Ansatz des Ovidukts am Uterus.

Zwei umfangreiche Vitellarien (v) haben Vitellodukte (vi), die kurz hinter dem Ansatz des Ovidukts ausmünden.

D is k u s s i o n : Auf Grund der typischen Asci gehört Diascorbyncbides arenaria einwandfrei in die Familie Diascorhynchidae. Die Errichtung einer neuen Gattung gründet sich im wesentlichen auf folgende, yon Diascorbynchus abweichenden Merkmale: Starke Differenzierung der Rüsselhaken, Existenz eines Uterus, Ausformung des Kutikularorgans mit mehreren Stacheln.

\section{ZUSAMMENFASSUNG}

1. Aus dem Eulitoral der deutschen Nordseeküste wurden auf Grund von Untersuchungen in den Jahren 1966, 1967 und 1968 insgesamt 85 Arten der Kalyptorhynchia (Turbellaria) erfaßt. Wichtigste Untersuchungsgebiete sind die Inseln Sylt, Amrum, Helgoland und Rømø. Die bevorzugten Lebensräume sind auf Sylt mittellotische Sandhänge und diesen vorgelagerte, sandige, vorwiegend lenitische Wattengebiete. 73 von den in der Nordsee nachgewiesenen 85 Arten sind Sandbewohner, sieben Arten sind Schlickbewohner und nur fün Species sind Phytalformen.

2. 29 Arten sind neu. Zahlreiche bislang nur unvollständig bekannte Species wurden genauer erfaßt. Der Schwerpunkt der morphologisch-systematischen Untersuchungen liegt auf der Gruppe der Schizorhynchia. 
3. Von den Eukalyptorhynchia wurden 39 Arten nachgewiesen. Innerhalb der Familien Polycystidae, Koinocystidae, Cystiplanidae und Gnathorhynchidae werden neue Gattungen und Arten beschrieben. Besonders auffällig ist der Artenzuwachs bei den Gnathorhynchidae, für die zahlreiche neue Merkmalskombinationen (Rüssel) nachgewiesen wurden.

4. Von den Schizorhynchia wurden 47 Arten erfaßt. Es wurden sechs neue Gattungen errichtet. Die Familiendiagnose der Schizorhynchidae wurde geändert. Innerhalb der formenreichen Gattung Proschizorbynchus wurden auf Grund der Ausprägung der männlichen Kulikularorgane zwei Untergattungen $P$. Proschizorbyncbus und $P$. Proschizorbynchella unterschieden. Für die neue Gattung Neoschizorbynchus wurden die kürzesten, bislang bekannten Spaltrüssel, kombiniert mit Besonderheiten der männlichen Organe, beschrieben. Je ein Bestimmungsschlüssel ist für die umfangreichen Gattungen Carcharodorbynchus und Thylacorbynchus aufgestellt worden, der sich auf neu entdeckte Merkmalskombinationen stiitzt.

5. Die Karkinorhynchidae wurden auf Grund der Ausformung der lateralen Drüsensäcke und der Konstruktion des Kopulationsorgans in die neuen Unterfamilien Karkinorhynchinae und Cheliplaninae aufgeteilt. Die Gattung Karkinorbynchus wurde in zwei Untergattungen (K. Karkinorbynchus und $K$. Karkinorbynchides) gespalten. Innerhalb der nah verwandten, formenreichen Gattungen Cheliplana und Rbinepera gelang der Nachweis weiterer neuer Species.

6. Die Diascorhynchidae wurden um die neue Gattung Diascorhynchides vermehrt, die durch stark asymmetrische Rüsselhaken und einzelne Stilettstacheln von der bisher einzigen Gattung Diascorbynchus unterschieden ist.

Danksagungen. Meinem Lehrer, Herrn Professor Dr. P. Ax, möchte ich für die Anregung zu dieser Arbeit und für seine beständige Unterstitzung und Förderung danken. Herrn Professor J. P. L'HARdx und Herrn Dr. M. BRuneT danke ich für briefliche Mitteilungen. Herrn Professor Dr. O. KINNE und der Litoralstation der Biologischen Anstalt Helgoland in List/Sylt habe ich für die Bereitstellung eines Arbeitsplatzes zu danken. Für besonders enge Zusammenarbeit innerhalb des Mitarbeiterkreises des II. Zoologischen Instituts danke ich Herrn S. HoxHoLd.

\section{Abkürzungen in den Abbildungen}

$\begin{array}{llll}a l m & \text { äußere Längsmuskeln } & e k & \text { Endkegel } \\ \ddot{a} r m & \text { äßßere Ringmuskeln } & e p & \text { Epithel } \\ a p & \text { Apex } & f d & \text { Frontaldrüse } \\ a s & \text { accessorisches Sekretorgan bzw. dessen } & f & \text { Flügel } \\ & \text { Ausfuhrgang } & g & \text { Germar } \\ b & \text { Bursa }\left(b_{1}-b_{n} \text { bursale Drüsen) }\right. & g a & \text { gemeinsames Genitalatrium } \\ b a & \text { Basalmembran } & g e & \text { Gehirn } \\ b a s & \text { Basalteil } & g n & \text { Genitalkanal } \\ c & \text { Cirrus } & g o ̈ & \text { Geschlechtsöffnung } \\ c b & \text { cellules bordantes (= Kanalzellen) } & b & \text { Haken } \\ d e & \text { Ductus ejaculatorius } & b a ̈ & \text { Häkchen } \\ d r u ̈ & \text { Drüsen, Drüsenorgan } & i l m & \text { innere Längsmuskeln } \\ d s p & \text { Ductus spermaticus } & \text { irm } & \text { innere Ringmuskeln } \\ d v & \text { Divarikator } & k & \text { Kopulationsorgan } \\ e & \text { Epidermis } & k a & \text { Kanal }\end{array}$




$\begin{array}{ll}k k & \text { Körnerkolben } \\ k s b & \text { Kornsekretblase } \\ k s d & \text { Kornsekretdrüse } \\ l & \text { Leiste im Kopulationsorgan } \\ l a & \text { lateraler Drüsensack } \\ l m & \text { Längsmuskel } \\ m a & \text { männliches Genitalatrium } \\ m b & \text { muskulöser Beutel } \\ m d & \text { basophile Drüse } \\ m o ̈ & \text { Mundöffnung } \\ m u & \text { Muskel } \\ m w & \text { Muskelwulst } \\ m z & \text { Muskelzapfen } \\ n a & \text { Nadeln } \\ n e & \text { Nebenapparat } \\ o & \text { Oesophagus } \\ \ddot{o} & \text { Offnung } \\ p & \text { Pharynx } \\ \text { pa } & \text { Parenchym } \\ p e & \text { Penispapille } \\ p o & \text { postrostraler Bulbus } \\ p t & \text { Pharynxtasche } \\ r a & \text { Radiärmuskel } \\ m m & \text { Ringmuskel } \\ & \end{array}$

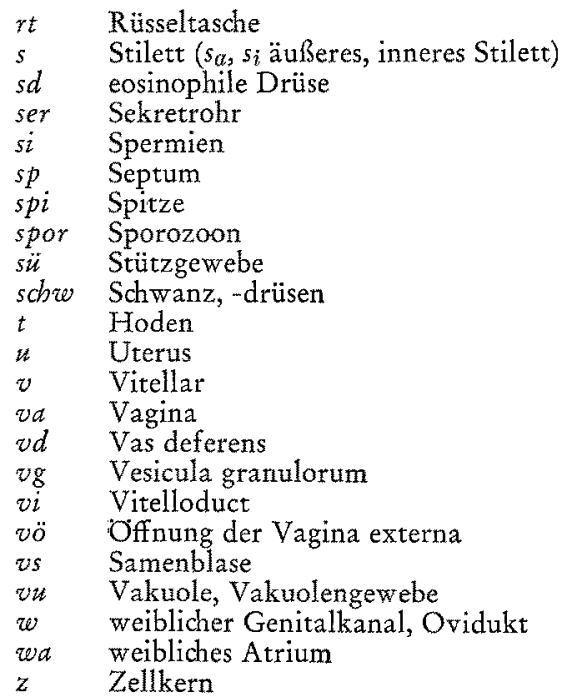

\section{ZITIERTE LITERATUR}

Aтtems, C., 1897. Beitrag zur Kenntnis der rhabdocoelen Turbellarien Helgolands. Wiss. Meeresunters., Kiel und Helgoland, NF, 219-232.

Ax, P., 1951. Die Turbellarien des Eulitorals der Kieler Bucht. Zool. Jb. (Syst. Okol. Geogr. Tiere) $80,277-378$.

- 1952a. Zur Kenntnis der Gnathorhynchidae (Turbellaria Neorhabdocoela). Zool. Anz. 148, 49-58.

- 1952b. Prognathorbynchus karlingi nov. spec., ein neues Turbellar aus der Familie Gnathorhynchidae aus der Kieler Bucht. Kieler Meeresforsch, 9, 240-242.

- 1959. Zur Systematik, Okologie und Tiergeographie der Turbellarienfauna in den pontokaspischen Brackwassermeeren. Zool. Jb. (Syst. Okol, Geogr. Tiere) 87, 43-184.

- 1969. Populationsdynamik, Lebenszyklen und Fortpflanzungsbiologie der Mikrofauna des Meeressandes. Zool. Anz, (Suppl. Bd) 32, 66-113.

Beauchamp, P. DE, 1927. Rhabdocoeles des sables à diatomées d'Arcachon. 1. Bull. Soc. zool. Fr. 52, 351-359.

Boaden, P. J. S., 1963. The interstitial Turbellaria Kalyptorhynchia from some North Wales beaches. Proc. zool. Soc., Lond. 141, 173-205.

- 1965. A new interstitial turbellarian Cheliplana bypergyna n. sp. Pubbl. Staz. zool. Napoli 34, 216-218.

- 1966. Interstitial fauna from Northern Ireland. Veröff. Inst. Meeresforsch. Bremerh. (Sonderbd) 2, 125-130.

Brunet, M., 1965. Turbellariés Calyptorhynques de substrats meubles de la région de Marseille. Rech. Trav. St. mar. Endoume 39 (55), 128-219.

- 1966. Sur quelques turbellariés calyptorhynques de sables fins de la région de Marseille. Bull. Soc. zool. Fr. 91, 721-730.

- 1967. Turbellariés schizorhynques de la région de Marseille. Sur Carcharodorbynchus subterraneus MeIXner et C. flavidus n. sp. Bull. Soc. zool. Fr. 92, 143-152.

- 1968. Turbellariés Karkinorhynchidae de la région de Marseille. Les genres Cbeliplana et Cheliplanilla. Cah. Biol. mar. 9, 421-440. 
DöRJEs, J., 1966. Paratomella unichaeta nov. gen. nov. spec., Vertreter einer neuen Familie der Turbellaria-Acoela mit asexueller Fortpflanzung durch Paratomie. Veröff. Inst. Meeresforsch. Bremerh. (Sonderbd) 2, 187-200.

- 1968a. Zur Oekologie der Acoela (Turbellaria) in der Deutschen Bucht. Helgoländer wiss. Meeresunters. 18, 78-115.

- 1968b. Die Acoela (Turbellaria) der deutschen Nordseeküste und ein neues System der Ordnung. Z. zool. Syst. Evolutionsforsch. 6, 56-452.

EvDonin, L. A., 1969. Ein neuer Vertreter der interstitiellen Kalyptorhynchia (Turbellaria, Neorhabdocoela, Kalyptorhynchia). Insel Kunašir. Zooloja, Vestnik Leningradskogo Universiteta, No. 15 (in russ.).

Graff, L. von, 1913. Turbellaria II. Rhabdocoelida. Tierreich 35, 1-484.

Hartog, C. DEN, 1968. Analysis of the Gnathorhynchidae (Neorhabdocoela, Turbellaria) and the position of Psittacorbynchus verreeyi nov. gen. nov. spec. in this family. Proc. K. ned. Akad. Wet. (Ser. C) 71, 335-345.

HELLER, R. (in Vorbereitung).

KARLING, T. G., 1931. Untersuchungen über Kalyptorhynchia (Turbellaria, Rhabdocoela) aus dem Bradkwasser des Finnischen Meerbusens. Acta zool. fenn. 11, 5-66.

- 1947. Studien über Kalyptorhynchien (Turbellaria). I. Die Familien Placorhyndidae und Gnathorhynchidae. Acta zool. fenn. 50, 1-64.

- 1949. Studien... II. Die Familien Karkinorhynchidae und Diascorhynchidae. Acta zool. fenn. 58, 1-42.

- 1950. Studien ... III. Die Familie Schizorhynchidae. Acta zool. fenn. 59, 1-33.

- 1952. Studien ... IV. Einige Eukalyptorhyndia. Acta zool. fenn. 69, 1-49.

- 1955. Studien ... V. Der Verwandtschaftskreis von Gyratrix Ehrenderg. Acta zool. fenn. 88, 1-39.

- 1956a. Morphologisch-histologische Untersuchungen an den männlichen Atrialorganen der Kalyptorhynchia (Turbellaria). Ark. Zool. 9, 187-279.

- 1956b. Zur Kenntnis einiger Gnathorhynchiden nebst Beschreibung einer neaen Gattung. Ark. Zool. 9, 343-353.

- 1961. Zur Morphologie, Entstehungsweise und Funktion des Spaltrüssels der Turbellaria Schizorhynchia. Ark. Zool. 13, 253-286.

- 1963. Die Turbellarien Ostfennoskandiens. V. Neorhabdocoela 3. Kalyptorhynchia. Fauna fenn. 17, 1-59.

-- 1964. Über einige neue und ungenügend bekannte Turbellaria Eukalyptorhynchia. Zool. Anz. 172, 159-183.

L'Hardy, J. P., 1963. Turbellariés Schizorhynchidae des sables de Roscoff. I. Les genres Carcharodorbyncbus, Scbizocbilus et Scbizorbynchoides. Cah. Biol. mar. 4, 459-472.

- 1965. Turbellariés ... II. Le genre Proschizorbynchus. Cah. Biol. mar. 6, 135-161.

- 1966. Karkinorbynchus megalopharynx n. sp. nouveau Turbellarié Calyptorhynque de la famille des Karkinorhynchidae. Bull. Soc. zool. Fr. 91, 179-185.

Marcus, E., 1949. Turbellaria brasileiros. 7. Bol. Fac. Filos. Ciênc. Univ. S. Paulo (Zool.) 14, 7-155.

- 1950. Turbellaria brasileiros. 8. Bol. Fac. Filos. Ciênc. Univ. S. Paulo (Zool.) 15, 5-191.

- 1952. Turbellaria brasileiros. 10. Bol. Fac. Filos. Ciênc. Univ. S. Paulo (Zool.) 17, 5-188.

MeIXner, J., 1925. Beitrag zur Morphologie und zum System der Turbellaria-Rhabdocoela. I. Die Kalyptorhynchia. Z. Morph. OKkol. Tiere 3, 255-343.

- 1928. Aberrante Kalyptorhynchia (Turbellaria Rhabdocoela) aus dem Sande der Kieler Bucht (I). Zool. Anz. 77, 229-253.

- 1929. Morphologisch-ökologische Studien an neuen Turbellarien aus dem Meeressande der Kieler Bucht. Z. Morph. Okol. Tiere 14, 765-791.

- 1938. Turbellaria (Strudelwürmer). I. Tierwelt N.- u. Ostsee 4b, 1-146.

- Turbellaria (Strudelwürmer). II. System. Korrekturfahnen. Tierwelt N.- u. Ostsee $4 \mathrm{~b}$.

Pawlak, R., 1969. Zur Systematik und Okologie (Lebenszyklen, Populationsdynamilk) der Turbellarien-Gattung Paromalostomum. Helgoländer wiss. Meeresunters. 19, 417-454. 
Schilke, K., 1969. Zwei neuartige Konstruktionstypen des Rüsselapparates der Kalyptorhynchia (Turbellaria). Z. Morph. Tiere 65, 287-314. (1969).

- 1970. Zur Morphologie und Phylogenie der Schizorhynchia (Turbellaria, Kalyptorhynchia). Z. Morph. Tiere 67, 118-171.

Schimid, P., 1968. Die quantitative Verteilung und Populationsdynamik des Mesopsammons am Gezeitenstrand der Nordseeinsel Sylt. I. Faktorengefüge und biologische Gliederung des Lebensraumes. Int. Rev. ges. Hydrobiol. 53, 723-779.

Scrulz, E., 1937. Das Farbstreifen-Sandwatt und seine Fauna. Kieler Meeresforsch. 1, 359-377.

- 1939. Uber eine Mikrofauna im oberen Eulitoral auf Amrum. Kieler Meeresforsch. 3, 158164.

- \& MeYer, H., 1940. Weitere Untersuchungen über das Farbstreifen-Sandwatt. Kieler Meeresforsch. 3, 321-336.

SteInböck, O., 1931. Marine Turbellaria. Zoology Faroes 8, 1-26.

Teuchert, U., 1968. Zur Fortpflanzung und Entwicklung der Macrodasyoidea (Gastrotricha). Z. Morph. Tiere 63, 343-418.

Westblad, E., 1942. Studien über skandinavische Turbellarien. Acoela II. Ark. Zool. 33A (14), $1-48$.

WESTHEnE, W., 1966. Zur Polychaetenfauna des Eulitorals der Nordseeinsel Sylt. Helgoländer wiss. Meeresunters. 13, 203-209.

- 1967. Monographie der Gattungen Hesionides FrIEDRICr und Microphthalmus MeczNIRow (Polychaeta, Hesionidae). Z. Morph. Ókol. Tiere 61, 1-159.

Anschrift des Autors: Dr. K. SchILKE

II. Zoologisches Institut und Museum

der Universität Göttingen

34 Göttingen

Berliner Str. 28

Deutschland (BRD) 